\title{
La otra cara del desarrollo. La ciudad excluyente del neoextractivismo.
}

\section{El aumento de la verticalización en}

\section{Bernal, 2006-2019}

\section{Ludmila Cortizas}

Tesis para optar por el grado de Magíster en Políticas de Desarrollo

Director Dr. Gastón Cirio

Universidad Nacional de La Plata

Ensenada, 17 de diciembre de 2019 


\section{Resumen}

Esta tesis propone una discusión sobre el extractivismo en la Argentina de hoy, y en un caso de la Región Metropolitana de Buenos Aires en particular, reflexionando sobre el territorio, y más precisamente sobre la realidad urbana producto de las transformaciones producidas de la mano de diferentes actores que persiguen diversos intereses. Se realiza un aporte al análisis de una expresión del extractivismo urbano, relacionado al aumento de la verticalización en los centros, y los impactos que ha tenido en el acceso diferencial a la centralidad urbana

Se parte de la premisa que la construcción de edificios ha ido en aumento, produciendo modificaciones que dan lugar a procesos de renovación urbana competitivos, marcando de este modo un dominio de los procesos especulativos llevados a cabo en la ciudad que

promueven modalidades de construcción para sociedades selectivas y desiguales, que intensifican y producen asimetrías en la nueva ciudad excluyente. Se hace referencia al modelo de ciudad que se vino consolidando en los últimos años, en donde se construye y se vende un ideario de desarrollo mediante un sistema donde prima la lógica de mercado, que construye ciudad para un único sector social. En este caso en particular, se analizó el área central de la localidad de Bernal (Partido de Quilmes) ya que constituye un caso relevante por manifestar importantes transformaciones territoriales, principalmente a partir del 2006, año en que se produce la rezonificación de usos del suelo, normativa que cristaliza un proceso de excepciones previas, y que traduce concretamente una toma de posición del Estado municipal ante el proceso estudiado.

Ante ello, el objetivo general de esta investigación apunta a analizar el proceso de verticalización que se produjo en el centro bernalense, con el fin de indagar en las lógicas adoptadas por los diferentes actores intervinientes, durante el periodo 20062018. Para su desarrollo, se describen los cambios urbanísticos, vinculados al perfil edilicio y las características socioeconómicas de los habitantes que se produjeron en la ciudad a partir de la rezonificación de usos del suelo, analizando el papel de la normativa en torno a la reconfiguración del centro de la ciudad de Bernal. En segundo lugar se indagan las lógicas (prácticas y discursos) de los actores que intervienen en el proceso de reconfiguración del centro de Bernal, a través del aumento del proceso de verticalización, y se identifican los impactos y tendencias del proceso estudiado en el régimen de tenencia habitacional, y en flujos de expulsión de habitantes. Por último, se analizan las interrelaciones entre los aspectos normativos y las lógicas de los actores en 
la promoción de modalidades de construcción que intensifican las asimetrías en la ciudad.

Para llevar a cabo la investigación se adopta una estrategia metodológica desde una perspectiva predominantemente cualitativa. Se realizó una lectura exhaustiva de bibliografía y artículos referidos al problema, y se recopilaron datos de fuentes secundarias (análisis de publicaciones periodísticas). De manera complementaria, se llevó adelante un relevamiento en terreno, a partir de la observación no participante, y registro de campo, para la elaboración de cartografía, acompañada por la fotointerpretación y comparación de imágenes satelitales. Además, se llevaron a cabo entrevistas semi-estructuradas e interpretativas a informantes clave para abordar todas las voces de los actores involucrados.

Finalmente, la estructura de la tesis está formada por dos partes y cinco capítulos, donde se abordan las cuestiones teórico-conceptuales, principales antecedentes, las tendencias recientes a nivel metropolitano, partido y localidad, y luego se lleva adelante el análisis del caso y el desarrollo de los objetivos propuestos. Se finaliza con un capítulo de reflexiones finales y futuras líneas de indagación.

Palabras clave: Desarrollo; neoextractivismo urbano; verticalización; ciudad excluyente.

\section{$\underline{\text { Índice de contenidos }}$}

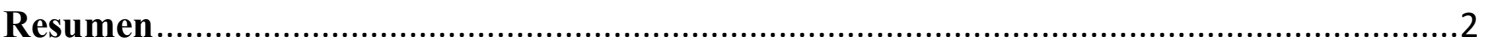

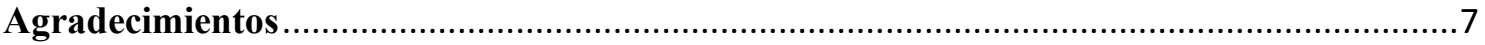

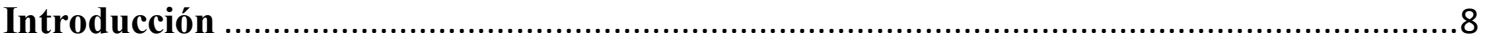

Parte I: Marco teórico-conceptual y estado de la cuestión ................................................20

Discusiones en torno al territorio y su vínculo con el modelo de desarrollo extractivo.

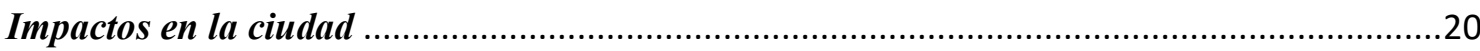

Capítulo I: Notas conceptuales para la elaboración de un enfoque territorial crítico del

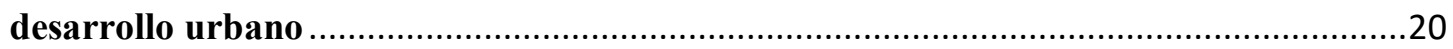

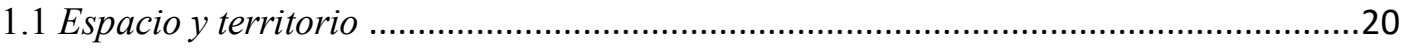

1.2 Debates en torno a modelos de desarrollo y su impacto en el territorio .......................23

1.3 Modelo de desarrollo extractivo y su expresión en la ciudad......................................28 
1.4. Estado, políticas públicas y gestión urbana: empresarialismo urbano .33

Capítulo II: Acerca de los actores y las disputas en torno a la ciudad .............................37

2.1 Derecho a la Ciudad y Acceso al hábitat urbano ......................................................37

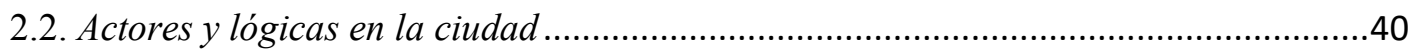

2.3. Crecimiento urbano, consolidación de (sub) centralidades y densificación en ciudades latinoamericanas. Estructura, régimen y modelos urbanos latinoamericanos ....................43

2.4 Gentrificación urbana, desplazamientos y segregación espacial .................................48

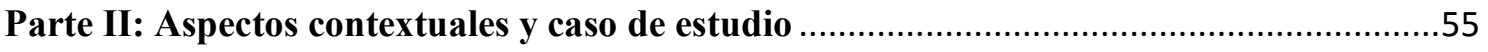

Capítulo III: La Región Metropolitana de Buenos Aires (RMBA) como escenario para

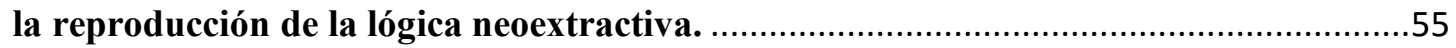

3.1 La RMBA como escenario de la lógica del extractivismo urbano ...............................55

3.2 El partido de Quilmes en la RMBA y su configuración territorial................................61

3.3 La localidad de Bernal y sus tendencias recientes .....................................................66

Capítulo IV: Caso de estudio. El centro de Bernal 2006-2019 .........................................69

4.1. Presentación del caso, y tendencias recientes en el perfil urbanístico y

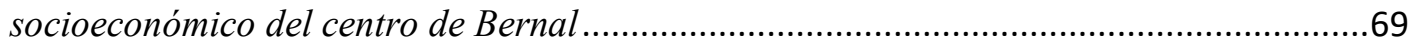

4.2. Reconocimiento de actores sociales y relaciones en la disputa por la centralidad

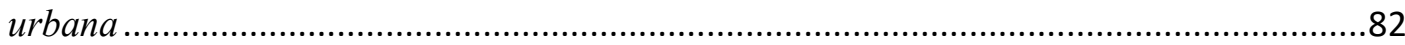

4.3. Aproximación cualitativa a las transformaciones recientes: Lógicas y discursos de los

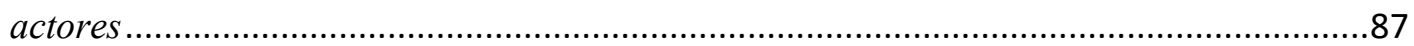

4.4. Aproximación a los impactos urbanos producto del proceso de verticalización del

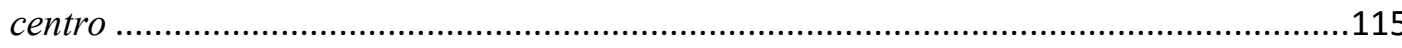

Capítulo V: Reflexiones finales y posibles lín eas de investigación ...................................132

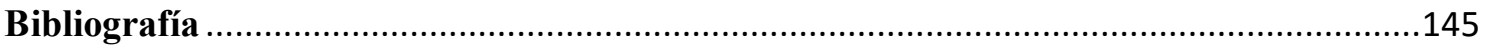

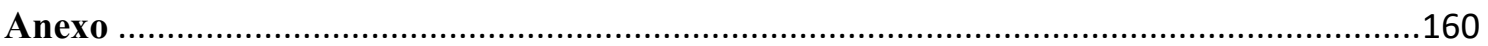

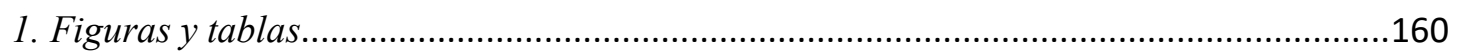

2. Relevamiento en terreno. Fotografias por manzana en área de estudio...........................164

\section{Índice de figuras}

Figura 1: Esquema conceptual. Síntesis y articulación de conceptos.................................54

Figura 2: Mapa de partidos de la Región Metropolitana de Buenos Aires. ........................55

Figura 3: Mapa de localidades del partido de Quilmes..................................................61 
Figura 4: Mapa del área de estudio. El centro de Bernal.

Figura 5: Presencia de viviendas multifamiliares en altura en área relevada de Bernal, año

2004.

Figura 6: Presencia de viviendas multifamiliares en altura en área relevada, año 2019...71

Figura 7: Mapa de obras de infraestructura vial en Bernal. .........................................76

Figura 8: Fotografías de las principales obras de infraestructura vial en Bernal centro...77

Figura 9: Conjunto de servicios destacables en el centro de Bernal. .............................80

Figura 10: Actores identificados ...............................................................87

Figura 11: Algunos de los folletos informativos distribuidos por Bernal Unido. ..............99

Figura 12: Asamblea de Bernal Unido. Reclamo año 2015.........................................100

Figura 13: Hitos significativos de Bernal. Período 2004-2019. ..................................101

Figura 14: Estrategias de comercialización en futuras construcciones..........................105

Figura 15: Estrategia de comercialización. Cartelería en emprendimiento de la calle Belgrano y 25 de Mayo. 106

Figura 16: Edificaciones de gran altura en el centro de Bernal para garantizar la vista al Río de La Plata. 109

Figura 17: Publicaciones relevantes sobre estrategias de comercialización de departamentos en revista "Todo Propiedades".

Figura 18: Grandes casas de Bernal centro en venta, y anuncios de las empresas desarrolladoras de "lo que se viene". 126

\section{$\underline{\text { Índice de Tablas }}$}

Tabla 1: Cantidad absoluta y relativa de edificios en altura en el Partido de Quilmes en distintos cortes temporales.

Tabla 2: Porcentaje de inquilinos y departamentos según los diferentes censos en el área relevada.

Tabla 3: Total de población en área relevada del centro de Bernal según censos de población .73

Tabla 4: Incremento en el nivel educativo en el área relevada y a nivel partido. .78 
Antes de los andenes la línea de la llanura verde y sola en la retina de la pampa.

Detrás del nuevo almacén sienten los más viejos el aroma a pulpería.

Dos veces fue fundada Buenos Aires, cinco intendentes inauguraron esta plaza flora de los yuyos.

Se adelanta la tarde con los balcones deshabitados, saludan decorativas sus plantas, y regalan sus pétalos de plástico a quienes buscan a dos metros del piso un recoveco de estacionamiento.

Debajo de la peatonal pavimentada desfilan en guardapolvos los mismos viejos con aroma a recuerdo.

Frente a la foto revelada, un niño sonrie sobre el ombú del centro:

Donde el niño, donde la sonrisa, donde el ombú, solo el CENTRO.

-Lucas Ballar-

Septiembre 2019

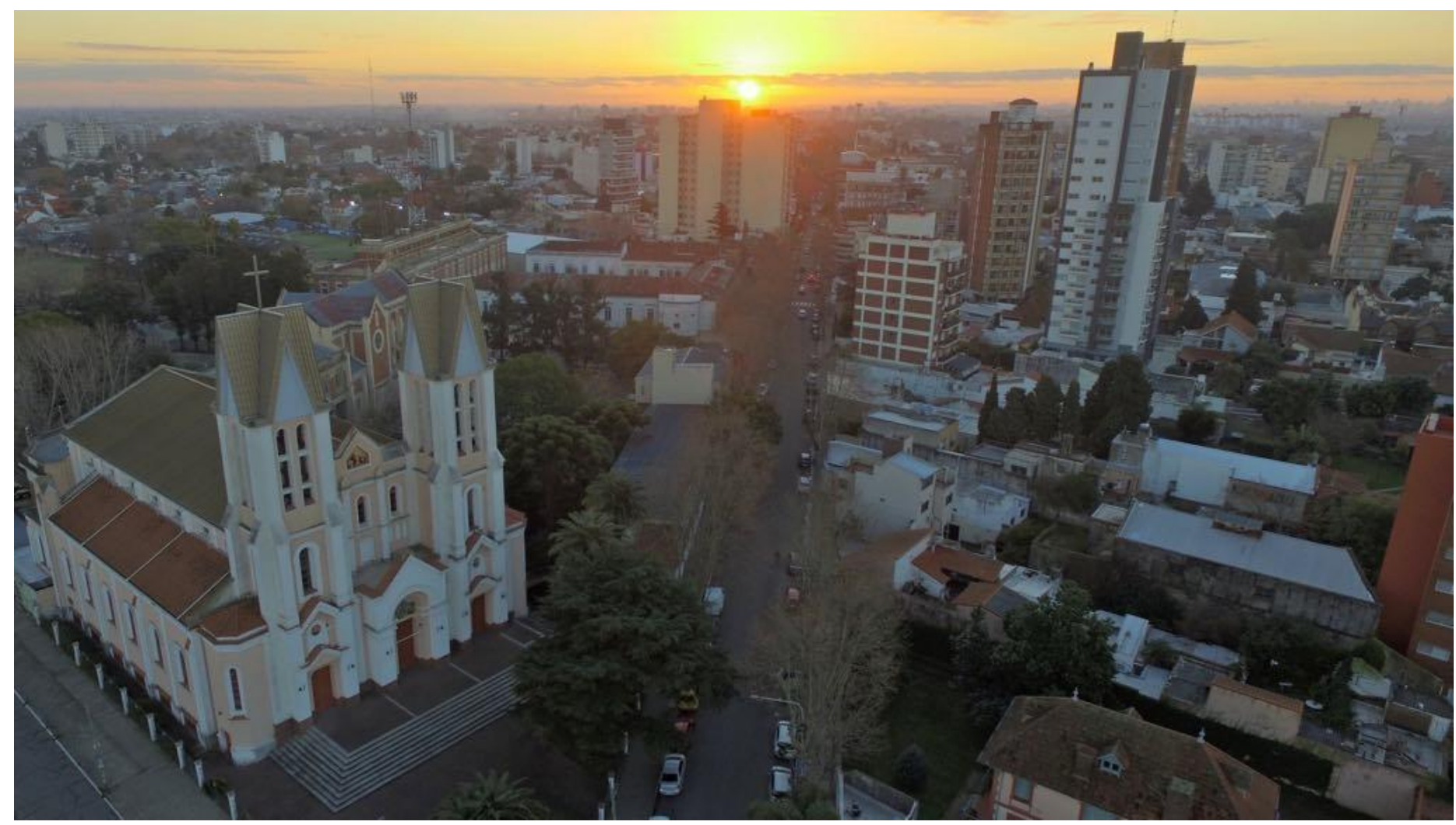

Parte de Bernal centro desde la altura. 


\section{Agradecimientos}

Siempre hay mucho por agradecer, porque escribir una tesis es una labor ardua, que implica muchas horas, días y meses dedicados, pero también involucra a muchas personas que aportan al camino transitado en mayor o menor medida.

El agradecimiento especial es para Gastón, quien supo guiarme y acompañarme desde el primer día. Su dedicación e impulso incansablemente fueron grandes motores para que este trabajo de investigación sea posible.

También extiendo la gratitud a mis compañeros del LINTA, en especial a Juan Pablo, Mari y mis compañeros/as becarios/as, quienes no solo me escucharon más de una vez sino que siempre colaboraron a través de sus aportes en cada encuentro.

Asimismo, con relación a la Maestría, quiero agradecer a los profesores y compañeros/as de la 3era cohorte, quienes han aportado sus diversos conocimientos no solo referidos a lo académico sino también sobre la gestión en los muy diversos intercambios que se producían clase a clase. En lo particular, agradezco a Leyla por su absoluta predisposición a siempre dar una mano.

No puedo dejar de agradecerle a todos los bernalenses (y también quilmeños) que brindaron su tiempo y buena voluntad al momento de las entrevistas y relevamiento en terreno. Sin dudas han facilitado en gran medida el trabajo de campo realizado para que en esta tesis se reflejen las voces de los actores.

La familia y los amigos no pueden faltar en esta instancia. A mamá por el acompañamiento incondicional durante parte del trabajo de campo. A papá por siempre querer saber sobre el estado de avance de la tesis. A Martín por la paciencia y el empuje diario. A Sol y Vicky por el apoyo y la palabra de aliento en momentos de crisis.

A mi madrina, siempre predispuesta a dar una mano.

A mi prima por la ayuda con la edición de muchas de las imágenes.

A Lucas por el poema.

A todos ellos, y a quienes han participado en alguna medida de este trabajo, este GRACIAS es para ustedes. 
"El acceso al suelo urbano constituye con frecuencia el factor decisivo de integración a la ciudad, la primera forma de reconocimiento de una plena ciudadania" (Durand-

Lasserve, 1997:10)

\section{Introducción}

La realización de la presente tesis supone la culminación de la carrera de Maestría en Políticas de Desarrollo de la Facultad de Humanidades y Ciencias de la Educación (FaHCE), Universidad Nacional de La Plata (UNLP). Intenta plasmar los conocimientos teóricos y metodológicos obtenidos a lo largo de un proceso formativo que se fue enriqueciendo en las instancias de grado y posgrado, en relación a la construcción del espacio urbano y las lógicas que en el intervienen.

La temática de interés en la cual se encuadra esta tesis se relaciona estrechamente con la línea de investigación que fui desarrollando a lo largo de mi formación, en torno a las problemáticas en el ámbito urbano, y que tiene como principal protagonista al territorio. Desde hace ya varias décadas, se fue convirtiendo cada vez más en una mercancía, producto de transformaciones territoriales con el objetivo de extraer el mayor provecho económico posible. El territorio resulta atractivo de ser explotado por prácticas extractivas que alimentan una dinámica de despojo o desposesión de bienes comunes, y por ende, de derechos individuales y colectivos.

En América Latina, la lógica extractiva, basada en la ocupación destructiva de los territorios (Svampa, y Viale, 2014), se ha ido expandiendo hacia territorios antes considerados improductivos, no solo en el ámbito rural sino también urbano. Las ciudades fueron marcadas por la especulación inmobiliaria, la emergencia habitacional, la multiplicación de construcciones "premium" y los megaemprendimientos urbanos y turísticos, tratando de captar la mayor renta urbana posible. Harvey (2008) sostiene que las metrópolis se convirtieron en el punto de colisión masiva de la acumulación por desposesión que se impone sobre los que menos tienen y pretende colonizar o depredar espacio para los ricos.

Sin dudas, el rol del Estado fue clave en todo este proceso, porque responde a la lógica política en la producción y gestión del espacio urbano (Pírez, 1995). El Estado, tuvo diversos roles dependiendo del contexto político. Tradicionalmente, durante los años '50, en el contexto latinoamericano, los estados desarrollistas sostuvieron una visión productivista del desarrollo donde se defendía el crecimiento económico como 
motor del desarrollo, que se sustentaría especialmente en dos pilares: exportaciones e inversiones. La garantía del crecimiento estaba basada en la sustitución de las importaciones, y en fomentar el mercado interno de cada país a través de la industrialización. Su caída fue seguida por Estados burocrático-autoritarios, que junto a un Estado que aceptaba las reformas de mercado, y que sostenía discursos definidos como neoliberales. De esta manera, el Estado avaló las leyes del mercado (Lechner, 1997), con la capacidad de operar sobre grandes escalas territoriales tanto en materia de modificación de la legislación urbanística, como de inversiones de interés para los actores del sector privado.

En el afán por conseguir un Estado más funcional con la racionalidad económica de las empresas desarrolladoras del mercado inmobiliario, se fue perdiendo la capacidad de regular y controlar funciones y actividades que requieren de su intermediación. Con el traspaso de las funciones reguladoras del Estado hacia empresas privadas, la autoridad del mismo se vio modificada. Esta situación convierte al Estado - de fines de los años '80 y principio de los '90-en promotor del capital privado, favoreciendo la desregulación de los mercados, la promoción de capital e iniciativas privadas, y replegando su intervención en el sector y en el espacio público. En este sentido, las políticas neoliberales tuvieron un rol importante en la construcción del territorio y por lo tanto en la planificación territorial, promoviendo una noción de desarrollo del territorio directamente vinculado con la mercantilización del mismo. Sin embargo, ya entrando en la primera década del siglo XXI, el Estado comienza a tener un rol más activo, como productor y regulador de la economía, y su accionar va de la mano con políticas sociales dirigidas a sectores vulnerables de la sociedad. Pero en una economía periférica como la latinoamericana, esta intervención estatal se ve limitada frente al poder de las grandes empresas, que continúan llevando adelante las prácticas extractivas en el territorio. De esta manera, la gestión pública del territorio por parte del Estado en el contexto de las interfaces entre el neoliberalismo y neo-desarrollismo, parecen continuar posibilitando los procesos provocados por la lógica extractiva, ya que terminan respondiendo de manera funcional a los procesos de desposesión (Pintos, 2012).

Nuestro país no fue la excepción a la regla ya que avanzó en la conformación de un patrón de acumulación de capital basado en la exportación casi sin procesamiento de los bienes comunes hacia los centros capitalistas, y de esta forma fue entrando en una etapa de acumulación capitalista vinculada, bajo una u otra forma, al modelo de desarrollo extractivo (Féliz, 2012). Esta dinámica no solo proveyó de alimentos y materias primas 
baratas para los países capitalistas del centro sino que -fundamentalmente- aportó a su desarrollo de formas de explotación basadas en la generación de plusvalía relativa. Así, se permitía la generación de elevados ingresos, concentrados en las clases propietarias, sin producir un efecto "derrame" hacia el conjunto de la sociedad. Esto llevó a promover la apropiación de rentas extraordinarias en manos de unos pocos, que luego dieron pie para que se desarrollara en las ciudades un gran proceso de especulación de la mano de diversas empresas constructoras y desarrolladores inmobiliarios.

Es decir que el modelo neoextractivo - prácticas extractivas con un nuevo rol de los Estados- encontró en las ciudades un espacio donde invertir los excedentes, dando lugar a procesos de especulación inmobiliaria y otros tipos de expresiones urbanas, que expulsan y provocan desplazamientos de población, acumulan capital, se apropian de lo público, y provocan daños ambientales. En este contexto, se entregan bienes comunes como el suelo urbano, diversos inmuebles del Estado, y espacios verdes, y se impulsa a la mercantilización de la vivienda. De esta manera, los inmuebles terminan por convertirse en un commodity o un bien de cambio, es decir, una mercancía, promoviendo espacios sacrificables en pos del crecimiento y modernización de la ciudad, que se convierten en renta para las corporaciones inmobiliarias (Svampa, y Viale, 2014). A partir de ello se transfiere renta urbana, donde el Estado termina muchas veces promoviendo este tipo de lógicas y reproduciendo la estructura y las reglas de funcionamiento de los procesos productivos capitalistas, volcados a la competitividad, la eficiencia, la maximización de la renta y la externalización de los impactos sociales y ambientales (Gudynas, 2010).

Los procesos antes mencionados, tuvieron y tienen expresión en las grandes ciudades latinoamericanas. Las formas particulares que asumen los procesos de producción y de apropiación del espacio urbano construido por parte del mercado inmobiliario o el mercado de suelo, promueven una articulación general entre el capitalismo y la estructura urbana. En otras palabras, dado que los rasgos y las funcionalidades del mercado de suelo cambian en cada una de las fases del capitalismo, las formas institucionales que asume dicho mercado sirven como uno de los principales mecanismos reguladores del patrón de acumulación urbana (Abramo, 2011). Una expresión de ello es el proceso de crecimiento urbano, producido por distintos cambios tecnológico-productivos, político-institucionales, y socio-culturales, y que se manifiestan en términos físicos, a partir de los procesos de densificación de las áreas centrales y pericentrales -a partir de la verticalización o crecimiento en altura-, en la 
expansión casi indefinida de los suburbios, y el desarrollo discontinuo del tejido urbano existente. Las distintas lógicas de urbanización van a tratar de apropiarse de las sobreganancias de localización, invirtiendo en las localizaciones favorables para la concentración espacial de los capitales. Este proceso es impulsado por la conectividad otorgada por los trenes, y la red de rutas y avenidas, que fueron contribuyendo a que se conformen, en ciertos territorios, mayores densidades de población y de actividades terciarias y, por lo tanto, que se eleven cada vez más los precios del suelo metropolitano (Ciccolella, Vecslir y Baer, 2015). Pero también estos profundos procesos de reorganización socio-espacial incluyen tendencias contradictorias, ya que por un lado producen fragmentación territorial, y por otro, genera reconfiguraciones de la centralidad. Es así como a partir de una nueva etapa de crecimiento económico en varios países latinoamericanos, y de un cierto cambio de rumbo en las políticas públicas, algunas ciudades comenzaron a mostrar indicios de revitalización y un considerable dinamismo inmobiliario volcado a la construcción, especialmente de vivienda multifamiliar de cierta calidad en centros y subcentros urbanos.

Este proceso genera impactos concretos en la ciudad, tales como el aumento de alquileres y del valor del metro cuadrado $\left(\mathrm{m}^{2}\right)$, incremento de población inquilina, demandas de infraestructura al Estado municipal que se socializa, y a prestadoras que trasladan costos a las tarifas. Esta metamorfosis de la ciudad consolidada ha generado diversos efectos, tales como la gentrificación, el desplazamiento y la desposesión (Janoschka, 2016). Muchos habitantes no están incluidos ni son destinatarios de los emprendimientos producidos en el centro de la ciudad, situación que llevaría a su expulsión por no estar en condiciones de acceder a los alquileres en aumento, u optan por escapar de la densificación del centro con todo lo que ello conlleva.

Sin dudas, esta situación genera diversas expresiones de la voluntad colectiva, vinculadas a la posibilidad de acceder o no a la ciudad, o permanecer en ella, y por lo tanto, gozar o no de los diferentes tipos de derechos, como el del acceso al hábitat urbano. El derecho a la vivienda constituye un componente sustantivo en las condiciones de vida de los grupos sociales. El problema del acceso y derecho a la vivienda, entendida como hábitat, resulta condición para la satisfacción de un conjunto de necesidades humanas primordiales. Asimismo, el acceso a la vivienda es indisoluble del problema de la segregación residencial, la cual se alimenta de la desigual distribución de la infraestructura y tiende a reforzar la diferenciación de la ciudad en zonas que concentran a quienes poseen mayores recursos, frente a áreas con población 
de menores recursos. Más allá de esta demanda colectiva, diversos autores, entre los que se destacan Lefebvre (1975), Carlos (1992), Harvey (2004), Borja (2011), y Soja (2013), eligieron hablar de derecho a la ciudad, que no solo consiste en ejercer el derecho al acceso a la vivienda sino también se basa en la posibilidad de elegir qué clase de entorno se desea y de construir una ciudad en la que se pueda vivir dignamente, reconocerse como parte de ella, y donde se posibilite la distribución equitativa de diferentes tipos de recursos. Ante ello, Pírez (2014) para su planteo toma la concepción más amplia de Lefebvre (1969) sobre el espacio urbano concebido como centralidad como posibilidad de participación de la totalidad heterogénea que define a lo urbanofrente a la exclusión. Este autor, explicita que el derecho a la ciudad ${ }^{1}$ se disputa en la centralidad, y consiste en gozar de la totalidad de la riqueza de una ciudad, es decir, tener derecho al suelo urbano, a la vivienda, al transporte, a las infraestructuras y equipamientos urbanos y sociales, a sus servicios, etc. Por su parte, Oszlack (2018) plantea el derecho al espacio urbano, inspirado en una pérdida de derechos debido a que diferentes actores no consiguen acceder a la ciudad o permanecer en ella, y por lo tanto, gozar o no de los diferentes tipos de derechos.

Dentro del contexto latinoamericano, la Región Metropolitana de Buenos Aires (en adelante RMBA) experimentó diversos proyectos inmobiliarios que producirían rentas extraordinarias bajo la lógica extractiva, como la construcción de shoppings centers, urbanizaciones cerradas, inmuebles para el turismo, y grandes edificaciones comerciales o residenciales, de la mano de grandes actores privados. A través de estas expresiones, se entrecruzan políticas públicas, diferentes lógicas de acción, y territorialidades diversas (Svampa y Viale, 2014). El dinamismo del desarrollo inmobiliario en los últimos años fue relevante, y visible en el aumento de los permisos de construcción, los tipos y usos de suelo habilitados en los centros y subcentros de diversos partidos de la RMBA. El partido de Quilmes no escapó a esta tendencia, al igual que algunos subcentros tradicionales que renovaron parte de sus funciones, como el caso de Bernal destacado además por su jerarquía en el sistema de centralidades del partido.

La presente tesis es abordada desde una aproximación paradigmática de hibridez, que procura articular elementos del paradigma crítico de investigación y del paradigma

\footnotetext{
${ }^{1}$ Pírez (2014) para su planteo toma la concepción más amplia de Lefebvre (1969) sobre el espacio urbano concebido como centralidad -como posibilidad de participación de la totalidad heterogénea que define a lo urbano- frente a la exclusión.
} 
constructivista. Por el contrario, intenta alejarse de postulados positivistas y postpositivistas en la investigación social.

Respecto al paradigma basado en la teoría crítica, repercute en una práctica investigativa que otorga protagonismo al esquema investigación-reflexión-acción, lo que implica en este caso que se busca aportar insumos de conocimiento potencialmente útiles para generar cambios y una disminución en la desigualdad de oportunidades en un determinado contexto social. La búsqueda de transformación social se basa en la participación comprometida con la investigación, la colaboración desde la reflexión personal crítica y los aportes para la acción, susceptibles de convertirse en insumos para políticas públicas orientadas al desarrollo.

Desde el punto de vista ontológico, y siguiendo a diversos autores (Guba y Lincoln, 2002; Ramos Galarza, 2015) la realidad es interpretada como un producto de la influencia de un conjunto de factores relacionados con lo social, político, cultural, económico, las diferencias de clase, entre otros. Ante la pregunta epistemológica este paradigma afirma que existe una interacción entre el investigador y el objeto investigado, dando lugar a la participación de todas las etapas de la investigación mediante un diálogo dialéctico (Martens, 2003 citado en Hernández et al, 2010; Ramos Galarza, 2015). Se procura comprender cómo pueden cambiar las estructuras de una sociedad y entender las acciones necesarias para efectuar el cambio. La teoría crítica, por lo tanto, considera a lo real como producto de un historicismo social y las estructuras sociales e instituciones, por tanto, como modalidades históricas coyunturales, no naturalizadas, susceptibles de modificaciones.

Si bien la metodología clásica de este paradigma es la investigación acción participativa, el diseño de la estrategia metodológica de esta investigación no responde a dicho esquema, sino que se nutre de los aspectos metodológicos derivados del paradigma constructivista. Según Gergen (2007, citado en Ramos Galarza, 2015) en el constructivismo se brinda gran interés al cómo se producen los significados, donde los individuos otorgan significados dentro de marcos de referencia interpretativos, basados en la historicidad y en lo cultural. Por su parte, Hernández et al (2010) afirman que el constructivismo es un sustento para la investigación cualitativa y aporta un abordaje basado en una reconstrucción necesariamente subjetiva parcial y situada de un determinado problema en un contexto socio histórico y espacial determinado. De allí la necesidad de trabajar con un caso y abordar la estrategia metodológica como una forma de construir evidencia empírica del problema abordado. 
Algunas premisas centrales de este enfoque paradigmático que tiene fuertes implicancias metodológicas e interpretativas en esta tesis son: a) La realidad se construye socialmente y coexisten diversas formas de percibirla. De allí que haya discrepancias en las interpretaciones de los fenómenos estudiados por parte de diversos actores, y entre estos y algunos datos construidos para este estudio; b) el conocimiento se construye de forma social por los participantes en el proceso investigativo, de allí la importancia brindada a la metodología cualitativa y las técnicas de observación y entrevistas; c) la investigación implica un compromiso vivencial y profesional para el investigador; y d) los resultados no pueden ser generalizados en forma ajena al contexto espacio temporal, sino que el método asumido es el de la teoría fundamentada emergente, que de acuerdo a lo hasta aquí expuesto, se pretende que constituya un punto de partida para la realización de aportes críticos susceptibles de enriquecer el arsenal conceptual y metodológico a la hora de diseñar e implementar políticas de desarrollo urbano en el contexto municipal.

Considerando lo expuesto, en esta investigación se parte de la premisa, a modo de hipótesis de trabajo, que sostiene que la construcción de edificios o urbanizaciones residenciales en altura ha ido en aumento, produciendo modificaciones que dan lugar a procesos de renovación urbana competitivos, marcando de este modo un dominio de los procesos especulativos llevados a cabo en la ciudad que promueven modalidades de construcción para sociedades selectivas y desiguales, que intensifican y producen asimetrías en la nueva ciudad excluyente. Se hace referencia al modelo de ciudad que se consolidó en los últimos años, en donde se construye y se vende un ideario de desarrollo mediante un sistema donde prima la lógica de mercado, que construye ciudad para un único sector social. Se considera pertinente trabajar con un caso del Partido de Quilmes, porque resulta un ejemplo significativo del fenómeno que intenta comprenderse y que trasciende al caso en sí mismo. En ese sentido, el área central de la localidad de Bernal constituye un caso relevante dado que se manifiestan importantes transformaciones territoriales en los últimos años. Con respecto al recorte temporal, se analiza el caso a partir del año 2006, porque coincide con la rezonificación de usos del suelo, normativa que cristaliza un proceso de excepciones previas, y que traduce concretamente una toma de posición del estado municipal ante el proceso estudiado. 
Se partió de dos interrogantes, que ayudaron a orientar y estructurar el trabajo de investigación. Por un lado, se parte de la pregunta, ¿de qué manera el proceso de verticalización promueve modalidades de vivienda para sociedades selectivas $\mathrm{y}$ desiguales, y que intensifican las asimetrías en Bernal?, y por otro, ¿Cuáles son las lógicas adoptadas por los diversos actores frente a esta problemática?. Entonces, el objetivo general que se persigue es el de contribuir a la discusión en torno al modelo extractivo en particular su reproducción en las ciudades, a través del análisis del proceso de verticalización y los impactos producidos en el centro de la localidad de Bernal (Partido de Quilmes), con el fin de indagar en las lógicas adoptadas por los diferentes actores que lo promovieron, durante el periodo 2006-2019. De ello se derivan los objetivos específicos: I) Describir los cambios urbanísticos, vinculados al perfil edilicio y las características socioeconómicas de los habitantes, que se produjeron en la ciudad a partir de la rezonificación de usos del suelo, analizando el papel de la normativa en torno a la reconfiguración del centro de la ciudad de Bernal; II) Indagar en las lógicas (prácticas y discursos) de los actores que intervienen en el proceso de reconfiguración del centro de Bernal, a través del aumento del proceso de verticalización; III) Identificar $\mathrm{y}$ ponderar impactos y tendencias del proceso estudiado en el régimen de tenencia habitacional, y en flujos de expulsión de habitantes; y IV) Comprender las interrelaciones entre los aspectos normativos y las lógicas de los actores en la promoción de modalidades de construcción que intensifican las asimetrías en la ciudad.

Es por ello que resulta de interés proponer una discusión sobre el extractivismo en la Argentina de hoy, y en un caso de la Región Metropolitana de Buenos Aires en particular, reflexionando sobre el territorio, y más precisamente sobre la realidad urbana producto de las transformaciones llevadas a cabo por diferentes actores con lógicas e intereses contrapuestos. Se aporta un análisis en torno a una expresión del extractivismo urbano, relacionado al aumento de la verticalización en los centros, y los impactos que ha tenido en el acceso diferencial a la centralidad urbana.

El abordaje metodológico es resultado de un proceso de aproximación a un objeto de estudio en constante reformulación. Es por ello que se parte de un diseño de investigación flexible que admitió una articulación entre las diferentes etapas de la investigación y contempló la posibilidad de que se desarrollen situaciones inesperadas que pudieran implicar nuevas posibilidades para el abordaje del objeto (Valles, 1999; Piovani, 2007). Para llevar a cabo esta investigación se adoptó una estrategia 
metodológica de triangulación (Marradi et al, 2007) que procura establecer un diálogo entre aportes de estrategias cualitativas y cuantitativas, para realizar una interpretación de manera compleja el problema. Con la adopción de perspectivas de tipo cualitativa, se busca obtener información que remita al orden de la significación, la perspectiva y la visión del investigado (Barrionuevo, 2011; Stake, 1999), y se complementa con estrategias cuantitativas, centradas en los aspectos observables susceptibles de cuantificación por medio del análisis de datos estadísticos.

Se llevó adelante el análisis de un caso, en términos de Stake (1994) considerado instrumental, siendo un ejemplo significativo del fenómeno que intenta comprenderse. Tomar un caso permite estudiar un fenómeno contemporáneo dentro de su contexto situado y real.

En cuanto a las técnicas, en una primera instancia se realizó la lectura de bibliografía para la construcción del abordaje teórico y de antecedentes sobre el tema, y artículos referidos al problema particular de este trabajo. Por otro lado, se recopilaron datos de fuentes secundarias, como el análisis de publicaciones periodísticas en los diversos medios de comunicación locales y nacionales, que expresaron información sobre los cambios que se produjeron en Bernal y las reacciones y expresiones de la población ante ellos. De manera conjunta, se llevó adelante un relevamiento en terreno, a partir de la observación no participante, y registro de campo, que posibilitaron, entre otras cuestiones, la producción de cartografía en entorno SIG (Sistemas de información geográfica) para llevar adelante un análisis espacial. Ello fue acompañado de la técnica de fotointerpretación, con el fin de dar visibilidad a esas transformaciones urbanas. Este trabajo permitió realizar una reconstrucción del proceso de verticalización en dicha área, y los cambios a nivel comercial, principalmente a partir de la comparación de imágenes satelitales en diferentes cortes temporales (2004 y 2017), y recorridos en campo. A ello se sumó, la recopilación de información publicada en las páginas web propias de los desarrolladores e inmobiliarias que dieron a conocer las características y amenities de edificios de vivienda multifamiliar, y los emprendimientos en desarrollo.

Respecto al relevamiento de datos de fuentes primarias, se llevaron a cabo diversos registros de campo que permitieron la sistematización y reconstrucción del problema analizado. Los registros implican entrevistas semi-estructuradas e interpretativas a informantes clave como habitantes del centro de Bernal, vecinos históricos y más 
recientes, residentes movilizados por los fenómenos estudiados ${ }^{2}$, comerciantes, funcionarios y técnicos del municipio, e inmobiliarias locales, con el fin de recopilar todas las voces de los actores implicados para analizar las lógicas adoptadas. Entre ellas, se intenta recuperar el papel del municipio en torno a la gestión de la ciudad y su perspectiva sobre el desarrollo urbano, las voces de los vecinos que se agruparon frente a la rezonificación y la llegada de los edificios a Bernal, y los intereses de los desarrolladores e inmobiliarias acerca del proceso de modernización del centro. El trabajo con entrevistas, permitió una aproximación a la respuesta de los entrevistados, con el objetivo de conocer y entender procesos, acciones, sensaciones y otros aspectos de los mismos, además de recuperar el papel estratégico de las maneras de pensar y sus comportamientos.

Para la selección de los casos a entrevistar, por un lado se realizó un tipo de muestreo teórico, donde los participantes se eligen a partir del conocimiento teórico que se va construyendo en el transcurso de la investigación, con la información que va emergiendo a lo largo del estudio (Martínez Salgado, 2012). También se llevó adelante el tipo de muestreo por bola de nieve (Valles, 1999; Martínez Salgado, 2012; Pérez Luco et al, 2017), donde un informante anticipa al investigador quien podría ser otro potencial informante y se genera de esta manera una cadena o secuencia de entrevistas a partir del aporte de un informante para llegar al siguiente. Durante el momento de realización de las entrevistas, el criterio de saturación teórica fue clave para culminar la etapa de trabajo con informantes, debido a la inexistencia de nuevos aportes y perspectivas para la caracterización y comprensión del fenómeno estudiado.

De manera complementaria, se respaldó la información con la búsqueda y análisis descriptivo de datos estadísticos de los censos de población 1991, 2001 y 2010 provistos por el Instituto Nacional de Estadísticas y Censos (INDEC), y la Dirección de Estadística de la Provincia de Buenos Aires. Se realizó una revisión de las principales modificaciones normativas, a través de la búsqueda, interpretación y análisis de contenido sobre documentos oficiales, como normativas y Planes Estratégicos para el partido de Quilmes. Esta técnica significó un aporte para al análisis del rol del Estado, quien a partir de la planificación territorial lleva adelante una actividad políticoacadémica prospectiva con un fuerte vínculo con los modelos de desarrollo vigentes al momento de su formulación e implementación (Clichevsky y Rofman, 1989, p.61).

\footnotetext{
${ }^{2}$ En el caso de estos informantes, se manifestó cierta restricción metodológica por negación a dar entrevista.
} 
Con respecto a la estructura, la presente tesis se organiza en dos partes y tiene un total de cinco capítulos.

La primera parte, titulada Discusiones en torno al territorio y su vínculo con el modelo de desarrollo extractivo. Impactos en la ciudad, consiste en dos capítulos que presentan el marco teórico-conceptual, desde los conceptos más generales hasta los particulares con los que se aborda la problemática estudiada, en conjunto con los antecedentes más significativos para encuadrar el enfoque de la tesis. Por un lado, en el capítulo uno, se abordan las relaciones entre conceptos clave como el de espacio, territorio, desarrollo (extractivismo), y políticas públicas con un fuerte anclaje territorial. Aquí se presenta el rol que adquiere el Estado en la gestión urbana, a través del empresarialismo urbano. Mientras que en el segundo capítulo se explican las nociones del derecho a la ciudad y al hábitat urbano, donde se pone de manifiesto como espacio político donde se expresan de voluntades colectivas frente a los impactos que generan los procesos de crecimiento urbano, consolidación de (sub) centralidades y densificación en las ciudades. Se hace referencia además a la estructura, régimen y modelos urbanos que imperan en países latinoamericanos, a modo de rastreo de antecedentes. Asimismo, a través de la clasificación de Pírez (2006) se identifican a los demás actores sociales que intervienen en la construcción de la ciudad y sus lógicas. Para finalizar este apartado, se exponen los principales debates en torno a los conceptos de segregación espacial y gentrificación urbana, los desplazamientos y movilidad residencial forzada por mercado, en un contexto de déficit urbano habitacional.

En la segunda parte de la tesis, se procura introducir al contexto de la Región Metropolitana de Buenos Aires como escenario para la reproducción de la lógica neoextractiva, y en particular su expresión en el caso de Bernal, dentro del partido de Quilmes. En el capítulo tres, de carácter descriptivo y contextual, se presentan las tendencias generales de la RMBA, el proceso de crecimiento y las condiciones urbano habitacionales. En este contexto, se caracteriza la configuración territorial del partido de Quilmes y luego, los procesos recientes de la ciudad de Bernal, con el fin de presentar sus antecedentes en materia urbana, su crecimiento, el proceso de rezonificación, la conflictividad social que se produjo en torno a ello, y la posterior consolidación del modelo. 
Por su parte, el capítulo cuatro, con un énfasis más analítico y explicativo, expone los cambios urbanísticos y el perfil socioeconómico en el centro de Bernal. Se analiza el papel de la normativa de rezonificación, se describe el proceso de verticalización y la complejización del perfil comercial, y las percepciones de los actores a partir de lo trabajado en el campo. A ello se suma una aproximación a los impactos urbanos generados por el aumento de las urbanizaciones en altura, principalmente la segregación socio-espacial y la gentrificación, vinculados a la elitización del centro y expulsión poblacional, la falta de oportunidades de acceso al suelo y vivienda en el distrito, y la expulsión por elección de los vecinos más conservadores.

El capítulo final, de carácter explicativo y sintético, retoma las conclusiones parciales expuestas en los capítulos precedentes y sistematiza los principales resultados de la investigación. Se reflexiona en torno a las dicotomías o polaridades que se experimentan en el proceso estudiado, que contrapone por un lado un discurso modernizante y desarrollista; y por otro lado un proceso excluyente que incrementa las asimetrías territoriales, como dos caras de una misma moneda. Por último, se ofrecen conclusiones que abordan la intensificación de asimetrías socio-espaciales como resultado de la densificación del centro de la ciudad, el aumento de dificultades para acceder al hábitat urbano por parte de sectores medios, la disminución del ejercicio de derecho a la ciudad y acceso al hábitat urbano, y la pérdida de oportunidad del Estado de financiar el acceso al hábitat de sectores medios y populares. 


\section{Parte I: Marco teórico-conceptual y estado de la cuestión}

Discusiones en torno al territorio y su vínculo con el modelo de desarrollo extractivo.

\section{Impactos en la ciudad}

\section{Capítulo I: Notas conceptuales para la elaboración de un enfoque territorial crítico del desarrollo urbano}

\subsection{Espacio y territorio}

Son diversas las discusiones y perspectivas en torno al concepto de espacio y territorio, que están fuertemente vinculados pero muchas veces se los aborda con vaguedad. Son conceptos que se han ido transformando, recibiendo sucesivas críticas, reformulaciones y adoptando distintas concepciones.

Hiernaux y Lindón (1993) clasifican diferentes miradas sobre el concepto de espacio geográfico que estuvieron en boga en las últimas décadas. Una primera perspectiva es la que considera al espacio como soporte y continente de las acciones sociales, en donde se localizan elementos y relaciones. Una segunda línea interpreta al espacio como producto social, como un reflejo de la intencionalidad humana, pero muy ligada a la idea de una causalidad directa y no la de una relación dialéctica. En las últimas décadas, se fue desarrollando una perspectiva en la que el espacio participa como condicionante de los procesos sociales y como su producto, ya que los procesos sociales se territorializan, y se construye el espacio a partir de la producción y reproducción de las relaciones sociales.

Por su parte, el territorio es un concepto que tradicionalmente en las ciencias sociales, se ha relacionado de una manera subordinada al espacio. En este sentido, el territorio ha constituido, para algunas tradiciones, un concepto referido a una porción del espacio caracterizada por su uso y ocupación social. Al respecto, Raffestín (1993) sostiene que el "territorio se forma a partir del espacio" (p.144) dado que el territorio se conforma por una acción de apropiación concreta o simbólica del espacio por parte de un actor. Este concepto fue cambiando en torno a la multidimensionalidad, es decir, en la posibilidad de abordarlo desde varias y diversas perspectivas e incluso por la combinación de varias de ellas, o de todas ellas. Previo a las perspectivas más contemporáneas, se desarrollaron algunas tradiciones que se destacaron en el abordaje 
del territorio, tales como: la tradición jurídico- política, la tradición naturalista, la marxista y la humanista (Benedetti, 2008).

La primera se centra en la visión del territorio desde la óptica del control político del mismo por parte del Estado y se asocia fuertemente a la idea de pérdidas o ganancias territoriales, relacionado con la porción de tierra delimitada en su dimensión jurisdiccional de dominio efectivo. Pero el territorio no se reduce a una entidad jurídica, y tampoco puede ser asimilado a una serie de espacios vividos sin existencia política o administrativa reconocida (Blanco, 2007). De allí, Raffestin (1993) realiza una crítica a esta visión del territorio ya que afirma que la geografía no tiene una sola dimensión de análisis, según la cual la idea central para definir el territorio se relaciona al poder estatal, sino que hace referencia a la existencia de múltiples poderes, y sus relaciones van a construir el territorio ${ }^{3}$.

En el otro extremo, la tradición naturalista se encontraría más ligada a la visión del territorio como el espacio necesario y natural de los animales. Esta concepción resulta muy sesgada, sin incluir las nociones implícitas del concepto, como la social y de apropiación del espacio, junto a la idea de ejercicio del dominio y control del territorio. A partir de dichos postulados, desde otra perspectiva teórica se ha reinterpretado que la tradición marxista pondría el acento en la idea de apropiación pero desde una base económica, ya que implica una forma de apropiación de recursos y de la naturaleza, como proveedora de esos recursos necesarios para la reproducción material de un grupo humano (Altschuler, 2008).

Por último, la tradición humanista -desarrollada mayormente en Norteamérica y a partir de la conjunción de las perspectivas de la geografía y la psicología se centraría en el territorio como el espacio vivido, el lugar donde se transita, el refugio.

En todas estas tradiciones, el territorio resulta algo externo a la sociedad, ya que este parece poder controlarse, usarse, aprovecharse, vivirse, desde una perspectiva más bien economicista, y en líneas generales por fuera de las relaciones sociales, como un sustrato material y externo a ellas. De ello surge un planteo más complejo en la concepción del territorio incorporando la dimensión de las relaciones sociales y con ella, la puesta en primer plano del poder, de la historia (temporalidad) y del conflicto,

\footnotetext{
${ }^{3}$ Este autor aporta las nociones de territorialización, desterritorialización y reterritorialización, en base al grado de accesibilidad a la información. El acceso (o no) a ésta, los símbolos y nuevos significados pueden favorecer nuevos territorios (territorialización), destruirlos (desterritorialización) o reconstruirlos (reterritorialización). En esta concepción, cuando un actor realiza una apropiación (concreta o abstracta) de un espacio, lo "territorializa".
} 
así como la deconstrucción de una visión naturalizada, estática del territorio y como soporte de la sociedad, lo que dará lugar a las perspectivas más contemporáneas a partir de los años '70, como la geografía crítica. Se empiezan a considerar las relaciones de poder, las heterogeneidades y asimetrías internas y externas y la distinción entre espacio y territorio.

Estos aportes resultan de los grandes cambios en las visiones sobre el tiempo y el espacio, de la incorporación del aporte de otras disciplinas y perspectivas (como la antropología, la sociología, la historia), y de los procesos de refundación crítica de cada una de estas disciplinas que plantean nuevas dimensiones y perspectivas de análisis, dando lugar a enfoques más complejos, integrados y transdisciplinares para comprender el territorio (Altschuler, 2008).

Uno de ellos es el aporte del enfoque histórico de Sack (1986), quien plantea la territorialidad como construcción social. Entiende que los territorios no son fijos, ni se definen de una vez y para siempre ya que, en tanto dependen de un esfuerzo constante para mantener las estrategias para influenciar y controlar el acceso a través de sus límites, a través de relaciones de poder, un área puede convertirse en territorio, o dejar de serlo. "Las relaciones sociales, por su diversidad, crean varios tipos de territorios, que son continuos en áreas extensas y/o son discontinuos en puntos y redes, formados por diferentes escalas y dimensiones" (Mançano Fernandes, 2008, p.4). Siguiendo esta línea, para Souza (1995), el territorio es entendido como un espacio definido y delimitado por y a partir de relaciones de poder. Y Rogério Haesbaert (2002 y 2004) agrega que los territorios están caracterizados por la superposición de diferentes territorios en un mismo espacio, lo que puede provocar el surgimiento de relaciones de poder nuevas, e incluso, nuevos territorios.

Estas acepciones de territorio, vinculadas a las nociones de apropiación, ejercicio del dominio y control, son las más difundidas y no sólo están limitadas a una dimensión política formal, sino que incluye la idea de espacios vividos y disputados por diversos colectivos sociales (Blanco, 2007). Es atravesado por una dinámica que lo mantiene en una constante construcción, capaz de integrar en sí mismo lo simbólico y lo material (Haesbaert, 2011). En este sentido, se coincide con esta idea de que el territorio es producto de la materialización concreta e histórica de vastas formas de organización social, cuyos componentes necesarios para su delimitación son el ejercicio de poder a través de un actor hegemónico como el Estado y también de otros actores que disputan 
la ocupación, construcción, apropiación y transformación de dicho espacio, proyectando sus propias prácticas atravesadas por proyectos y relaciones afectivas y simbólicas.

\subsection{Debates en torno a modelos de desarrollo y su impacto en el territorio}

El concepto de desarrollo, se ha ido transformando, recibiendo sucesivas críticas y reformulaciones, y adoptando distintas concepciones del territorio. En primera instancia, la utilización del concepto de territorio desde el enfoque del desarrollo es mayormente acrítica y conceptualmente imprecisa, ya que por un lado, al territorio se le da un uso instrumental (y a veces ideológico) desde las teorías del desarrollo, de carácter más normativo que analítico; y por otro, por mucho tiempo operó la hiperespecialización disciplinar que sólo recientemente comenzó a romper sus fronteras y permitió analizar de forma transdisciplinar y más crítica.

Se han dado diversas conceptualizaciones en torno al desarrollo con intensos debates durante su surgimiento en los discursos oficiales, particularmente en Estados Unidos y Europa, en la década del '50, en el contexto de la segunda post-guerra. Una preocupación central de los economistas fue la reflexión acerca de las diferencias económicas entre las regiones y las naciones. La presencia de países con diferentes niveles de crecimiento implicó una desigual distribución del ingreso y la existencia de un porcentaje elevado de la población en condiciones de pobreza y marginalidad. A partir de entonces,

\footnotetext{
“Las décadas del'50 y '60 estuvieron dominadas por teorías desarrollistas, dentro de las cuales podemos señalar como principales a la Teoría de la Modernización y el Estructuralismo de la CEPAL, y también por prácticas intervencionistas desde organismos internacionales en países del Tercer Mundo, en post de promover los cambios necesarios que producirían el desarrollo" (Altschuler, 2008, p.71).
}

La primera de ellas, la Teoría de la Modernización parece plantear una evolución en torno al desarrollo, ya que sostiene que el subdesarrollo es la situación que atraviesan algunos países por estar en una fase del desarrollo anterior, que ya atravesaron los países "más avanzados", es decir, desarrollados. Desde este enfoque, es que Rostow (1965) plantea su análisis correspondiente a la existencia de un solo proceso de desarrollo lineal, acumulativo e igual para todos los países. La idea de capitalismo había 
sido prácticamente desterrada del texto, para justamente reforzar la naturalización de este modo de producción, basado en que cualquier economía, sin excepción, se enfrentara a lo largo de una sucesión de etapas, y sus problemas desde cuestiones técnicas. Es decir, que para esta tradición de pensamiento, los países hoy desarrollados fueron en un primer momento naciones pobres y subdesarrolladas. Sostenía que los obstáculos al desarrollo no poseían fundamentos estructurales o restricciones económicas, sino que eran producto de malas decisiones políticas.

Por su parte, el Estructuralismo intentaba comprender y explicar las características estructurales de la economía latinoamericana. Desde este enfoque, fue la $\operatorname{CEPAL}^{4}$, la que coordinaba las acciones hacia la promoción del desarrollo económico de la región. Frente a los desequilibrios macroeconómicos visibles en América Latina, la solución que planteaba la teoría estructuralista era nacional, motorizada por el Estado y con la contribución del capital internacional que debía ser orientado para constituirse en elemento esencial de apoyo al desarrollo económico e industrial de estos países. Con ella coincide Rofman (2015), ya que insiste en que el rol del Estado es fundamental para asegurar un nuevo equilibrio con pleno empleo, para ir cerrando la brecha de desarrollo que hoy todavía existe entre las estructuras socioeconómicas de la periferia con respecto a sus similares en las áreas de mayor desarrollo relativo.

Mientras tanto, la teoría de la dependencia parte de los procesos de acumulación a nivel mundial y se concentra en la búsqueda de las causas de los desequilibrios entre un centro y la periferia, dentro del capitalismo. Este enfoque analiza la relación entre subdesarrollo y estructuras sociales, desde la teoría del intercambio desigual. Pero a diferencia de los desarrollistas, la solución que plantean los dependentistas fue nocapitalista. Aunque la solución sigue siendo la industrialización, ellos consideraron que la mejor salida es el socialismo, destacando también el rol del Estado, que no fuese burgués y no domine a las clases (Narodowski, y Chain, 2009). Pero lo que sucede, es que las periferias generalmente productoras de recursos naturales, terminan respondiendo a las demandas de los países centrales, inherentes al sistema capitalista dominante de las relaciones comerciales mundiales.

Además, existe otra teoría de la mano de Hirschman (1961), quien dentro del desarrollismo habla de subdesarrollo y da cuenta de los desequilibrios entre regiones, generalmente debidos a la falta de innovación. Algunos países, tienen la necesidad de

\footnotetext{
${ }^{4}$ Es la Comisión Económica para América Latina y el Caribe, y una de las cinco comisiones regionales de las Naciones Unidas.
} 
importar máquinas y tecnología, para llegar a la tan ansiada industrialización. Pero si el consumo supera a la producción, muchas veces implica que se importe en mayor medida y por lo tanto la balanza comercial difícilmente mejore. Ante esta situación de descontento, los actores sociales reaccionan de manera activa, mediante la salida, o alzando su voz participando en diversas acciones que van desde la queja estrictamente privada hasta la acción pública en aras del interés general.

Es decir, que las líneas centrales del debate sobre el desarrollo también se centraron en su carácter reduccionista, economicista, y hasta hegemónica en los círculos de poder de los países centrales, y a partir de entonces se crea la visión de dos terceras partes de la humanidad como subdesarrolladas, a través de los discursos y prácticas del desarrollo, en el marco de una concepción que se califica de "etnocéntrica, arrogante e ingenua" (Escobar, 1996, p.21). Como señala este autor, esto se traduce en la existencia de países con mayores niveles de hambre, crisis, pobreza, y por lo tanto mayor desigualdad. Estos hechos implicarían el fracaso del desarrollo y requeriría el desvelamiento del discurso modernizador como ideológico y construido desde los centros de poder de occidente. Así, se abogó a nuevas reformulaciones y adjetivaciones del concepto de desarrollo tales como el concepto de desarrollo humano (noción de desarrollo multidimensional e integral) que pudiera diferenciarse de la idea del mero crecimiento económico, basado en la evolución del ingreso per cápita, y que diera relevancia a los aspectos políticos, sociales, culturales y ambientales del mismo. Otra conceptualización se da en el marco de la crisis ecológica que comienza a sentirse desde los años '70, donde la Comisión Mundial sobre Medio Ambiente y Desarrollo5', introduce el concepto de desarrollo sostenible o sustentable que intenta incorporar al concepto de desarrollo las preocupaciones y críticas ambientalistas que ya eran fuertes en los años '80. Buscaba un estilo de desarrollo que no comprometa el porvenir de las futuras generaciones.

El desarrollo, empieza a remitir al rol de los gobiernos y actores sociales en general, y a partir del enriquecimiento conceptual, se fue produciendo una diversificación de los significados del término junto a una serie de adjetivos que van a involucrar al territorio, tales como desarrollo territorial, desarrollo regional y local, desarrollo endógeno, entre otros. El concepto de desarrollo territorial comienza a utilizarse frente a las intervenciones que realizaban los Estados sobre los territorios

\footnotetext{
${ }^{5}$ Creada por las Naciones Unidas en 1983.
} 
nacionales con el objetivo de lograr equilibrios entre regiones (Tobío, 2012). Se entendía desde esta perspectiva al territorio en su complejidad, incluyendo su historia, los recursos naturales y económicos, los actores públicos, económicos y de la sociedad civil y su forma de relacionarse, la cultura local y las formas institucionales, entre otros aspectos. De allí, es de donde el enfoque de desarrollo local se centra en la relación entre lo local y lo global; el papel que juegan en el mismo los niveles provincial y nacional; la inserción de los procesos de desarrollo en el marco de procesos más amplios a nivel regional y los proyectos nacionales; las formas de participación y de gestión asociada entre el sector público, el sector privado y la sociedad civil. Pero esto muchas veces resulta contradictorio, como es el caso de las propuestas de desarrollo territorial con un sesgo neoliberal dominantes en el ámbito de las políticas públicas de América Latina a partir de la década del ' 70.

Frente a ello, surgen otros planteos de algunos economistas que tratan al territorio como una dimensión del desarrollo, reduciéndolo a una determinada relación social. En palabras de Mançano Fernandes (2008), así como el desarrollo, el territorio es multidimensional, por lo tanto no existe una única dimensión del desarrollo. "La comprensión del territorio como espacio unidimensional lo trata como un sector, denominandolo equivocadamente territorio. Esta es una práctica muy común en la implementación de los denominados proyectos de "desarrollo territorial” (p.5).

Sin embargo, la complejidad planteada en la concepción del territorio desde el enfoque del desarrollo, así como la integralidad del concepto mismo de desarrollo, parecen en la mayoría de los casos permanecer en lo discursivo, ya que por un lado, normalmente se parte de la consideración de la importancia de la multidimensionalidad del desarrollo y la visión compleja del territorio, abogando por un enfoque integral de los mismos, pero con una cierta dificultad. Entonces, en la práctica se terminan ignorando los principales aportes del debate sobre el territorio señalados anteriormente. Especialmente en cuanto a la consideración de las relaciones de poder, no se problematiza sobre las relaciones complejas y no lineales entre lo local, lo nacional y lo global o entre territorio y cultura. En términos generales, se termina realizando un uso pragmático, poco preciso y problematizado de estos conceptos.

En síntesis, se puede ver que en la mayoría de las teorías y enfoques del desarrollo la utilización que se le da al concepto de territorio resulta acrítica, instrumental, naturalizada o idealizada. A partir de la incorporación de la dimensión de las relaciones sociales y de poder, lo cual implica deconstruir y desnaturalizar buena parte de estos 
preceptos y abordajes, se intenta complejizar el debate, y adoptar una definición de territorio que tenga en cuenta su multidimensionalidad.

No obstante, al hablar de desarrollo la mayoría de las veces se hace referencia al concepto de "modelo de desarrollo", muy trabajado en diversos artículos, pero que difícilmente lo definen. Ante la falta de claridad empírica del alcance del término, muchas veces se lo utiliza como sinónimo de otros conceptos, desde una perspectiva principalmente económica. De manera complementaria, otros autores han operacionalizado conceptos relacionados, tales como los de régimen de acumulación (Basualdo, 2007), modelo de acumulación (Varesi, 2012), o como propone Garófoli (1991) tipologías de modelos locales de desarrollo o modos de organización productiva, a través de una serie de variables ${ }^{6}$.

Siguiendo a Basualdo (2007), el concepto de régimen o patrón de acumulación sería una categoría sintética que permitiría diferenciar los distintos comportamientos económicos que se suceden en el tiempo aludiendo a la “(...) articulación de un determinado funcionamiento de las variables económicas, vinculado a una definida estructura económica, una peculiar forma de Estado y las luchas entre los bloques sociales existentes" (Basualdo, 2007, p. 6). La regularidad y el orden de prelación en las variables económicas son determinantes, según el autor, para la identificación de un régimen de acumulación concreto. Por su parte, Varesi (2012) reconociendo las articulaciones con el concepto de régimen, define al modelo de acumulación a través de las políticas y variables económicas, y las fracciones de clase, observando el cambio en sus relaciones de fuerza. Asimismo, señala que el concepto de modelo de acumulación remite a recortes temporales más cortos y alcances espaciales más específicos que el régimen de acumulación. De esta manera, habría un mayor grado de especificidad y menor nivel de abstracción en la noción de modelo de acumulación, siendo posible identificar diversos modelos de acumulación en el marco de un régimen o patrón de acumulación que los contiene.

También, aparece el concepto de estilos de desarrollo, presentado por Clichevsky y Rofman (1989) que implica reconocer que "hay estrechos vasos comunicantes entre los objetivos globales que se pretenden imponer a la sociedad por los sectores dominantes en cada coyuntura histórica y la normativa espacial” (p. 61). Siguiendo esta

\footnotetext{
${ }^{6}$ La estructura económica y la organización productiva; los sistemas tecnológicos; el mercado laboral y las relaciones industriales; los actores sociales y la estructura social; la estructura del mercado y de las formas de competencia; el sistema de información; y las instituciones de regulación (Garófoli, 1991).
} 
noción, Tobío (2011) va a exponer que en nuestro país se consolida un modelo económico de desarrollo relacionado directamente con los procesos de acumulación por desposesión, característicos de la fase de expansión del capitalismo. La acumulación por desposesión también podría abordarse desde la noción de régimen de acumulación, y al extractivismo como modelo de acumulación dentro de ese régimen. Por otro lado, Svampa (2008) va a concebir a los modelos de desarrollo en términos de proyectos alternativos de sociedad. Sin embargo, sería interesante incorporar a esta noción, para complejizarla, las diferentes formas de organizar política, económica, social y culturalmente un territorio.

\subsection{Modelo de desarrollo extractivo y su expresión en la ciudad}

Las nociones recorridas anteriormente no escapan a la compleja realidad latinoamericana, inmersa en el contexto capitalista, donde el desarrollo para diversos actores está directamente relacionado con el crecimiento económico y el progreso, mientras que otros entienden que el desarrollo se vincula con el acceso a distintos derechos. Tal como se mencionó previamente, según algunas perspectivas el territorio continúa teniendo un sesgo puramente economicista y se lo considera como una mercancía, posible de explotar y utilizar. Y es desde esta perspectiva que el desarrollo se puede asociar con la acumulación por desposesión que involucra entre otras cuestiones,

"La mercantilización y privatización de la tierra; la expulsión forzosa de las poblaciones campesinas; la conversión de diversas formas de derechos de propiedad -común, colectiva, estatal, etc. - en derechos de propiedad exclusivos; la supresión del derecho a los bienes comunes; la transformación de la fuerza de trabajo en mercancías y la supresión de formas de producción y consumo alternativos; los procesos coloniales, neocoloniales e imperiales de apropiación de activos, incluyendo los recursos naturales" (Harvey, 2004, p.113).

Siguiendo esta línea, autores como Svampa y Viale (2014), han planteado que el supuesto desarrollo es en realidad un "maldesarrollo". Desde la década del '70, el marxismo latinoamericano, junto a grandes personalidades del mundo de la política, plantearon el carácter deformante y predatorio del desarrollo en una economía capitalista, y su condición de ser un proceso incapaz de mejorar el bienestar de los pueblos (Boron, 2012). También, Shiva (1995) va a hablar de maldesarrollo cuando 
afirma que el desarrollo pone en movimiento un proceso de explotación, desigualdad, e injusticia. Por último, de modo más reciente, el español Unceta Satrustegui (2009) retoma el concepto para referirse a problemas "que afectan al sistema en su conjunto y que representan una merma en la satisfacción de las necesidades humanas y/o en las oportunidades de la gente" (Unceta Satrustegui, 2009 citado en Svampa y Viale, 2014, p.28). Entonces el maldesarrollo apunta a subrayar el carácter insostenible o insustentable de los modelos de desarrollo hoy vigentes; insustentabilidad que es necesario leer desde diferentes dimensiones: social, económica, ecológica, cultural, política, de género, sanitaria, entre otras.

En América Latina se ha producido una apertura a la voracidad de las grandes transnacionales, impulsadas por las perspectivas de obtener enormes ganancias. De esta forma, es que se fue consolidando un modelo de desarrollo basado en el extractivismo, vinculado a la extracción y exportación de bienes naturales, bajo una perspectiva que concibe a la naturaleza como mercancía ${ }^{7}$ (Giarracca y Teubal, 2010). Y además debe ser entendido como un patrón de acumulación basado en la expansión de las fronteras hacia territorios antes considerados como "improductivos". Bajo este modelo, se fueron cimentando las bases de una ilusión desarrollista que recorre, más allá de las diferencias y matices, al conjunto de los países latinoamericanos, promoviendo la idea de desarrollo en coincidencia con la de depredación del territorio.

Es decir que el capital organiza los territorios a su medida, profundiza los procesos de despojo territorial y recurre a viejas y nuevas formas de dominación para apropiarse de los bienes comunes y mantener en funcionamiento la dinámica del sistema de producción (Maraggi, 2017). Si bien la extracción de recursos no es un proceso actual en América Latina, Gudynas (2010) distingue el extractivismo clásico, del nuevo extractivismo progresista. El primero, el más común en las décadas de 1980 y 1990, propio de gobiernos conservadores (neoliberales), donde las empresas transnacionales se posicionaban con un rol determinante, mientras que el Estado aceptaba las reformas del mercado y se mantenía al margen de las acciones empresarias con políticas funcionales al capital y regulaciones y controles acotados. Prevalecía un contexto de libre circulación del capital, asumiendo que el efecto derrame que producirían las exportaciones generaría los beneficios esperados para el resto de la sociedad. Por su parte, en el neoextractivismo progresista, característico de la década neodesarrollista

\footnotetext{
${ }^{7}$ Según Gudynas (2002) en esta cuestión se ve reflejada la herencia europea que considera a la naturaleza como "canasta de recursos", "inagotable", "posible de controlar para imponer el progreso".
} 
latinoamericana (cuyo inicio en la región, según señalan diversos autores, se daría durante la década de los 2000), el Estado ocupa un lugar central en las prácticas extractivas mediante la nacionalización de los recursos, la renegociación de los contratos (en lo vinculado a mayores impuestos y regalías), la emergencia de las empresas estatales, y participando de manera indirecta mediante asistencias financieras, subsidios, apoyos en infraestructura, entre otros, considerando que los beneficios se lograrían mediante mecanismos mercantiles con la participación del Estado. Si bien anteriormente los discursos progresistas se opusieron al extractivismo como estrategia para alcanzar el desarrollo (económico), estos gobiernos no sólo mantuvieron el proceso extractivista sino que incluso en muchos casos lo profundizaron, sosteniendo que permiten recaudar fondos para financiar programas de lucha contra la pobreza. "Apunta en ese sentido a actuar en el campo de la justicia social (un elemento clave para poder sostener sus autodefiniciones de izquierda), a la vez que intenta algunas medidas de compensación social y ambiental" (Gudynas, 2010, p.136). De esta manera, aunque se evidenciaron ciertos cambios -políticos y económicos-, la reprimarización de la economía de países latinoamericanos (Teubal, 2008; Svampa, 2011; Slipak, 2013; entre otros) perduró, siguiendo el mito del progreso y del desarrollo bajo una nueva hibridación cultural y política.

No solo Gudynas (2010) hace referencia al neoextractivismo en América Latina, sino que también hay otros autores - de diversas disciplinas- que discuten en torno a ello. Desde Ecuador, Acosta (2012) reconoce que varios países de la región con gobiernos progresistas han impulsado algunos cambios importantes en lo que se refiere a ciertos elementos de la modalidad extractivista. Sin embargo, más allá de los discursos y planes oficiales, no hay señales claras de que pretendan superar realmente dicha modalidad de acumulación. Y en Colombia, Portillo Riascos (2014) sostiene que la diferencia fundamental está dada por el papel asumido por el Estado, ya que busca asumir un mayor control en términos económicos y, como resultado de lo anterior, se produce un cambio importante en las relaciones con las empresas transnacionales. Para el caso mexicano, Azamar Alonso y Ponce Sánchez (2015) también identifican que el extractivismo fue reconfigurado en lo que se ha denominado neoextractivismo, destacando el rol del Estado y manifestando los impactos que produce. Mientras que Villafuerte Solís (2014) realiza un análisis, en particular de Guatemala y Nicaragua, que están impulsando el modelo neoextractivo en América Latina a través de alianzas entre el Estado y el capital transnacional. En esta misma línea, la academia venezolana con 
Lander (2014) expone las contradicciones del modelo neoextractivista, sin embargo se lo considera el modelo de desarrollo latinoamericano.

En nuestro país, se coincide con los procesos hasta aquí expuestos. Camposto (2012) caracteriza los diversos modelos socio-económicos y formas de Estado que actualmente se disputan el futuro latinoamericano, indagando sobre sus respectivas relaciones con el avance y profundización del neoextractivismo en la última década, e incorpora el análisis de la praxis emancipatoria de los movimientos socioambientales que se multiplicaron a lo largo y ancho del subcontinente. Por su parte Féliz (2012) realiza un estudio sobre el periodo neodesarrollista en Argentina, que comienza en 2003, y se extiende hasta el año 2015, y está caracterizado por una serie de políticas que fueron dando lugar a un nuevo modelo de acumulación, vinculadas con un reparto diferencial de cargas y beneficios, y centrándose sobre la fracción productivoexportadora del capital. Es decir que el proceso de acumulación de capital continúa estando profundamente integrado de manera dependiente al ciclo del capital global. "Nuevas formas de extractivismo (neoextrativismo) están siendo desarrolladas en el marco de la reedición de experiencias desarrollistas que reformulan la articulación entre el desarrollo, el extractivismo, la industrialización y las luchas sociales" (Féliz, 2012, p.2).

Durante este periodo, en nuestro país se llevaron adelante diversas lógicas de generación de rentas extraordinarias vinculadas al monopolio de la propiedad sobre los bienes comunes, donde el capital presiona para mercantilizar todas las esferas de la vida con el objeto de su propia valorización (Harvey, 2004). Como sostienen algunos autores (Svampa y Viale, 2014; Carlos, 2005; De Mattos, 2007; Tellier y Vainer, 2013), este modelo no solo se desarrolla en ámbito rural, sino que también tiene expresión en la ciudad, considerada como mercancía, donde el mercado es el nexo en el análisis de las relaciones sociales de producción. El espacio urbano se (re)produce como producto y condición general del proceso productivo por lo cual la ciudad, desde este punto de vista, es entendida como espacio de la reproducción de capital. Gutiérrez Ríos (2014) destaca que también se pueden percibir rasgos del modelo extractivo en actividades desarrolladas en ámbitos urbanos, como ocurre con el mercado inmobiliario, problemáticas urbanísticas y el turismo.

Es decir que el extractivismo también llegó a las grandes ciudades, pero no son las empresas sojeras, ni las megamineras, sino la especulación inmobiliaria la que aquí expulsa y provoca desplazamientos de población, acumula riqueza, se apropia de lo 
público, provoca daños ambientales generalizados y construye ciudad para algunos. El bien común disputado es el suelo urbano y con él la renta, impulsado por la mercantilización de la vivienda, "convirtiendo a los inmuebles en una especie de commodity, una mera mercancía, mera especulación, un bien de cambio" (Svampa y Viale, 2014, p.248).

En este marco, el mercado inmobiliario es asumido como el motor transformador de la ciudad (Ciccolella, Vecslir, y Baer, 2015; Jaramillo, 1999; Rodríguez y Abramo, 2012; Marengo, 2013), y como resultado de esta dinámica urbana, las ciudades latinoamericanas vienen experimentado de manera exacerbada procesos de fragmentación y desigualdad socio-espacial (Prevot Schapira, 2002; Segura, 2014; Cuenya, 2016).

La inversión en el mercado inmobiliario brinda un refugio seguro para el capital y permite su reproducción. En palabras de Harvey (1974), inspirado por Lefevre, por la rigidez del entorno urbano ya construido, existe un dilema perpetuo para el capital, provocando que se re-localice continuamente para seguir manteniendo alta la tasa de ganancia (Narodowski, 2007). Asume a la ciudad como el lugar del capital fijo acumulado, donde ese capital genera una cierta división del trabajo, una forma social jerárquica, al mismo tiempo, explica cómo esa ciudad, el resto de las ciudades y la relación entre ellas, se va modificando para que el capital contraríe la ley de la caída tendencial de la tasa de ganancia. Así, en Argentina luego de 2003, el mercado inmobiliario se reposicionó y las estadísticas comenzaron a mostrar un aumento constante en la industria de la construcción (Vidal-Koppmann, 2007). El creciente uso del suelo para la inversión privada y el desarrollo urbano trae aparejado un encarecimiento del costo del suelo. En este marco, el mercado de suelo se convierte en el elemento central del proceso de generación y distribución inequitativa del ingreso y en uno de los elementos determinantes del acceso al suelo urbano y de las posibilidades de localización para diferentes sectores de la sociedad (Capdevielle, Ceconato, y Mandrini, 2013). Entonces la ciudad se vuelve cada vez más fragmentada, clasista, exclusivista y segregativa (Ferrero y Gallego, 2012; Valdés, 2007).

A este escenario, Svampa y Viale (2014) aseguran que se suman las conductas del Estado y de la clase dominante sosteniendo una narrativa jurídica de acuerdo a sus intereses económicos, o directamente pensando y creando un derecho que no sea un obstáculo al "desarrollo". Son los grandes intereses económicos los que terminan definiendo el ordenamiento territorial y la producción del espacio urbano, a medida de 
sus incumbencias lucrativas, y que poco tienen que ver con un enfoque del desarrollo territorial integral. "En las grandes ciudades esto se ve claramente con la cooptación de los códigos de planeamiento urbano, que deberían garantizar la calidad de vida de la población pero son alterados para satisfacer los negocios de la especulación inmobiliaria" (Savmpa y Viale, 2014, p.57).

\subsection{Estado, políticas públicas y gestión urbana: empresarialismo urbano}

Adentrándonos en el rol del Estado, este actor social es quien toma posición frente a una cuestión socialmente problematizada en un determinado momento y lugar, a través de las políticas públicas (Oszlak y O’Donnell, 1984), que van a formar parte de un proceso social más amplio que supone espacios de interlocución acción y diálogo entre múltiples actores, o grupos sociales. A ello, Torres (2004) agrega que la participación de los distintos actores es estratégica porque las actividades que realizan responden a visiones, valores e intereses específicos y, al mismo tiempo, tienen la capacidad de incidir en el proceso político dependiendo de los recursos que administran (Repetto, 2009). Por su parte Aguilar (2009) va a hablar de políticas públicas como agregados de decisiones congruentes y consistentes, argumentadas, formuladas e implementadas en espacios gubernamentales y no gubernamentales en el marco de un Estado de derecho democrático. En conjunto se deciden los objetivos y los medios para resolver situaciones problemáticas (Villareal Cantú, 2010). Pero en el marco de una política pública, Repetto (2009) plantea que la formulación e implementación de soluciones no es armónica, sino que es resultado de una disputa-generalmente conflictiva- de intereses entre agentes con importantes diferenciales de poder. Y a ello se suman ideas que consideran que las políticas públicas incluyen, la no acción, la omisión de ciertas decisiones y prácticas por parte de los actores gubernamentales (Villareal Cantú, 2010).

Las políticas tienen una dimensión y un impacto en el territorio (Rodríguez y Di Virgilio, 2011), e inciden en las estructuras territoriales. El territorio se vuelve un objeto privilegiado de la acción pública, no como una simple proyección espacial de las iniciativas públicas sino que éste es una construcción social, que condensa acciones y comportamientos múltiples, acumulados en el tiempo, con capacidad de influir también de forma significativa sobre el desarrollo de la política en un sistema de 
retroalimentación dialéctico. Estas políticas involucran a un conjunto de actores que buscan realizar sus intereses por medio de diferentes estrategias (Castells, 1974), reconocen un anclaje territorial y también urbano. El calificativo urbano refiere, en ese marco, a unidades territoriales en las que se realizan y especifican procesos de producción, consumo, intercambio y gestión (Castells, 1992). Aquí operan las políticas urbanas, que articulan modalidades específicas de producción de ciudad en las cuales el territorio juega como instrumento y elemento transformador de las relaciones sociales y políticas que se expresan en los conflictos- explícitos o latentes- por su apropiación (Rodríguez, 2007).

El Estado es quien gestiona las políticas urbanas, y es quien en las últimas décadas ha estado fuertemente sesgado hacia una tendencia de facilitación para la realización del capital en el territorio, con una fuerte impronta privatista (De Mattos, 2007). Este rol que fue adquiriendo el Estado, en palabras de Harvey (1989; 2001) se denomina empresarialismo urbano, entendido como una forma de regulación política y social que ha reflejado y acompañado los procesos de reestructuración de las economías capitalistas, asignándole un rol protagónico al capital privado en el desarrollo urbano. Se expresa a través de modificaciones a las normativas urbanas de zonificación por parte de los actores estatales locales, permitiendo el desarrollo de negocios inmobiliarios, que implican una transferencia masiva de renta urbana en favor de los actores privados que impulsan y realizan proyectos. El empresarialismo constituye uno de los ejes reconocibles de las políticas de regeneración urbana motorizadas a través de grandes proyectos que crean fragmentos exclusivos de la ciudad y que expanden estrategias urbanas orientadas a maximizar el atractivo del espacio local para el desarrollo capitalista (Cuenya y Corral, 2011). En otras palabras, el empresarialismo urbano implica la asunción por parte del Estado de un rol activo en términos de promoción de la actividad económica en la que la transformación del territorio juega un rol fundamental (Di Virgilio y Guevara, 2014).

Se postula que el eje clave que orienta el empresarialismo se ubica en su proceso de producción, que exige una articulación entre actuaciones inmobiliarias, urbanísticas y desarrollo constructivo, a cargo del sector público y los agentes privados, abriendo la posibilidad de crear y captar rentas y ganancias. Ha contribuido a producir nuevas configuraciones espaciales o nuevas formas urbanas, entre las que se incluyen los espacios exclusivos de centralidad construidos a través de proyectos de renovación urbana. Es decir que el posicionamiento estatal en materia de política pública urbana 
tiende a facilitar la realización del capital sobre el territorio, considerando a éste como un mero receptáculo para las inversiones. Harvey (2003, p. 191) ante ello advierte de la existencia de "utopías de la forma espacial" en los procesos de planificación tradicional, en la cual se asume que la transformación de las formas espaciales y de entorno constructivo puede solucionar problemas espaciales. Así es como el Estado resulta el intermediario frente a la construcción de la ciudad, principalmente partir de la política pública y la normativa, que configuran un sistema de regulaciones que enmarcan y condicionan las prácticas sociales de producción y reproducción, la apropiación, ocupación y transformación del ámbito urbano. Es a través del instrumento de zonificación que se produce una modificación de los alcances espaciales e indicadores urbanísticos de un instrumento de política urbana específico en el marco de un entramado normativo legal.

En el contexto bonaerense, el marco regulatorio sobre el uso, subdivisión, ocupación y equipamiento del suelo, está establecido por el decreto ley 8.912, sancionado a fines de la década del '70. En ese marco, los municipios bonaerenses adquirieron la capacidad de llevar adelante las etapas de planeamiento, donde se despliegan todos los instrumentos reguladores, entre ellos el de zonificación, con el cual, entre otras funciones, se le asigna valor al suelo urbano, y contribuye a incrementar (y, en ciertos casos, a disminuir) la renta urbana. Pero desde la perspectiva del derecho a la ciudad, no toda la población puede acceder a estos procesos, profundizando la brecha existente para el acceso al mercado formal de sectores medios y bajos. Es por ello que si no se dispone de una legislación o de instrumentos que permitan movilizar la renta que se produce con la intervención pública, los recursos terminan transfiriéndose hacia los propietarios de los inmuebles. Es decir, que la actuación estatal en la materia no termina favoreciendo el acceso al suelo urbano de la mayor parte de la población, por dos motivos. Por un lado, porque los terrenos pasan de un uso a otro que es superior y/o aumentan su capacidad de edificación, produciéndose una suba rápida de sus precios. De esta manera, hay sectores que quedan por fuera de este esquema, mientras se crean las condiciones propicias para prácticas especulativas orientadas a capturar esos incrementos de valor del suelo. Y por otro lado, en muchos casos no se implementan instrumentos de actuación que tengan una contraparte fiscal que puede ser utilizada en beneficio de la comunidad, como las herramientas de captura de plusvalías (Reese, 2011; Blanco et al, 2016) que sirven para la distribución de recursos fiscales, contempladas en las legislaciones más avanzadas de América Latina 
(como en Brasil y Colombia). Según Blanco et al (2016) tienden a "facilitar el desarrollo urbano, incluyendo el progreso económico local, la creación de empleo, la provisión de servicios, la promoción de la equidad social y la sostenibilidad ambiental" (p.17).

La provincia, en el año 2012 precisamente, se sumó a esta iniciativa de la mano de la Ley $14.449^{8}$ que manifiesta, entre otras cuestiones, la implementación de normas e instrumentos orientados a reducir las expectativas especulativas, sancionar y gravar progresivamente la retención de inmuebles (sin uso ni destino real de alquiler o venta) y repartir equitativamente las cargas y los beneficios de los procesos de urbanización. Se apoya precisamente en la idea de que el gobierno local debe recuperar en beneficio de la comunidad al menos una parte de los beneficios que capturan los terrenos por efectos de obras públicas y normativa urbana, o según Gudynas (2010) realizar transferencias de dinero hacia sectores más empobrecidos o de riesgo. Los grandes proyectos urbanos ponen a la luz la paradoja de que sea el sector público el que cumpla estos dos roles (Cuenya y Corral, 2011), y de este modo, termina siendo el Estado, quien "busca lograr delicados equilibrios entre sus concesiones al capital y la necesidad de regularlo, entre alentar el extractivismo urbano y amortiguar sus impactos sociales, y así sucesivamente" (Gudynas, 2010, p.139).

\footnotetext{
8 Se trata de la Ley de Acceso Justo al Hábitat. Sus fundamentos pueden recuperarse en
} http://www.gob.gba.gov.ar/legislacion/legislacion/f-14449.html 


\section{Capítulo II: Acerca de los actores y las disputas en torno a la ciudad}

\subsection{Derecho a la Ciudad y Acceso al hábitat urbano}

Las centralidades antes caracterizadas, tienen una jerarquía en la urbe, pues alojan funciones, usos, símbolos y prácticas que la ciudad y los ciudadanos le asignan. Justo por ello, la centralidad también ha sido entendida como espacio público por excelencia y cualidad distintiva del derecho a la ciudad (Delgadillo, 2016). Este concepto ha sido abordado por una serie de autores, que fueron adaptando sus conceptualizaciones a partir de la referencia icónica de Henri Lefebvre (1975) en su libro El Derecho a la Ciudad $^{9}$. Este texto marcó la consolidación entre ese cuerpo teórico, la urbanización capitalista, y las problemáticas y desigualdades territoriales que se fueron profundizando, principalmente con las políticas neoliberales de los '70. Lefebvre hablaba del derecho a una ciudad concebida como la sociedad urbana, era el conjunto de todos usando, pensando e imaginando la ciudad.

El debate por el derecho a la ciudad surge a partir de la explosión de nuevas luchas urbanas contra las expresiones espaciales del dominio del capital, como la gentrificación o la degradación ambiental, pero también, al esfuerzo de muchos actores sociales por lograr una mayor injerencia en la definición de las políticas urbanas. Pero hoy en día, el concepto es discutido a partir de las posibilidades de la lucha anticapitalista urbana, y evidenciando que la mayor globalización económica, así como la subordinación del Estado al capital internacional, obligan a una relectura y actualización del planteamiento lefebvriano. Además, se viene dando una intervención urbana del capital financiero y la privatización de los servicios urbanos y del suelo urbano, profundizando las contradicciones sociales urbanas, y que dificultan el acceso a la ciudad a la mayoría de sus habitantes. Frente a ello, se fueron dando una serie de reapropiaciones por geógrafos que proponen diferentes análisis teóricos del concepto, así como diversas implicaciones políticas del mismo.

Harvey (2004) retoma los estudios lefebvrianos, y considera que el derecho a la ciudad es la posibilidad de transformar, reconstruir, recrear y recuperar la ciudad y que

\footnotetext{
${ }^{9}$ Como formulación teórica surgió en los 70' y en Europa, ligada a diversas movilizaciones sociales en ciudades del hemisferio norte en contra de la creciente alienación de la vida urbana. Para el caso de Latinoamérica, fueron necesarias una serie de reformulaciones, por la particularidad de nuestro contexto.
} 
las prácticas de los actores estén mediadas por el bien común. No obstante, a diferencia de Lefebvre, postula la reivindicación de las prácticas ciudadanas insurgentes, quienes plantean alternativas espaciales que restrinjan los efectos urbanos de la apropiación capitalista del espacio, y que tengan la posibilidad de incidir en la gestión urbana. Por su parte, Edward Soja (2013) también releyó a Lefebvre y reivindicó la lucha por la justicia espacial, que se afirma en las posibilidades culturales, simbólicas y sociales que surgen en los intersticios de la posmetrópolis. Su planteamiento sobre el derecho a la ciudad se sostiene en tres elementos centrales: la construcción social del espacio (donde intervienen multitud de fuerzas), la ciudad entendida como posmetrópolis y las luchas por la justicia espacial y la democracia regional. Otra autora, Carlos (1992) entiende la ciudad como una construcción colectiva y conflictiva en la que participan diversas clases sociales, y por lo tanto es un producto histórico-social. Lo urbano como producto de aspiraciones y necesidades sociales diversas es escenario de confrontación entre las tendencias a la mercantilización y privatización del suelo urbano para favorecer la circulación de mercancías, materias primas y mano de obra, y la tendencia al ejercicio de la ciudadanía y al derecho a la ciudad. Este último, según la autora, estaría encarnado en los habitantes urbanos que se resisten a la apropiación de la ciudad por parte de sectores poderosos, ya sea por la acumulación de tierras, los negocios inmobiliarios, el control del trabajo o el monopolio de las decisiones. Además, el derecho a la ciudad está circunscrito a lo que el Estado está dispuesto a ceder en la gestión de la ciudad, sin interferir en la realización del circuito del capital, al contrario, creando plenas condiciones para su realización (Molano Camargo, 2016).

En investigaciones más actuales, Borja (2011) sostiene que el derecho a la ciudad es un espacio político, donde es posible la expresión de voluntades colectivas, y además se trata de un espacio para la solidaridad, pero también para el conflicto. Es la posibilidad de construir una ciudad en la que se pueda vivir dignamente, reconocerse como parte de ella, y donde se posibilite la distribución equitativa de diferentes tipos de recursos (trabajo, salud, educación, vivienda), así como de recursos simbólicos tales como participación, acceso a la información, etc. Por otro lado, Oszlack (2018) consideró que el derecho a la ciudad aparecía como la posibilidad de que la gente volviera a adueñarse de la ciudad, rescatando a la sociedad como protagonista central e instaurando la posibilidad de una vida digna para todos, convirtiéndola en escenario de encuentro para la vida colectiva. Pero esta noción no expresaba cabalmente la idea del autor, por eso decidió hablar de derecho al espacio urbano, inspirado más en una 
pérdida que en una conquista de derechos. Esta noción pretende colocar en el centro de debate el conflicto entre la lógica individual o colectiva, y la lógica estatal, en el desenlace de los enfrentamientos sociales urbanos, que pueden tener lugar en múltiples escenarios o arenas de conflicto (como los procesos de gentrificación, suburbanización o periurbanización, entre otros), en los que oferentes y demandantes de espacio urbano consiguen o no acceder a la ciudad o permanecer en ella, y por lo tanto, gozar o no de los diferentes tipos de derechos. Ante ello, Pírez (2016) hace referencia al derecho a la centralidad como una dimensión dentro del derecho a la ciudad, que supone "el reconocimiento de la necesidad del soporte material urbano en un sentido de equidad para la sobrevivencia de las familias. Por otro lado, el derecho a permanecer, a no ser expulsado del asentamiento del que se forma parte" (p.295). El autor entonces explicita que el derecho a la ciudad se disputa en la centralidad, y consiste en gozar de la totalidad de la riqueza de una ciudad, es decir, tener derecho al suelo urbano, a la vivienda, al transporte, a las infraestructuras y equipamientos urbanos y sociales, a sus servicios, etc., y a permanecer en ella.

Entre los derechos disputados en la ciudad, uno es el del acceso al hábitat urbano. El derecho a la vivienda constituye un componente sustantivo en las condiciones de vida de los grupos sociales. El problema del acceso y derecho a la vivienda, entendida como hábitat, resulta condición para la satisfacción de un conjunto de necesidades humanas primordiales. Ante ello, distintos autores discutieron sobre la cuestión el acceso diferenciado a la vivienda en la ciudad. Por su parte, Duhau y Giglia (2008) pudieron identificar que la polarización y fragmentación social se refleja en nuevas formas de organización del espacio residencial, configurando un nuevo escenario urbano marcado simultáneamente por la privatización de la vida cotidiana para los que pueden pagarla, mientras que la clase media queda relegada. Enfatizan la continuidad en la estructura de la división social del espacio urbano y de los patrones de segregación, enraizando la tendencia actual hacia la fragmentación. Segura (2012) suma a la discusión que el espacio urbano no es homogéneo, ya que las residencias, infraestructuras y servicios urbanos no se encuentran distribuidos de manera uniforme en él. Esta dinámica del acceso desigual al suelo urbano constituye el principal factor que determina la distribución territorial de los estratos sociales en la ciudad.

Otras autoras como Marcos y Mera (2011) invitan a repensar la problemática de la distribución espacial de los individuos y grupos sociales en el espacio urbano en un contexto en el que los espacios metropolitanos son protagonistas de importantes 
transformaciones socio-territoriales. Se redefinieron las estructuras y dinámicas urbanas, generando nuevas desigualdades territoriales, formas espaciales discontinuas, y una preeminencia de las especificidades y microdiferencias territoriales. De manera complementaria, Linares (2012) también realiza su aporte al analizar las estructuras socioespaciales urbanas y el patrón de diferenciación socioespacial de algunas ciudades bonaerenses.

En suma, el acceso a la vivienda en la ciudad es indisoluble del problema de la segregación residencial, alimentada de la desigualdad territorial y tiende a reforzar la diferenciación de la ciudad en zonas que concentran a quienes poseen mayores recursos, frente a áreas con población de menores recursos.

\subsection{Actores y lógicas en la ciudad}

El espacio urbano es construido a través de las decisiones y acciones que los diferentes actores asumen, y también es disputado por ellos, desde quienes adquieren las lógicas territoriales propias del poder, vinculadas a las corporaciones y las élites económicas, las cuales se enmarcan en un paradigma economicista que enfatiza la importancia de transformar "los espacios en territorios eficientes, productivos, vaciables y sacrificables" (Svampa, 2008, p.8); hasta actores que podrían llamarse de la resistencia, quienes despliegan estrategias en defensa del territorio, considerándolo un derecho. Oszlack (2018) refiere al espacio urbano como el resultado de las transacciones entre oferentes y demandantes de oportunidades de acceso, permanencia y/o aprovechamiento de las externalidades de la ciudad, dentro del marco de políticas estatales que promueven, facilitan o impiden tales transacciones, o las sesgan en favor de alguna de las partes.

En palabras de Pírez (1995), los actores sociales son tomadores y ejecutores de decisiones de la sociedad que inciden en la realidad. Están dotados de intereses y recursos, disponen de una cierta autonomía para desarrollar estrategias, tienen capacidad para hacer elecciones, y están más o menos guiados por sus intereses materiales y simbólicos. Siguiendo a Matus (1987) un actor social puede definirse como una agrupación u organización humana -transitoria o estable- con capacidad de desarrollar y expresar intereses propios y compartidos, definir y satisfacer necesidades, acumular recursos, e intervenir en una situación determinada produciendo hechos significativos. Paralelamente, Robirosa (2002) sostiene que un actor social puede ser desde un grupo, 
organización o institución hasta un individuo, que adopta una posición particular en un escenario, y adquiere un papel o rol donde pone de manifiesto sus propósitos o intereses. En el mismo sentido, Ibáñez y Brie (2001) explican que el actor social opera siempre con orientaciones, motivos, expectativas, fines, representaciones, valores, en una situación determinada.

Dicho esto, y reconociendo la multiplicidad de procesos y actores que producen el espacio urbano, por un lado se pueden reconocer actores económicos, que reproducen su capital en función de relaciones dentro del territorio, y por otro, políticos que reproducen su poder en relación a los otros actores. Las lógicas de toma de decisiones suelen ser distintas, como también las capacidades para enfrentarse a diversos procesos en el territorio. Ante ello, Pírez (1995) reconoce actores que a partir de sus intereses, despliegan diversas lógicas. Están quienes actúan bajo la lógica de obtención de ganancias, empresas de distintas escalas y orígenes, u oferentes (Oszlack, 2018) que incluyen por ejemplo a locadores, constructores, desarrolladores, bancos, firmas inmobiliarias, entre otros. La literatura especializada describe a los desarrolladores (developers) como agentes del mercado inmobiliario que conjugan varios perfiles: detectan el negocio, lo estructuran, consiguen el financiamiento o lo aportan con capital propio, llevan adelante la obra y comercializan el producto final. Son caracterizados como personas de negocios emprendedores (típicamente arquitectos, ingenieros, brokers inmobiliarios, eventualmente abogados o contadores), con intuición suficiente como para anticipar los cambios urbanos y las tendencias en el mercado, con capital propio o de terceros, con capacidad empresaria, creatividad, convicción y habilidad de negociación. Los desarrolladores emprendedores son quienes pueden transformar un pantano en un distrito de lujo (Cuenya y Corral, 2011). Si se tratase de empresas, suelen estar asociadas entre sí para expandir su escala o capacidad de operación en otras ciudades o países. A veces también crean sus propios departamentos o empresas especializada en comercialización y/o consultoría que trabaja para la firma madre y para terceros.

Otros actores, participan en función de la lógica política, generando condiciones y parámetros para todos los demás actores. La presencia estatal puede manifestarse a través de políticas activas o de omisiones, deliberadas o no, capaces de alterar las relaciones de fuerza y los intereses de oferentes y demandantes en favor de unos u otros (Oszlack, 2018). Los demandantes en la ciudad son los potenciales propietarios, inquilinos, usurpadores de casas o terrenos, autoconstructores, etc. Algunos de ellos 
actúan bajo la lógica de la necesidad, que se desarrolla fuera (total o parcialmente) del mercado y de las políticas públicas.

Además, Pírez plantea una cuarta lógica, aquella basada en el conocimiento (puede ser científico, técnico y/o ideológico), que no genera procesos autónomos de toma de decisiones y acciones, sino que introducen perspectivas que inciden muchas veces en las decisiones de los otros actores.

De manera complementaria, Cirio (2016) da cuenta de una clase de actor social que escapa de la clasificación de las lógicas expuestas. Se trata de actores que no se movilizan ni producen acciones en función de una lógica económica, ya que no realizan una búsqueda de obtención de ganancias, y tampoco están determinados por la búsqueda de satisfacción inmediata de necesidades, relacionadas a escasez de recursos. Y con respecto a la lógica política, Pírez hace particular énfasis en el accionar del gobierno, entonces resulta necesario dar cuenta de otro tipo de actor, que entre otras formas de organización de la sociedad civil, tiene mayor vínculo con movimientos colectivos reactivos (Karol, 2014). Están conformados por grupos de personas, agrupadas formales o informalmente, que son afectadas por un determinado problema, y que desarrollan acciones colectivas irrumpiendo en un espacio de conflicto con el objeto de modificar decisiones, situaciones o hechos particulares. Estos conflictos dan lugar a un tipo de acción colectiva, entendida como una acción conjunta de individuos para la defensa de sus intereses comunes. Aquí actúan un sinfín de organizaciones vecinales, foros, asambleas, agrupaciones y $\mathrm{ONG}^{\prime}$ s con diferentes grados de tradición y formas organizativas, y con diversas temporalidades. "La lógica de su accionar se encuentra más vinculada a la reivindicación de derechos, a la elección de formas de vida y valores y/o a la negación de determinadas transformaciones en el entorno urbano. Propondremos, entonces, la idea de actores cuya lógica de actuación en la producción de la ciudad es predominantemente la lógica de la elección" (Cirio, 2016, p.251). Ante este tipo de lógicas, Pírez (2014) hace referencia a que se trata de sectores populares y clases medias de la ciudad que se movilizan desde situaciones de inclusión que son significadas como deterioros del ejercicio del derecho a la ciudad, y que tienden a sostener demandas "conservadoras" que apuntan al mantenimiento del orden existente. Por su parte, la lógica del conocimiento brinda a estos actores asesoramiento o información técnica sobre los conocimientos con los que están familiarizados, que luego servirán para influir en las decisiones de los otros actores para concretar sus elecciones, o bien para impedir aquellas intervenciones que consideren negativas para sus causas. 


\subsection{Crecimiento urbano, consolidación de (sub) centralidades y densificación en ciudades latinoamericanas. Estructura, régimen y modelos urbanos latinoamericanos}

Los procesos antes mencionados, tuvieron y tienen expresión en las grandes ciudades latinoamericanas. Las formas particulares que asumen los procesos de producción y de apropiación del espacio urbano construido son abordadas desde el concepto de régimen urbano, donde el mercado inmobiliario o el mercado de suelo juegan un rol central, promoviendo una articulación general entre el capitalismo y la estructura urbana. En otras palabras, dado que los rasgos y la funcionalidad del mercado de suelo cambian en cada una de las fases del capitalismo, las formas institucionales que asume dicho mercado sirven como uno de los principales mecanismos reguladores del patrón de acumulación urbana (Abramo, 2011). Entonces, la ciudad, que tiene como base la producción de objetos inmobiliarios, termina constituyendo un conjunto de mercancías producidas con vistas a la ganancia, y son los actores que se mueven en razón de una lógica de acumulación de capital los que toman las decisiones frente a la producción urbana (Topalov, 1979).

Una expresión de ello es el proceso de crecimiento urbano, producido a partir de distintos cambios tecnológico-productivos, político-institucionales y socio-culturales. Por otro lado, en términos físicos, el crecimiento fue expresado en los procesos de densificación de las áreas centrales y pericentrales -a partir de la verticalización, o crecimiento en altura, también llamado proceso de compactación (Abramo, 2011)-, en la expansión casi indefinida de los suburbios, y el desarrollo discontinuo del tejido urbano existente. De aquí que existen infinitas razones y formas por las cuales una ciudad puede crecer. Según el Atlas CIPUV de Crecimiento Urbano, cualquiera sea el caso, todas las ciudades comparten cuatro atributos fundamentales: 1) la extensión o cobertura del área urbana, que es medida por el total de la superficie construida (o área no permeable) de las ciudades; 2) la densidad, que suele medirse como el ratio entre la población total de una ciudad y la superficie total ocupada por lo construido; 3) la fragmentación, se mide a partir de la cantidad relativa y la estructura de los espacios abiertos que son fragmentados por el desarrollo no continuo del tramado urbano hacia la periferia; y 4) la compacidad, que mide la diferencia entre la superficie de un círculo y la huella urbana, por lo que a medida que la forma del desarrollo urbano se asemeja a la de unos tentáculos, la compacidad será menor. 
Pero además de estos cambios físicos, se fueron dando cambios en la base productiva (de un modelo productivo basado en la industria se pasa a otro especializado en servicios complejos y avanzados a la producción, y en servicios banales vinculados básicamente al consumo), cambios en los patrones socioculturales (particularmente en la esfera del consumo), cambios en las formas de gestión del espacio urbano, cambios en las formas de acceso al suelo y de producción y apropiación de renta urbana, y cambios en la estructura social y la distribución del ingreso (Ciccolella, y Vecslir, 2012).

Las distintas lógicas de urbanización van a tratar especialmente de apropiarse de las sobreganancias de localización, invirtiendo en las localizaciones favorables para la concentración espacial de los capitales. Este proceso es impulsado por la conectividad otorgada por los trenes, y la red de rutas y avenidas, que fueron contribuyendo a que se conformen, en ciertos territorios, mayores densidades de población y de actividades terciarias y, por lo tanto, que se eleven cada vez más los precios del suelo metropolitano (Ciccolella, Vecslir y Baer, 2015).

Estos procesos pudieron observarse en vastas metrópolis latinoamericanas. Algunas han experimentado un virtual deterioro e incluso vaciamiento de su área central histórica, y el traslado bastante radical de funciones de comando (sedes empresariales, bancarias, centros de negocios, etc.) hacia la periferia o emplazamientos pericentrales. En este sentido, los casos de Ciudad de México, Santiago de Chile, São Paulo o Lima, resultan paradigmáticos ${ }^{10}$. Del mismo modo, estas ciudades y otras de América Latina, han sufrido un proceso de desconcentración productiva industrial hacia la periferia extrema o hacia otras regiones. Es extensa la bibliografía latinoamericana que recoge estos procesos y las singularidades de algunas metrópolis (Ciccolella, 2007 y 2011).

Paralelamente, existió una tendencia a la "concentración expandida" (De Mattos, 1997) de usos terciarios y nuevos artefactos de la globalización en los puntos de máxima accesibilidad y exposición visual que ofrece la red de autopistas, con rasgos de polarización debido a la llegada de los nuevos espacios vinculados al consumo en forma de hipermercados, shopping centers, home centers, etc. Se trata de las centralidades complejas donde los usos comerciales y de ocio coinciden con la localización de funciones de comando (gestión, coordinación, articulación y control) y la expansión de la economía financiera, formando nuevos distritos de negocios y estableciendo

10 Estos casos son desarrollados con mayor detalle en Ciccolella, y Vecslir, 2012. 
asimismo sinergias con otros usos direccionales (hotelería internacional, grandes equipamientos privados de salud o centros educativos, etc.). Esto permite visualizar la expansión del sector terciario que, junto a otros sectores, contribuyen al surgimiento y consolidación de nuevas centralidades complejas, que han asumido progresivamente un gran dinamismo en la atracción y polarización de usos hasta ahora propios de la ciudad compacta.

Por su parte, en Buenos Aires la monocentralidad y la vitalidad de su área central tradicional resisten, e incluso no han sufrido procesos de deterioro avanzado, tal como puede observarse en la mayoría de los espacios centrales históricos de las grandes metrópolis latinoamericanas. Y con respecto a las industrias, ha habido una dispersión y relocalización de la actividad industrial hacia la segunda y particularmente hacia la tercera corona metropolitana, pero sin afectar el proceso general de localización de inversiones y desarrollo industrial de la región. Ciertamente, los patrones residenciales alternativos y la revitalización de subcentralidades también parecen mostrar una cierta singularidad de Buenos Aires, ya que luego de dos décadas, la ciudad dispersa y la suburbanización (propia de Norteamérica) parecían las únicas alternativas de crecimiento metropolitano.

Es así como la ciudad adoptó una estructura de tipo fragmentada (Borsdorf, 2003), donde el capital financiero la transforma y a la vez altera la cotidianidad, mediante la modificación de la experiencia del tiempo y el espacio. La ciudad vivida como fragmento reduce las posibilidades de entrelazamiento de las acciones capaces de permitir la renovación la cotidianidad, dándole sentido. En ella se van degradando las condiciones de trabajo y de habitación en áreas delimitadas por barreras físicas, edificios cercados y condominios fortificados, el cerramiento de barrios con garitas y calles bloqueadas al transporte para las clases de altos y medios-altos ingresos; y el rediseño de las líneas de autobuses que impiden accesos. Se va produciendo un nuevo cuadro de representación que orienta la vida, presa cada vez más en un espacio privado (Carlos, 2014). Es así como los modelos tradicionales de ciudad van siendo alterados sustancialmente por nuevos procesos urbanos, junto a la instalación de infraestructura privada en sus cercanías, como establecimientos educativos y de salud; centros de compras -como hipermercados-, y de entretenimiento urbano; y el creciente aislamiento de los barrios de la clase baja, que comienzan a competir con los sectores altos por los espacios suburbanos. Muchos de estos cambios se dieron por el traslado de funciones básicas de un lugar central a un lugar no integrado al continuo urbano, lo que aumenta 
la dispersión. El impulso que fueron teniendo los principales ejes centrales de transporte automotor, como atractivos y aspectos decisivos de localización, provocó una distribución dispersa en la totalidad del espacio suburbano de las metrópolis, mientras que la infraestructura de transporte férrea quedó marginada en el desarrollo urbano (Janoschka, 2002, 2006). Estas modificaciones de los elementos estructurantes, transformaron el espacio urbano y caracterizaron las dinámicas del desarrollo urbano de la década del '90 hasta la actualidad.

Estos nuevos procesos de reestructuración del espacio urbano pueden considerarse comunes a muchas ciudades latinoamericanas, siendo detectados en numerosos estudios como el de Borsdorf (2002) quien releva situaciones de este tipo en Quito y Lima, así como también Rodríguez y Mollá (2002) describen similares transformaciones del espacio urbano en diversas ciudades de México, y de Mattos (2007) y Meyer y Bähr (2001) en Santiago de Chile. Las transformaciones presentadas subrayan la tendencia hacia una ciudad extremadamente segregada y dividida que Janoschka $(2002,2006)$ denomina «ciudad de islas».

Pero también estos profundos procesos de reorganización socio-espacial incluyen tendencias contradictorias, ya que por un lado produce fragmentación territorial, y por otro, genera reconfiguraciones de la centralidad. Luego de la crisis del 2001/02, particularmente a partir de una nueva etapa de crecimiento económico en varios países latinoamericanos y de un cierto cambio de rumbo en las políticas macroeconómicas vinculadas a transformaciones en el régimen y modelo de acumulación, algunas ciudades $^{11}$ comenzaron a mostrar indicios de revitalización y un considerable dinamismo inmobiliario volcado a la construcción, especialmente de vivienda multifamiliar de cierta calidad en centros y subcentros urbanos. De acuerdo a Lefebvre (1972), la centralidad constituye lo esencial del fenómeno urbano y asume una dinámica compleja que dialécticamente se constituye y destruye, se crea y extingue. Es en la ciudad capitalista e industrial donde se concentraron objetos, productos, medios de producción, pero también las fuerzas productivas y las relaciones sociales que impulsan este modelo productivo, adquiriendo el centro urbano una función esencial en este proceso de acumulación de capital. Por ello la centralidad urbana, más que un lugar, es un conjunto de atributos: lo que la define es la concentración, la intensidad y la variedad de funciones. Se trata de funciones que sirven a las colectividades, y de funciones

\footnotetext{
${ }^{11}$ Ciudades como Santiago de Chile (Truffello, e Hidalgo, 2015), Buenos Aires (Ciccolella, y Vecslir, 2012), Cali en Colombia (Martínez Toro, 2005), entre otros.
} 
sociales y simbólicas que se destinan para el uso y el consumo de los habitantes y visitantes de una ciudad.

Por su parte, las subcentralidades se convirtieron no sólo en una forma de revitalización del tejido compacto tradicional, sino también en una alternativa de estilo de vida urbano-céntrico. Tres aspectos caracterizarían a estas subcentralidades metropolitanas: 1) se trata de antiguos cascos suburbanos ya maduros hacia los años' 70 , de moderada complejidad, relativamente densos, con una población que a nivel departamental o partido, se situaba entre los 400.000 y 500.00 habitantes, y ya para entonces con numerosos edificios residenciales en altura; 2) predomina el uso del suelo residencial, revitalizándose la tipología multifamiliar, y el uso comercial con un proceso de sofisticación, que recuerda vagamente los síntomas de la gentrificación; y 3) el tejido tradicional, predominantemente unifamiliar se densifica y se verticaliza consistentemente. El entorno urbanístico y el espacio público recuperan o adquieren rasgos de prestigio que realimentan el proceso de valorización del suelo y la atracción de estos subcentros (Ciccolella, Vecslir y Baer, 2015).

En síntesis, se trata de antiguos centros secundarios que se revitalizan a través de la densificación, modernización y verticalización de su tejido tradicional, predomina el uso residencial (con mejoras respecto de las edificaciones multifamiliares tradicionales en cuanto a los acabados, materiales constructivos, condiciones de seguridad y aspectos tipológicos), pero también se recupera el comercio y aparecen usos comerciales más "sofisticados", como gastronomía especializada, cafés boutiques, diseño e indumentaria de primeras marcas y oficinas bien equipadas, entre otros. Entonces, los desarrolladores parecen haber advertido una demanda insatisfecha creciente, interesada en habitar los centros, por parte de las clases medias con ingresos similares a aquellos sectores que dispararon la demanda de vivienda en los barrios cerrados y en algunos barrios de la ciudad formal.

Estas modalidades residenciales presentes en las subcentralidades, se vinculan con el crecimiento económico que experimentó nuestro país entre los años 2003 a 2007. Las bases de este período de crecimiento económico- conocido como neodesarrollistaconsistían en un tipo de cambio competitivo, la actividad económica se volcó hacia la producción y el consumo interno, y el balance comercial mostró signos de superávit. Durante este proceso, la construcción se destacó como una de las actividades más dinámicas, a partir de proyectos inmobiliarios que se convirtieron en una de las alternativas de inversión más seguras (Baer, 2011). Es decir que los excedentes que se 
producían a nivel económico, promovidos por este modelo de desarrollo neodesarrollista, se volcaron al mercado inmobiliario, y se expresaron en un boom de la construcción, sobre todo en centros y subcentros de la ciudad. Sin embargo, la oferta residencial solo se expandía para aquel segmento de población (propietarios de todo tipo, entre ellos patrimonialistas e inversionistas) que disponía de ahorro suficiente como para comprar una vivienda al contado u otras modalidades de acceso como la inversión en pozo y/o mediante la figura de fideicomiso, produciendo de esta manera menos oportunidades de acceso y otros impactos para sectores medios y bajos de la población.

\subsection{Gentrificación urbana, desplazamientos y segregación espacial}

Bajo el empresarialismo urbano, abordado previamente, se han acelerado los procesos de transformación urbana en las áreas centrales, y de reconquista de áreas pericentrales por parte del capital inmobiliario. Como todo proceso urbano estructural, se enmarca en una modificación de los mecanismos de acumulación, junto con la implementación de políticas urbanas de atracción de inversiones que generan nuevas posibilidades de beneficio mediante el aumento del valor del suelo, habitualmente apropiado por agentes inmobiliarios privados. Esta metamorfosis de la ciudad consolidada ha generado diversos efectos, tales como la gentrificación, el desplazamiento y la desposesión (Janoschka, 2016).

Hay diversas formas de entender y definir el fenómeno de gentrificación, por eso existen distintas acepciones del mismo. Siguiendo a Casgrain y Janoschka (2013), son cuatro los procesos que deberían cumplirse para hablar de gentrificación, poniendo énfasis en el contenido económico, social y funcional del proceso: a) reinversión y alza del valor del suelo, b) llegada de agentes con mayor capacidad de pago, c) cambios en las actividades y el paisaje urbano, y d) desplazamiento de los grupos sociales con menores ingresos. Otra posición pone el énfasis en un grupo colonizador (según algunos autores -Hamnett, 2003; Sabatini et al, 2009- principalmente de clase media) de sectores urbanos, que previamente les eran ajenos, produciendo en algunos casos perjuicios para los viejos residentes circundantes. Finalmente, López Morales (2013) ha avanzado en la identificación de los roles de los agentes fundamentales en los procesos de renovación 
urbana y apropiación de diferenciales de renta, aunque no necesariamente impliquen una sustitución de población.

Sin embargo, una definición bastante difundida en América Latina es la de Clark (2005), quien entiende a la gentrificación como la relación entre el desplazamiento de población vulnerable y el asentamiento de nuevas clases medias, mediada por la inversión en entorno construido. Mientras que en las palabras de Neil Smith (2002), la gentrificación es un vehículo para la transformación de zonas en nuevos paisajes impuestos por intereses de clase, como nuevos complejos de recreación, consumo, producción, y ocio, así como de vivienda, entrelazados con los mercados financieros globales, junto a grandes y medianos promotores inmobiliarios, comerciantes y agentes de la propiedad, y con apoyo de los gobiernos municipales y locales para quienes los beneficios sociales derivan del mercado más que de su regulación. Por lo tanto, la gentrificación puede implicar tanto suelo vacante como ocupado, y siempre implica el desplazamiento y el despojo de una forma u otra (Slater, 2009).

Así, el fenómeno tendría su expresión más evidente en el cambio de estatus social dentro de sectores urbanos sometidos a algún tipo de renovación urbana o la transformación de áreas centrales degradadas de las ciudades, con el consecuente desplazamiento de población de bajos ingresos y su reemplazo por sectores más acomodados o por actividades comerciales y económicas avanzadas (Di Virgilio y Guevara, 2014). Bajo esta perspectiva, se pone el foco en el desplazamiento de usos y/o población, que aparece como una consecuencia prácticamente inevitable de una reinversión exitosa en un sector, dirigida a un grupo con mayor poder de compra (Díaz Parra, y Apaolaza, 2018). Ante ello, Sassen (1999) alude a un concepto que engloba varias de las definiciones previas, ya que sostiene que la gentrificación consiste en la renovación o el "ennoblecimiento" de ciertos espacios urbanos, degradados o tradicionalmente populares, que son colonizados por grupos pertenecientes a la clase media-alta, ligados a la nueva economía de servicios. La gentrificación quedó asociada entonces a los efectos sociales y urbanos negativos de los procesos de renovación urbana en áreas centrales. Desde esta perspectiva, la clase trabajadora se ve desplazada por una naciente clase media vinculada a la economía de los servicios. Di Virgilio y Guevara (2014) suman al Estado en este proceso, ya que entienden a la gentrificación como una estrategia de desarrollo urbano impulsada por diversos gobiernos locales de la región, en un contexto de difusión del empresarialismo urbano. En este marco, el Estado se pone al servicio de prácticas predatorias y de desposesión que pueden 
incluir desplazamientos y relocalizaciones forzosas o indirectas a través del mercado (Harvey, 2012).

En este sentido, la economía política de los países latinoamericanos está generando nuevas lógicas de expulsión (Sassen, 2014). Estas son variadas, desde la expulsión de trabajadores con bajos ingresos o en paro de sus puestos de trabajo; el desplazamiento forzoso de comunidades agrícolas a través de la expropiación de sus tierras por gobiernos y corporaciones para la explotación especulativa de cultivos industriales; y el desalojo forzoso de personas de sus hogares ya sea de alquiler, en propiedad u ocupados (Kothari, 2015). Frente a la transformación urbana que se fue llevando a cabo, principalmente a través de la expansión urbana hacia la periferia suburbana de manera centrífuga, una serie de procesos políticos y económicos urbanos asociados a la gentrificación han reafirmado el papel de los centros históricos en el contexto de una amplia re-articulación socioespacial de áreas centrales, semi-periféricas o peri centrales (Hidalgo y Janoschka, 2014). Se fue desplegando un proceso de "creación destructiva", donde se recuperan las ciudades como lugares centrales en la acumulación de capital financiero y el consumo de élite a través de la privatización de servicios públicos e infraestructura, mega proyectos urbanos y proyectos de urbanización cerradas, mientras se destruyen partes de la ciudad destinadas a sectores con menores recursos. Como resultado de la continua mercantilización del espacio público y la creación de nuevos espacios urbanos exclusivos para el consumo de las élites, la población con capital insuficiente -ya sea trabajadores o consumidores- han de ser expulsados en sigilo o por la fuerza. La gentrificación, por lo tanto, genera nuevos patrones de segregación socioespacial en sociedades que ya son desiguales, re-agrupando a la población en base a sus ingresos, así como a la identidad social (Alexandri et al, 2016).

Los desplazamientos, producto de la expulsión, en las ciudades pueden iniciarse de varias maneras y tomar diversas formas. Pueden ser directos, es decir, forzosos e impuestos a través de medios violentos como desalojos y embargos; o indirectos, vinculados a las fuerzas económicas y sociales más amplias que producen cambios tan profundos en los barrios que los residentes no pueden permitirse ya vivir ahí o no se identifican ya con su lugar de residencia. El desplazamiento, retomando a Alexandri et al (2016), también puede entenderse de forma más sutil como un proceso excluyente donde los hogares más pobres son excluidos de zonas destinadas a nuevos residentes de ingresos más altos. Incluso, se entiende por desplazamiento al abandono especulativo de vivienda, y en cadena de varios residentes (Marcuse, 1985; Slater 2009) en los que 
fuerzas exteriores al hogar hacen que seguir viviendo en el lugar sea imposible, peligroso o inaccesible. $\mathrm{O}$ aún puede ser el resultado de acciones por parte de grandes inversores urbanos, que compran terrenos o viviendas, las recuperan y desplazan a la población mientras suben los alquileres y los precios de las casas locales.

En cada uno de estos tipos de desplazamiento, la lógica violenta de despojo reclama aún más espacio para aquellos con mayores recursos, profundizando la injusticia social que impide a determinados grupos defender su derecho a quedarse, y ejercer su derecho a la ciudad. El resultado final es la creación de espacios aburguesados, homogéneos, carentes de diversidad para no entrar en conflicto con las demandas de clases medias y bajas. En contraste a estos paisajes, las periferias de la ciudad reciben a la población vulnerable expulsada, invisibilizándolos aún más, y profundizando el proceso de segregación (Linares, 2011; Janoschka, 2016; Blanco y Apaolaza, 2016), entendido como el proceso de distanciamiento socio espacial entre una clase y el resto, y está ligado a la accesibilidad a la ciudad (Cravino, 2008).

De ahí que el desplazamiento -incluyendo aquel generado por la gentrificacióndebe inscribirse dentro de los múltiples procesos de acumulación por desposesión, es decir formas de acumulación que no dependen de una lógica económico-productiva sino de avanzadas de saqueo y depredación de bienes o recursos no producidos por el capitalismo (Harvey, 2004). Esta ubicuidad del desplazamiento en los procesos de desposesión llevó a que algunos autores incluso propongan la idea de "acumulación por desplazamiento" (Janoschka y Sequera, 2016) como una manera de resaltar esta dimensión de la gentrificación, ya que produce un despojo mediante la usurpación excluyente de la centralidad, es decir de un producto colectivo de la sociedad urbana (Blanco y Apaolaza, 2016).

En síntesis, a partir de este recorrido conceptual, se pone de manifiesto que las políticas macro relacionadas a los modelos de desarrollo y acumulación tienen su manifestación en la escala local a través de los distintos procesos que se vienen llevando a cabo en el espacio urbano. La reconfiguración de la ciudad tiene su expresión en los distintos procesos de crecimiento urbano, traducido en la suburbanización, concentración expandida, la desconcentración productiva, y la densificación de los centros y subcentros. Bajo estos últimos, se fue dando una compactación de la ciudad a partir del crecimiento en altura o verticalización. Esta tendencia, podría interpretarse 
como una forma paliativa vinculada a la reducción estructural del déficit urbano habitacional $^{12}$, sin embargo la disminución absoluta y relativa de dicho déficit en un agregado territorial no permite observar la diferenciación socioeconómica, que termina redundando en un incremento en las brechas de déficit según estratos socioeconómicos y zonas intraurbanas de diferenciación del espacio residencial.

Para abordar esta dimensión del problema estudiado, un indicador habitualmente utilizado en la literatura especializada para dar cuenta de transformaciones y tendencias en la división residencial del espacio urbano, es el de régimen de tenencia de la vivienda $^{13}$, que se refiere a la relación que existe entre los residentes y la propiedad de la vivienda, con o sin referencia al terreno en el cual está ubicada la misma (DGEyC, 2019). Entonces, y a partir de este indicador, se sostiene que la profundización de dicha diferenciación residencial del espacio urbano será de importancia para reconstruir una problemática que afecta al partido de Quilmes en general y a Bernal centro en particular. Es posible que con el aumento de la construcción en altura, disminuya el déficit habitacional absoluto, pero con grandes diferencias socioeconómicas, una disminución del régimen de tenencia propietario, un incremento en la modalidad de inquilinato bajo tendencias de fuerte presión al alza de los precios, y una buena parte del stock habitacional construido con funciones de atesoramiento, con bajo nivel de ocupación y fines eminentemente especulativos, lo que redunda en una ampliación de las brechas entre quienes pueden o no acceder a la vivienda como bien de uso, y a la centralidad de la ciudad, como parte sustantiva del derecho a la ciudad.

Frente a ello, son los distintos actores sociales quienes despliegan sus intereses y acciones en la ciudad, y que muchas veces profundizan los procesos antes mencionados. Por un lado, bajo la lógica política, es el Estado quien a través de políticas públicas territoriales y urbanas despliega distintas estrategias para construir ciudad y dar solución

\footnotetext{
${ }^{12}$ Este indicador mide las deficiencias habitacionales bajo un enfoque integral, que incorpora factores que dan cuenta de la importancia del entorno y los modos de construir ciudad. Este se define como el conjunto integrado de carencias urbanas y habitacionales que afectan significativamente el hábitat residencial y la calidad de vida de la población. En su versión integral incorpora cuatro componentes: el déficit de vivienda convencional, déficit de infraestructura, déficit de servicios urbanos y déficit de espacio público (Caggiano, 2013).

${ }^{13}$ Cuando el régimen de la vivienda es propiedad, se entiende que el propietario de la vivienda es uno de los residentes en ella. También están involucrados en esta categoría los inquilinos, quienes pagan por la utilización de toda o parte de una vivienda; ocupantes por préstamo, constituido por aquellos que utilizan la vivienda que le es facilitada gratuitamente por el propietario; y ocupantes por relación de dependencia, quienes utilizan la vivienda que es facilitada gratuita o semigratuitamente por el patrón, organismo $u$ empresa donde trabaja alguno de los miembros del hogar en virtud de su relación laboral (un ejemplo son los porteros, serenos, caseros, trabajadores rurales, etc.) (DGEyC, 2019).
} 
a los problemas que vienen consigo. Sin embargo, en las últimas décadas ha estado fuertemente sesgado hacia una forma de regulación política y social que ha reflejado y acompañado los procesos de reestructuración de las economías capitalistas, asignándole un rol protagónico al capital privado en el desarrollo urbano. Bajo este empresarialismo, se fue permitiendo y promoviendo el desarrollo de negocios inmobiliarios, que implican una transferencia masiva de renta urbana en favor de los actores privados que impulsan y realizan proyectos que benefician a ciertos sectores de la población.

Mientras tanto, de la mano de esta metamorfosis de la ciudad consolidada, otros actores son afectados por procesos de segregación, gentrificación y movilidad. Muchas de las migraciones intraurbanas se articulan con diversos procesos urbanos como la división social del espacio, la segregación espacial, y la reestructuración metropolitana donde entran en juego el acceso a la vivienda, el rol del mercado inmobiliario, y las políticas públicas. Aquí es donde aparece el estudio de la movilidad residencial ${ }^{14}$ (Cravino, 2008; Del Rio, 2012; Cosacov, 2014) para observar la dinámica de las ciudades, puesto que remite a un proceso que involucra cambios de residencias que están vinculados a las transformaciones urbanas que se desarrollan estructuralmente, y al despliegue de las prácticas de los habitantes, en tanto sujetos que experimentan, usan, perciben, construyen, interpretan y viven la ciudad (Ramírez, 2016). Esta multiplicidad de cambios en el barrio, en el paisaje, en los comercios y servicios, puede conllevar a un desfasaje social e identitario entre los antiguos habitantes y su barrio (Slater, 2009), y puede llevarlos a movilizarse a otras áreas de la ciudad. Pero también Janoschka y Sequera (2016) reconocen que el desplazamiento puede darse como una presión simbólica, forzada por una amplia gama de políticas urbanas, discursos y prácticas. Es así como cada vez con más frecuencia la expulsión o la ausencia de oportunidades de acceso y derecho a la ciudad son entendidas como variables relacionadas, que intentarán ser abordadas empíricamente en este caso de estudio en los siguientes apartados de la tesis, por tratarse de uno de los impactos que hacen a la problemática estudiada.

\footnotetext{
${ }^{14}$ Es entendida como "aquellas prácticas espaciales que involucran cambios en el lugar de residencia en la ciudad" (Di Virgilio, 2014, p. 13). La movilidad residencial (Cravino, 2008; Del Rio, 2012; Cosacov, 2014) es, por un lado, producto de condicionantes estructurales ligados a procesos urbanos y económicos, entre otros. Por otro lado, depende de las necesidades y expectativas habitacionales de las familias, las cuales al mismo tiempo están influidas por cuestiones relacionadas a las dinámicas familiares y a los niveles de ingreso, por esto el desplazamiento puede ser entendido, fundamentalmente, como un cambio de localización sin atribuir, al menos de antemano, un sentido compulsorio o expulsivo.
} 
En el siguiente gráfico (ver figura 1) se expone la articulación de los múltiples conceptos que explican el problema central de esta tesis y que fueron hasta aquí desarrollados.

Figura 1: Esquema conceptual. Síntesis y articulación de conceptos.

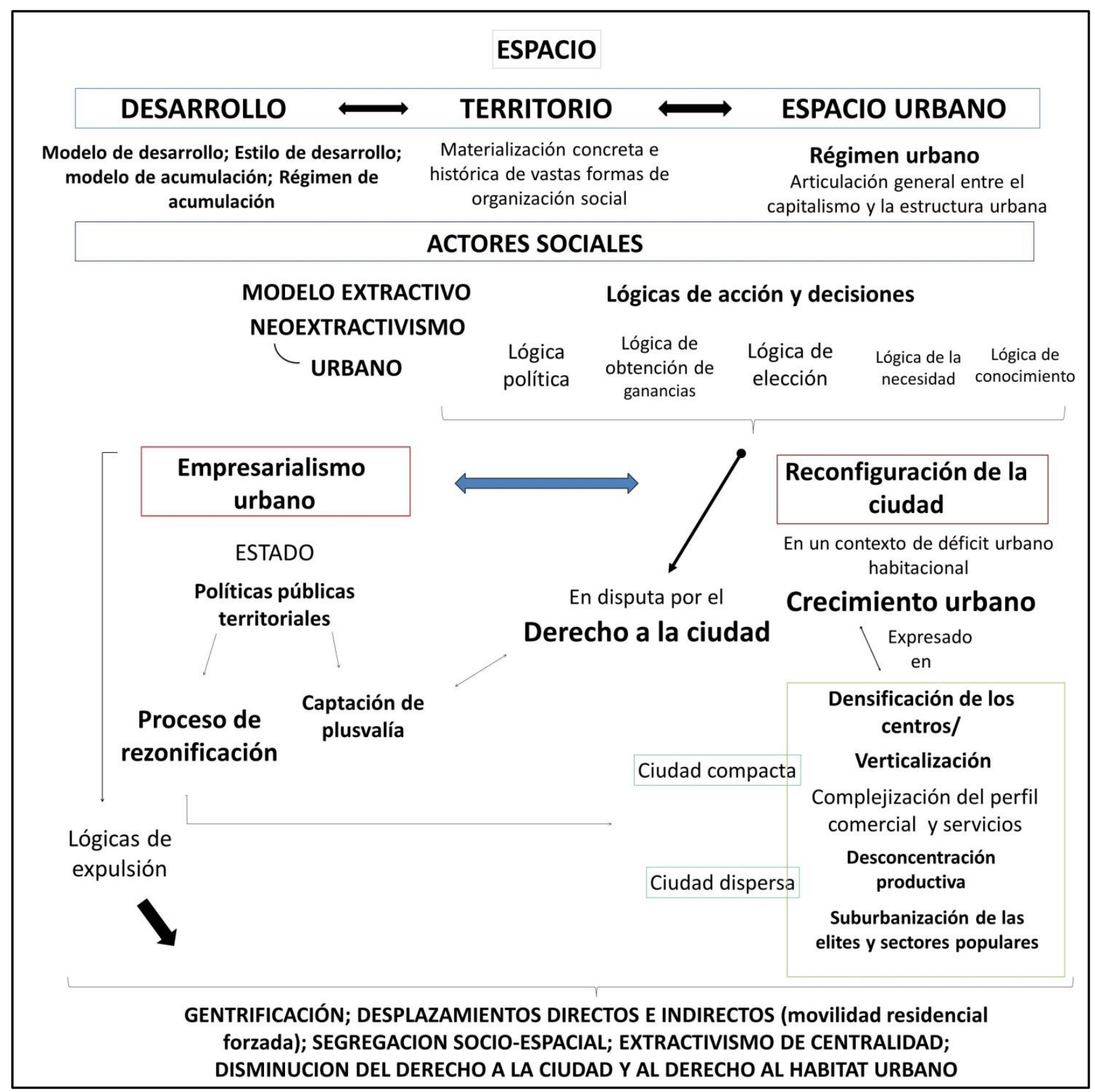

Fuente: Elaboración propia. 
Parte II: Aspectos contextuales y caso de estudio

\section{Capítulo III: La Región Metropolitana de Buenos Aires (RMBA) como escenario para la reproducción de la lógica neoextractiva.}

Luego del planteo realizado, en este capítulo se llevará adelante un análisis empírico del centro de Bernal (Partido de Quilmes) que se encuentra en el contexto de la Región Metropolitana de Buenos Aires. Se caracterizará la RMBA en general, para luego presentar las tendencias experimentadas a nivel partido y luego en el caso de estudio.

\subsection{La RMBA como escenario de la lógica del extractivismo urbano}

Según la Dirección de Ordenamiento Urbano y Territorial de la Provincia de Buenos Aires, la Región Metropolitana de Buenos Aires (RMBA) es un conglomerado urbano integrado por la Ciudad Autónoma de Buenos Aires y 40 municipios. Abarca una superficie de $13.934 \mathrm{~km}^{2}$, incluyendo a los siguientes partidos: Almirante Brown, Avellaneda, Berazategui, Berisso, Brandsen, Campana, Cañuelas, Ensenada, Escobar, Esteban Echeverría, Exaltación de la Cruz, Ezeiza, Florencio Varela, General Las Heras, General Rodríguez, General San Martín, Hurlingham, Ituzaingó, José C. Paz, La Matanza, La Plata, Lanús, Luján, Lomas de Zamora, Malvinas Argentinas, Marcos Paz, Merlo, Moreno, Morón, Pilar, Presidente Perón, Quilmes, San Fernando, San Isidro, San Miguel, San Vicente, Tigre, Tres de Febrero, Vicente López, y Zárate (Garay, 2007).

Figura 2: Mapa de partidos de la Región Metropolitana de Buenos Aires. 


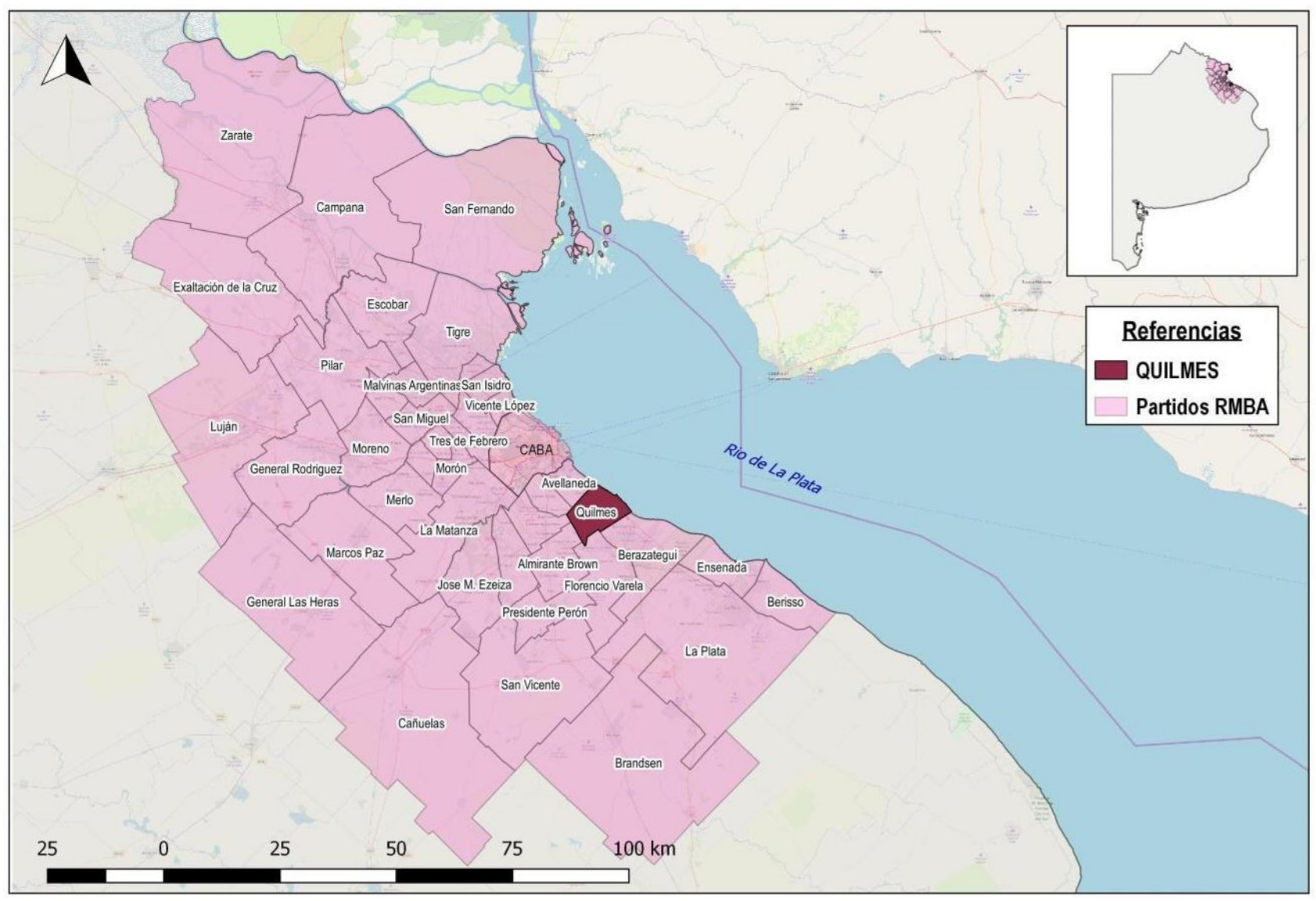

Fuente: Elaboración propia a partir de QGIS en base OSM. Cartografía IGN.

La RMBA en distintos momentos históricos experimentó diferentes tendencias ligadas a procesos de expansión que implicaron una serie de transformaciones. En primera instancia, entre 1870-1930, se dio una fase de formación, donde se organizó la matriz productiva, de movilidad y crecimiento de la RMBA. Buenos Aires funcionaba como la capital del país agrícola exportador, fue el espacio de radicación de actividades vinculadas al puerto y a los servicios, y luego al desarrollo industrial como factor clave de la economía urbana alentado por un modelo de desarrollo basado en la sustitución de importaciones (Garay, 2007). La RMBA creció de manera extraordinaria a partir de la década de 1930, por la expansión de las clases medias y las clases populares formadas en su mayoría por migrantes, consolidándose de esta forma la primera corona metropolitana. Durante estos años la periferia metropolitana se urbanizó con escasa infraestructura y escasas normas que regulasen el uso del suelo, lo que posibilitó a potenciar la especulación del mercado de tierras desarrollado por promotores privados en un marco de regulación y control muy débil (Ríos, 2005). La consecuencia fue una gran dispersión de los asentamientos, siguiendo la expansión a partir de las líneas del ferrocarril, a los que se agregan las autopistas. De esta manera, se consolida un modelo 
de "el centro y los barrios", a la vez que se fortalece un sistema de subcentros metropolitano (Garay, 2007).

En la década del '60, se produjo un progresivo debilitamiento de las políticas del Estado que sostenían el modelo de expansión periférica (transporte, vivienda), y a ello se le fue sumando el deterioro de las condiciones habitacionales en el conurbano. Además, se radicaron grandes industrias en esta zona, en general signadas por la inversión de capitales extranjeros. Durante estos años pudo observarse el crecimiento poblacional más importante de la periferia metropolitana, alcanzando un total del $70 \%$ de toda la población de la ciudad metropolitana de Buenos Aires para 1970 (Ríos, 2005). Luego de la crisis del modelo de industrialización por sustitución de importaciones (ISI), comenzó a darse una disminución del ritmo de inversión pública en infraestructura urbana, así como en políticas de vivienda, alquileres y transporte que habían sustentado el crecimiento metropolitano. El conglomerado se expande hacia la tercera corona de la Región Metropolitana, y a la vez, se configuran las tendencias a la segregación socio-espacial que se verían luego acentuadas en los '90,

"[...] hacia el norte, con las autopistas, crecen las clases medias y altas; hacia el sur, con los ferrocarriles y en asentamientos informales, crecen los sectores populares. Con el nuevo dinamismo de los barrios cerrados en el periurbano surgen nuevos procesos de microsegregación: los viejos fraccionamientos populares pasan a convivir con los countries, barrios cerrados y barrios de chacras y los nuevos centros comerciales y parques industriales, en una lógica de archipiélago" (Garay, 2007, p.51).

Aparecen los actores privados de gran poder y capacidad de decisión sobre la configuración metropolitana y la producción del suelo, sumado a un cambio en los patrones de asentamiento residencial de las clases media-alta y alta. Es decir, que el resultado fue una mayor privatización de la producción de suelo metropolitano en expansión. Desde esta perspectiva, la ciudad empieza a pensarse cada vez más como resultado de la suma de operaciones privadas y sus intersticios, que se van implantando “en un medio caótico, lleno de contradicciones y desventajas" (Pírez, 2006:42).

En la década del '90, se dieron algunas rupturas respecto del modelo anterior, como la reestructuración de la economía, redefinición del rol del Estado y reorganización territorial de la ciudad (Theodore et al, 2009). Estas características provocaron una 
creciente desigualdad y dualización entre sectores sociales incluidos y excluidos en relación con las nuevas dinámicas de crecimiento.

Por un lado, la reestructuración económica se resume en la crisis del modelo ISI y por lo tanto una desindustrialización de la metrópolis. Entretanto avanza la terciarización de las actividades económicas, y la expansión del comercio y los servicios sustituye a la industria como principal demandante de espacio, orientándose a las periferias y a la renovación intersticial en áreas centrales. Con respecto al rol del Estado, se produce el abandono de las políticas propias del ciclo del Estado de Bienestar, y se pasan a imponer las políticas de sesgo neoliberal que incluyeron la apertura económica, la desregulación, la privatización de las empresas públicas y la concesión de los servicios urbanos. "El Estado abandona sus funciones de planificación, retrocede en materia de regulación y controles, y deja de lado las políticas de desarrollo social urbano que contribuían al desarrollo progresivo y la sostenibilidad de las periferias populares" (Garay, 2007, p.51). Termina respondiendo a la lógica política en la producción y gestión del espacio urbano, promoviendo al capital privado. En el afán por conseguir un Estado más funcional con la racionalidad económica de las empresas desarrolladoras del mercado inmobiliario, éste fue cediendo la capacidad de regular y controlar funciones y actividades que requieren de su intermediación (Pírez, 1995). Para que el mercado se desarrolle en materia urbana, el Estado capitalista operó sobre grandes escalas territoriales en materia de modificación de la legislación urbanística, posibilitando las inversiones de interés privado.

Entonces, de la mano de una lógica eminentemente económica, se promovió a la expansión de la ciudad de forma dinámica, "con áreas centrales reconvertidas o adaptadas, ingentes inversiones en infraestructuras y vialidades, viejos polígonos industriales abandonados transformados ahora en espacios para el consumo y el esparcimiento" (Pintos, 2011, p.2), sumado a la transformación de espacios vacantes de la trama urbana en objeto de especulación y rentabilidad inmobiliaria para la construcción de urbanizaciones cerradas, entre otros objetos urbanos. De esta manera, de la mano de diversas políticas se dieron una serie de transformaciones en las pautas de urbanización, donde la lógica de expansión a través de las líneas de transporte masivo de ferrocarril que caracterizó el crecimiento de Buenos Aires durante más de un siglo se vio definitivamente finalizada, dando paso a las autopistas urbanas y suburbanas (Janoschka, 2006). 
Este tipo de gestión pública del territorio también se reproduce durante el neodesarrollismo (década del 2000), respondiendo de manera funcional a los procesos de desposesión. De ello emerge, un territorio marcado por la segregación socioespacial y por una economía fragmentada, con nuevas formas y reglas que afectan la espacialidad de las funciones residenciales y del consumo. Se promovió la apropiación de rentas extraordinarias en manos de unos pocos, que se tradujeron en excedentes económicos para grandes empresas constructoras y desarrolladores inmobiliarios (Féliz, 2012).

Ante el aumento de la capacidad de edificación del espacio construido en las ciudades, el precio del suelo urbano subió rápidamente y generó las condiciones propicias para prácticas orientadas a capturar esos incrementos de valor del suelo (Jaramillo, 2003). Svampa y Viale (2014) asumen la existencia en la RMBA de varios proyectos inmobiliarios para la obtención de rentas extraordinarias como la construcción de hotelería internacional, shopping centers y edificios inteligentes para sedes empresariales, un gran auge inmobiliario destinado a la sectores medio-altos y altos, como edificios con equipamiento deportivo y vigilancia privada (conocidos como torres-country o torres-jardín), urbanizaciones cerradas y en altura, entre otros (Girola, 2007). Es decir que se fue dando paso al surgimiento de emprendimientos privados y proyectos inmobiliarios de gran envergadura, muy difundidos por diversas estrategias de marketing. Se ofrecen en constantes campañas de difusión realzando imaginarios de grupos sociales que quieren la exclusividad, conexión, cercanía a lugares de ocio y paseo, además de valorar el aspecto de seguridad. Así es como actores locales se alían a grandes empresas para la modificación de un determinado territorio. $\mathrm{Y}$ de esta manera se va instalando un discurso eficientista sobre el territorio, que apela a la noción de desarrollo entendido como una fuerza transformadora que redunda en el progreso del ámbito urbano (Escobar, 2007), acompañado de operaciones como reordenamientos territoriales, y modificaciones a las normativas urbanas de la mano del Estado (Pírez, 2006).

El dinamismo del desarrollo inmobiliario en los últimos años fue pujante. Los permisos de construcción permiten tener una idea aproximada sobre su magnitud. En investigaciones de Vecslir y Baer (2011), entre 2003 y 2011, se autorizaron 33 millones de $\mathrm{m}^{2}$ (con un promedio anual de 3,7 millones de $\mathrm{m}^{2}$ ), cifra que supera ampliamente los 19,8 millones de $\mathrm{m}^{2}$ autorizados en los diez años que componen el período 1992-2001, con un promedio anual de 1,98 millones de $\mathrm{m}^{2}$. Pero la diferencia entre ambos períodos 
no sólo refiere a la cantidad de superficie permisada, sino también a la localización y el tipo de usos habilitados en tales permisos. Mientras en los años noventa, el uso residencial (uni y multifamiliar) fue responsable del 55,8\% del espacio solicitado para construir, esta proporción aumentó para el período 2003-2008 a 58,5\%. Esta tendencia puede identificarse en las localidades cabeceras de algunos municipios del sur de la primera y segunda corona de la RMBA, tales como Lanús, Lomas de Zamora y Quilmes. Independientemente de su ubicación en el sistema de centralidades, el crecimiento actual de los emprendimientos residenciales en altura, manifiesta la existencia de una demanda inmobiliaria que se inclina por algunos subcentros tradicionales que renuevan parte de sus funciones. En la mayoría de los casos, estos procesos se encuentran motorizados principalmente por la vía y necesidades del mercado, mientras que en otros, aparecen también fomentados por políticas urbanas de regeneración de "centros comerciales a cielo abierto" e intervenciones sobre el espacio público: plazas, "calles modelo" y paseos peatonales.

Como contracara a los desarrollos anteriores, persisten y se multiplican dentro de la región amplias zonas urbanas en situación de informalidad, que presentan además de la irregularidad en la tenencia o propiedad del suelo, diferentes tipos de carencias. Estos sectores organizan "tomas", como estrategia de búsqueda de legitimación de la ocupación de ciertas áreas de la ciudad ante el Estado, para iniciar el proceso de regularización dominial, en la expectativa de obtener paulatinamente servicios y llegar a ser propietarios (Cravino, 2001). La ocupación irregular de la ciudad se da a partir de la construcción de villas y asentamientos, que en los años '90, debido a las altas tasas de desocupación, se situaban alrededor del 45\% (Cravino, 2006). Para el año 2011, en 30 partidos de la RMBA, existían 864 villas y asentamientos donde residen 508.144 familias. Entre 1981 y 1990 se registró el mayor porcentaje de conformación de nuevos asentamientos con un 18,3\%, mientras que entre los años 2000 y 2011 se manifestó un crecimiento significativo $(16,7 \%)$ y un fuerte proceso de densificación de los mismos (55,6\%) (Ciccollela y Vecslir, 2012). Respecto a su distribución territorial, en las áreas urbanas más consolidadas tienden a localizarse en las cuencas de los arroyos que recorren la región en sentido este-oeste. En las áreas externas, en cambio, suelen ocupar los bordes externos de los corredores radiales, definiendo una interfase entre los tejidos más consolidados y las entrantes verdes que alternan con dichos corredores (DPOUyT, 2007). Según el mencionado relevamiento, los municipios que concentran la mayor 
cantidad de barrios informales son La Matanza, Quilmes, Moreno, Pilar, Merlo y Florencio Varela.

\subsection{El partido de Quilmes en la RMBA y su configuración territorial}

El partido de Quilmes se encuentra en el sudeste de la RMBA, a $17 \mathrm{~km}$ de la Ciudad Autónoma de Buenos Aires (ver figura 2). Limita con los partidos de Avellaneda al noroeste, Lanús, Almirante Brown y Lomas de Zamora, al oeste, y al sur con Florencio Varela y Berazategui. Sin embargo sus principales límites están constituidos por el Río de la Plata, la ruta provincial $\mathrm{N}^{\circ} 4$ y el arroyo Las Piedras. Ocupa una superficie de $94 \mathrm{~km}^{2}$ con una población en 2010 cercana a los 583.000 habitantes ${ }^{15}$, pero según proyecciones realizadas para el 2019 el partido contaría con 657.123 habitantes ${ }^{16}$, volviéndolo el tercer partido más poblado del Conurbano Bonaerense, sumando casi el $5 \%$ de la población total de toda la provincia de Buenos Aires. Está formado por las localidades de Don Bosco, Bernal Este, Bernal Oeste, Quilmes Este, Quilmes Oeste, Ezpeleta Este, Ezpeleta Oeste, San Francisco Solano, y Villa La Florida (ver figura 3).

\section{Figura 3: Mapa de localidades del partido de Quilmes.}

\footnotetext{
15 El dato fue obtenido de la página oficial del Municipio de Quilmes, http://www.quilmes.gov.ar/ciudad/la-ciudad.php. Según datos oficiales del INDEC del último censo realizado en 2010, la población del partido era de 582.943 habitantes.

${ }^{16}$ Este aporte fue realizado por la Dirección Provincial de Estadística, quien realizó un documento en el año 2016 con las proyecciones de población por municipio de la Provincia de Buenos Aires hasta el año 2025. Recuperado de:

http://www.estadistica.ec.gba.gov.ar/dpe/images/Proyecciones_x_municipio_2010-2025.pdf
} 


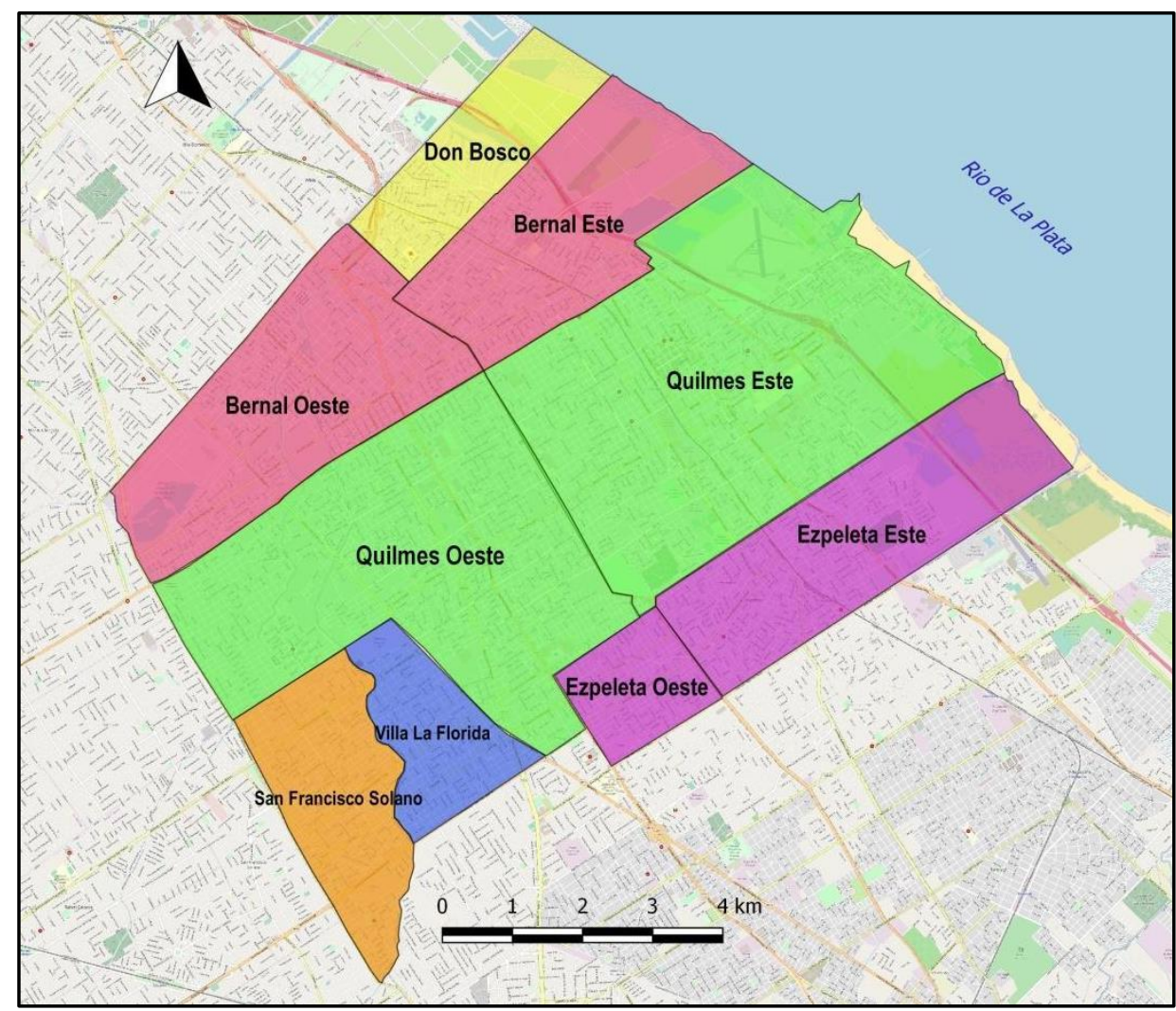

Fuente: Elaboración propia a partir de QGIS en base OSM. Cartografía IGN.

Cabe señalar que el partido presenta una clara estructuración territorial a lo largo del tendido ferroviario y de los grandes ejes de comunicación (autopista, avenidas y rutas), observándose que la trama urbana está significativamente consolidada en torno a las estaciones del tren de la línea General Roca, que comunica a la Ciudad de Buenos Aires con los partidos del sur del Gran Buenos Aires hasta llegar a la Ciudad de La Plata. Estas características son típicas de partidos ubicados en la segunda corona de la región metropolitana. En las últimas décadas, Quilmes manifestó importantes transformaciones territoriales "relacionadas a las dinámicas industriales, los grandes equipamientos de consumo, las nuevas tipologías residenciales, la creciente tendencia en la densificación de su localidad cabecera (Quilmes), el incremento de la fragmentación espacial y de la informalidad urbana" (Cirio, 2016, p.104).

En primer lugar, se dio un fuerte proceso de desindustrialización en el nivel regional y local, debido a la aplicación de políticas de ajuste estructural y de apertura ensayadas a nivel nacional (principalmente en la década de 1970, y luego en los '90). Así, mientras Quilmes había sido uno de los partidos, junto a Avellaneda, en observar 
un fuerte crecimiento industrial ${ }^{17}$ durante la etapa sustitutiva, dichas estructuras industriales tendieron a la retracción, afectando especialmente a las zonas de mayor concentración industrial del partido y a los antiguos corredores industriales. Es decir que la mayor parte de las grandes empresas vinculadas a los "buenos tiempos" de Quilmes, dejaron de existir.

Por otro lado, a esta dinámica se le suman otros procesos tendenciales que se manifiestan desde mediados de la década del ' 80 , y se fortalecieron durante las décadas siguientes. En el caso puntual de Quilmes, la inauguración en 1995 de un tramo de la autopista Buenos Aires-La Plata que unía al partido con estos dos grandes nodos regionales, y su finalización en el año 2002 significó un profundo cambio, contribuyendo a un proceso de densificación y encarecimiento del suelo que se profundizaría y expandiría a toda el área central de Quilmes y Bernal. En el marco de la ampliación de los accesos metropolitanos, se dispara en el partido un proceso de suburbanización de las elites (Torres, 2006) a través de tres formas: los barrios privados, los countries en altura (como modalidades de urbanización cerrada), y los complejos comerciales. Los primeros, mostraron un desarrollo moderado en comparación con otros partidos de la región metropolitana, pero cabe destacar algunos barrios como Aires de Quilmes, Barrancas de Guido, el reciente Nuevo Quilmes, entre otros. Los segundos, muestran un desarrollo menor, pero que vienen adquiriendo mayor presencia en el partido, con localizaciones puntuales en los complejos Terrazas de Quilmes y Bernal, Parque Bernal, y otros que próximamente se construirán como Sensum y el Nuevo Quilmes Plaza. Por último, los complejos comerciales ${ }^{18}$ que incluyen grandes hipermercados, shoppings-centros de compras, cines y patios de comidas, han tenido un desarrollo amplio en Quilmes principalmente en antiguas locaciones industriales o en espacios intersticiales en los corredores viales como Avenida Calchaquí y Avenida La Plata. También vinculado al consumo, pero de sectores populares, se desarrollaron y crecieron en importancia, diversos espacios de comercio minorista informal como la feria de Solano, y constituyen también hitos significativos en la conformación del territorio quilmeño.

\footnotetext{
17 Principalmente, las industrias que se destacaban eran sobre todo textiles, alimentos y bebidas, papel, metal-mecánica, y además contaba con un fuerte tejido de PyMEs en alguno de esos sectores y en plásticos.

${ }^{18}$ Se incluyen Carrefour, Wallmart, Makro, el complejo Quilmes Factory que concentra a Easy, Jumbo, cines Hoyts y Showcase, entre otros.
} 
A partir del contexto de crisis de los años 2000, en Quilmes se generaron algunas experiencias de economía social que impactaron en el proceso de organización territorial del partido, como la recuperación de fábricas por parte de sus trabajadores, el inicio de la red de trueque en el ex espacio industrial La Bernalesa, y la experiencia de la Cooperativa de Consumo y Vivienda Quilmes Ltda ${ }^{19}$.

En esta etapa, el partido también experimentó diferentes tendencias en la ocupación residencial y el acceso a la vivienda por parte de distintos sectores. Es durante el año 2005, que el gobierno municipal propició un proyecto orientado a generar un cambio normativo en las ordenanzas de usos del suelo ${ }^{20}$, dando inicio a principios del año 2006 formalmente a una Comisión de Rezonificación en el marco del Honorable Concejo Deliberante de Quilmes (HCD). Dicha comisión tuvo a su cargo la rezonificación para cuatro áreas del Distrito declaradas "en estado emergencia" (HCD, 2006), que fueron Quilmes Centro, Bernal Centro, Don Bosco centro, y Don Bosco Este.

De esta manera se dio un incesante proceso de densificación en altura del centro de la localidad cabecera del partido, profundizado a partir del año 2006 cuando se modificó la zonificación de usos del suelo ${ }^{21}$ vigente -acompañada por diversas modificaciones que facilitaron el proceso- permitiendo y fomentando la densificación y el crecimiento en altura de los centros urbanos más consolidados del partido. Esta situación fue parcialmente frenada, a partir de una medida del intendente municipal Sergio Villordo en 2007, mediante la cual se exigió a las empresas constructoras y desarrolladores del partido una audiencia ante la Comisión de Urbanismo y una certificación por parte de las empresas de servicios que habilite la factibilidad de realización de los distintos emprendimientos inmobiliarios. Dicha ordenanza aprobada por el HCD no tuvo convalidación provincial, siendo motivo de fuertes disputas con la cámara de la construcción local. Luego de dicho periodo, se reanudó la tendencia creciente a la densificación en altura, derivando en distintos conflictos por las

\footnotetext{
${ }^{19}$ La Cooperativa comenzó con la acción de un grupo de vecinos asociados para resolver el acceso a la vivienda propia ante la falta de una respuesta adecuada del gobierno municipal a esta carencia. Su accionar consistía en la construcción de un barrio de viviendas para los socios de la Cooperativa en la localidad de Ezpeleta.

${ }^{20}$ El uso y la ocupación del suelo del Municipio de Quilmes está regulado por la Ordenanza Municipal $\mathrm{N}^{\circ} 4545 / 79$ y modificatorias. Una de ellas es la Ordenanza 4930/82, otra es la 10568/06 que modifica, incorpora y deroga algunos artículos e incisos de la ordenanza 4545/79. Además, a los años se sancionó la Ordenanza 11613/10, donde varían diversos aspectos regulados por la ordenanza 4545/79. Recuperadas de: http://www.urbasig.gob.gba.gob.ar/urbasig/

${ }^{21}$ Se trata de la Ordenanza $N^{\circ} 10337 / 06$. Recuperada de: http://www.urbasig.gob.gba.gob.ar/ordenanzas/pdf/86-ord-10337-2006.pdf
} 
transformaciones que se producirían. Esta situación impulsó a las organizaciones sociales del partido a exigir un plan de ordenamiento (Cirio, 2018).

Pese a la fuerza que establecieron diferentes grupos, esta tendencia por primera vez se expandiría a otros centros y subcentros tales como Bernal Este y Ezpeleta Este, además del propio Quilmes. También, fue posible gracias a las crecientes expectativas de valorización generadas por las obras de infraestructura vial para el partido, el proceso de modernización comercial y debido a una gran inversión de capitales en desarrollos inmobiliarios, a partir de la expansión de mercado y en un contexto local de escasez de suelo urbano. Esto produjo una dinámica inmobiliaria, en algunos casos tendientes a procesos especulativos, se dio un crecimiento en los precios del suelo, y se fueron produciendo artefactos urbanos para la clase alta, llevando a constituir un escenario de densificación que tendió a segregar a ciertos sectores y a fragmentar el partido. Vinculado con esto, aumentó el acceso informal al suelo urbano por parte de sectores medios y bajos de la población en Quilmes. Es así como las formas de hábitat popular bajo las modalidades de villas y asentamientos constituyó un fenómeno que fue en crecimiento, como resultado de las políticas regresivas implementadas durante los distintos modelos de desarrollo ${ }^{22}$ que se vivenciaron en nuestro país, y la insuficiencia de las políticas habitacionales del período 2003-2014 que venían a revertir la situación deficitaria de los sectores populares. En este marco, mientras que en el año 2001 se identificaron 20 villas y asentamientos en el partido (Cravino, Del Río y Duarte, 2008), una década después, en el año 2013, según un informe realizado por la fundación TECHO Argentina y registros oficiales ${ }^{23}$ (a través de una cifra aportada por el entonces Director de Tierras del municipio), había alrededor de 60 asentamientos con 35.000 familias, convirtiendo a Quilmes en el segundo distrito con más asentamientos del área metropolitana de Buenos Aires ${ }^{24}$.

Es decir que las formas en que estas tendencias se manifiestan son polarizadas, ya que por un lado parece darse con una fuerte incidencia un proceso de verticalización selectiva y densificación del centro de Quilmes, mientras que se produce un incremento de la informalidad (en población y superficie), la expulsión de numerosas familias hacia

\footnotetext{
22 Se hace referencia a la etapa final del período sustitutivo de importaciones que produjo una gran migración interna, y limítrofe; las tendencias socioeconómicas regresivas y las políticas de erradicación de villas de capital federal instauradas en la última dictadura cívico-militar (1976), y profundizadas durante el modelo neoliberal en los '90; y la profunda crisis estructural de los años 2000.

${ }^{23} \mathrm{http}$ ://www.perspectivasur.com/3/32092-rcord-de-asentamientos-ahora-admiten-67-eran-31-en-el-2010

${ }^{24}$ Primero está La Matanza con 89 asentamientos.
} 
zonas alejadas y carentes de servicios de la ciudad, el incremento de las ocupaciones de inmuebles y el aumento de los desalojos forzados (Baer, 2011). De aquí resultan las dos caras de fenómenos que se vienen dando en los últimos años y que están vinculados en el partido de Quilmes en general.

A continuación se analizarán las tendencias recientes que se fueron dando en la localidad de Bernal enmarcada en el sistema de jerarquías urbanas del partido y a escala metropolitana.

\subsection{La localidad de Bernal y sus tendencias recientes}

Desde hace dos décadas la localidad de Bernal tampoco estuvo exenta de las transformaciones urbanas características que sucedieron a nivel partido. De esta forma la verticalización en la producción de viviendas, así como también la aparición de diversos proyectos residenciales con diferentes grados de avance, vinculados con la construcción de urbanizaciones privadas, han seguido las pautas de producción y valorización del suelo urbano de toda la región. Como se anticipó en el apartado anterior se pueden destacar, la construcción del country Nuevo Quilmes y el megaproyecto Nueva Costa del Plata. Por un lado, el fenómeno de las urbanizaciones náuticas, que no tardó en llegar a la localidad, a través de la construcción de un country que ocupa unas 100 has., hacia el oeste de la Autopista Bs.As.-La Plata, cuya superficie se encuentra por debajo de la cota de edificabilidad, y que a partir del relleno y movilización del suelo, se dieron las condiciones para que el proyecto del fideicomiso integrado por Caputo Construcciones SA, Landmark Sur y Deingra se lleve a cabo. Su ubicación no fue casualidad, ya que lo que lo volvió tan atractivo fue la relativa proximidad al centro de Bernal, su óptima accesibilidad, y que sus tierras fueran más económicas en relación con otros municipios como por ejemplo, Pilar (Cortizas, 2016). Por otro lado, hace unos años se viene discutiendo sobre el desarrollo del megaemprendimiento inmobiliario Nueva Costa del Plata (NCdP), que abarca tres kilómetros de franja ribereña en los partidos de Avellaneda y Quilmes. Se trata de un proyecto que plantea la construcción de un "Puerto Madero II" sobre espacios vacantes, tierras del relleno sanitario Villa Domínico en la localidad de Wilde (Avellaneda), y en la zona ribereña de Bernal, abarcando terrenos ubicados entre el Río de la Plata, el canal Santo Domingo, y la Autopista Bs.As.-La Plata (Cirio, 2018). 
Al igual que en la totalidad del partido, en la localidad de Bernal también se experimentaron tendencias inversas a las recién mencionadas, y tiene que ver con las formas de hábitat popular bajo las modalidades de villas y asentamientos. El caso más emblemático de la zona es la Villa Itatí, la más antigua y numerosa del partido, que para el año 2010, según el último Censo de Población contaba con más de 13.000 habitantes. Unos años más tarde, se realizó un Censo en Barrios Populares de la provincia de Buenos Aires, que arrojaba que para el 2018, la población en Itatí había superado los 15.000 (DPE, 2019). Es decir que se trata de un barrio que aún se encuentra en crecimiento, pero con altos niveles de vulnerabilidad social y habitacional.

Con respecto al proceso de verticalización en la producción de viviendas, y ya entrando en el caso de análisis de esta tesis, en el corredor sur -dentro de una tendencia generalizada en la RMBA-, los procesos de densificación y revitalización fundamentalmente motorizados por el desarrollo inmobiliario y la iniciativa privada, no son uniformes y resultan especialmente significativos en algunas cabeceras $\mathrm{o}$ localidades importantes. En Quilmes - entre otros partidos del sur de la RMBA-, según un relevamiento realizado por Ciccolella, Vecslir y Baer (2015), la cantidad de emprendimientos residenciales en altura desarrollados durante la década del 2000, supera ampliamente -casi duplicando- la cantidad construida en los '90 (Ver tabla 1).

Tabla 1: Cantidad absoluta $y$ relativa de edificios en altura en el Partido de Quilmes en distintos cortes temporales.

\begin{tabular}{|c|c|c|}
\hline Periodos & $\mathbf{N}^{\circ}$ & $\mathbf{\%}$ \\
\hline Antes de los '90 & 73 & 31 \\
\hline $1990-2000$ & 56 & 23 \\
\hline $2000-2012$ & 82 & 34 \\
\hline En construcción & 28 & 12 \\
\hline Total & 239 & 100 \\
\hline
\end{tabular}

Fuente: Relevamiento realizado por Ciccolella, Vecslir y Baer (2015) 
Esto puede explicarse al analizar el rol del Estado municipal, quien en alianza con actores económicos, pusieron sobre la mesa un proceso de planificación territorial del partido, a partir de la revisión de algunos instrumentos para la gestión urbana, bajo la figura de diversas normativas de regulación (Reese, 2011). Tal como se mencionó previamente, dichas regulaciones son establecidas principalmente mediante el control de uso del suelo (Ordenanza Municipal $N^{\circ} 4545 / 79$ y ordenanzas modificatorias) y la regulación del volumen edilicio, a través del proceso de rezonificación en la ciudad, que permitió, entre otras cuestiones, la transferencia de renta urbana al municipio, y la producción de espacios residenciales en altura, principalmente orientados al consumo de sectores de altos ingresos. El municipio a través del Plan Estratégico Quilmes (2009) ${ }^{25}$ presentaba como uno de los lineamientos específicos, promover "el crecimiento en las centralidades existentes como Quilmes y Bernal, con una densidad alta y media, tratando de recuperar en el proceso morfológico el paisaje urbano”. Es decir, que el centro se terminó densificando a partir de la permisión de la construcción de urbanizaciones en altura, en un contexto de una gran valorización del suelo y presión al alza de precios (Baer, 2012). Frente a este panorama, una diversidad de actores estuvieron involucrados y desplegaron sus diferentes lógicas frente a la construcción de esta área de la ciudad, y es por ello que se destina el siguiente capítulo a poner de manifiesto sus voces e intereses, en tanto ello constituye un eje clave de la presente tesis.

\footnotetext{
${ }^{25}$ Para mayor conocimiento de los lineamientos, se puede consultar el trabajo de Cirio (2016), donde realiza una explicación detallada de este instrumento para el contexto quilmeño (Pág. 212).
} 


\section{Capítulo IV: Caso de estudio. EI centro de Bernal 2006-2019}

4.1. Presentación del caso, y tendencias recientes en el perfil urbanístico y socioeconómico del centro de Bernal

El centro de Bernal explica en buena medida la tendencia antes mencionada, ya que en los últimos años, el proceso de verticalización creció exponencialmente. El área seleccionada para dar cuenta de estos cambios y del crecimiento observado en la última década comprende 23 manzanas limitadas por avenidas y calles importantes de la ciudad, tales como Avellaneda (al noroeste), Lavalle (al sudoeste), Av. San Martín (al noreste) y la calle Rodríguez Peña (al sudeste) (Ver figura 4).

Figura 4: Mapa del área de estudio. El centro de Bernal.

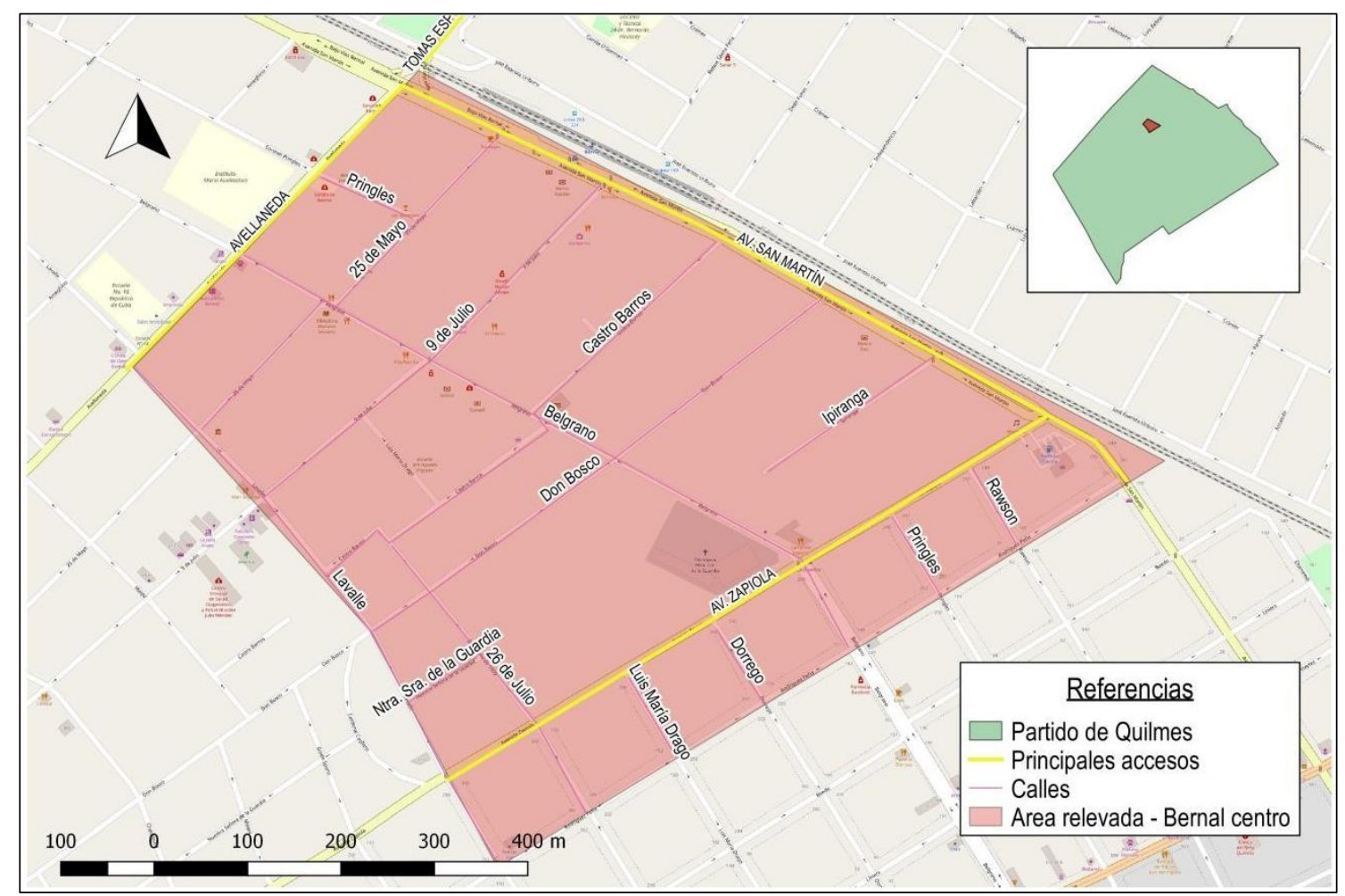

Fuente: Elaboración propia a partir de QGIS en base OSM. 
El área está fraccionada en cinco radios censales ${ }^{26}$ y hacia el 2010 se registraron más de 4000 habitantes. Esta zona nuclea diversos usos de suelo (ver figura 1 en anexo) tales como Comercial (C2), Comercial Lineal (CL), Residencial de alta densidad (R1.2), Residencial Exclusiva (RE), y Residencial de densidad media (R2). Es decir que coexiste lo residencial (entre bajas y altas densidades) con lo comercial, contemplando y permitiendo usos complementarios afines tales como instituciones educativas (de todos los niveles), entidades bancarias públicas y privadas, y centros de salud.

Luego de un relevamiento realizado en la totalidad de las manzanas del área y de la fotolectura de imágenes satelitales Google Earth del año 2004, se pudo dar cuenta de que el aumento de viviendas multifamiliares en altura hacia el 2019 fue más que significativo. De un total de 69 viviendas multifamiliares registradas hacia el 2019, en la imagen 2004 se pudieron identificar 12 terrenos sin edificación, 36 viviendas unifamiliares, y 21 viviendas multifamiliares en altura. Es decir que en poco más de diez años, la presencia de este tipo de edificaciones en altura aumentó tres veces, con alrededor de 1000 unidades funcionales donde antes había menos de $400^{27}$. Esto puede visualizarse en las figuras 5 y 6 .

\footnotetext{
${ }^{26}$ Según los censos 1991 y 2001 los radios eran: 6581008, 6581010, 6581011, 6581012, 6581013, y en el censo 2010 se los identificó con los códigos: 6581206, 6581207, 6581208, 6581209, 6581210.

27 Se trata de un dato de proximidad a partir de contabilizar las unidades funcionales de cada emprendimiento de vivienda multifamiliar en altura durante el relevamiento en terreno mediante observación no participante, utilización de la herramienta Street View (de Google Earth) y consultas a martilleros y responsables de inmobiliarias locales. .
} 
Figura 5: Presencia de viviendas multifamiliares en altura en área relevada de Bernal, año 2004 ${ }^{28}$.

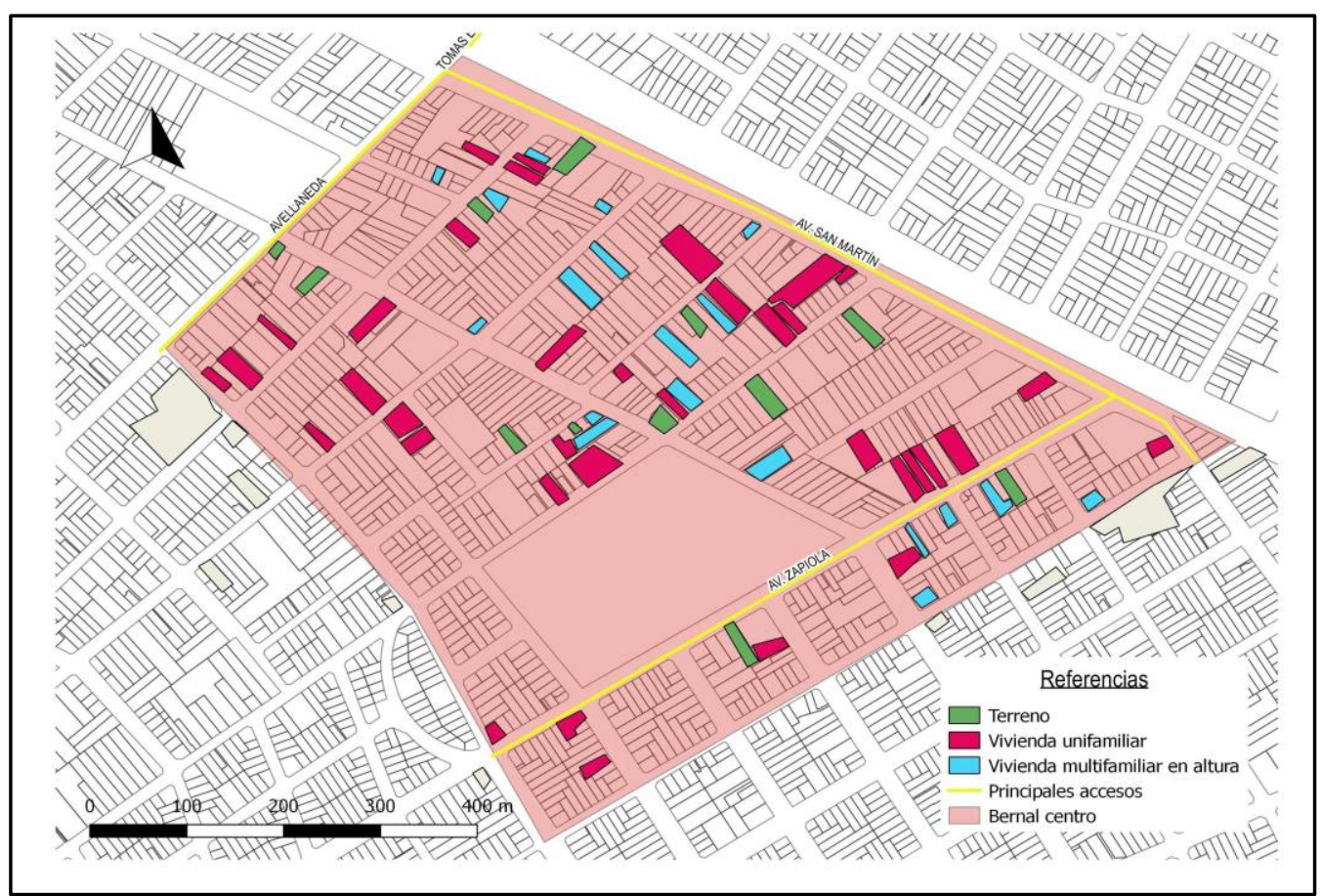

Fuente: Elaboración propia a partir de QGIS en base OSM.

Figura 6: Presencia de viviendas multifamiliares en altura en área relevada, año 2019.

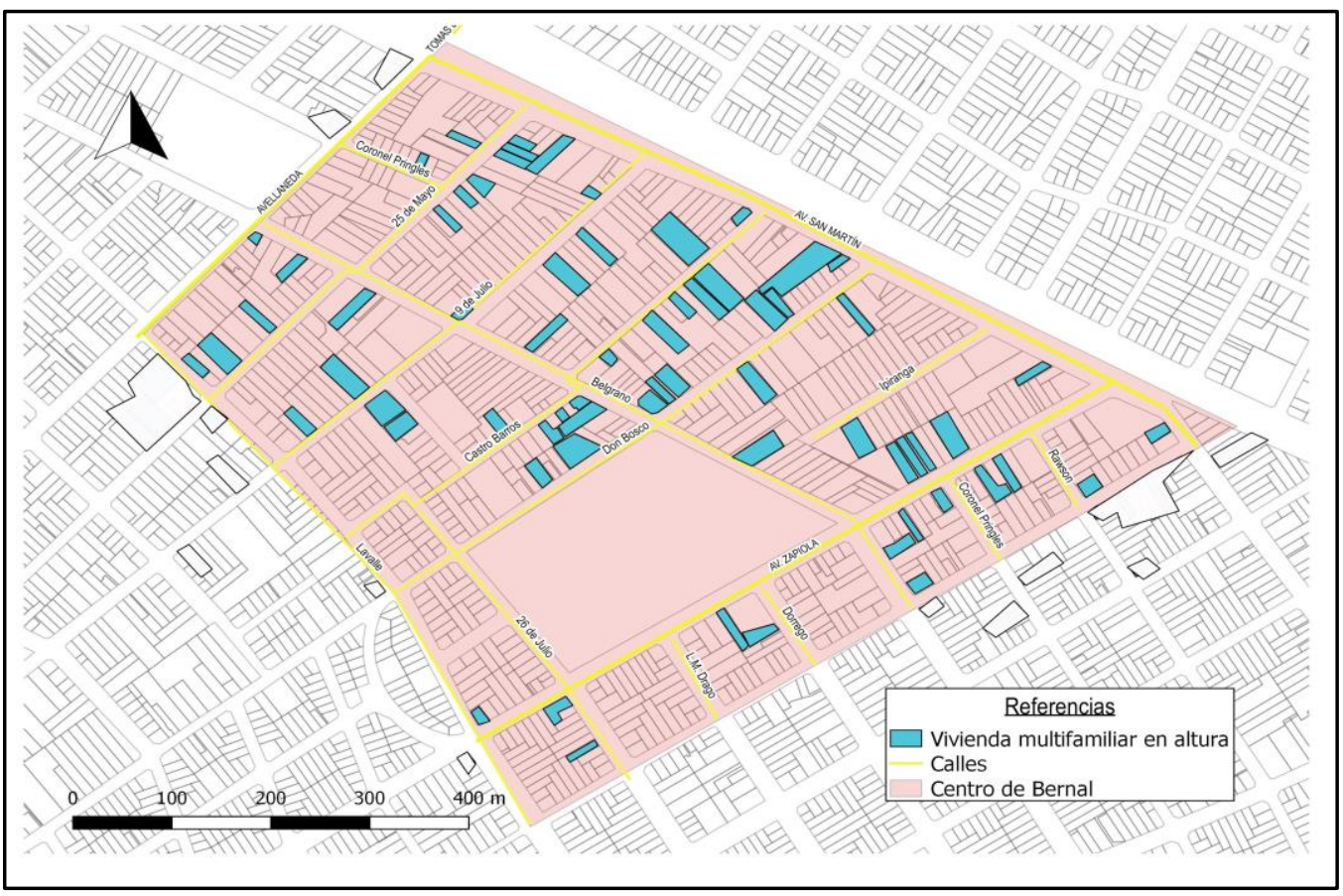

Fuente: Elaboración propia a partir de QGIS en base OSM.

\footnotetext{
${ }^{28}$ La elección del año 2004 para realizar la cartografía se debe a la restricción de fuentes respecto de la imagen satelital y por tratarse del año previo a que comenzaran a darse las excepciones a la normativa.
} 
Con estos cambios, se dio un aumento de la modalidad de tipo de vivienda particular "departamento", y del inquilinato (ver tabla 2).

Tabla 2: Porcentaje de inquilinos y departamentos según los diferentes censos en el área relevada.

\begin{tabular}{|c|c|c|}
\hline Censo & $\begin{array}{c}\text { Tipo de vivienda } \\
\text { particular }\end{array}$ & Régimen de tenencia \\
\hline & Departamentos & Inquilinos \\
\hline 1991 & $41 \%$ & $16 \%$ \\
\hline 2001 & $38 \%$ & $12 \%$ \\
\hline 2010 & $45 \%$ & $20 \%$ \\
\hline
\end{tabular}

Fuente: Elaboración propia a partir de datos censales.

Es importante resaltar, que de ese número de inquilinos que presentan los datos, según el censo 2010, el 76\% reside en viviendas tipo departamento. Este dato es realmente significativo si lo comparamos con datos a nivel partido. Según el censo del año 2001, de un total de inquilinos residiendo en Quilmes, un 25\% se encontraba ocupando viviendas departamentos, y según el censo 2010, el 27\% de los inquilinos residía en este tipo de viviendas (Ver tablas 1 y 2 en anexo). Como puede verse, el aumento fue leve en comparación con el porcentaje que presenta el caso de estudio. Sin embargo, cabe rescatar que de la información brindada por los censos en términos de población, en las últimas décadas se dio un estancamiento poblacional en dicha área. Esta situación se acompaña con una desaceleración y un estancamiento poblacional a nivel partido, que según Reese (2001) podría estar relacionado, a dos fenómenos principales: el proceso de desindustrialización, y el incremento sustantivo de los precios del suelo de los últimos años, lo que podría haber restado atractivo a la ciudad como destino de corrientes migratorias. Al interior del partido, dicha tendencia al desaceleramiento del crecimiento poblacional resulta evidente en áreas centrales, como 
ocurre con el caso de Bernal $^{29}$ (Ver tabla 3). Además de estas razones, no se puede perder de vista que existen otros motivos que pudieron aportar a esta tendencia como los periodos de transición entre la construcción del emprendimiento y el momento de su terminación, la existencia de muchos de ellos en venta o alquiler, o bien la presencia de aquellos construidos o comprados con fines especulativos, inversión y/o ahorro, sin ocupación efectiva.

Tabla 3: Total de población en área relevada del centro de Bernal según censos de población

\begin{tabular}{|c|c|}
\hline Censo & Población \\
\hline 1991 & 4663 \\
\hline 2001 & 3939 \\
\hline 2010 & 4041 \\
\hline
\end{tabular}

Fuente: Elaboración propia a partir de datos de los censos 1991, 2001 y 2010.

Lo que influyó para que el proceso de verticalización se desarrolle en un corto periodo fueron las características que presenta el área central y su localización. Muchos de los factores que incidieron en la producción de valorización de centro fueron la accesibilidad, la edificabilidad, la composición socioeconómica del área, la calidad del equipamiento y los servicios urbanos, y su valor simbólico (Baer, 2012).

Ante ello, el Estado municipal a través de cambios normativos y de la rezonificación, intentó regular la tendencia espontánea de crecimiento urbano que se venía desarrollando en la ciudad procurando, a partir de la superposición de un dispositivo normativo, ordenar ese crecimiento y establecer restricciones y correcciones a los usos incompatibles con la zona. Es a principios de la década del 2000, que

\footnotetext{
${ }^{29}$ Según se ha relevado a partir de entrevistas a informantes clave, esta tendencia podría explicarse por diversos motivos. Uno generacional, a partir de la migración de hijos de vecinos de edad avanzada hacia otras localidades, partidos o hasta la Ciudad Autónoma de Buenos Aires, entre otros destinos, dejando las viviendas ocupadas por personas mayores, en pareja o viudos. Por otro lado, al momento de realizar el censo, en muchos casos se coincidió con el periodo de compra, demolición y construcción de las viviendas multifamiliares en altura, produciendo que el terreno quede desocupado por un tiempo. Y por último, no se puede dejar de mencionar que ha habido problemas metodológicos de implementación del último censo en el año 2010, por lo que también existió población que quedó sin censar.
} 
empiezan a darse excepciones a la ordenanza de usos de suelo del partido, produciendo un incesante proceso de densificación en altura del centro de la localidad cabecera del partido, situación que se vio profundizada a partir del año 2006, cuando se produjo el proceso de rezonificación. Tal como se manifestó anteriormente, este cambio en la normativa vino acompañado por diversas modificaciones que facilitaron el proceso de densificación y el crecimiento en altura. Por ello es que para el análisis puntual de esta tesis, el período abordado es la etapa que inicia en el 2006 con los cambios normativos clave para que el proceso de desarrolle, hasta el año 2019, en virtud de la significatividad de las transformaciones ocurridas en la centralidad bernalense.

Además, se realizaron diversas obras de infraestructura vial (ver figuras 7 y 8 ) que llevaron a que este proceso se desarrolle, y que generaron una creciente valorización en el centro bernalense. Por un lado, se llevó adelante la construcción de la bajada de la autopista Buenos Aires-La Plata en la calle Espora (a 6 cuadras del centro de Bernal), inaugurada en el año 2006. Al poco tiempo los problemas comenzaron, debido a una gran cantidad de tránsito automotor una vez inaugurada la bajada, que comenzó a utilizar el cruce de vías a nivel para dirigirse del Este al Oeste de la localidad y viceversa. Esta situación llevó a que vecinos y comerciantes realicen una campaña de recolección de firmas para presentar un proyecto al Ejecutivo comunal para hacer un cruce bajo vías en la calle Espora, otro a la altura de la Plaza Suiza (a unas diez cuadras de Espora, al sudeste) o un cruce en Las Heras-Lamadrid (a doce cuadras de Espora, al sudeste $)^{30}$.

Luego de algunos años y de distintas evaluaciones realizadas por el municipio, se decidió realizar el cruce bajo vías en la calle Espora, para comunicar Bernal centro con Barrio Parque ${ }^{31}$, y para producir una mayor fluidez vehicular, conectando la autopistaBarrio Parque- Bernal centro en unos pocos minutos. Esta obra maravillosa para muchos, fue una obra inolvidable para otros. Se la llamó "la obra emblema de la inoperancia ${ }^{32,}$, porque tardó en realizarse unos cinco años. En agosto del año 2013, el Municipio de Quilmes llamó a licitación para la realización de la obra “Cruce bajo nivel

\footnotetext{
30 Información obtenida de nota periodística del año 2008 del Diario El Día. Recuperada desde: https://www.eldia.com/nota/2008-5-26-nuevo-impulso-a-cruce-bajo-las-vias-en-bernal

${ }^{31}$ Parque Bernal es un barrio de la localidad de Bernal ubicado hacia el noreste del centro y de las vías del ferrocarril. Sus límites se conforman por las calles Ascasubi y Monteagudo hacia el este, Av. Caseros al norte, Uriburu al sur, y Espora al Oeste. Mapa disponible en: http://www.quilmes.gov.ar/gobierno/sigmapa.php

32 Frase obtenida de artículo periodístico del diario Perspectiva Sur. Recuperado de: http://www.perspectivasur.com/3/64812-qued-oficialmente-inaugurado-el-bajo-vas-de-bernal
} 
calle Espora y vías del ex ferrocarril Gral. Roca", y en enero del siguiente año se adjudicó y comenzaron los trabajos, con un plazo de obra de 600 días corridos, es decir veinte meses. Pero se dieron una serie de irregularidades que hicieron que la obra se demore, y se estipulen nuevos plazos, llegando a diciembre de 2015, con un nuevo intendente -Martiniano Molina- y con apenas el 35\% de la obra realizada, sin permisos de ocupación de vías ni planos de remoción de cañerías aprobados. Recién a mediados de 2016, el Municipio junto con la empresa volvió a conveniar una readecuación de plazos y se reinició la obra, y un año después se inauguró ${ }^{33}$.

A su vez, existieron vecinos que no estaban a favor de que la obra se desarrollara. Un funcionario de la gestión de Gutiérrez contaba,

\begin{abstract}
"la gente me decía <acá queremos vivir como hace 50 años atrás>, yo les decía ¿50 años atrás? ¿Usted y su familia tienen auto?, la respuesta era sí, y yo pensaba, cuando andan los tres en auto dando vueltas por acá, ya está. Culturalmente, urbanísticamente, y socialmente esto es imposible. Por eso mis peleas con el ingeniero Siat, que decía <esto del bajo vías va a matar a Bernal>, y yo le digo, tenemos autopista, tenemos bajada en Bernal, ya está, no podes poner el bajo vías en la plaza Suiza. Tan equivocado no estaba porque el bajo vías funciona".
\end{abstract}

Desde la gestión actual del municipio, se coincidía en que este último resultó un problema histórico para Bernal, pero que fue necesario resolver en el corto plazo, ya que el bajo vías ayudó,

\begin{abstract}
"a que se vuelva a revitalizar toda la cuestión comercial, un centro comercial que se había pinchado, que estaba, no digo en el ocaso, pero que estaba decayendo bastante. Hoy se ve el movimiento, se puede ratificar obviamente la cantidad de negocios que han reabierto, que han abierto nuevamente, te diría que es la zona que más empujó en este último tiempo, tiempo de dificultad, no?" (Entrevista al intendente Molina, mayo de 2019).
\end{abstract}

A esta obra se sumaron las puestas en valor de las avenidas, el mantenimiento de los espacios públicos y la estación de Bernal nueva, con seguridad, andén eléctrico y otras mejoras. El intendente sostenía además que estos cambios en el centro urbano se

\footnotetext{
${ }^{33}$ La obra se inauguró con algunos faltantes como la dársena de salida del lado de la Av. San Martín, el semáforo, no se permite doblar en U, y tampoco hay rampa para discapacitados, ni ascensor (Aporte de la entrevista a funcionario del municipio durante la gestión de Gutiérrez).
} 
dieron con mayor facilidad por tratarse de un área con instituciones educativas de todos los niveles, desde el inicial hasta el universitario, y la presencia del country Nuevo Quilmes a pocas cuadras, junto con el desarrollo que este generó en Bernal Este. Este conjunto de factores, "va a desplazar el desarrollo y lo va a ir derramando hacia otras avenidas, la posibilidad de acceder a los servicios y a los negocios, comercios, entonces me parece que sobre todo pensando en Bernal, los edificios no son un problema sino una oportunidad para que se desarrolle" (Entrevista al intendente Molina, mayo de 2019).

Figura 7: Mapa de obras de infraestructura vial en Bernal.

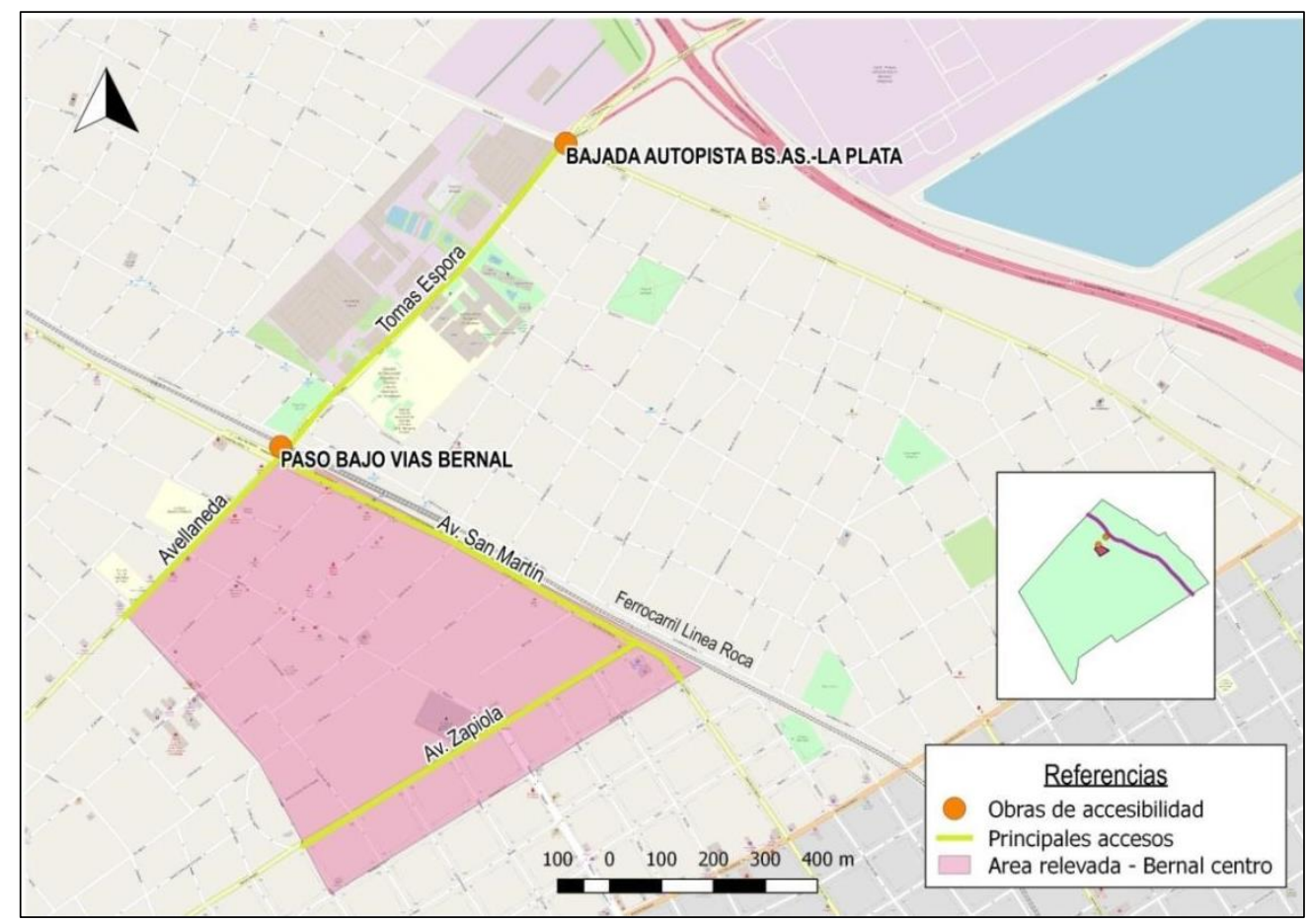

Fuente: Elaboración propia a partir de QGIS en base OSM. 


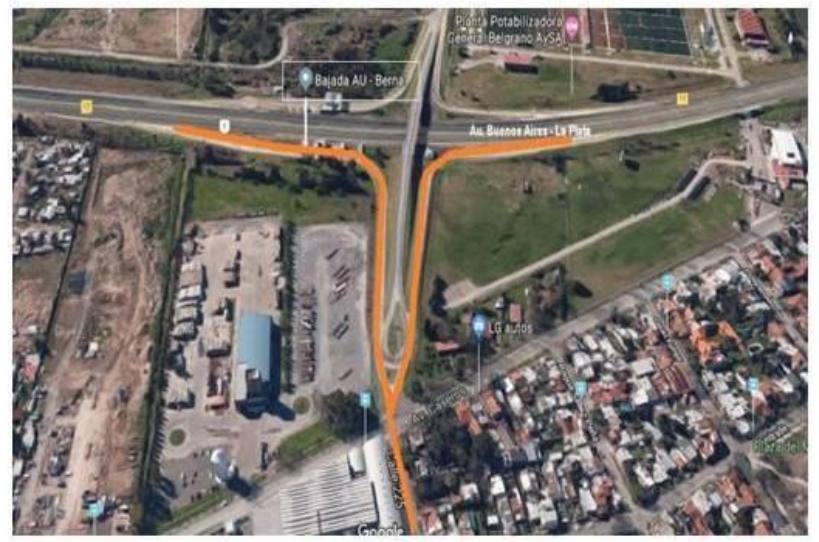

Bajada de autopista en Bernal.

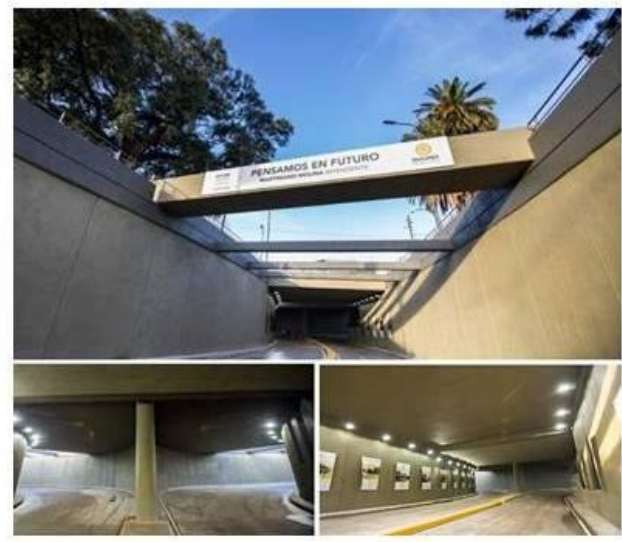

Paso bajo vías Bernal.

1) Fotografía de la bajada de autopista en Bernal, fuente: Elaboración propia a partir de Google Earth.

2) Fotografía del paso bajo vías Bernal, fuente: artículo de la revista "Vivienda", recuperada desde: http://www.revistavivienda.com.ar/destacadas/se-inauguro-el-bajo-vias-de-bernal

Además de las inversiones realizadas en estas obras para mejorar la accesibilidad a la ciudad, la inversión mayor de capitales se produjo en desarrollos inmobiliarios en el marco de un mercado en expansión y en un contexto local de relativa saturación y escasez de suelo urbano. A ello se sumó el bajo costo de la construcción y el uso de modalidades innovadoras de financiamiento de la construcción de los edificios (Cosentino, 2005). Así, el fideicomiso se convirtió en una herramienta eficaz para el financiamiento del desarrollo inmobiliario. Otro factor, no menos importante, que alentó la inversión en el desarrollo inmobiliario y la compra final de inmuebles fueron las bajas tasas de interés real que ofrecieron los depósitos, o el pago "en pozo". Estos instrumentos permitieron que los emprendimientos inmobiliarios se financiaran con fondos de terceros, donde los inversores terminaban haciendo frente a los costos de la obra, mientras que las empresas constructoras se encargan del proceso de construcción. En definitiva, estas últimas no arriesgaban demasiado frente al proyecto, y especulaban con la posibilidad de obtener rentas elevadas en tiempos cortos (Cuenya y Corral, 2011). El riesgo únicamente estaría ante la posibilidad de que finalmente los inmuebles no pudieran venderse. Sin embargo, debido a la exitosa gestión inmobiliaria muchos 
edificios lograron venderse con anterioridad, en parte porque lograron captar fondos de terceros para "fondear el negocio" minimizando el uso de capital propio.

Pero la venta o alquiler no solo dependía de las estrategias adoptadas por las inmobiliarias sino también de la existencia de los posibles compradores e inquilinos. Del análisis de algunos datos estadísticos, se pudo verificar un posible cambio en el perfil socio-económico de la ciudad y que esto podría haber significado la existencia de ese público capaz de invertir en las nuevas construcciones. Según los datos censales, principalmente en el nivel educativo alcanzado se visualiza un gran incremento en la población con estudios superiores completos, entre terciario, universitario y posuniversitario (ver tabla 4), lo que permite dar cuenta de un incremento del status social (Ley, 1988) y del nivel socioeconómico asociado a este indicador de proxy, ampliamente aceptado en la bibliografía especializada.

Tabla 4: Incremento en el nivel educativo en el área relevada y a nivel partido.

\begin{tabular}{|c|c|c|}
\hline Censo & Nivel de instrucción & Nivel de instrucción \\
\hline & $\begin{array}{c}\text { Superior completo (incluye terciario, } \\
\text { universitario y postuniversitario) en Pdo. de } \\
\text { Quilmes }\end{array}$ & $\begin{array}{c}\text { Superior completo (incluye terciario, } \\
\text { universitario y postuniversitario) en área de } \\
\text { estudio }\end{array}$ \\
\hline 1991 & $9 \%$ & $29 \%$ \\
\hline 2001 & $14 \%$ & $43 \%$ \\
\hline 2010 & $18 \%$ & $47 \%$ \\
\hline
\end{tabular}

Fuente: Elaboración propia a partir de datos censales.

En la tabla 4 se puede apreciar que en el área de estudio se produjo un aumento de población que completó el nivel superior, panorama que también puede apreciarse a nivel partido. Sin embargo, es significativo el porcentaje (47\%) que presenta hacia el 2010 el centro de Bernal en el marco del contexto quilmeño.

Además se indagaron en las percepciones de algunos vecinos de la ciudad al respecto, y se pudo constatar que no existe una única forma de ver el panorama en el centro bernalense. Esto sin dudas puede leerse desde el sesgo autoperceptivo que poseen 
los habitantes, y que no necesariamente se trate de lo que ocurre en términos objetivos. Producto de las entrevistas, por un lado están quienes consideran que el perfil socioeconómico de la ciudad se mantiene, tal como puede verse en algunos fragmentos de entrevistas realizadas a habitantes históricos.

“Para mí el perfil de Bernal permanece como años atrás. Acá hay gente con pretensiones de ostentación económica que en un momento ocupaban grandes caserones, y ahora muchos se están comprando departamentos en edificios bien céntricos como el edificio de San Martín que está frente al río y además es de primera calidad, como el de la calle Castro Barros" (Arquitecto y vecino histórico de Bernal, residente en calle Zapiola, 80 años).

"Bernal siempre fue caro y se sigue manteniendo y puede ser que las personas que vienen a vivir a Bernal tienen por ahí un poder adquisitivo distinto que el que puede ir a vivir a otra ciudad porque acá es todo muy caro. Se ve gente joven que por ahí viene a estudiar a la facultad, a la UCA y que viene porque el padre compró un departamentito mono ambiente como inversión y el chico se mudó ahí’ (Vecina residente en calle Maipú, 56 años).

Mientras que hubo otros informantes que percibieron que algún cambio hubo con respecto al perfil socioeconómico de la zona, por la existencia de aquellos que eligen tener su lugar en el centro con todos sus beneficios como localización estratégica, oferta educativa y de salud, comercios, etc.

"Si bien digamos que Bernal fue siempre medio cheto ${ }^{34}$, ahora me parece más todavía. Es la clase media un cuarto, la gente sacrifica muchas cosas para vivir en el centro y bueno come una vez por día, pero vivo a 20 minutos del obelisco" (Vecino residente en calle Ipiranga, 55 años).

Con ello, el perfil comercial también se fue complejizando, produciéndose una revitalización y cierta "sofisticación” del área comercial y los servicios. En primer lugar, a inicios de la década del 2000 se realizaron obras por parte del municipio para modernizar la calle principal de Bernal, la 9 de Julio ${ }^{35}$. Se rehicieron las veredas, se cambiaron las luminarias y los pavimentos, se instalaron bancos de madera, produciendo una modificación severa en la fachada de la misma. Esto fue acompañado por cambios en los frentes de algunos negocios históricos, y con la llegada de locales de

\footnotetext{
${ }^{34}$ Se designa a una persona de posición económica elevada que hace ostentación de ello.

${ }^{35}$ Según un agrimensor de la ciudad que estuvo frente a las obras, la nueva calle 9 de Julio se inauguró el 14 de agosto del año 2000.
} 
indumentaria y electro de primeras marcas, como Wrangler, Garbarino, Deport Show, Ona Saenz, etc. También se dio la proliferación de gastronomía especializada y cafés boutique, con restaurantes con cocina gourmet, lugares de comida rápida de cadenas y franquicias como Burger King, y aparecieron cafeterías de renombre como Havanna, Bonafide, Vía Cosenza.

Todo el impulso que tuvo esta área también puede explicarse por la presencia de un conjunto de centros educativos (de todos los niveles), y centros de salud y atención médica privada. Se acompañan nuevos servicios como gimnasios, centros de belleza, aseguradoras, aumento de entidades bancarias, principalmente privadas (se trata de bancos ubicados en dos de las avenidas más importantes del área central, Av. San Martín y Av. Belgrano), una explosión de inmobiliarias, entre otros (Ver figura 9).

Figura 9: Conjunto de servicios destacables en el centro de Bernal.

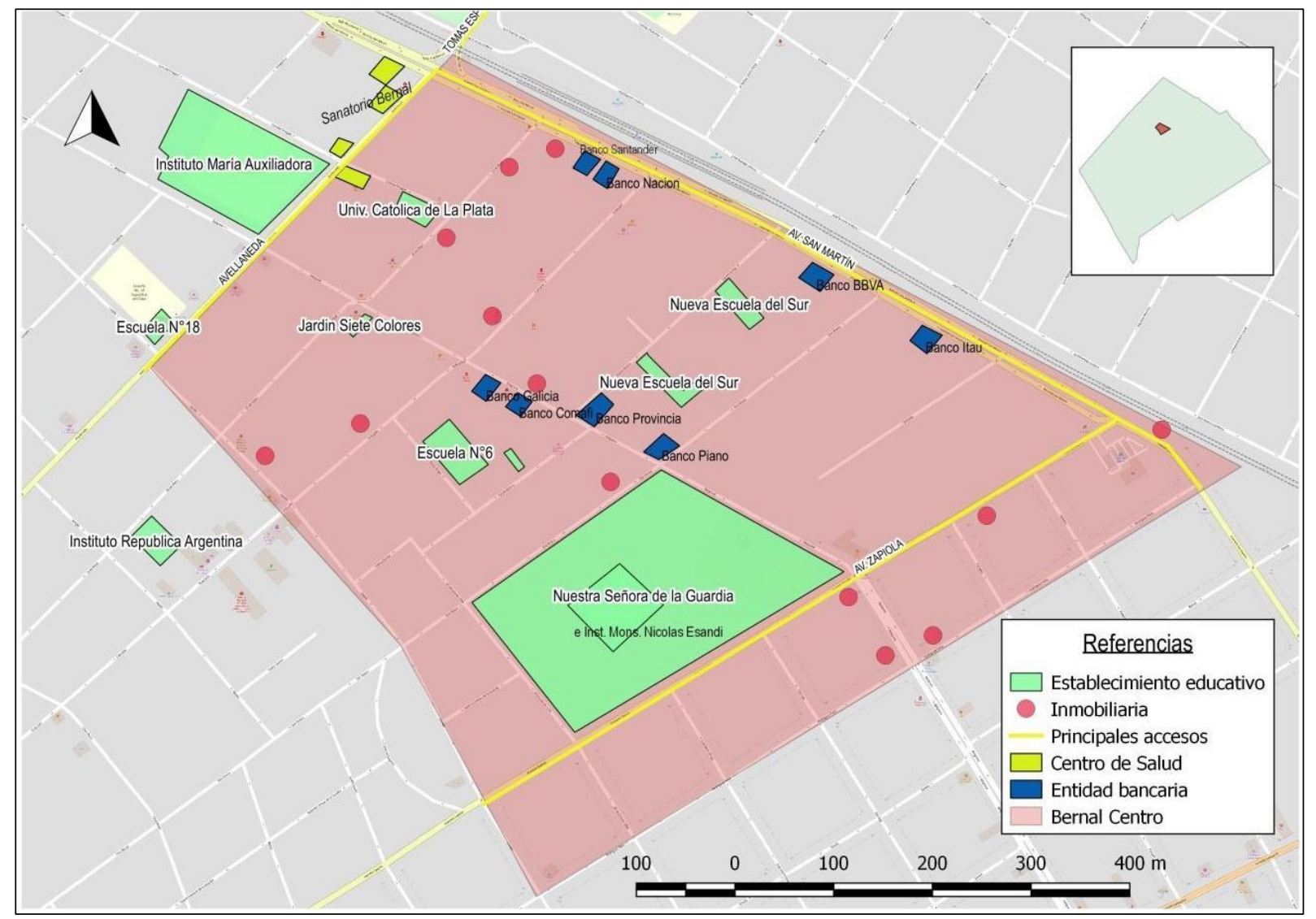

Fuente: Elaboración propia a partir de QGIS en base OSM. 
Un martillero público y vecino de Bernal de toda la vida daba cuenta de todas estas modificaciones,

"Se abrieron más comercios, hay mucha más actividad gastronómica que antes no había, barcitos, cafecitos. Años antes ahí en frente de estación antes estaba El Piave (heladería histórica en Bernal centro) y ahora está el Burger King. Antes había otra lógica, no había un nivel gastronómico de gran calidad porque evidentemente la gente comía en la casa entonces este tipo de negocios como La Farola (ubicado en Zapiola y Belgrano) era impensado. Fueron apareciendo en Bernal diferentes polos comerciales y gastronómicos, como los de la calle 25 de Mayo, Belgrano, 9 de Julio, ¿por qué? Porque hoy existe la población de los departamentos que requiere de ese servicio porque esa gente como no tiene espacio físico se tiene que reunir en un barcito. El polo comercial, principalmente de 9 de Julio, mantiene un cierto nivel, un estatus, cierta élite compra ahí. Después un fenómeno que se dio es que al haber tanto edificio han venido muchas instituciones bancarias que antes no estaban. Acá por años lo único que había era el Banco Provincia y el Nación, punto. Después apareció el Galicia que ocupa dos terrenos donde había dos casas viejas y a partir de ahí empezaron a venir el Banco Río, ahora el Banco Francés, y el Itaú. Era impensado que alguien comprara el chalet de la envergadura que era ese de la calle San Martín donde está el banco itaú. Lo mismo pasó con el otro chalet que tenía 700 metros, era un terrenazo, que tiraron abajo donde se hizo el banco francés, y bueno evidentemente ven que hay necesidad, hay una gran densidad de población y necesitan del servicio bancario. Entonces todo eso es beneficioso sin duda" (Entrevista realizada a dueño de inmobiliaria y vecino histórico de Bernal, junio 2019).

Esta descripción del emergente empírico ilustrado con las transformaciones recientes relevadas y percibidas por los informantes, dan cuenta de los procesos ya mencionados en el apartado teórico donde se dejó de manifiesto la manera en que se fue complejizando el perfil comercial y de servicios de subcentros metropolitanos, junto a un proceso de revalorización residencial de estas áreas, en parte debido a una creciente revitalización y dinamismo adquirido por parte del sector inmobiliario. Estos cambios además fueron acompañados por modificaciones en las formas de acceder al suelo urbano y en la producción y apropiación de renta urbana, y cambios en la estructura social. Todo ello impulsado por la presencia de infraestructura vial que mejoró accesos y permitió que la localización de estas áreas resulte sobrevalorada.

Estos factores contribuyeron a que se conformen territorios más densos en términos de población y de actividades terciarias, en un entorno urbanístico y un espacio público 
con un cierto prestigio, produciendo un proceso de valorización del suelo y la atracción hacia estos subcentros.

4.2. Reconocimiento de actores sociales y relaciones en la disputa por la centralidad urbana

Retomando a Pírez (1995), quien realiza una clasificación de la multiplicidad de actores que intervienen y toman decisiones en el espacio urbano, resulta necesario identificar quienes son los que despliegan diversas lógicas en este caso de estudio. Se conoce hasta aquí que en el centro de Bernal se dieron una serie de transformaciones de la mano de diferentes actores sociales que pugnan por establecer de manera hegemónica sus propios intereses vinculados al desarrollo territorial de la ciudad. Cabe aclarar que en este apartado se realizará una primera aproximación a las lógicas que los actores adoptaron, mientras que el nudo del conflicto se desarrollará con mayor profundidad en el apartado siguiente.

Un actor de gran importancia como ya se ha anunciado es el municipio, quien despliega la lógica política frente a la construcción de la ciudad. Tiene la capacidad de llevar adelante las etapas de planificación, donde se despliegan todos los instrumentos reguladores. De la mano de una serie de actualizaciones y reformulaciones a esos instrumentos de gestión, intentó liderar los procesos de ordenamiento territorial que se requerían en la zona. De esta manera se fue conformando un cuerpo normativo que iba adaptándose progresivamente a las tendencias evidenciadas en el territorio, con el objeto de disminuir la brecha entre lo establecido normativamente y lo que realmente ocurría en el territorio con relación al uso y ocupación del suelo. Este proceso, en palabras de Tella (1996) es conocido como zonización, es decir la formación espontánea de zonas urbanas dominadas por notas de coherencia común. El autor entiende que es justamente un concepto que evidencia la carencia respecto a la capacidad del proceso político para planificar y orientar las actuaciones, pero en lugar de ello, sigue las tendencias que el mercado y los cambios de hecho imponen en la ciudad.

Con estos instrumentos, el Municipio tiene la capacidad de asignarle valor al suelo urbano, lo que contribuye a incrementar o disminuir la renta urbana. Ello habilitó a que a principios de la gestión de Villordo (periodo 2003-2007), y de la mano de modificaciones a la ordenanza vigente, comiencen a construirse una serie de torres 
residenciales, y a comprarse inmuebles con el fin de desarrollar proyectos residenciales multifamiliares (Cirio, 2016). De esta manera, los terrenos pasaron a aumentar su capacidad de edificación, produciéndose una suba rápida de sus precios. Este proceso se profundizó durante las gestiones siguientes, en 2007 con Francisco Gutiérrez (del Frente para la Victoria), quien estuvo frente a la intendencia del municipio hasta el 2015, y luego Martiniano Molina de Cambiemos, quien gobierna desde el año 2015 a la actualidad. De la mano de estos actores que estuvieron frente al poder político del partido, en coincidencia y alianza con los grandes desarrolladores y constructoras se dieron las bases para la extracción de renta urbana en un área estratégica de la ciudad, que generó ganancias extraordinarias.

Estos últimos son quienes desplegaron la lógica de obtención de ganancias en el área, y se incluyen a constructores, desarrolladores, inmobiliarias, e inversores privados. Fueron quienes detectaron el negocio, consiguieron el financiamiento o lo aportan con capital propio, llevaron adelante las obras y se encargan de comercializar el producto final.

Las empresas desarrolladoras en el centro de Bernal son un número reducido de grandes estudios de arquitectos, constructoras, y también inmobiliarias que se encargan de construir las torres no solo de Bernal y Quilmes, sino también de otras áreas de Buenos Aires, y una vez que atraen las inversiones buscan casas en venta para demoler y llevar adelante la obra en altura. Un arquitecto de Bernal afirmaba

“(...) vos pensá esto, viene la empresa constructora como Surbania, Santos Barrero, Gustavo Santos. Hay 4 o 5 empresas que construyen en Quilmes y Bernal, son los grandes monstruos, son estudios de arquitectura con muchos inversionistas atrás. Vos tenés inversionistas y tenés el poder, entonces, ¿qué hacés? Compran las casas viejas, las tiran a la mierda, y hacen una torre. Son empresas muy conocidas".

Tal como manifestaba el profesional y en coincidencia con otros informantes, las empresas constructoras que operan en el mercado y que sobresalen por llevar a cabo grandes proyectos son pocas. Entre ellas, se destacan por un lado Surbania ${ }^{36}$, que se trata de una empresa encargada de comercializar diversos desarrollos inmobiliarios, a través de diferentes opciones de inversión. Está en la búsqueda constante de nuevos mercados, apuntando a aquellos segmentos de más alta rentabilidad, y toma como punto

\footnotetext{
${ }^{36}$ Sitio web http://www.surbania.com/
} 
de partida ubicaciones privilegiadas por su valor estratégico. También se distingue el estudio de arquitectura y construcción $\operatorname{Trassa}^{37}$, formada por tres socios, con ya varios años de experiencia en el rubro -desde 1989-, llevó adelante diversos proyectos priorizando el diseño integral en todas sus escalas. En el centro de Bernal realizó el 90\% de sus emprendimientos, según la información que sostiene su sitio web, con "una arquitectura superadora, pura y sostenible pensada para la calidad de vida del ser". Otros constructores significativos son Santos Barrero y Suarez\&Asociados ${ }^{38}$, quienes han llevado adelante diversos emprendimientos inmobiliarios en la zona. Este último, se encarga del proyecto, la dirección, la construcción de obras y el Gerenciamiento de Proyecto para que los inversores realicen sus emprendimientos con el asesoramiento y guía que necesiten. Según sus propias palabras, sus proyectos "se destacan por ser innovadores, confiables y exitosos".

Mientras tanto, las inmobiliarias ${ }^{39}$ también jugaron un papel importante en todo el proceso de verticalización. Junto a los desarrolladores implementaron diversas estrategias de comercialización, dándole un gran impulso a la verticalización. Entre ellas se destacan los muy diversos amenities con los que cuentan los edificios, como los ambientes que poseen -en general son departamentos espaciosos, con 3 o 4 ambientes o semipisos y pisos-, los materiales utilizados para la construcción -muchos de ellos se primera calidad como pisos de porcelanato y madera-, si cuentan o no con cocheras (cubiertas y descubiertas) y/o piscina de uso común, balcones en el frente y contrafrente, espacios de ocio para niños, puestos de vigilancia y seguridad privada, entre otros. Esto abrió camino a que se lleven adelante nuevos proyectos de edificios, que se distinguían de los anteriores por la búsqueda por mejorar los acabados (ladrillo visto, carpinterías metálicas, balcones más amplios, predominantemente curvos o con detalles de barandas, lenguaje arquitectónico minimalista o art decó, etc.), y el tamaño de los departamentos, entre los que prevalecen aquellos de tres y cuatro ambientes, resueltos funcionalmente a manera de semipisos y pisos. En muchas oportunidades, cuando los emprendimientos ya están pensados, los inversores con el arquitecto y su

\footnotetext{
${ }^{37}$ Sitio web http://www.trassanet.net/arg/index.html

${ }^{38}$ Sitio web http://suarezyasociados.com.ar/

${ }^{39}$ Del relevamiento en terreno, se pudo constatar que existen actualmente más de 15 inmobiliarias en el área relevada.
} 
equipo presentan carpetas y los renders ${ }^{40}$ con la estética del edificio. Un martillero de una inmobiliaria zonal afirmaba,

"El estudio de arquitectura arma todo el tema visual y gráfico, te arma no solamente la planta tipo de departamento, con los metros cuadrados y demás, te arma el frente del edificio aunque no exista con las casas reales al lado, con las personitas caminando, etc. Entonces te viene con todo eso armado en una carpeta, y con un descriptivo, y sino te lo mandan por mail, diferentes archivos con el descriptivo, determinaciones, bueno esto va a tener las aberturas tales, los pisos tales, los muebles de cocina tales, toda la información técnica del departamento, dibujo de cómo van a ser las plantas, cuantos departamentos por planta, metros y demás y después visuales del edificio terminado" (Entrevista a martillero público de una inmobiliaria del centro de Bernal, julio 2019).

Por otro lado, están los actores de la sociedad civil, que tienen mayor vínculo con movimientos colectivos reactivos (Karol, 2014). Son grupos de personas que se sintieron afectadas por el avance de los edificios en la zona, y que por ello desarrollaron acciones colectivas irrumpiendo en un espacio de conflicto con el objeto de modificar decisiones, situaciones o hechos particulares. Se trató de un movimiento conocido como Bernal Unido ${ }^{41}$, formado por vecinos de la ciudad, cuyos argumentos tenían como objetivo impedir las transformaciones impulsadas por los procesos de rezonificación, y buscaban la preservación principalmente del área residencial. Tal como se enfatizó anteriormente, la lógica de su accionar se encuentra más vinculada a la reivindicación de derechos, a la elección de formas de vida y valores y/o a la negación de determinadas transformaciones en el entorno urbano. Al mismo tiempo, tienden a sostener demandas "conservadoras" que apuntan al mantenimiento del orden existente.

Además, otros actores que han tenido un rol importante en este proceso son aquellos basados en la lógica del conocimiento. Por un lado, investigadores de la Universidad Nacional de Quilmes (UNQ) mostraron una alineación clara de cooperación, ya que intervinieron a los fines de asesorar a la Comisión del Honorable

\footnotetext{
${ }^{40}$ El render es una imagen digital que se crea a partir de un modelo o escenario 3D realizado en algún programa de computadora especializado, cuyo objetivo es dar una apariencia realista desde cualquier perspectiva del modelo.

${ }^{41}$ Bernal Unido es una asamblea que nació el 31 de julio de 2005, para frenar la construcción ilegal de edificios en el centro de Bernal. Los vecinos se reunieron por primera vez en la esquina de Chacabuco y 9 de Julio, y al tiempo ya lo hacían varias veces a la semana. Luego se trasladaron a la biblioteca Mariano Moreno (Recuperado de nota de La Noticia Web del año 2006).
} 
Concejo Deliberante de Quilmes -conformada para la realización del proceso de rezonificación de cuatro áreas del distrito-, principalmente en la organización del evento de consulta pública y participación ciudadana. El objetivo era conocer las opiniones de todos los vecinos de las zonas implicadas, propiciando una instancia de diálogo constructivo entre ciudadanos, políticos y expertos, permitiendo a través del debate grupal, pensar y soñar la ciudad deseada y fomentar la capacidad de innovación y creatividad social (Leva, Fernández y Paz, 2006). A ellos, se les sumó la Universidad Tecnológica Nacional (UTN), la Asociación de Entidades Profesionales Universitarias de Quilmes $^{42}$, y aquellos técnicos y profesionales locales, en su mayoría arquitectos, agrimensores, comunicadores sociales, antropólogos, entre otros., quienes brindaron información técnica sobre el proceso y aquellos conocimientos con los que estaban familiarizados.

También los comerciantes de los locales del centro de Bernal intervinieron en el proceso, pero con discursos más polarizados. Por un lado parece haber un conjunto de comerciantes que no estaban dispuestos a ceder frente al boom del proceso de verticalización, mientras que otros mostraron un cierto entendimiento y aceptación a los edificios, debido a que los creían como parte del crecimiento "natural" de la ciudad, y que su presencia los podría beneficiar de manera particular.

Por último y luego de realizar la identificación de los actores que participaron en mayor o menor medida de muchas de las decisiones que se tomaron frente al proceso de verticalización en el centro de la localidad de Bernal, y que sin dudas produjo una serie de transformaciones en el área, se presenta a continuación un esquema a modo de síntesis donde quedan expresados quienes son los actores involucrados y en diálogo, y cuáles son sus lógicas adoptadas (Ver figura 10).

\footnotetext{
${ }^{42}$ Esta institución fue constituida en el año 1976 en defensa de los derechos de los profesionales universitarios en el ejercicio de sus actividades, defendiendo también la dignidad y el prestigio de todas las profesiones y sus entidades. Luego la AEPUQ, ya en democracia, comenzó a trabajar promoviendo el bienestar de la comunidad con trabajos interdisciplinarios (como desagio de honorarios, ingresos brutos, ejercicio ilegal de la profesión), tuvo un rol importante en el crecimiento de la región colaborando con la creación de la Universidad Nacional de Quilmes, instalación de tribunales de justicia, realizó trabajos sobre la electrificación del ferrocarril Roca, del aprovechamiento racional de la ribera local, sobre antenas de telefonía celular y también sobre nocturnidad. Actualmente se encuentra trabajando dando colaboración al municipio con el plan estratégico municipal (Información obtenida de la página web de la AEPUQ, disponible en: https://www.aepuq.org/).
} 


\section{Figura 10: Actores identificados}

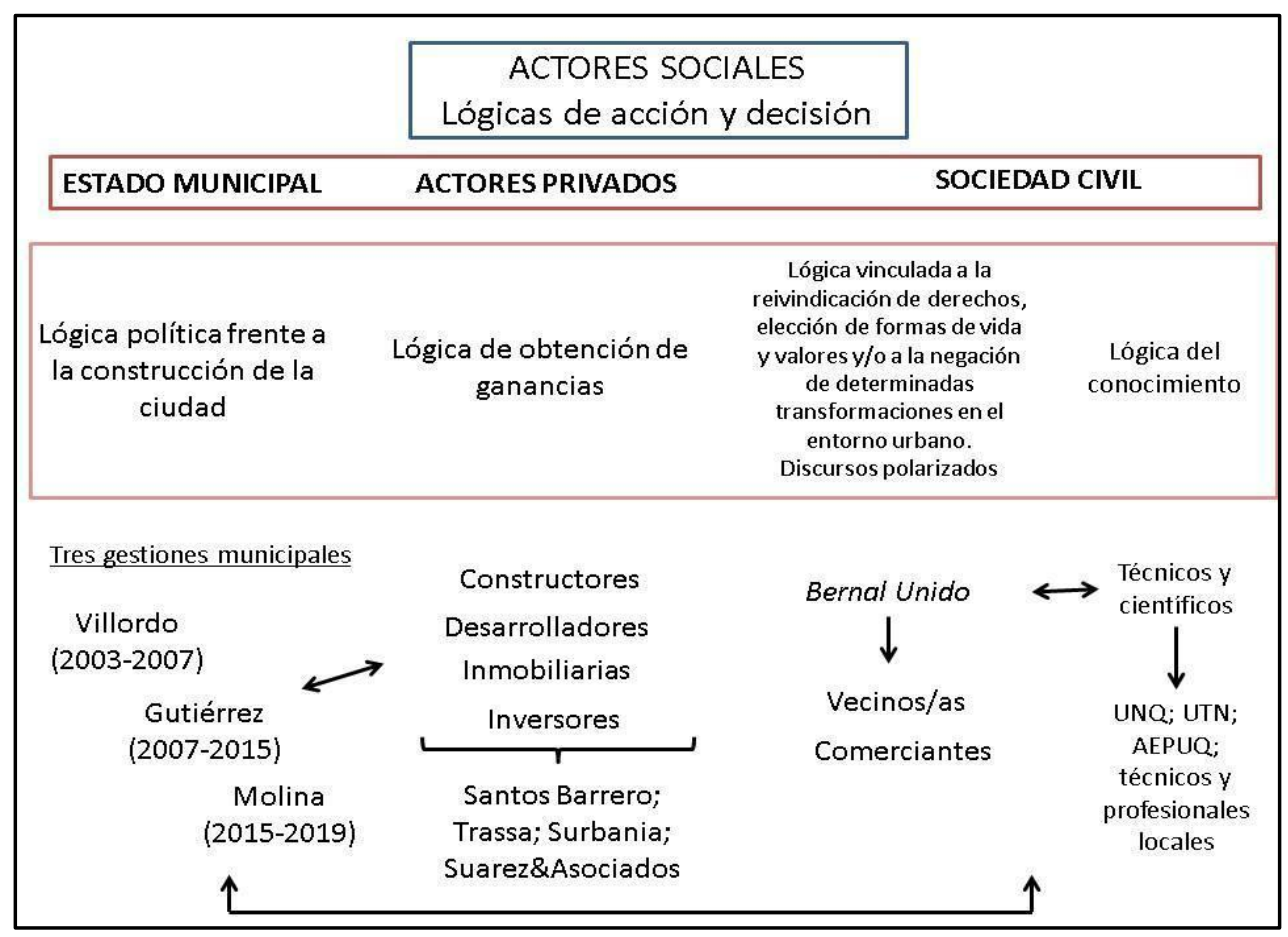

Fuente: Elaboración propia.

4.3. Aproximación cualitativa a las transformaciones recientes: Lógicas y discursos de los actores

Retomando las ideas previas que se presentaron en el apartado relacionado a las tendencias recientes del Partido, para el caso puntual de análisis de esta investigación, se puede enfatizar que a partir del año 2004 (durante la gestión de Sergio Villordo) es que comienzan a percibirse distintas transformaciones en la ciudad. Dos años más tarde, es que empiezan a darse una serie de modificaciones a la normativa de usos de suelo vigente, con la creación de la Comisión de Rezonificación. Es en esta instancia que se declara a Bernal Centro (entre otras partes del partido) "en estado emergencia", mediante la Ordenanza $\mathrm{N}^{\circ} 10337 / 06$, fomentando la densificación y el crecimiento en altura en el área. Dicho proceso de aprobación, según fuentes periodísticas zonales ${ }^{43}$, fue fuertemente cuestionado por concejales, miembros de la oposición y organizaciones

\footnotetext{
${ }^{43}$ Nota del 16 de marzo del año 2006, del Diario Perspectiva Sur.
} 
civiles por haberse desarrollado a "libro cerrado", aprobación apresurada y ocultamiento de información (Cirio, 2016).

Pese a la intención del intendente de turno de "frenar" las transformaciones que se venían produciendo post proceso de rezonificación, en el año 2007 se da un cambio en la gestión municipal, y con un nuevo intendente a la cabeza -Francisco "Barba" Gutiérrez, desde el año 2007 al 2015- se asumieron diversos requerimientos de agrupaciones vecinales en torno a un plan de ordenamiento de la ciudad. Asimismo, el intendente electo sostenía en una entrevista para el diario El Sol (julio de 2008) que cuando comienza a haber un desarrollo, el crecimiento se hace de manera abrupta, sin pensar en la ciudad hacia adelante. Como resultado, la ciudad se construye de manera desordenada, y sin respetar determinadas normas. Entonces, se lanzó en el año 2008 el Plan de Ordenamiento Urbano (POU), donde entre otros lineamientos, se manifestaba la necesidad de "potenciar nuevos centros urbanos y la identidad barrial" (POU, 2008). Luego de una serie de propuestas presentadas para mejorar el Plan, y de un contexto de grandes disputas entre actores que priorizaron sus intereses, elecciones y valores en torno a la construcción del territorio quilmeño, en 2009 se presenta el Plan Estratégico Quilmes. El mismo retomaba y reformulaba el POU, incluyendo a los principios de este en el marco de un Plan general de mayor alcance y escala (Cirio, 2016).

Es decir, parecería que hubo intenciones de resolver los problemas urbanísticos presentes en la ciudad a partir de la construcción de estos instrumentos de planificación. Sin embargo el crecimiento en altura se produjo, y sin el acompañamiento de la infraestructura necesaria. En una entrevista a un funcionario del municipio de la gestión de Gutiérrez se sostenía:

"La ciudad tiene que crecer así -de forma vertical-, no puede crecer así -de manera horizontal-, eso es verdad, los centros crecen, que pase esto no está mal, pero tiene que ir acompañado por infraestructura de todo tipo. Esto empezó cuando terminó Villordo, en Quilmes centro se detonó, mucha gente tuvo que vender, se tuvo que ir por el olor a mierda, los cortes de luz. Ahora nadie se queja porque la infraestructura llegó, vino después del crecimiento. Acá (haciendo referencia a Bernal) en algún momento va a haber que hacer algo, porque en un terreno donde vivían dos viejos, hoy viven 50 familias, y todo va al mismo cañito, entonces algún día va a explotar”. 
No obstante, durante la gestión de Gutiérrez fueron otorgados diversos derechos de construcción para nuevos emprendimientos de viviendas multifamiliares, lo que se tradujo en grandes recaudaciones ${ }^{44}$ para el Municipio, desde el sellado para el ingreso de planos, hasta los permisos y derechos de construcción según los metros cuadrados a construir. Un informante decía al respecto,

"El municipio tiene una gran contribución con los derechos de construcción que cada uno paga si hace un edificio, porque estamos hablando de muchos miles. Fortuna en derechos de construcción, multiplicado en la cantidad de proyectos que hay. Después recauda a partir de la tasa municipal que tiene que pagar el dueño de cada emprendimiento" (Funcionario del municipio durante la gestión de Gutiérrez).

Sin embargo, no todas las construcciones cumplieron con los permisos otorgados, y ante ello se utilizó la figura del exhorto ${ }^{45}$, para declarar aquellos metros cuadrados construidos de manera antirreglamentaria. Esta situación se producía cuando las empresas constructoras y/o desarrolladores construían más metros cuadrados de los habilitados y aprobados por el Municipio (excedente de FOS y FOT de los terrenos), y la única manera de "blanquearlos" era pagando una multa estipulada por el Concejo Deliberante a partir del exhorto. Un funcionario daba prueba de ello,

"El municipio cada tanto saca el exhorto y aquellos que están excedidos en metros cuadrados presentan los planos y dentro de ese periodo de tiempo podés aprobarlo y te cobran una multa. Pagas la multa y te aprueban el plano. En la época del 2013, 2014 muchos edificios se mandaron un par de pisos de más, y entonces no lo podían aprobar" (Funcionario del municipio durante la gestión de Gutiérrez).

Pese a diversos obstáculos que la secretaría de Obras Públicas puso para que los edificios (viviendas multifamiliares en altura) queden eximidos del exhorto, el Concejo en 2017 (y ya durante la Gestión de Molina) permitió que entre en vigencia el exhorto que dio vía libre a muchas construcciones no declaradas.

\footnotetext{
${ }^{44}$ Cabe aclarar que además el Municipio recibe un aporte de la Provincia por coparticipación, una vez que se informa sobre las construcciones aprobadas.

${ }^{45}$ Algunos medios de comunicación zonales (Diario "Perspectiva Sur", y Diario "5 Días Periodismo del Sur") daban testimonio de esta situación en el partido. Se recuperaron algunas noticias disponibles en: http://www.perspectivasur.com/3/nota.php?nota id $=56690$ https://diario5dias.com.ar/noticia/entr\%C3\%B3-en-vigencia-el-blanqueo-para-las-construccionesirregulares-en-quilmes-?fbclid=IwAR13vMgVz74KI3MlxPVEecRVDISho3C3oIMsorZ9itwtNOakNiQW8jWxKg
} 
"Desde la Secretaría de Obras Públicas decíamos de esa irregularidad, que estaban fuera de la ley. Quisimos hacer un exhorto pero sin incluir edificios, solo viviendas y comercios, pero el Concejo Deliberante no lo permitió porque tiene sus intereses, imagínate la presión que ejercían los constructores para que salgan los exhortos y blanquear todas las irregularidades que se mandaban. En fin, no nos permitieron sacar el exhorto para viviendas por no querer incluir a los edificios, y en el 2017, yo ya no estaba en el municipio, lo terminaron sacando, blanquearon todo y recaudaron mucho dinero" (Funcionario del municipio durante la gestión de Gutiérrez).

Antes que finalizara la gestión de Gutiérrez, y siguiendo con uno de los lineamientos del PEQ sobre el crecimiento de las centralidades existentes -Quilmes y Bernal- a desarrollarse con densidad alta y media, el Director de Obras Públicas sostuvo que se realizaron acciones para ampliar el área a densificar. Pese a este testimonio que da cuenta de prácticas institucionales de hecho, se han rastreado las normativas correspondientes a procesos de zonificación, y se pudo constatar que estas acciones no se ven cristalizadas en dichos documentos.

“vos no podes permitir una normativa que te permita hacer un edificio acá a 6 cuadras y no poder hacer un edificio acá enfrente. Entonces eso se arregló todo, se amplió y se le dio densidad a calles céntricas y con esto fomentas también la construcción inmobiliaria".

Desde su discurso, las intenciones del Estado municipal para permitir la construcción de edificios en más manzanas de las ya establecidas fueron posibles. Uno de los objetivos era que el centro se expandiera hacia la Avenida Dardo Rocha y de esa manera "desarrollar el oeste" de la ciudad, aunque finalmente esto no sucedió. Existieron algunos intentos de impulsar la zona con una serie de obras, como la mejora de la plazoleta de la Av. Dardo Rocha, la colocación de juegos y aparatos para hacer ejercicios, bacheos, y también se produjeron mejoras en algunos comercios como restaurantes, pizzerías, heladerías, y fueron apareciendo nuevos. En palabras del informante,

"la intención del municipio era que esto crezca para allá linealmente (hace referencia a la Av. Dardo Rocha), aparecieron negocios en Chacabuco y 9 de julio, los negocios se fueron extendiendo para allá. Eso iba a ir acompañado con densidad, pero no se dio porque todo el mundo quiere vivir acá, en el centro. Todo el mundo quiere bajar y tener el kiosco, la rotisería, tomar una cerveza, y salir de joda, todo al mismo tiempo y en el mismo lugar. 
Está todo acá, sumado a las escuelas, los institutos de inglés, y por eso yo creo que no hubo crecimiento para allá, pero la idea era que el crecimiento se amplíe".

Esta idea de expansión para el oeste también fue sostenida por algunos vecinos de Bernal Unido, con el apoyo de la gestión de Gutiérrez. El testimonio de una vecina fue clave para recuperar esta cuestión.

"Cuando asumió Gutiérrez nos escucharon, nosotros propusimos y el que estaba en obras particulares, había pensado en cortar la edificación en esta zona de Bernal para promocionar más Bernal oeste, o sea hacer un mejor acceso desde capital para Bernal oeste y tratar de que se edificara en Bernal oeste. Bueno los constructores no quisieron saber nada, terminaron haciendo renunciar al tipo ese, y bueno digamos que lograron torcerle el brazo al intendente".

A fines del año siguiente, en 2015, la gestión cambia y asume Martiniano Molina, sin realizar modificaciones a las normativas aprobadas previamente, pero con la idea de ordenar la ciudad a partir de un código urbanístico nuevo. Al indagar respecto a la particular tendencia a la verticalización que se vive desde hace unos años en el centro de Bernal, el intendente tuvo un discurso contundente.

"Estoy a favor de las inversiones, a favor de las inversiones privadas porque en definitiva lo que traen es desarrollo económico, traen economía en los barrios, necesidades de consumo, gastronomía, lo que ya sabemos. Donde se reproduce ese desarrollo vertical, es donde se genera un nuevo valor de la tierra y genera economía, genera empleo" (Entrevista realizada al intendente Molina, en mayo de 2019).

Sin embargo, reconoció que ese "desarrollo" se dio sin el acompañamiento de la infraestructura necesaria para evitar que se produzcan problemas con la provisión de servicios y de ordenamiento de la ciudad, pero responsabiliza a gestiones anteriores de no haberlo resuelto con anterioridad. Durante la entrevista mencionó: "obviamente nos encontramos con una ciudad con un déficit digamos en todo lo que tiene que ver con los servicios muy importante y estructural e histórico" (Entrevista realizada al intendente Molina, en mayo de 2019). Frente a este contexto, es que aparecen las inversiones privadas, en primer lugar para motorizar la ciudad a través de la generación de empleo, una revitalización del sector comercial, y generar viviendas, y en segundo lugar, para la generación de recursos al interior del Municipio que sustenten algunas de las obras de 
infraestructura necesarias para afrontar los problemas de la ciudad. El entevistado afirmó

"todas las inversiones privadas que nosotros estamos promoviendo para que sucedan tienen esa misma lógica, obviamente la inversión le va a generar al municipio nuevas tasas, derechos y demás que van a mejorar su recaudación, pero a la vez no solo generan empleo y economía sino que a través de una ordenanza de plusvalía ${ }^{46}$, similar al código de la ciudad de Bs. As., le va a generar al municipio una gran cantidad de recursos que van a estar contemplados por ordenanza donde van a ser puestos para que no haya ningún tipo de especulación".

Es decir que, discursivamente, el "desarrollo" financiado por inversiones privadas y recursos para obras de infraestructura, vendría a tratar de resolver diferentes temas para el partido en general ligados a problemas estructurales, como el déficit habitacional en algunas áreas, el mejoramiento y puesta en valor de diversos espacios públicos, y los servicios que tenga que garantizar el Estado. Remitiendo a los datos, el partido en el contexto metropolitano hacia el 2001 poseía un 5\% de déficit urbano habitacional, mientras que según el censo 2010, el déficit era de 4\% (ver tabla 4 en anexo). Es decir que en términos cuantitativos, en el partido de Quilmes el déficit urbano habitacional se redujo, pero no de manera uniforme, ya que en sectores populares esta cuestión se vio recrudecida, tal como puede observarse en datos sobre déficit habitacional por calidad de viviendas y en el crecimiento del hábitat informal.

Detrás de estos discursos, se reconocen estrategias políticas orientadas a maximizar el atractivo del espacio local y que responden al desarrollo capitalista. El Estado asume en este sentido un rol activo en términos de promoción de la actividad económica, transformando el territorio y produciendo nuevas configuraciones espaciales o nuevas formas urbanas, entre las que se incluye este espacio exclusivo de centralidad.

No obstante los discursos del municipio en pos del proceso de verticalización, existió una contracara con reacciones de todo tipo. Por un lado, un grupo de vecinos reactivos que formaban parte de Bernal Unido, comenzaron desde el año 2005 a realizar

\footnotetext{
${ }^{46}$ Cabe aclarar que esta cuestión no se ha materializado en una nueva ordenanza. Es más, luego de 13 años de iniciado el proceso a través de la rezonificación, aún no se evidencia la aplicación de instrumentos de captación de plusvalía o participación municipal en la valorización inmobiliaria.
} 
denuncias que aparecieron en diversas notas periodísticas, tal como se comprobó con la revisión y análisis de fuentes documentales varias.

"No estamos en contra de la construcción en general, sino de la edificación indiscriminada de edificios de altura. Rompen con la arquitectura del lugar y, "con suerte", el edificio más lejano ahora lo vamos a tener a 100 metros", dijo Javier Pecot. Agregaba que "si se levantan edificios altos, la infraestructura de Bernal no va a dar abasto. Las cloacas tienen 75 años y faltan escuelas y servicios. Además, los que vivamos en las 14 cuadras preservadas vamos a tener los edificios a nuestras espaldas" (Nota al Diario Clarín ${ }^{47}$, en 2006).

Frente a este tipo de reclamos, existieron otros discursos más conservadores frente a la llegada de edificios a Bernal. Con poca disposición a ceder, utilizaron como argumento que la falta de infraestructura urbana no era compatible con la modernización.

"En el caso de Quilmes Unido y Bernal Unido, el reclamo que se hace es por ni un edificio más. Ya no se está discutiendo si en la ciudad de Quilmes o en el centro de Bernal se puede construir un edificio de tres, de seis o quince pisos, de lo que se trata es de proteger la salud de los vecinos, ya que las cloacas están totalmente colapsadas, como consecuencia de este desarrollo urbano totalmente desorganizado" (Mario Sanisgali en nota al diario El Día $^{48}$, del año 2008).

"Queremos lograr un plano urbano ambiental que contemple la construcción ilegal de torres, y otras cuestiones como el estado de los servicios públicos, ya que las cloacas de Bernal centro son del año 1932, sin haberse ampliado pese al crecimiento poblacional, con problemas como cortes de luz y falta de agua" (Javier, comerciante y miembro de Bernal Unido, en nota al diario La Noticia $\mathrm{Web}^{49}$, del año 2006).

\footnotetext{
${ }^{47}$ Recuperado desde: https://www.clarin.com/ediciones-anteriores/vecinos-quieren-torresbernal_0_rkHeCLry0Kl.html

${ }^{48}$ Recuperada desde: https://www.eldia.com/nota/2008-8-30-autazo-en-reclamo-del-plan-urbanoambiental

${ }^{49}$ Recuperada desde: https://www.lanoticiaweb.com.ar/25946/bernal-unido-es-una-asamblea-que-nacioel-31-de-julio-de-2005-para-frenar-la-construccion-ilegal-de-edificios-en-el-centro-los-vecinos-sereunieron-por-primera-vez-en-la-esquina-de-chacabuco-y-9-de-j/
} 
Este tipo de expresiones siguieron presentes al día de hoy, a más de diez años de aquellos reclamos realizados cuando el proceso comenzaba a construir sus cimientos. En los siguientes fragmentos de entrevistas, diversos vecinos del centro expresaron su perspectiva en torno a ello.

\begin{abstract}
“Acá cada vez se hacen más edificios y no tenemos agua, cuando tiran las losas tiran todos los desechos que van a parar a las cloacas y los de Aysa están siempre destapando porque se compacta todo junto con los excrementos" (Vecina, residente de la calle Zapiola hace 53 años. Entrevista realizada en marzo de 2019).
\end{abstract}

"Vivimos rodeados de problemas urbanísticos, problemas de agua, de luz, de esto, es como que todo está sobrecargado" (Vecina, residente de la calle Ipiranga hace 53 años. Entrevista realizada en abril de 2019).

"Ahora creció tanto la edificación que la infraestructura no está preparada para recibir tantas personas. Las cloacas están en este momento, en el año 2019 desbordando porque la calle Zapiola se llenó de edificios aprobados por el municipio y ni hablar de lo que falta" (Vecina, residente de la calle Zapiola hace 75 años. Entrevista realizada en marzo de 2019).

"Cada vez hay más edificios uno al lado del otro. Es un hecho que vamos a padecer todos porque con el tiempo tantos edificios, siempre se careció de agua, de luz, y con esto, van a volver a faltar servicios y yo no he visto que hayan hecho muchas obras como para mejorar" (Vecino, residente de la calle Lavalle hace 71 años. Entrevista realizada en mayo de 2019).

Muchos pretendieron que los certificados de factibilidad para la construcción de nuevos edificios dejen de expedirse hasta que no se actualice o renovara la red claocal, de agua, iluminación, etc., para que sea acorde a la nueva cantidad de habitantes que iban a alojar las construcciones multifamiliares. Frente a esta situación los vecinos reactivos al proceso desplegaron diversos argumentos que apelaban a los derechos que tenían como ciudadanos a decidir sobre la ciudad en la que estaban habitando, 
"Nosotros estamos reclamando nuestros derechos, con el apoyo de Poder Ciudadano ${ }^{50}$. De todas las manzanas que conforman el barrio residencial, sólo el 9 por ciento quedará libre de edificios, lo que es un índice muy bajo. Queremos que esa proporción aumente a un 60 o un 70 por ciento, y por eso no llegamos a un punto de acuerdo", comentó Mario Maio, otro vecino (Nota al Diario La Nación ${ }^{51}$, en 2006).

Y otros sostenían que las construcciones iban a generar serias consecuencias en viviendas linderas. También esta situación generó graves denuncias y cortes de calle por parte de los vecinos afectados.

"Rompieron la medianera que no debían tocar y cavaron debajo de nuestra casa, provocando grietas en todas las paredes", contaba Diego Lavolpe ${ }^{52}$ cuando se refería a los desastres que había generado la construcción de un edificio de 8 pisos en la calle San Martín y Rodríguez Peña.

"En la calle Castro Barros hay un edificio donde hicieron las cocheras hacia abajo que se vino para adelante, se le empezó a desmoronar la estructura. Imaginate cómo están los que viven al lado" (Vecino residente en la calle Ipiranga).

"A mí me rompieron caños, me destruyeron bastante pero sobre todo sufrí bastantes sobresaltos y después cuando terminaron la edificación me lo arreglaron, pero mal, me lo volvieron a arreglar y porque tenía toda la casa llena de filtraciones" (Vecina residente en la calle Zapiola y Pringles).

"Mi papá decía que esto era el progreso (haciendo referencia a los edificios), y yo ahora pienso que si viviese y tuviese la casa con los manchones de humedad, con la rajadura, con el quilombo de la construcción, se muere de vuelta" (Vecino residente en la calle 25 de Mayo).

\footnotetext{
${ }^{50}$ Poder ciudadano era una fundación apartidaria y sin fines de lucro que nació en 1989 como iniciativa de un grupo de ciudadanos preocupados por la defensa de los derechos cívicos. Su misión era la de promover la participación ciudadana, la transparencia y el acceso a la información pública para fortalecer las instituciones de la democracia a través de la acción colectiva. Esta fundación participó en Bernal mediante charlas a los vecinos de Bernal Unido para asesorarlos frente a la problemática. Ellos sugirieron hacer una consulta popular, de donde se obtuvo el $97 \%$ de negativas frente a los edificios. Página web: http://poderciudadano.org/

${ }^{51}$ Recuperado desde: https://www.lanacion.com.ar/sociedad/protestas-por-la-construccion-de-nuevosedificios-en-bernal-nid792210

52 Denuncia recuperada de nota del diario Popular en el año 2012. https://www.diariopopular.com.ar/quilmeno/protesta-vecinos-la-construccion-un-edificio-n136885
} 
Del trabajo colectivo de sus integrantes (vecinos, comerciantes y profesionales, tales como abogados, arquitectos, ingenieros, etc.) se formaron distintas comisiones de acción para la prensa y difusión de la problemática, para la movilización, y también para el estudio de las normas de construcción. Realizaron diversas actividades, entre marchas por el centro de la ciudad, autazos, ruidazos, reparto de folletería informativa (ver figura 11) y globos verdes durante las fiestas patronales que decían "No a los edificios" 53 , petitorios de firmas de adhesión, hasta pasadas por las casas de Bernal para contar al resto de los vecinos la problemática con una consigna muy clara: "Si hasta ahora no lo hiciste, te pedimos que pongas una cinta verde en el frente de tu casa, así demostraremos que estamos unidos en un reclamo, que más que eso es un derecho" (Frase extraída de un folleto distribuido por la agrupación, ver figura 11). Los discursos en los folletos apelaban por un lado a anhelos a la idea de barrio y la conservación del mismo, ya que aparecían frases como: “Barrio de primera o ciudad de segunda?”, “los vecinos tenemos derecho a decidir en qué barrio vivir", "No queremos que la construcción indiscriminada de edificios le pasara a nuestro barrio, al que queremos preservar en idiosincrasia y espíritu". Por otro lado, ponían de manifiesto las problemáticas que podrían traer los edificios a la ciudad, tal como se expresa a continuación:

"Los edificios van a invadir la zona residencial. Con suerte el edificio más lejano lo vas a tener a 100 metros de tu casa... Sin suerte, lo vas a tener al lado, enfrente o en tu fondo...”.

"Seguro vos sos el perjudicado. Sobre 150 manzanas que componían el Bernal residencial, solo 14 (el 9\%) quedará libre totalmente de edificios. Pero el $21 \%$ va a sufrir un aumento en las tasas e impuestos".

"Las obras que se están haciendo son para unos pocos, con mayor poder adquisitivo".

"No se cumple la Ley Nacional 25675 (Ley General del Ambiente), que establece que se debe asegurar la participación ciudadana en los planes de ordenamiento del territorio y propone la Consulta Pública como un método para conocer la vocación de cada zona" (La negrita está presente en el folleto).

\footnotetext{
${ }^{53}$ Información aportada por vecina que formó parte de muchas de las actividades de Bernal Unido.
} 
A raíz de este último discurso, y con respecto al mecanismo de consulta pública llevado adelante, la asamblea de vecinos utilizó también la folletería para nombrar explícitamente a aquellos actores responsables de que el proceso de rezonificación permitiera la vía libre a la verticalización. Entre ellos, la Universidad Nacional de Quilmes (UNQ) tuvo una participación activa a los fines de asesorar a una Comisión Especial del Concejo Deliberante local en la organización del proceso de participación ciudadana para la planificación y el ordenamiento urbano territorial del partido. Se convocó a integrantes del grupo Hábitat Metrópolis (HM) y del equipo de investigación del Proyecto Gestión Estratégica Urbana de la UNQ, para asesorar en la organización del proceso de consulta pública y participación ciudadana. Desde el discurso, lo que se propuso fue conocer las opiniones de todos los vecinos de las zonas implicadas en el proceso de rezonificación, propiciando una instancia de diálogo constructivo entre ciudadanos, políticos y expertos, para aportar a la construcción de la ciudad deseada, y para optimizar la eficiencia en la toma decisiones. Así fue como en marzo del 2006 se llevó adelante la Jornada de Participación Ciudadana en la UNQ, convocada por la Comisión de Rezonificación del Honorable Concejo Deliberante quilmeño, y basada en la metodología de intervención en Grandes Grupos (IGG). Ésta permitía focalizar la atención de los participantes en posibilidades positivas y generar un entorno favorable al diálogo constructivo, relacionando a actores que generalmente tienen poca interacción.

Finalmente, los vecinos convocados fueron un total de 154, lo que permite visibilizar que el proceso participativo fue cuestionable e insuficiente, primero por la escasa cantidad de ciudadanos que asistieron; segundo, no fue posible visibilizar qué tipo de participación existió (si es que la hubo); y por último, no se considera posible realizar un proceso de tal magnitud en una única jornada (Cirio, 2016).

Esta situación permite hacer una doble lectura. Por un lado, desde los actores del poder político en connivencia con la lógica del conocimiento representada por aquellos integrantes de los proyectos de la UNQ, la participación en el proceso de rezonificación se sostuvo desde un discurso idealizado, mientras que en la práctica, o ante las evidencias de las fuertes movilizaciones llevadas adelante por grupos reactivos, la interpretación del fenómeno fue distinta. Y por otro lado, estos actores esperaban que la universidad cumpla otro rol en el proceso, demostrando su aval al reclamo ya que era un partícipe necesario para los vecinos.

Además, la Universidad Tecnológica Nacional (UTN) y la Asociación de Entidades Profesionales Universitarias de Quilmes (AEPUQ) también actuaron en alianza con el 
municipio y en contra de los intereses de la asamblea. A un año de la conformación de la misma, se repartió un folleto que explícitamente decía:

"Se comprobó que la Comisión Rezonificadora no tuvo ni tiene avales suficientes. Ante nuestra consulta:

- La UNQ envió una carta a Bernal Unido deslindando su participación en la rezonificación.

- La UTN tenía acuerdos previos con el Municipio.

- El representante de la AEPUQ ahora tiene el puesto de defensor adjunto del pueblo. La AEPUQ lo destituyó de la entidad por votar contra la participación de la prensa y de los vecinos en las reuniones de rezonificación" (Las negritas están presentes en el folleto).

De forma paralela, la folletería también servía para informar a la comunidad los logros obtenidos, y las acciones que se iban a realizar en otras instancias como,

"Este año conseguimos: i) el acompañamiento de parte de la prensa local y nacional ${ }^{54}$ (como Clarín y La Nación), lo que nos permitió hacer conocer nuestros reclamos dentro y fuera del distrito; ii) fuimos recibidos en numerosas oportunidades por distintas autoridades del gobierno de la Provincia de Buenos Aires, quienes ya saben que el $\mathbf{9 7 \%}$ de los vecinos de Bernal fue contundente al pronunciarse contra la construcción indiscriminada de edificios; que la falta de infraestructura impide seguir autorizando edificaciones sin un plan integral y coherente; que los vecinos de Bernal no fuimos escuchados ni consultados a la hora de decidir sobre nuestro futuro; iii) logramos con esto que hasta ahora la provincia no convalide la ordenanza votada por los concejales oficialistas de Quilmes; iv) logramos acompañamiento de Poder Ciudadano que es una ONG de reconocimiento internacional, en nuestra lucha; v) logramos que las nuevas obras de más de 9 metros de altura se suspendan por 90 días; vi) se amplió la zona residencial exclusiva, por lo tanto no se puede construir edificios en un sector del casco de la ciudad", entre otros logros (La negrita es de los folletos).

De aquí en más, continuaron las propuestas de trabajo para conseguir una ampliación de la zona protegida de edificios ${ }^{55}$, participar en la conformación del Plan Urbano Ambiental, y asegurar que se cumpla la palabra del intendente (en ese momento

\footnotetext{
${ }^{54}$ Cabe destacar que además tuvieron una gran repercusión en medios como radio Del Plata, Radio Mitre, Continental, y algunos programas de cable, además de los medios locales.

${ }^{55}$ Buscaban ampliar la zona residencial protegida, al área comprendida entre las calles Belgrano, Avenida Dardo Rocha, Avellaneda y Zapiola. Sin embargo, los datos recabados en este trabajo demuestran que esta cuestión no fue lograda.
} 
Francisco Gutiérrez) de investigar los permisos de obra otorgados en el área durante la gestión anterior de Villordo, y en la actual de la mano del "barba" Gutiérrez. Años posteriores, en el año 2011, relanzaron algunos folletos manifestando la situación de Bernal, (re)invitando a los/as vecinos/as a poner la cinta verde en las casas para (re)motivar la propuesta de un Bernal sin tantos edificios, aprovechando el contexto de elecciones. Sostenían que

\footnotetext{
"se vienen las elecciones y debemos dejar bien en claro en qué tipo de ciudad queremos vivir: más segura, más limpia, más ordenada, sin edificios que nos tapen el sol y saturen los servicios, con mejor calidad de vida, respetando la naturaleza, sin contaminación industrial, disfrutando de la ribera..." (Fragmento extraído del folleto repartido el 30 de junio de 2011).
}

Figura 11: Algunos de los folletos informativos distribuidos por Bernal Unido.

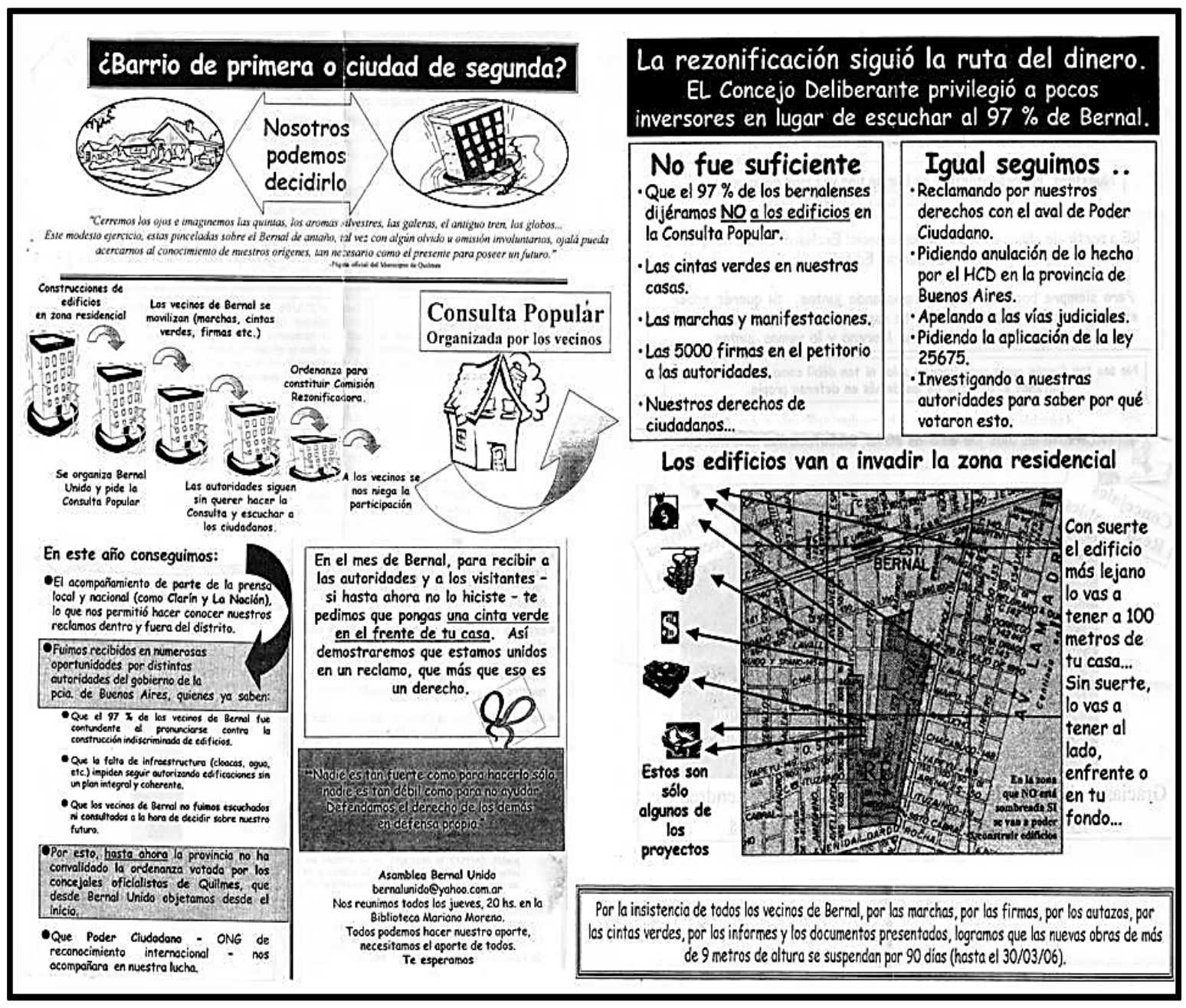

Fuente: Folletería brindada por una vecina entrevistada. 
Además, realizaron una encuesta o consulta popular en 35 manzanas afectadas, con resultados contundentes, donde un gran porcentaje de vecinos se oponía a la construcción de torres. La siguiente imagen es ilustrativa de la capacidad de organización y despliegue de estrategias de algunos participantes de la asamblea.

\section{Figura 12: Asamblea de Bernal Unido. Reclamo año 2015.}

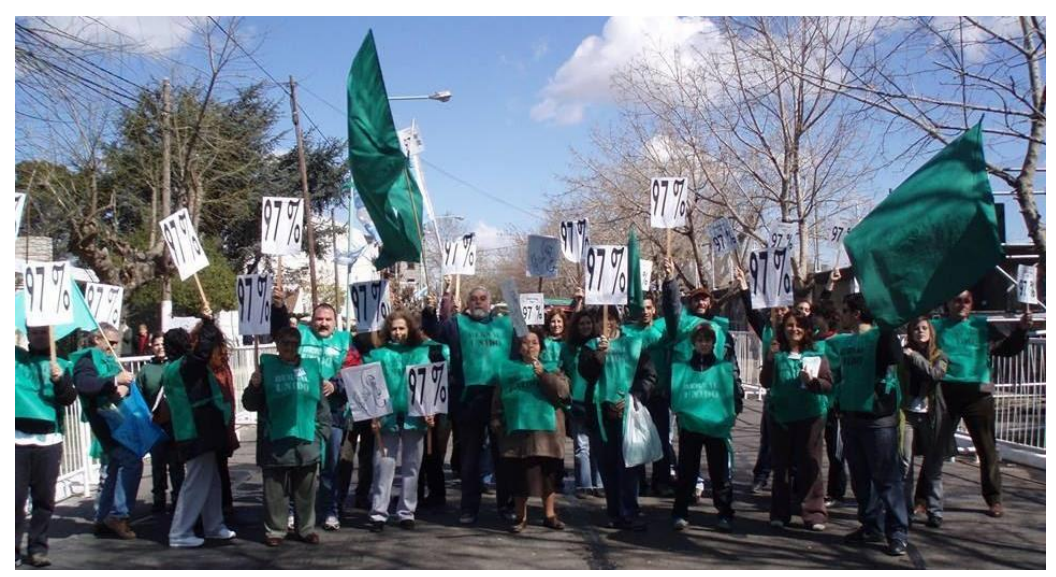

Fuente: Fotografía recuperada de la página de Facebook de la asamblea. https://www.facebook.com/asamblea.bernalunido/

De este recorrido puede leerse que en la folletería y también en el imaginario de muchos vecinos de Bernal Centro aparecen representados los intereses de actores conservadores electivos. No llegan a visualizarse preocupaciones vinculadas a la expulsión y desplazamiento de población que a raíz del avance del proceso de verticalización en el centro podría producirse. Esto podría explicarse por la inexistencia de un grupo consolidado y activo de desplazados/expulsados del centro de la ciudad, con demandas puntuales que convoquen al Estado municipal a pensar estrategias para que esa población pudiera quedarse.

Sin embargo, el freno al avance del proceso de verticalización resultó difícil por la presencia de otros intereses. Muchas veces las reuniones de la asamblea eran interrumpidas por distintas asociaciones profesionales como los colegios de arquitectos, las inmobiliarias, y hasta el gremio de la construcción ${ }^{56}$. Esto produjo que pese a toda la movilización realizada por el grupo de vecinos, y a partir de la presión de ciertos sectores, el proceso de construcción de viviendas multifamiliares en altura en el centro

\footnotetext{
${ }^{56}$ Información aportada por informante calificado, vecino participante de asamblea Bernal Unido.
} 
de Bernal se consolide, y se termine debilitando la instancia de asambleas que se fueron construyendo. Pesó más la localización que el centro garantizaba, la bajada de la autopista Bs.As.-La Plata a pocos minutos, la oferta educativa que tenía la ciudad para todos los niveles, entre otros beneficios que aseguraba vivir en la centralidad.

Con el fin de organizar la información hasta aquí planteada, se presenta un esquema línea de tiempo (ver figura 13) donde se sintetizan los principales hitos llevados adelante en la localidad en materia política, social y urbana, que explican en gran medida los vaivenes del conflicto en cuestión.

Figura 13: Hitos significativos de Bernal. Período 2004-2019.

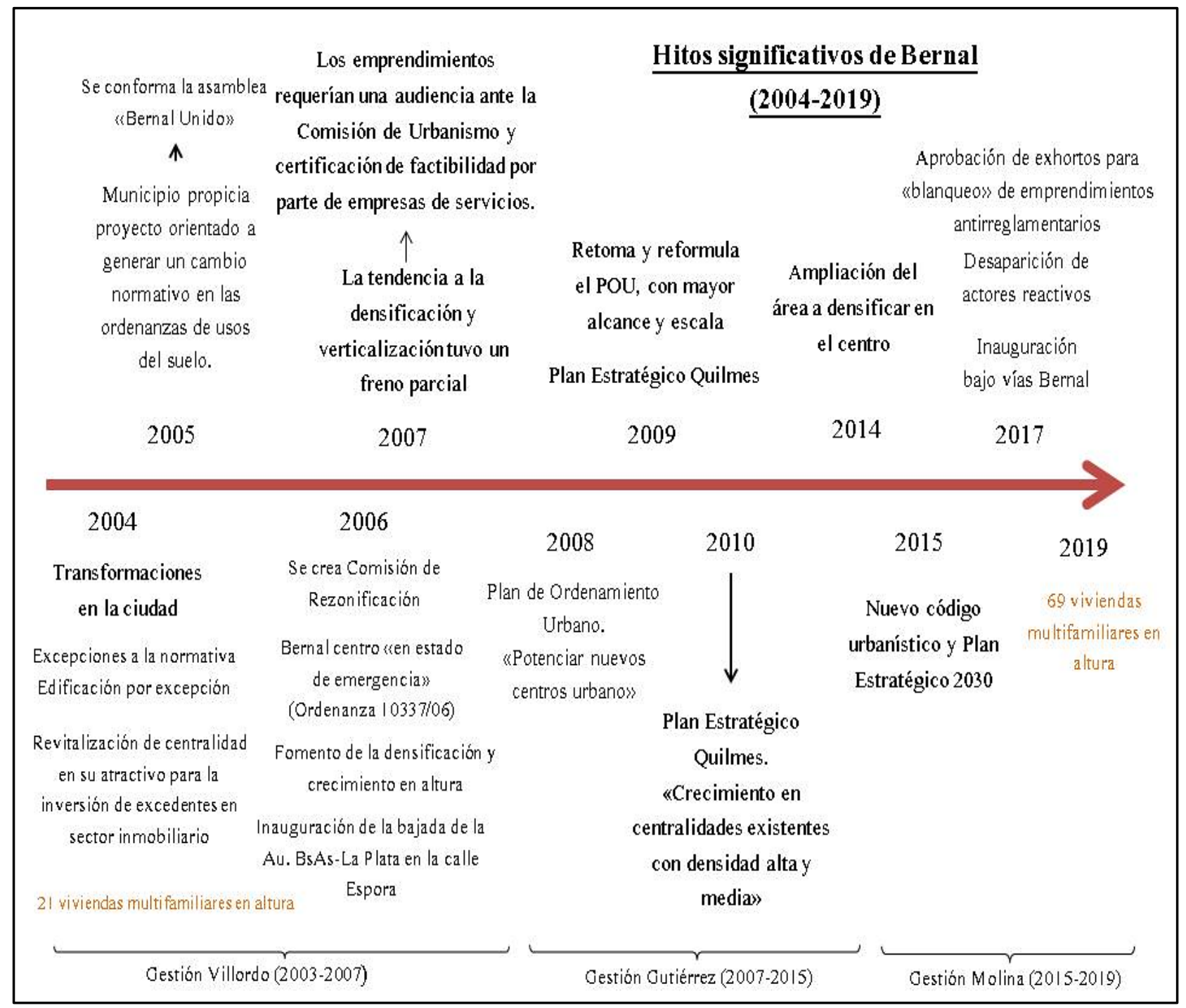

Fuente: Elaboración propia. 
Por otro lado, y retomando la clasificación realizada por Pírez, existió otro grupo de actores que se reproduce en base a la lógica de obtención de ganancias con la producción de la ciudad, y que intervino frente al avance de las edificaciones en altura: los comerciantes. Estos sostienen diferentes discursos con posiciones antagónicas pero con intereses conservadores y electivos al igual que quienes integraron Bernal Unido. Por un lado, algunos comerciantes entienden que el proceso de verticalización es prácticamente inevitable, sin embargo no están del todo conformes con la construcción indiscriminada y poco regulada.

"La cantidad de edificios me asusta muchísimo. Yo entiendo que sobre todo Bernal es una ciudad muy pequeña, su centro también. Pero supongo que así como yo me quiero quedar y mis hijos también, ¿dónde van a vivir? Son 10 manzanas el centro, entonces tenes que ir para arriba pero creo que ya se nos está yendo de las manos. No me gustaría llegar a ser como Quilmes, que me parece terrible. Me parece que hay que cuidar mucho, y que los edificios no sean altos acá, bueno suponte las 2 o 3 manzanas principales sí, pero que después no se expanda" (Entrevista realizada a comerciante de local de indumentaria femenina de la Galería Crimau, junio 2019).

“[...] el $80 \%$ del comercio de Bernal somos bernalenses, somos tipos que vivimos en Bernal, pero ahora se nos está metiendo gente que no es de Bernal. Desde que hay cada vez más edificios vinieron comercios nuevos como Garbarino, Ser Bazares, Burger King, Clandestine, son platos voladores para nosotros. Son empresas que son gigantes, entonces a medida que eso va creciendo, también va a ir cambiando nuestra historia" (Entrevista realizada a comerciante de local de indumentaria femenina sobre la calle 9 de Julio, junio 2019).

"Hace unos años atrás, la construcción de edificios acá era un furor, uno al lado del otro, pero yo tengo el local hace 25 años y no veo que venga mucha más gente a comprarme, ni tengo clientes nuevos, así que no se si está bueno todo este crecimiento" (Entrevista realizada a comerciante de local de indumentaria masculina de la Galería Grimau, julio 2019).

Pero también, existen otras miradas que sostienen que los edificios iban a ser la forma de vivienda que garantizaría que muchos bernalenses se quedaran, y no se vayan a Quilmes centro u otros partidos cercanos. Desde su percepción, el proceso de verticalización es inevitable y es parte del progreso, entendiendo que el desarrollo es sinónimo de crecimiento y modernización. 
"Yo me enojaba mucho cuando no permitían hacer obras en altura acá en Bernal. Hubo un momento que no se permitía, y yo estaba en contra de toda la movilización que hubo contra de los edificios [...] yo veía que la gente me decía "Mis hijos en Bernal no pueden vivir", porque una pareja de veintipico de años no puede comprarse una casona con pileta. ¿Por dónde empezás? Por el departamento de 2 ambientes. Después si las cosas te van bien, bárbaro, te cambiarás a 3 y después te tiras a una casa pero antes el arranque el departamento era en Wilde o Quilmes. Entonces los hijos de todos los matrimonios que venían acá me decían "Se me van mis hijos, se me van a Wilde porque en Bernal no pueden". [...] La otra era el matrimonio grande que decía "yo nací en Bernal, soy de Bernal, me quiero quedar en Bernal, pero mi casa es grande y no la aguanto más", 400 metros cuadrados al pedo porque no lo usa nadie, y ¿qué querés? Y...quiero un departamento, pero claro, estoy acostumbrado a una casa grande, cómoda, tengo poder adquisitivo, quiero venir al centro de Bernal, así bajo y me tomo un café, me pongo a hablar con uno, me voy a la heladería, que acá no había, entonces el tipo me decía "me tengo que ir a Quilmes porque acá no hay departamentos". En el medio de eso vinieron las cintas verdes y digo "No muchachos, se nos está yendo la gente de Bernal porque no tienen lugar donde vivir". Hoy el departamento es casi primordial" (Entrevista realizada a comerciante de local de indumentaria femenina sobre la calle 9 de Julio, junio 2019).

"Yo quería que se hiciese la construcción de edificios. Mira hay 5 manzanas, en estas 5 manzanas se pueden hacer y en estas no. Las 5 manzanas, ¿Dónde están? ¿A 40 cuadras del centro? No, alrededor del centro y listo. Eso era lo que se quería, lo que se pretendía. Bueno después viste cómo es esto, se fue acomodando desacomodando pero más o menos se permitió y hoy se han hecho unos cuantos y en varias cuadras. Asique los pueblos tienen que crecer, es así" (Entrevista realizada a comerciante de local de indumentaria femenina sobre la calle 9 de Julio, junio 2019).

Por fuera del discurso conservador, están quienes le ven el lado positivo al avance de los emprendimientos multifamiliares en altura, y por lo tanto ven conveniente el cúmulo de cambios que se fueron dando en la ciudad. Dichas concepciones se vinculan con la falta de visiones integrales y la imposición de intereses y elecciones individuales por sobre las colectivas.

"A mí a nivel comercial me conviene porque entra más gente y tengo más ventas. Entiendo que los edificios pueden servir, que pueden albergar un montón de gente y que es más barato que una casa grande" (Entrevista realizada a comerciante de local de indumentaria masculina en la Galería 9 de Julio, julio 2019). 
"Cuando se dio paso a todos los edificios que concentran tanta población en poco espacio, hubo más actividad comercial, te genera más movimiento comercial, y sin dudas, esto trae progreso" (Entrevista realizada a comerciante de almacén, calle Belgrano, julio 2019).

Asimismo, hay otros comerciantes que también dejaron de manifiesto su elección en torno a que el proceso de verticalización se produzca pero sin perder su condición de "pueblo". Se trata de una característica que los propios bernalenses tienen internalizada en sus imaginarios, en particular en quienes nacieron o permanecen desde hace muchos años, y llevan adelante su cotidianidad en las pocas manzanas del entorno bernalense.

"Yo no estaba en contra de que cambiara la fisonomía de la ciudad, pero quería que esto siga siendo un pueblo" (Entrevista realizada a comerciante de local de indumentaria masculina sobre la calle 9 de Julio, junio 2019).

"Banco a los edificios pero bueno, cambia la fisionomía, se pierden los jardines, se pierde la visual que había antes, las arboledas que caracterizaban a la ciudad y el pueblo que vivía en ella" (Entrevista realizada a comerciante de almacén, calle Belgrano, julio 2019).

"Bernal tiene vocación de pueblo y hace que el vecino de Bernal se sienta muy propietario del pueblo y lo disfruta. A los que vivimos acá nos gusta no ser millones y conocernos entre todos. Para mí los edificios tienen que estar porque de esa manera hay más movimiento a nivel comercial pero no quisiera dejar de reconocer mi ciudad" (Entrevista realizada a comerciante de local de indumentaria femenina en la Galería 9 de Julio, julio 2019).

“Acá somos un pueblo, pero tiene que crecer, y de hecho fue el mismo pueblo el que pide que vaya creciendo, porque para mí estamos creciendo en número y es normal, y tenemos que tener donde vivir. Ahí es donde los edificios tienen un rol fundamental en retención de los bernalenses" (Entrevista realizada a comerciante de local de indumentaria femenina en la calle 9 de Julio, julio 2019).

Aunque contrapuestos, sus discursos están fuertemente atravesados por una lógica vinculada a la elección de formas de vida con o sin determinadas transformaciones en el entorno urbano. Sus elecciones se asocian con la representación que construyen de la ciudad, lo que explica que mientras algunos sectores de la sociedad se organizaron para impedir las modificaciones que la verticalización iba a traer, otros expresen explícitamente y con fuerte presencia su aceptación a los cambios. 
Por su parte, las inmobiliarias supieron poner sobre la mesa las características que poseen los departamentos para comercializar sin perder de vista la amplia financiación con la que cuentan muchos de estos emprendimientos, y en particular, aquellos que están por construirse (Ver figura 14).

Figura 14: Estrategias de comercialización en futuras construcciones.

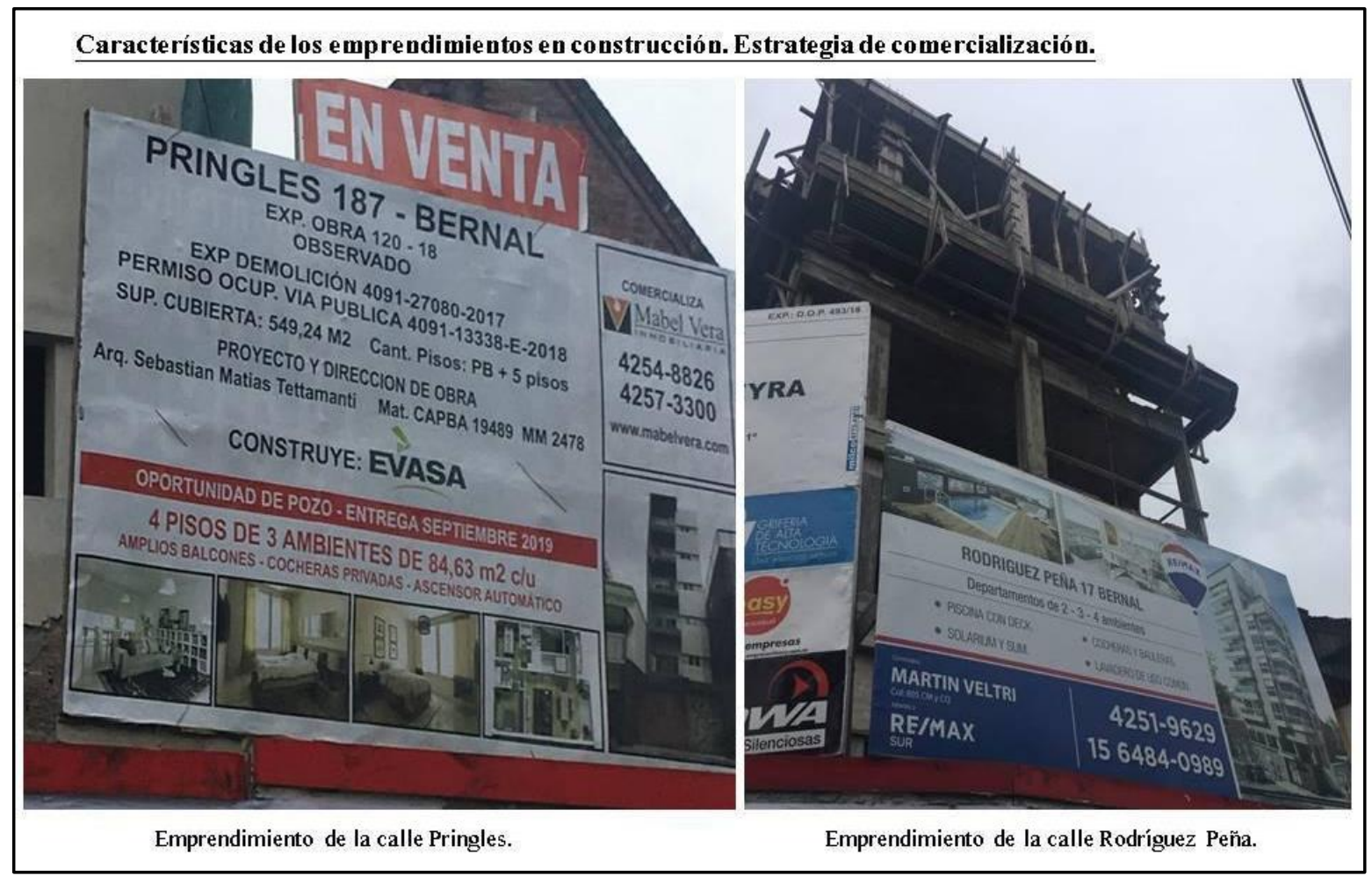

Fuente: Fotografías tomadas en abril 2019.

Tal como puede observarse en las figuras 14 y 15, en los carteles de venta muchos muestran cómo quedará la construcción terminada, y en él no dejan de mencionarse los diversos departamentos que ya se encuentran vendidos, utilizados para mostrar que se trata de un emprendimiento llamativo y de fácil acceso. 
Figura 15: Estrategia de comercialización. Cartelería en emprendimiento de la calle Belgrano y 25 de Mayo.

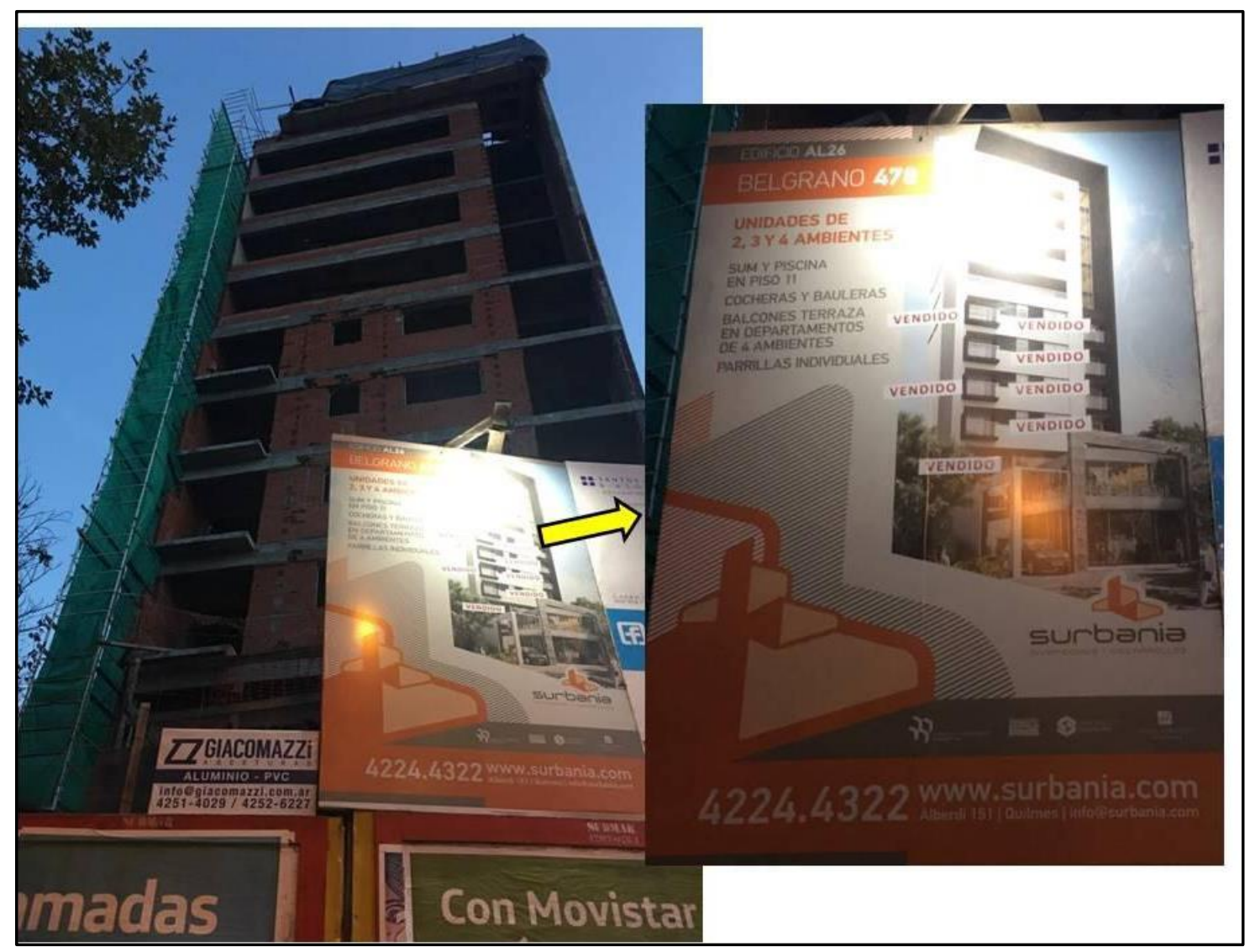

Fuente: Fotografías tomadas en abril 2019.

Tres arquitectos de la zona daban cuenta de muchas de estas cuestiones, y contaban:

"Los departamentos son grandes, vos ya ves que la construcción no está en el mínimo reglamentario, tiene una buena ejecución, y son departamentos de buenas dimensiones. Deben tener oferta de uno, dos y tres dormitorios, los del frente deben ser mínimo de dos/tres dormitorios y tienen estares (referido a los ambientes de estar) importantes, balcones". (Entrevista realizada en abril 2019 a profesional en arquitectura y vecino de la zona)

“[...] normalmente acá son departamentos de 2, 3 y 4 ambientes, que se venden en dólares el metro cuadrado, [...] Por supuesto tienen cocheras, algunos tienen su lavadero individual, alguna piletita arriba, con su baulera. Depende del terreno y la superficie que 
les permiten pueden tener alguna que otra cosa más" (Entrevista realizada en mayo 2019 a profesional en arquitectura y vecino de la zona).

"Acá hay edificios que tienen departamentos monoambientes de $36 \mathrm{~m} 2$, de dos ambientes de $44 \mathrm{~m} 2$, y más. En estos edificios hay terraza con parrilla, piscina y sum, con cocheras. Con respecto a las características interiores, por ejemplo, todos tienen muebles de cocina, los baños completos (con bañera, inodoro, bidet y vanitory), calefacción por radiador, y en general se deja la instalación de aire acondicionado ya preparada para que el propietario lo coloque" (Entrevista realizada en febrero 2019 a profesional en arquitectura, contratada por empresa constructora).

También los martilleros de algunas inmobiliarias de la zona aportaron sobre este tema, manifestando,

"La gran mayoría son departamentos de 2 ambientes, o sea chicos, de un dormitorio. Ahora le están dando bolilla a lo que no había y están apareciendo algunos con 2 dormitorios, o sea que empiezan a pensar en los nuevos emprendimientos en departamentos más grandes. Es una demanda que no estaba satisfecha porque como hacían todo para negocio, todo era chiquitito, cosa que sea fácil de vender o alquilar y hacer más cantidad. Iban únicamente al número y ahora entendieron que por ejemplo Bernal tiene muchas casas de gente grande $\mathrm{y}$ la casa le queda súper grande, entonces esa persona vende una casa importante y no escatima en pagar una buena cantidad de plata en un departamento grande. Entonces empieza a haber tendencia a construir menos unidades más grandes". (Entrevista a martillero público de una inmobiliaria del centro de Bernal, julio 2019).

"En Bernal hay complejos de torres de estilo neoclásico con departamentos de dos, tres y cuatro ambientes que se asemeja a los Chateau de avenida Libertador y Puerto Madero. Los edificios son el presente y el futuro de la zona, por motivos de bajas expensas, seguridad y amenities" (Entrevista a martillero público de una inmobiliaria del centro de Bernal, junio 2019).

"Los edificios nuevos que están construyendo son construcciones importantes, en el corazón del centro de Bernal, y son de un nivel constructivo para un poder adquisitivo importante. Son pisos o semipisos, estás hablando de mercadería que no va a estar por debajo de los 250/300 mil dólares, entonces para llegar a ese bolsillo tenés que hacer un nivel constructivo importante. Además, cuentan con parquización, pileta, parrilla, sum, 
gimnasio, y demás" (Entrevista a martillero público de una inmobiliaria del centro de Bernal, junio 2019).

Estos actores no solo enfatizan las características que presentan los emprendimientos, sino que también señalan los beneficios que tiene el centro de Bernal. Principalmente, ponen el acento en tres cuestiones primordiales que garantizan su comercialización. En primer lugar, la localización es estratégica. Tal como se mencionó previamente, la cercanía a diversos centros y subcentros urbanos, hacen a la centralidad bernalense muy atractiva. Los martilleros aportan,

"El perfil de compradores son familias que buscan estar próximos a la autopista por razones laborales, ya que viajan todos los días a Capital Federal. Los nuevos emprendimientos coinciden en ofrecer buenos accesos" (Entrevista a martillero público de una inmobiliaria del centro de Bernal, julio 2019).

"La gente de Bernal es muy localista y tiene un gran poder adquisitivo. Invierten acá porque tiene buenos medios de comunicación" (Entrevista a martillero público de una inmobiliaria del centro de Bernal, julio 2019).

"No se puede negar que estamos en un punto estratégico con relación a Ciudad Autónoma de Buenos Aires. Acá en 10 minutos estamos en el centro" (Entrevista a martillero público de una inmobiliaria del centro de Bernal, julio 2019).

"Un requisito que se está buscando mucho es estar bien al centro, cerca del centro comercial de Belgrano y 9 de Julio, de la estación, y de la autopista. En cambio si te vas para la calle Avellaneda pasando Chacabuco por ejemplo o Cerrito (es decir, al noroeste), ya está muy desavalorizado el departamento" (Entrevista a martillero público de una inmobiliaria del centro de Bernal, julio 2019).

En segundo lugar, muchos de los edificios que se comercializan actualmente en el mercado son de una gran altura (ver figura 16) y esto se debe a que cuentan con una excelente vista hacia el Río de La Plata. De esta manera, las campañas de difusión realzan imaginarios de grupos sociales que quieren vivir en el centro de la ciudad y con cercanía a la "naturaleza". Entonces se comienza a priorizar la visualización al cuerpo 
de agua pero estando en la centralidad, rodeados de seguridad y exclusividad. Algunos martilleros destacaron esta cuestión,

"Bernal cuenta con un plus muy valorado, como la cercanía al río. Está comprobado en el historial de valores de las propiedades que aquellas con vista al agua llegan a diferenciarse hasta en un $300 \%$ de crecimiento en su valor respecto de las que no lo están" (Entrevista a martillero público de una inmobiliaria del centro de Bernal, julio 2019).

"Hay edificios que tienen una gran altura, lo que les da una ventaja, y es la vista al Río de La Plata de por vida" (Entrevista a martillero público de una inmobiliaria del centro de Bernal, julio 2019).

"Lo que se privilegia es que tenga buena vista, los pisos altos son los más cotizados por la vista. La orientación es fundamental, o sea se busca siempre la mejor, que es la noreste, porque tenés más horas de sol" (Entrevista a martillero público de una inmobiliaria del centro de Bernal, julio 2019).

Figura 16: Edificaciones de gran altura en el centro de Bernal para garantizar la vista al Río de La Plata.

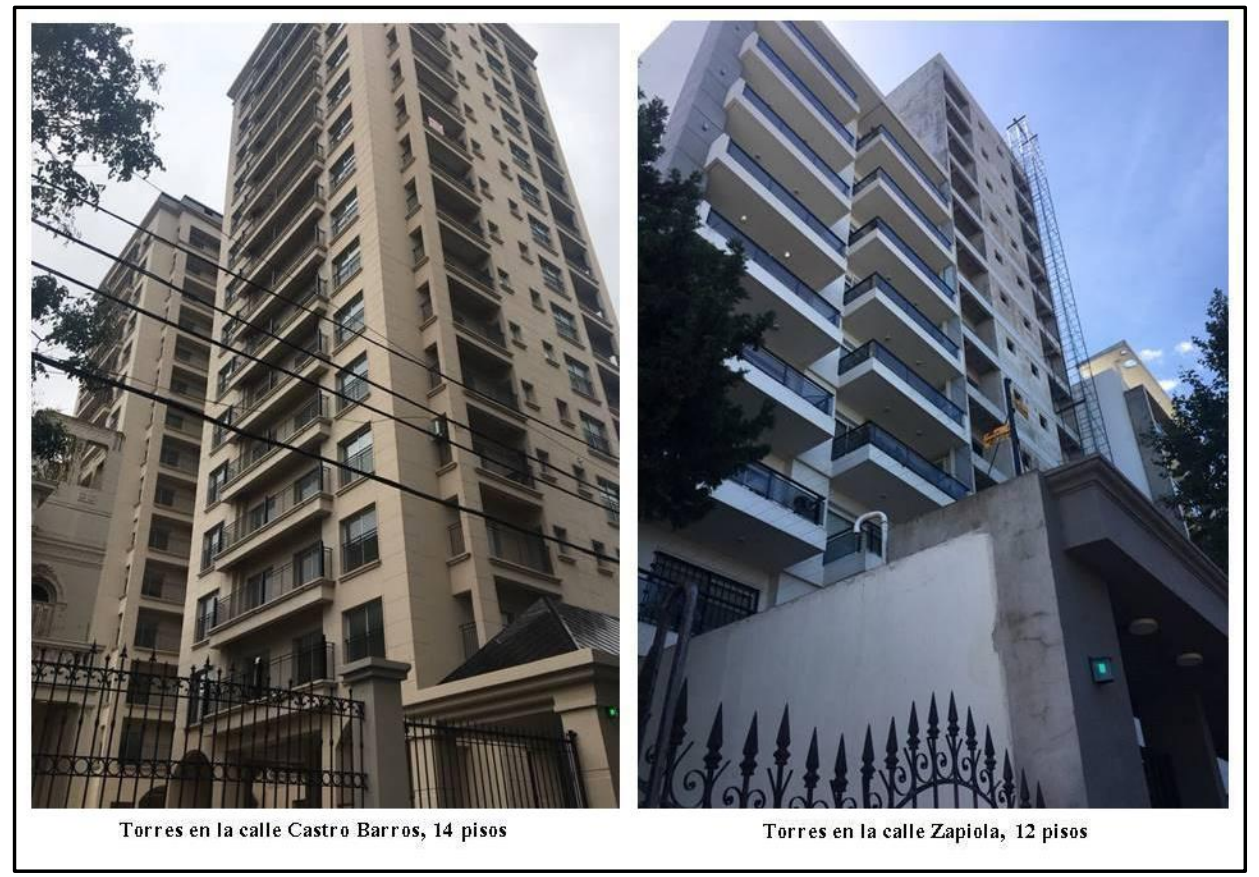

Fuente: Fotografías tomadas en abril 2019. 
Y por último, la seguridad también jugó un papel interesante al momento de ofrecer y vender o alquilar departamentos en los edificios. Continúan señalando,

"Otra de las ventajas de estos proyectos es la seguridad. Se ofrecen como predios cerrados, donde sus habitantes pueden vivir su tiempo de ocio puertas adentro". (Entrevista a martillero público de una inmobiliaria del centro de Bernal, julio 2019).

"El departamento hoy es la vedette a nivel comercial en el mercado porque el padre que le compra al hijo prefiere comprar un departamento por una cuestión de seguridad de que los chicos están trabajando todo el día, no están en todo el día en casa y el departamento es más práctico. Aunque tenga la oportunidad de comprarle al hijo una casita al mismo precio, prefiere el departamento porque aparte hasta te diría que tiene un valor de reventa el día de mañana" (Entrevista a martillero público de una inmobiliaria del centro de Bernal, julio 2019).

"Hoy juega muy fuerte el tema seguridad, es una herramienta fundamental que ayudó al edificio [...] tanto los jóvenes como las personas mayores están tranquilos porque estadísticamente tienen menos posibilidades que les roben" (Entrevista a martillero público de una inmobiliaria del centro de Bernal, junio 2019).

En estos fragmentos de entrevistas puede percibirse el perfil del comprador de este tipo de emprendimientos. Entre estos motivos y los diversos amenities con los que cuentan los departamentos, se deja entrever el cambio en el perfil socioeconómico que anteriormente se vio plasmado no solo en datos, sino en las percepciones de quienes residen y/o trabajan en Bernal centro. En este sentido, parece priorizarse una modalidad de acceso al centro para aquellos que poseen altos ingresos, lo que confiere a que en materia urbana se produzca un perfil de elitización en ascenso.

Estas estrategias utilizadas por las inmobiliarias para vender y/o alquilar los departamentos también están presentes en revistas de pública circulación. A continuación se presentan algunas de las publicaciones que presenta la guía inmobiliaria y del hogar "Todo Propiedades" del mes de julio de 2019. 
Figura 17: Publicaciones relevantes sobre estrategias de comercialización de departamentos en revista "Todo Propiedades".
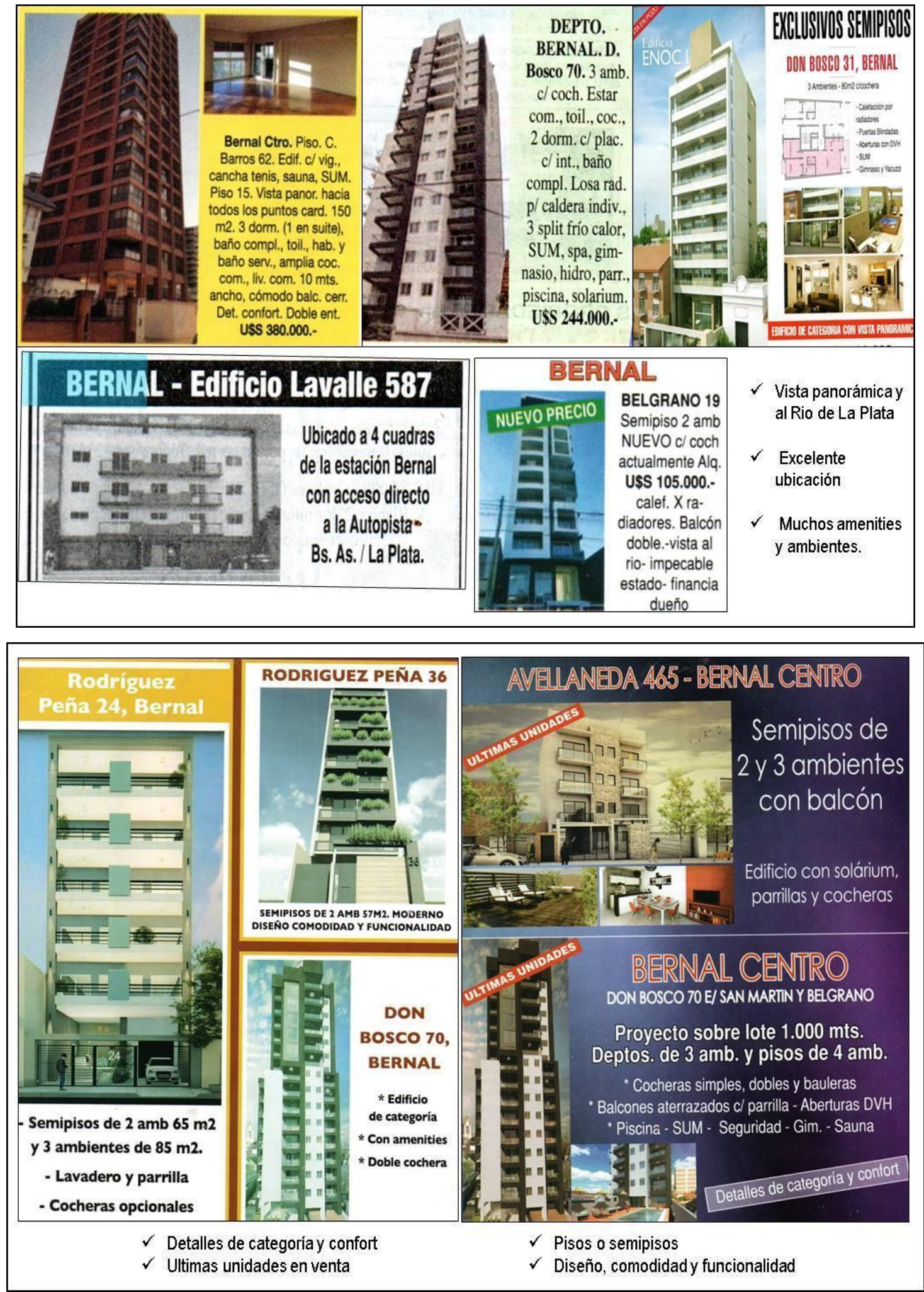

Fuente: Elaboración propia a partir de publicaciones en Revista “Todo Propiedades” del mes de julio de 2019. 
Retomando lo mencionado en el apartado 4.1, en referencia al perfil del público que participa en la comercialización de este tipo de urbanizaciones, otros informantes resaltan que los cambios en el perfil de población fueron leves porque siempre Bernal mantuvo un cierto estatus y poder adquisitivo, y muchos de los posibles compradores y/o inquilinos podrían ser residentes de la ciudad desde hace años y que tienen un gran arraigo. Esta cuestión fue enfatizada por diversos actores ${ }^{57}$.

"Normalmente, el $80 \%$ de la gente que alquila o compra es toda gente local, son viejos vecinos, hijos o nietos de antiguos bernalenses o quilmeños, o sea es una población que es muy fiel a la zona y tienen mucho arraigo al lugar. Aunque hay unos pocos que vienen de afuera, de capital, de Barracas, gente de Avellaneda, la zona está muy visitada pero no es muy frecuente, por el tema de la autopista y la bajada" (Entrevista a martillero público de una inmobiliaria del centro de Bernal, julio 2019).

"Apuntamos a un mercado con mucho poder adquisitivo. Bernal es un mercado muy particular. El Bernalense quiere estar en el centro y demanda eso a las constructoras" (Entrevista a martillero público de una inmobiliaria del centro de Bernal, julio 2019).

"En parte el perfil fue cambiando, es distinta la historia de hace 20/30 años que la de ahora. Puede haber hoy un mayor nivel de gente de poder adquisitivo, mientras que antes eran $5 \mathrm{o}$ 6 familias con mucha plata. Hoy hay más gente con dinero" (Entrevista realizada a comerciante del centro de Bernal y vecino de la zona, mayo 2019).

Sin embargo, cabe resaltar que aquí se produce una contradicción entre la percepción de algunos informantes y los datos analizados. Mientras en las entrevistas e imaginarios de los entrevistados aparece el pensamiento de que al existir desde siempre un buen poder adquisitivo en Bernal, la población local sería la que se disputaría el centro, adquiriendo los departamentos construidos y en construcción. No obstante, pierden de vista que los compradores e inversores pueden no ser estrictamente vecinos de Bernal y que la demanda solvente viene mayormente de otras áreas, según se pudo constatar con informantes, desarrolladores, comercializadores y registros, teniendo en cuenta que durante el periodo de crecimiento económico neodesarrollista produjo grandes ganancias a distintos sectores que se volcaron en la construcción de proyectos inmobiliarios convertidos en una de las alternativas de inversión más seguras.

\footnotetext{
${ }^{57}$ Cabe aclarar que las citas de la página 64 también pueden ser ilustrativas para demostrar esta cuestión.
} 
El problema radicó en la posibilidad de acceso a este tipo de emprendimientos. Si se remite a los datos sobre el perfil socioeconómico de población que se destaca en Bernal, muchos podrían acceder a un departamento en el área. Pese a la novedad y lo llamativo que puede resultar el vivir en el centro en un departamento de buenas características, amenities y en una localización estratégica, los distintos actores tienen diferentes discursos en torno al porcentaje de ocupación de los mismos. Por un lado, los martilleros sostienen que el porcentaje de inquilinos ocupando los edificios es muy alto, pero aquellos departamentos que están a la venta podrían tener una ocupación menor.

"No creo que haya mucho departamento vacío en Bernal, obviamente siempre puede haber un porcentual de constructores que construyen exclusivamente para vender y algunos que construyen y después alquilan. El alquiler de un departamento nuevo en Bernal centro es muy fácil de ubicar. A veces se da que hay emprendimientos sólo destinados a la venta entonces ahí podes encontrar departamentos desocupados, porque los dueños si no quieren otra cosa que vender, van a esperar. Acá también pasa que se pone a la venta mientras está en construcción, entonces a veces pasa que el tiempo de venta es absorbido durante la construcción y eso ya le da un margen de año y medio, dos años para que el constructor lo vaya vendiendo" (Entrevista a martillero público de una inmobiliaria del centro de Bernal, julio 2019).

"Con respecto a los que son para alquiler, entre un $90 \%$ y un $100 \%$ de los departamentos están ocupados, porque los que no pueden comprar terminan alquilando, pero a lo sumo para eso hay productos de tres ambientes. Si un edificio es solo para alquiler, está bien que comprimas los departamentos, y el negocio termina siendo más rentable. La compra está muy caída, así que no podría decir un porcentaje, pero es baja" (Entrevista a martillero público de una inmobiliaria del centro de Bernal, julio 2019).

"La ocupación de los departamentos acá es alta, porque al tener un montón de servicios y otras cosas, la gente no se va. La ocupación siempre es importante porque la gente se va renovando. Desde ya que la venta depende del momento económico, va variando y quizás ahora es poca. La propiedad no está cayendo en función de valores, porque la inversión en ladrillo lo podes mantener, y eso va en función de que hay un núcleo de gente que busca este sector" (Entrevista a martillero público de una inmobiliaria del centro de Bernal, julio 2019). 
Tal como manifiestan en las entrevistas, existen en Bernal departamentos que han sido construidos exclusivamente para vender, entonces los inversores en muchas oportunidades quedan a la espera de esos compradores y mientras tanto, especulan con la valorización de los mismos. En este caso, la propiedad inmobiliaria se comporta como reserva de valor, y como medio de acumulación de riqueza. Al poder comprarse los departamentos con diversas facilidades de pago, como en pozo o fideicomiso, se adquieren por un valor de mercado más accesible y luego se revenden a un precio mayor. Sobre esta cuestión los actores manifestaban,

"A veces pasa que los departamentos se venden dos o tres veces, pasan por varias manos, entonces hasta que no llega alguien que lo compre y lo meta en alquiler puede ser que el departamento esté un tiempo vacío" (Entrevista a martillero público de una inmobiliaria del centro de Bernal, julio 2019. La negrita es propia).

"Hoy lo que hay en el mercado comprador es gente adulta grande, que quiere dejar su casa porque no quiere o puede mantenerla, y tiene una posibilidad económica de comprar un departamento de cuatro ambientes. El resto es un público ficticio, ya que hay muchos edificios en construcción en las 10 cuadras a la redonda que es el área más acomodada de Bernal (en función a la localización), pero todos esos edificios están siendo construidos por inversores que tienen un poder adquisitivo alto, que pueden invertir, pero no hay un público comprador genuino de esos departamentos. Los hacen con la expectativa de venta en un futuro, tienen la lógica de "tengo dólares, sirve construir en dólares, entonces la pongo en ladrillos que siempre fue un resguardo positivo en este país, entonces hago e invierto". Pero no existe el comprador genuino de dos, tres o cuatro ambientes, o existe pero es muy poco, y sobre todo en este mercado que es acotado, a diferencia de Palermo que es más Premium, y quizás exista el público comprador" (Entrevista a dueño de desarrolladora de un gran porcentaje de edificios en Bernal centro, julio 2019. La negrita es propia.)

Dicho esto, puede distinguirse el rol que juegan los departamentos en el área principalmente para atesoramiento de aquellos actores de gran poder, y la pérdida de la vivienda como bien de uso, para volverse más que nunca un bien de cambio, un commodity o mercancía. En ello reposa el modelo extractivo dando lugar a procesos de especulación inmobiliaria y entregando bienes comunes como el suelo urbano a través de la mercantilización de la vivienda. 
En paralelo, retomando la voz de algunos vecinos y/o comerciantes, que viven diariamente con el entorno bernalense, más aún perciben que la ocupación de los departamentos es baja. Dejan en evidencia esta cuestión en los siguientes fragmentos de entrevista.

"Yo sé que hoy en día hay más posibilidades de pago, se puede comprar en pozo o fideicomiso, sin embargo para mi hay tantos edificios, que no llegan a llenarse (Entrevista realizada a comerciante del centro de Bernal y vecino de la zona, mayo 2019).

"Lo que yo estoy viendo hoy es gente que se ha ido y se vuelve a la casa de los padres. Hay muchos departamentos que están vacíos porque no logran alquilarlos. Me pregunto ¿Quién los puede pagar?, depende mucho de lo que ganen" (Entrevista realizada a vecina, residente de la calle Ipiranga, abril 2019).

"Hay gente que ha invertido en comprar un departamento y capaz lo tiene ahí esperando, especulando a que en algún momento explote todo, no sé. Te aseguro que los departamentos no están todos ocupados ni de casualidad" (Entrevista realizada a vecina, residente de la calle Zapiola, julio 2019).

Muchos consideran que el éxito de la ciudad se busca a través de indicadores como la construcción de metros cuadrados y el aumento de la valuación de los inmuebles. Así, en los últimos años, se construyeron tres veces más edificios, pero muchos de los departamentos construidos en una zona con una alta valorización del suelo, están vacíos u ocupados bajo forma de inquilinato. Entonces cabe preguntarse, ¿para quién se construye y para qué? La ciudad parece diseñarse desde una lógica que excluye a una parte importante de la población (Ríos, 2005), y es esa población la que luego recibe los impactos más negativos producto del avance de la lógica privada en la construcción de ciudad. Dichos impactos serán analizados en el próximo apartado.

\subsection{Aproximación a los impactos urbanos producto del proceso de verticalización del centro}

Retomando algunas ideas planteadas con anterioridad, el centro de Bernal fue la zona más demandada para la construcción de nuevas viviendas en altura porque posee, 
entre otras cuestiones, una buena accesibilidad y estratégica localización, alta calidad urbana, cercanía al centro comercial y de servicios, y un nivel socioeconómico homogéneo de sus habitantes (Baer, 2011). La selectividad de la zona también fue acorde al tipo de vivienda que se construyó de manera predominante: multiviviendas destinadas a sectores medios altos y altos. Esto produjo la demolición de tejido urbano existente y su sustitución por usos más intensivos del suelo, reemplazando casas por edificios o torres (Azuela y Cosacov, 2013). De la mano de este proceso, se desataron una serie de impactos que vale la pena señalar y analizar, principalmente desde las distintas representaciones que los actores tienen del territorio. A raíz de evidencia empírica, y los debates académicos, los impactos están vinculados a procesos de segregación y gentrificación relacionados principalmente con,

I) la elitización del centro y expulsión poblacional;

II) la falta de oportunidades de acceso al suelo y vivienda en el distrito;

Con respecto al primero, y volviendo sobre algunas nociones previas, diversos actores manifestaron que en los últimos años se produjo un cambio en el perfil socioeconómico de la ciudad que llevó a un proceso de elitización del centro.

"Se dio un cambio de clase social, no es el Bernal que conocí en 1993 cuando entré a la UCALP (Universidad Católica de La Plata, subsede Bernal). No es lo mismo, no es el mismo vecino. Los vecinos van cambiando porque la calidad de vida acá es más cara. No cualquiera vive en Bernal. Muchos han vendido, se han ido y ha cambiado. Por ejemplo, acá en la facultad, ahora los chicos que vienen tienen un apoyo familiar importante" (Entrevista realizada en abril 2019 a profesional en arquitectura y vecino de la zona).

"Conozco gente que vive en el edificio, que dicen que vivir puntualmente en Bernal centro es muy caro. Las viviendas son inaccesibles, y no son para todos" (Entrevista realizada a vecina, residente de la calle Zapiola, abril 2019).

"Para mi cambió el perfil de Bernal, porque ninguno de esos departamentos es barato, al contrario son carísimos" (Entrevista realizada a vecina, residente de la calle Ipiranga, abril 2019).

"La gente de Bernal cambió. Yo creo que es un proceso que todavía se está dando, cada edificio que viene es gente que viene que no es de clase media, sino que son de clase 
media-alta, gente que quiere vivir en el centro de Bernal, que tiene algo elitista, y tiene esa imagen todavía de pequeña ciudad. Subió el metro cuadrado, las viviendas tienen otro precio y otras se van quedando. Entonces vos ves casas que van desapareciendo, y torres que van creciendo, porque en estos proyectos hay empresas con inversionistas que saben que multiplican el precio en dólares, y hay público para eso" (Entrevista realizada en abril 2019 a profesional en arquitectura y vecino de la zona).

Sin dudas, esta situación genera expulsión de población que, como sostenían algunos vecinos, no pueden acceder a las construcciones que se proyectaron para un perfil determinado. Ante ello, existió gente que se vio obligada a movilizarse del centro, a otras zonas dentro del partido, o a otros partidos linderos como Berazategui o Avellaneda, principalmente por cuestiones económicas. Es decir que el mercado terminó expulsando a un público incapaz de llevar adelante el costo de vida que se le proponía. Este panorama fue anunciado por varios informantes,

"Mucha gente se movilizó del centro de Bernal, sobre todo por los alquileres, y mucha de esta gente se fue a vivir a Wilde que es más económico" (Entrevista realizada a vecina, residente de la calle Zapiola, abril 2019).

"Mis hijos acá no pueden vivir, no llegan a alquilar, por eso se fueron a alquilar a Villa Cramer, un monoambiente. En Barrio Parque, cerca de la UNQ, la gente reformó sus casas e hicieron unos minis departamentos que se alquilan y ahí van a vivir los pibes porque acá en el centro no pueden alquilar" (Entrevista realizada a vecina, residente de la calle Ipiranga, abril 2019).

"Hay gente que se ha ido a vivir a otro lado, porque con lo que salen los alquileres, no se puede. Como está en este momento no logran acceder, esto tendría que mejorar mucho económicamente" (Entrevista realizada a vecina, residente de la calle Zapiola, abril 2019).

“Acá se preservó para un nivel socioeconómico puntual, que no sé, son todos de Bernal. Con esto quiero decir que vivir en Bernal centro es caro, en comparación con otros partidos cercanos como Berazategui, por ejemplo. Si te corres un poco de acá cambia" (Entrevista realizada a vecina, residente de la calle Ipiranga, abril 2019).

Aquí el desplazamiento se inscribe dentro de múltiples procesos de acumulación por desposesión, es decir formas de acumulación que dependen de una lógica 
económico-productiva que opera sobre el suelo urbano, entendido como un bien dentro del ámbito urbano. Esta presencia del desplazamiento en los procesos de desposesión, llevó a una acumulación por desplazamiento, debido a que se produce una usurpación excluyente de la centralidad, es decir de un producto colectivo de la sociedad urbana (Blanco y Apaolaza, 2016).

Ante este panorama, también se indagó en la voz de los propios residentes movilizados por el proceso estudiado, que podemos denominar "desplazados",58. Se indagaron diferentes aristas de sus percepciones en torno a la verticalización en aumento. Por un lado, al indagar en las razones de las tendencias percibidas, una informante sostiene:

"Las razones de estas tendencias se vinculan con el cambio en la normativa que permitieron y alentaron este tipo de edificaciones, y a la accesibilidad de la zona, ya que está ubicada en una zona estratégica por transporte, la mejora del tren Roca, y la bajada de la autopista... la conexión rápida con Capital y La Plata"

Por otro lado, otras informantes desplazadas manifestaron en sus testimonios la imposibilidad de acceso y permanencia en el centro una vez que se potenció su valorización. Sus voces reflejaron la oportunidad de acceso a un crédito para comprar una vivienda, pero dados los elevados precios de los inmuebles en Bernal se vieron desplazadas hacia otras áreas del partido, como Quilmes Oeste, Don Bosco.

"Yo siempre alquilé en Bernal centro, pero cuando quise comprar no tuve acceso en la zona porque cotiza alta. Me salió un crédito y donde tuve acceso fue en Don Bosco casi Villa Cramer. Si pudiese elegir, me hubiese quedado en el centro" (Vecina que residió ocho años en 9 de Julio y Lavalle).

"Alquilé en Bernal hasta que no pude solventar el alquiler. Pedi un credito y me salió, pero la plata que me daban acorde a mi sueldo no me alcanzaba ni para comprarme un departamento de 30 metros cuadrados, asique termine desistiendo del crédito y me fui a vivir al departamento de mi mamá (...) Bernal se transformó en una ciudad con alquileres muy altos. Por este motivo, mi mama en un momento tuvo que dejar su departamento y

\footnotetext{
${ }^{58}$ Cabe destacar que se han encontrado algunas restricciones para esta etapa del trabajo de campo, vinculadas a la dificultad para acceder a informantes desplazados, dado el carácter no organizativo e invisibilizado que ha caracterizado a este grupo de vecinos afectados. Para salvar estas restricciones, se recurrió a diferentes informantes que pudieron colaborar con la identificación de aquellos residentes que fueron desplazados del centro, varios de los cuales accedieron finalmente a otorgar sus testimonios sobre el proceso.
} 
nos fuimos a vivir a Quilmes Oeste, a un departamento más chico pero entre las dos lo podíamos resolver (...) Lamentablemente el contexto te obliga a mudarte a donde te da el bolsillo" (Vecina que residió en Bernal Centro, en calle 9 de Julio).

"Yo me tuve que ir por el proceso de aumento constante del alquiler que se dio en dónde vivía, y porque me salió un crédito hipotecario que sólo me permitía comprar fuera del partido de Quilmes" (...) "Hubo una creciente aumento de la presión inmobiliaria, mucha construcción de torres de departamento en lugares donde había terrenos amplios con casas de mucho valor, que fueron demolidas, perdiéndose mucho valor patrimonial arquitectónico" (Vecina del centro de Bernal entre 2008 y 2015).

Asimismo, otros testimonios dan cuenta de este tipo de desplazamientos forzados por mercado y/o por las características conflictivas de las tendencias desarrolladas. Al respecto, un informante calificado ha manifestado:

"El proceso se empezó a notar con mucha fuerza para 2008, 2009, luego de la etapa de mayor movilización vecinal con Bernal Unido. Los resultados tuvieron que ver por un lado, con una sensación, una percepción de que se había perdido la discusión. La avanzada de los edificios y la desaparición progresiva de las asambleas ya ponían en evidencia que el proceso en el centro era irreversible. Por otro lado, se empezaron a notar consecuencias concretas en el impacto que dicho proceso tenía para quienes vivíamos allí. Es decir, al menos tres o cuatro cuestiones articuladas se empezaron a sentir con fuerza, cuestiones que "invitaron" $" 59$ a pensar en que ya no era posible vivir en el centro de Bernal por mucho más tiempo" (Residente histórico de la zona céntrica de Bernal, con incumbencias profesionales en política urbana).

Al indagar en profundidad sobre las causas de la percepción sobre la imposibilidad de sostener una posición de centralidad en la ciudad, entre los diversos motivos, los informantes sostienen que la infraestructura de servicios no fue acorde al crecimiento, y fueron enormes las molestias ocasionadas durante los periodos de construcción de los inmuebles, al igual que la presión ejercida por agentes inmobiliarios y los dueños de las unidades.

"Por un lado ha sido una desventaja importante, porque se dieron muchas problemas con los servicios urbanos, como la luz especialmente, problemas de cortes y tensión... la vida se hizo muy difícil por momentos, especialmente en verano" (Vecina del centro de Bernal entre 2008 y 2015).

\footnotetext{
${ }^{59}$ La persona informante enfatiza el entrecomillado y el carácter sarcástico de la expresión.
} 
"Una de las cuestiones tenía que ver con algo muy sencillo, un conflicto cotidiano que hace a la calidad de vida: la incomodidad de los constantes ruidos por las obras, desde primera hora de la mañana y sin parar hasta entrada la noche. Los cortes de calle por descarga de materiales y camiones, la imposibilidad de estacionar en las cercanías de donde vivís, las miradas constantes desde la altura de las torres en construcción que eliminaron toda posibilidad de intimidad, los cortes de luz (...)

Otra de las cuestiones tiene que ver con la imposibilidad de planificar a largo plazo, dadas las constantes sugerencias y/o amenazas implícitas de los agentes inmobiliarios y dueños del inmueble sobre el futuro inmediato en nuestra condición de inquilinos (...) El agente inmobiliario percibía lo que ocurría en la zona, y las presiones al alza de los precios de alquiler y renovación eran superiores al 35, 40\%, muy por encima de la media en otros lugares y por encima del contexto inflacionario de la época. La especulación con la valorización de la zona, por la complejización de la oferta gastronómica, comercial y de servicios, se traducía constantemente y concretamente en un intento de renogociación de precios de alquiler y de sumas de renovación que cada dos años ponía en jaque la continuidad (...) Al mismo tiempo, los dueños del inmueble todo el tiempo especulaban con la posibilidad de no renovar alquiler porque recibían ofertas para vender el terreno con todo el complejo de ph y locales, con fines de demolición para construir una nueva torre. Eso se dió cada dos años constantemente, como un mecanismo de presión en contra de los inquilinos. Por otro lado, la posibilidad, contemplada inicialmente, de generar condiciones para la compra de los inmuebles fue descartada de la negociación por parte de la familia propietaria y del agente inmobiliario, dando por cerrado el proyecto de que quienes vivíamos en esos departamentos compráramos" (Residente histórico de la zona céntrica de Bernal, con incumbencias profesionales en política urbana).

Al cuestionar sobre el carácter electivo o impositivo del fenómeno referido, el testimonio refleja las limitaciones de pensar estas categorías de manera dicotómica, complejizando y enriqueciendo las posibilidades de análisis.

"Por un lado, claramente hay un carácter de imposición de mercado que hace que las condiciones de permanencia para los inquilinos de clase media fuesen insostenibles a largo plazo. A todo lo mencionado hay que sumarle que para mantener precios similares de alquiler la opción era trasladarse a sectores mucho más alejados de la ciudad, con menos servicios e infraestructura, y espacios más reducidos, menos metros cuadrados, en definitiva, peores lugares para vivir (...) Las opciones pasaban por seguir pagando cada vez más, por pagar lo mismo resignando centralidad, espacio y servicios, o bien por configurar un proyecto de largo plazo de acceso a la propiedad de la vivienda, que en el contexto 
económico de la época y de las líneas de crédito hipotecario existentes para los sectores medios, suponía la expulsión, no sólo del centro de Bernal, sino incluso de todo el partido de Quilmes.

En este sentido, en mi caso, la expulsión no se dio concretamente, pues ante este panorama elegí irme. Sin embargo, poco tiempo después de la mudanza, unos dos años después, el inmueble fue finalmente vendido y demolido, dando lugar a la construcción de una torre de muchos pisos, y con la expulsión concreta de los vecinos que aún se habían quedado alquilando. Con lo cual, la expulsión hubiese sido inevitable, tarde o temprano. Creo que hay mucho más de imposición que de elección en estos casos y en varios que conozco, aunque nadie te desaloje por la fuerza" (Residente histórico de la zona céntrica de Bernal, con incumbencias profesionales en política urbana).

Se advierte en estos testimonios, el carácter impositivo de los mecanismos de movilidad forzada por mercado, vinculados a mercados expansivos, tendientes a concentrar una oferta para sectores solventes de altos ingresos, en el marco de procesos de transición y transformaciones del entorno céntrico de la urbe en espacios de elitización de la población, de homogeneización, y de realización del capital mediante amplios stocks de conjuntos habitacionales con fines de reserva de valor. Asimismo, el carácter sutil de estos mecanismos de mercado, se conjugan con vectores electivos, que tensionan los análisis simplistas y permiten complejizar la mirada sobre el carácter forzado de los desplazamientos, poniendo en juego los matices respecto a modos de vida, elecciones que realizan los residentes céntricos en la ponderación de una multiplicidad de factores condicionantes.

Siguiendo esta línea, se indagó sobre sus percepciones en torno a la intervención y rol adquirido por el Municipio frente al proceso, y en coincidencia con otras apreciaciones, los informantes fueron contundentes.

"Para mi el municipio nunca tuvo un papel preponderante, sino que aprueba. Hasta hace unos años solo se podían hacer edificios con 3 pisos, pero ahora hay una ordenanza que dice que si se edifica cierta cantidad de metros hacia adentro, pueden hacerse más de 3 o 4 pisos. Así y todo no se cumple porque los participantes del municipio actúan a su conveniencia. Dicen que todo crece, la población crece y contra eso no se puede luchar" (Vecina que residió en Bernal Centro, en calle 9 de Julio).

"El rol del Estado fue crucial porque es el responsable de impulsar y cristalizar las normativas bajo las presiones del sector inmobiliario y desarrolladores. El municipio 
otorgó nuevas regulaciones dando lugar a un proceso de formación de precios que hace imposible acceder a un terreno o vivienda por un individuo, sino que queda sujeto a grupos económicos y desarrolladores que apuntan a edificios multifamiliares de varios pisos (...) Creo que el Estado debería ejercer una regulación más controlada y no de libre acceso, y ejercer un control específico que tienda a la conservación del patrimonio identitario de Bernal. En definitiva un rol de mayor control y regulación sobre el proceso de transformaciones urbanas del centro de Bernal" (Vecina del centro de Bernal entre 2008 y 2015).

"El municipio ejerció su papel de garante mediante la sanción de las normativas que avalaron lo que se venía dando en el territorio en función de los intereses económicos. Ante esto, no solo alentó el proceso mediante el otorgamiento de excepciones, y la sanción de ordenanzas que regularon y profundizaron este modelo de ciudad tendiente a la expulsión, sino que además lo hizo con un discurso de modernización, de embellecimiento, de claro perfil clasista, sin observar ningún mecanismo de alternativa para quienes nos vimos desplazados sin otras opciones asequibles en el mercado inmobiliario local. El estado municipal legitimó una forma de expulsión de residentes de Bernal centro sabiendo que no existían otras alternativas en la localidad y en el partido. Y además lo hizo con mecanismos participativos vergonzosos, desconociendo e ignorando a toda la masa de ciudadanos movilizados en contra de todos estos procesos, que impulsaban la necesidad de un plan integral de desarrollo urbano y hábitat para todos los sectores de la ciudadanía, reclamos que sólo fueron incorporados de manera retórica en documentos sin ningún tipo de injerencia real en las políticas públicas efectivamente impulsadas en el periodo" (Vecino de Bernal con incumbencias profesionales en política urbana, residente histórico de la zona céntrica de Bernal).

Respecto a esta última cuestión mencionada por el informante sobre los procesos organizativos y reactivos de asambleas barriales como reacción al proceso estudiado, una vecina desplazada señaló la falta de consideración por parte de Bernal Unido a incorporar otros argumentos y problemáticas que complementasen los discursos sostenidos vinculados a proteger el "pueblo" en términos arquitectónicos y el perfil tradicional de población residente.

"Yo no formé parte de ninguna iniciativa de reacción ante estos cambios, conocí Bernal Unido pero nunca participé porque no me sentí identificada con sus convocatorias por redes sociales y folletos, dado que principalmente sus intereses se vinculaban a proteger el patrimonio arquitectónico, los valores de los residentes tradicionales, los vecinos históricos... yo no era dueña ni histórica, por lo que no me representan, no aparecían los 
problemas vinculados a los alquileres, y había una cierta discriminaciòn respecto a los que no eran dueños de casas en Bernal centro. Se problematizaban las infraestructuras, el perfil arquitectónico y se señalaba como algo malo la llegada de toda persona que no haya nacido en Bernal" (Vecina del centro de Bernal entre 2008 y 2015).

Estrechamente vinculado con el proceso de expulsión, y ya entrando en el segundo impacto señalado, la problemática resulta aún más compleja dada la falta de oportunidades para dichos sectores en el suelo urbano de todo el distrito, por escasez y precios. Se generó una falta de oportunidades de acceso al suelo y también a la vivienda, por tratarse de construcciones de un alto valor, y que por estar ubicadas en la centralidad de Bernal, terminan por convertirse en viviendas inaccesibles para un público que demanda donde vivir.

En relación a los impactos mencionados que principalmente afectaron a los inquilinos de la zona, los propietarios también sintieron la presión ejercida por el proceso de verticalización, ya que muchos quizás podían acceder al departamento céntrico únicamente si vendían su casa, debido al alza en los precios, igualados a un departamento que se vende en áreas de alto poder adquisitivo de la Ciudad de Buenos Aires.

"Creo que no cualquiera puede acceder, o puede haber vecinos que vendiendo su casa, compran un departamento. Ahora, aquel que se quiera quedar con una casa de inversión y seguir viviendo en Bernal, o que quiera transferir el inmueble a alguno de los hijos, se puede dar siempre y cuando cuente con el dinero suficiente para comprar el departamento nuevo, pero sino imposible" (Entrevista realizada a vecino, residente de la calle Pringles, abril 2019).

"No es nada fácil vivir en esta zona (haciendo referencia al centro y específicamente a la calle Castro Barros). El departamento pude comprarlo, pero solo de expensas pago seis mil pesos por mes, y a eso obvio tengo que sumarle los gastos cotidianos como internet, celular, etc. No me puedo ni imaginar lo que paga la gente que alquila. No sé bien como son los departamentos, pero el mío tiene 3 ambientes, así que no se cuánto deben estar pagando los que tiene más ambientes y metros cuadrados. Con esto quiero decir que no debe ser fácil" (Entrevista realizada a vecina, residente de la calle Castro Barros, abril 2019).

"Hay una cosa que es verdad, Bernal es caro y mantiene algunos valores que son inexplicables. Los departamentos en Bernal van en esa línea y eso hace que haya una 
franja de gente que todavía no lo puede pagar" (Entrevista realizada a vecino, residente de la calle 25 de Mayo, junio 2019).

“Acá en Bernal las propiedades siempre fueron muy caras, y me parece un despropósito porque que a vos te guste vivir en Bernal porque te parece lindo es una cosa, pero no somos Palermo ni Belgrano, o sea es una locura lo que vale acá un departamento de 2 o 3 ambientes. Hay gente que paga un valor astronómico por un departamento que quizá no lo vale" (Entrevista realizada a vecina, residente de la calle Maipú, junio 2019).

"Hoy un departamento en pleno centro se paga igual que una casona de diez metros de frente por cincuenta de fondo. Entonces es una locura que alguien venda una casa con pileta, con quincho a cuatro cuadras del centro, lo mismo que cuesta un departamento de tres ambientes" (Entrevista realizada a vecino, residente de la calle 25 de Mayo, junio 2019).

Hasta acá, se pudo constatar que la posibilidad de acceso resultó dificultosa, si se piensa en población de clase media. Ni hablar de la falta de oportunidades también para otros sectores, que también disputan por la centralidad y el espacio público en la ciudad. Siguiendo a Sassen (2014), en el escenario actual, el proceso de acumulación por desposesión se formaliza mediante la expulsión territorial de aquellos actores a los que el mercado no necesita, al mismo tiempo que incorpora a los circuitos de la acumulación capitalista los valores simbólicos y materiales del centro considerado como "territorio deseado". Entonces, termina configurando una centralidad que expulsa a ciertos sectores, porque con ellos no "funcionan" las estrategias de revalorización. Se produce entonces una "modernización selectiva" (Delgadillo, 2016) de la ciudad, donde se fundamentan los mecanismos de acumulación por desposesión del hábitat.

Mientras esto ocurría, el centro de Bernal resultó un territorio preciso de proteger y preservar de ciertas dinámicas por parte de una serie de vecinos y comerciantes zonales. Aún continuaba presente la idea de conservar a Bernal como "pueblo" (tal como se manifestó anteriormente), y por ello se mostraron reactivos al proceso de verticalización que venía a cambiar el perfil urbanístico de la ciudad. Sin embargo, esta población, a diferencia de quienes no pudieron acceder o fueron expulsados, tuvo la posibilidad de elegir la centralidad, y quedarse a convivir con los cambios. Son actores enmarcados en una lógica más de elección que de expulsión, ya que es ejercida por aquellos que reaccionan frente a los cambios en el perfil edilicio, pero optan por la centralidad, e intentan ejercer su derecho a elegir qué tipo de ciudad quieren para vivir. Algunos 
informantes contaban que muchos decidieron vender sus grandes casas (ver figura 18), comprarse algún departamento y continuar viviendo con las comodidades del centro, aunque posiblemente no suceda en todos los casos.

"En los últimos años, Bernal tuvo un gran crecimiento en cuanto a la edificación que no favorece a los habitantes, porque cuando vine a vivir a Bernal, lo elegimos porque era un lugar tranquilo, y ahora eso se perdió" (Entrevista realizada a vecina, residente de la calle Zapiola, abril 2019).

"Cuando vos tenés un edificio en el barrio, el barrio cambia. Ya no conoces a los vecinos, porque alquilan o porque no están en todo el día, viste, se encierran ahí adentro. Eso hizo que cambien mucho las relaciones entre vecinos, con respecto a hace unos años" (Entrevista realizada a vecina, residente de la calle Ipiranga, abril 2019).

"Está la gente anticrecimiento de Bernal que es la misma gente antiurbanismo, y que después vende su casa a la empresa que va a hacer la torre. Cuando la apuras un poco, vendió la casa" (Entrevista realizada en abril 2019 a profesional en arquitectura y vecino de la zona).

“Acá se viene dando un negocio tentador, porque hay gente que vendió su terreno y a su vez, cuando hicieron la torre, se quedó con 2 departamentos en la torre, entonces cambió un inmueble por dos" (Entrevista realizada a vecina, residente de la calle Zapiola, abril 2019).

"La construcción de torres está permitida, pero va a llegar un momento que va a haber un verdadero caos. Yo conocí gente que ha dicho "yo no vendo la casa si no la van a conservar", pero después le podes vender la casa a alguien que termina vendiendo a la empresa constructora. Entonces, no podes mantener un avance de esta categoría" (Entrevista realizada a vecina, residente de la calle Maipú y comerciante de Bernal, mayo 2019). 
Figura 18: Grandes casas de Bernal centro en venta, y anuncios de las empresas desarrolladoras de "lo que se viene".

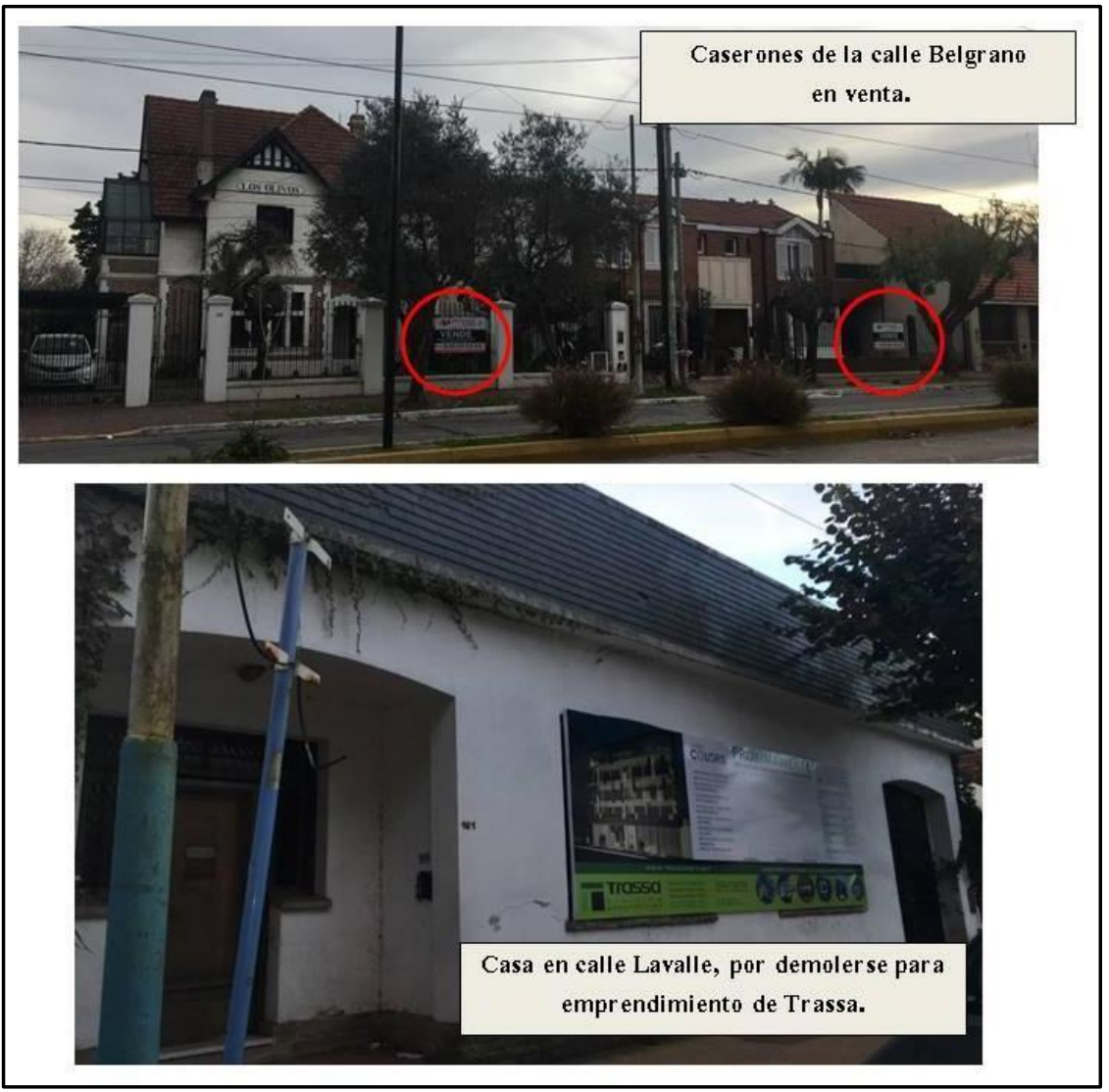

Fuente: Fotografías tomadas en abril de 2019.

Algunos residentes no olvidaron mencionar al Estado como participe y cómplice de este proceso. Por medio de la acción política y de los distintos cambios normativos, se tomaron decisiones que tuvieron un impacto en el territorio. Aunque no puede perderse de vista que la acción pública es una construcción social, que condensa acciones y comportamientos múltiples. La diversidad de actores tiene la capacidad de influir también de forma significativa sobre el desarrollo de la política a través de sus intereses y estrategias. Es decir que las políticas se construyen a partir de distintas relaciones de poder, reconocen un anclaje territorial y también urbano, y por esto están implicadas en los impactos destacados. Aquí es el Estado quien gestiona dichas políticas urbanas, y es quien en las últimas décadas ha estado fuertemente sesgado hacia una tendencia de facilitación para la realización del capital en el territorio, con una fuerte impronta privatista. De hecho, algunos de los informantes dieron cuenta de la responsabilidad que tuvo el Estado local frente a este panorama. 
"Al Estado le faltó presencia, y en vez de administrar calidad de vida para toda la población se administraron para ellos, hicieron negocios, a mi dejame el departamento de arriba y hacé 700 mil pisos. Ahí el Estado en vez de hacerse presente para controlar, se borró, hizo negocio para él o para los vivos que estuvieron de turno en ese momento" (Entrevista realizada a vecino, residente de la calle Ipiranga, mayo 2019).

"Al municipio esta situación le conviene porque tiene más impuestos para cobrar, si son más viviendas, son más impuestos" (Entrevista realizada a vecina, residente de la calle Ipiranga, junio 2019).

"El municipio hace años que no participa en nada, o participa desde otro lado, no desde la protección del ciudadano, sino que habilita a que hagan lo que quieran, es $100 \%$ responsable de que el boom de los edificios sea posible" (Entrevista realizada a vecina desplazada de Bernal Centro).

Retomando la noción del desarrollo, e intentando indagar en el rol del Estado frente al mismo, surgió un interrogante sobre si el proceso de transferencia de renta por parte del Estado, fue aprovechado para financiar el acceso a la vivienda de sectores menos favorecidos. Pero en este contexto, los instrumentos de gestión urbana implementados principalmente en el proceso de rezonificación, donde se definieron patrones de uso de suelo que apuntarían a definir qué territorios serían eximidos de la actividad extractiva mientras que otros estarían disponibles para su recepción, fueron limitados a la recalificación del área central, incrementando drásticamente su atractivo y su potencial constructivo (Cirio 2018). Entonces, se remite a la idea de la existencia de territorios sacrificables (Svampa, 2008), expuestos a la lógica de captación de renta, en pos de producir un modelo de desarrollo para un cierto sector.

Las intervenciones por parte del Estado tendientes a captar parte del incremento generado en el valor del suelo por la decisión normativa fueron escasas. Ante ello, los vecinos expresaron sus opiniones y percepciones al respecto.

"Con este boom de los edificios, el municipio recauda más y lo que hagan con eso dependerá de la gestión. La economía venía bien y la construcción reactivaba un montón, entonces era difícil que eso se cortara. Lástima que no se pudo tratar de urbanizar un poco más el oeste de Bernal, hacerlo más accesible, y que no queden los edificios nucleados en 
6 manzanas a la redonda" (Entrevista realizada a vecina, residente de la calle Ipiranga, junio 2019).

“Acá no hay políticas para que pasen otras cosas, para que la gente no se mude a los edificios. Es muy simple, si el intendente hubiera podido hacer barrios como se hacían antes, por ahí podes hacer dúplex, y no depender del edificio" (Entrevista realizada a vecina, residente de la calle Ipiranga, junio 2019).

"La municipalidad pretende recaudar cada vez más porque cuanto más edificio hay, más plata tienen ellos. Los barrios son necesarios y no se hacen, así que no sé realmente a dónde va esa recaudación porque yo no veo nada bueno, ni nuevo (Entrevista realizada a vecina, residente de la calle Zapiola, abril 2019).

Además, en algunas declaraciones pudieron dar cuenta que el Estado podría pensar realmente en el desarrollo de la ciudad, invirtiendo en otras áreas del partido donde sea necesario procurar viviendas sociales. Las sociedades aceptan en mayor o en menor medida la necesidad de construir vivienda social, pero ¿dónde? Este tipo de vivienda parece ser incompatible con el de centralidad (Del Rio, 2008), ya que en general éstas se construyen en áreas marginales de la ciudad. Es decir que las condiciones de acceso al hábitat para sectores populares y en este caso también de clase media resultaron escasas, y se profundizó la pérdida de oportunidades frente a la captación de renta, no se produjo una disminución del déficit habitacional, y se termina perdiendo la oportunidad de financiar el desarrollo para otras áreas del partido. Los vecinos contaron lo que piensan sobre ello,

"Y mira, creo que todos tenemos derecho a una vivienda digna o poder pagar un alquiler y además vivir dignamente o podes comprar una vivienda y vivir dignamente, lo que pasa es que es letra muerta digamos" (Entrevista realizada a vecina, residente de la calle Ipiranga, junio 2019).

"Justamente el Estado tiene que poder recaudar para cumplir sus funciones, pero frente a la construcción de edificios se lavó las manos. Hablábamos con una amiga que me decía ¡es trabajo!, y si pero bueno que se yo también podes hacer viviendas sociales y dar trabajo, pero los inversores no querían eso, ¿qué van a querer?, llenarse los bolsillos" (Entrevista realizada a vecino, residente de la calle Don Bosco, junio 2019). 
Frente a este panorama, el municipio también pudo revelar su discurso. Ambas gestiones -haciendo referencia a la gestión Gutiérrez y Molina- resaltaron la importancia de la participación del Estado frente al desarrollo urbano y la implementación de instrumentos de planificación-gestión, aunque no resultó suficiente. Por su parte, un funcionario de la gestión Gutiérrez hacía hincapié en que a partir del proceso de verticalización es mayor la recaudación para el municipio, y que muchas veces se reinvierte en la ciudad en términos de obra pública. Sin embargo, según su interpretación, en diversas situaciones se podría haber hecho aún más, en pos de mejorar la situación de sectores populares. Ante ello sostenía que

"cuando vivía un viejo, pagaba un impuesto, ahora hay 50 tipos que pagan impuestos y eso va al municipio. Eso no se invierte directamente en un beneficio para ese edificio, sino que se cambian las luces, se hizo el recarpetado en la calle Avellaneda, se hacen algunas obras de mejora, pero eso va al arca del municipio, y después el municipio decide y elije donde poner esa plata, como por ejemplo en plazas, son políticas públicas”.

Estas políticas implementadas durante la intendencia del "Barba" Gutiérrez estipulaban donde realizar las inversiones. Había áreas que no tenían grandes necesidades entonces se realizaban algunas obras de bacheos y plazas, mientras que en otros barrios de Quilmes y Bernal Oeste se dieron las condiciones para la producción de modalidades de hábitat popular y arreglos de viviendas sociales ya existentes. Sin embargo, el director de Obras Públicas durante la gestión Gutiérrez asumió, “[...] En mi opinión se podría haber hecho mucho más [...] se logró bastante poco en 7 años, si yo hago una plaza en 3 meses, y 11 calles por mes, ¿cuántas casas hubiésemos hecho?” (Entrevista a funcionario de la gestión Gutiérrez).

Por su parte, el intendente Molina, en la entrevista manifestó que hubo un aprovechamiento del despegue de Bernal, que se tradujo en obras aprovechando la valorización que se generaba. Aun así esperan contar con el plus que podría generar la revitalización de la franja ribereña, a partir del proyecto propuesto por el grupo Techint para construir un complejo residencial o como lo llaman muchos "El Puerto Madero II". Según el discurso del intendente podría servir para financiar directamente en términos de infraestructura, primero para entubar los arroyos y empezar a pensar en un camino de sirga, y luego en realizar obras para el espacio público. Ante esta cuestión el intendente mencionaba, "el sostén de inversión va a tener mucho que ver con la Ribera, no sólo para los arroyos sino para todos los barrios que tengan una deficiencia estructural, 
digamos, histórica, de infra en todo Quilmes, asique hacia eso vamos" (Fragmento de la entrevista a Martiniano Molina, intendente de Quilmes). Sin embargo, es una idea que se sostiene en el discurso que luego difícilmente se terminará materializando en las ordenanzas, principalmente por el cambio de gestión que se producirá en el mes de diciembre luego de los resultados de la última elección (octubre 2019).

Aquí, es donde el Estado intenta intervenir en la distribución de recursos fiscales, buscando lograr un equilibrio entre lo que le concede al capital y la necesidad de regularlo, es decir, que alienta el modelo extractivo, intentando amortiguar sus impactos sociales (Gudynas, 2010). Pero los proyectos de intervención parecen tener que ver más con la mejora de un área de la ciudad, sin necesariamente mejorar las condiciones de vida de la población, pudiendo traer como una de sus principales consecuencias, que esa población se desplace a otras áreas. Mientras que en el discurso oficial ${ }^{60}$ la intervención por parte del Estado recibe diversos nombres tales como "recuperación urbana", "revitalización", "regeneración" o "renovación", entre otros, la imagen urbana que se propicia, parece tener un único objetivo, que es la atracción de inversión privada, a través de diversos emprendimientos en altura y cuyo propósito final es la reproducción del capital. Tal como manifestó un informante, la alianza público-privada se da cuando el Estado municipal busca generar las condiciones económicas propicias para atraer nuevas inversiones directas, esto es, a partir de diversos mecanismos como los incentivos financieros, la extensión de derechos de construcción, e incentivos fiscales. También están las políticas de regulación y gestión favorables a los inversionistas, encaminadas hacia el uso del suelo, régimen de propiedad, entre otros.

Es decir, que en este contexto, es posible hablar de ciudad excluyente, haciendo referencia al modelo de ciudad que se vino consolidando en los últimos años, en donde se construye y se vende un ideario de desarrollo mediante un sistema especulativo y de acumulación de capital, promoviendo beneficios solamente para las clases medias-altas y altas (Svampa y Viale, 2014). La contracara de este proceso, es la falta de acceso a la vivienda que afecta a los sectores más vulnerables de la sociedad y que no están incluidos ni son destinatarios de éstas grandes torres que se están construyendo en la ciudad. En esta misma línea y coincidiendo con Massuh (2014) la centralidad de la ciudad también ha sido objeto de privatización, ya que la industria de la construcción

\footnotetext{
60 Se pudo constatar que en los discursos oficiales de las tres gestiones municipales abordadas en este trabajo, retomaron algunos de los conceptos aquí mencionados. En el caso del proceso de rezonificación del año 2006, se habló de área en "estado de emergencia", mientras que en los Planes estratégicos se hace referencia a "recuperar el centro" (PEQ 2009) o "revitalizar" (Entrevista al Intendente Molina, 2019).
} 
"destruye la ciudad como espacio habitable para todos los actores, aumenta la brecha social, privatiza los espacios públicos, y dificulta e imposibilita el acceso a la vivienda de las capas medias y bajas" (Massuh, 2014: 105).

Por este motivo es que se insiste en hablar de neoextractivismo urbano, un modelo de desarrollo basado en los procesos de captación de renta urbana para un sector de la población que expulsa y provoca desplazamientos de otros sectores. Este modelo "termina reproduciendo la estructura y las reglas de funcionamiento de los procesos productivos capitalistas, volcados a la competitividad, la eficiencia, la maximización de la renta y la externalización de los impactos sociales" (Gudynas, 2010:133). Se instala desde un discurso productivista y excluyente, por parte de actores con poder político y económico, mientras que para otros, los excluidos en términos físicos como simbólicos, el discurso es otro. Para ellos, el territorio y la ciudad, resultan un espacio de resistencia frente a un modelo de desarrollo que tiende a mercantilizar los bienes comunes de la ciudad, priva a la población de ejercer su derecho a la ciudad y los expulsa. 


\section{Capítulo V: Reflexiones finales y posibles líneas de investigación}

La ciudad es esencialmente centralidad, que reúne, amontona, congrega, concentra creaciones; es proximidad, relación, simultaneidad, punto de encuentro de lo diferente. La idea de centralidad encierra heterogeneidad y conflicto. La ciudad es entonces centralidad, es diferencia y contradicción (Henri Lefebvre, 1972)

Durante la primera parte del período analizado en la Región Metropolitana de Buenos Aires se produjo un boom inmobiliario que, entre otros procesos, se tradujo en la densificación y la construcción en altura en áreas centrales. En muchos casos fueron aprovechadas las sobreganancias de localización, produciéndose inversiones en las localizaciones favorables para la concentración espacial de los capitales. Este proceso fue impulsado por la conectividad otorgada por los trenes, y la red de rutas, autopistas y avenidas, que fueron contribuyendo a que se conformen ciertos territorios con mayores densidades de población y con diversas actividades terciarias y, por lo tanto, que se eleven cada vez más los precios del suelo metropolitano. Aquí es donde el mercado inmobiliario encontró la manera de generar un aumento en el precio de los inmuebles urbanos, explicado por diferentes motivos, entre ellos, la existencia de expectativas de valorización que podrían generarse, la presencia de una población con poder adquisitivo necesario para invertir, el incremento de la actividad de la construcción y la posibilidad de contar con el excedente del sector primario. A ello se sumó la presencia del fideicomiso inmobiliario, como un dispositivo que contribuyó a acelerar la rotación del capital inmobiliario, y que permitió a los inversores comprar con mejores condiciones. En este contexto, la escasez de suelo urbano se combina con los diversos proyectos inmobiliarios, en gran medida construidos para obtener rentas diferenciales acentuadas por la creciente valorización del suelo urbano. Esto a su vez se traduce en restricciones concretas en las oportunidades de acceso al hábitat de vastos sectores de la población, y la generación de desplazamientos de habitantes a otras áreas.

En esta tesis, se contribuyó con una discusión en torno al modelo de desarrollo extractivo, en particular su reproducción en las ciudades, desde una perspectiva donde lo territorial adquiere primacía, y más precisamente sobre la realidad urbana producto de las transformaciones producidas de la mano de diferentes actores que persiguen diversos intereses. Se aportó un análisis del proceso de verticalización que se produjo en 
el centro de la localidad de Bernal (Partido de Quilmes), y los impactos que ha tenido en el acceso diferencial a la centralidad urbana.

Se indagaron diversas cuestiones. Por un lado, se describieron los cambios urbanísticos, vinculados al perfil edilicio y las características socioeconómicas de los habitantes, que se produjeron en la ciudad a partir del año 2006, cuando se dio la rezonificación de usos del suelo por parte del Estado municipal. Esto habilitó un incesante proceso de densificación en altura del centro de la localidad de Bernal, produciendo la conformación de territorios más densos en términos de población y de actividades terciarias, en un entorno urbanístico y un espacio público con un cierto prestigio, produciendo un aumento de la valorización del suelo.

Este trabajo pudo demostrar un cambio en el perfil socio-económico de la ciudad, en términos cuantitativos, visualizado en el gran incremento de población con estudios superiores completos, lo que permite dar cuenta de un incremento del nivel socioeconómico y de status social. Desde una perspectiva cualitativa, el trabajo empírico realizado puso en evidencia cómo las percepciones de los informantes sobre estos cambios de perfil socioeconómico son divergentes y relativas, destacando percepciones vinculadas a la relativización de las modificaciones en dicho perfil. Al respecto, muchos informantes acuden a un imaginario conservador, donde el nivel socioeconómico y status de la población local se mantiene vigente, tal como lo fue históricamente. En este marco, la complejización del perfil comercial y de servicios, la revitalización céntrica y la "sofisticación" en las transformaciones urbanas percibidas son elementos considerados positivamente por parte de la población local como indicadores -materiales y simbólicos- de crecimiento, modernización y desarrollo acordes a las características históricas de la población de este subcentro metropolitano. En este sentido, el abordaje de triangulación permitió observar como los mecanismos de modificación de estos perfiles socioeconómicos son sutiles y quedan subsumidos a una lógica de apropiación perceptiva que tiende a su invisibilización.

Respecto al segundo objetivo de esta tesis, se analizaron las lógicas (sus prácticas y discursos) de los actores que intervinieron en el proceso de reconfiguración del centro de Bernal, como el Estado, los desarrolladores e inmobiliarias, profesionales, comerciantes, vecinos del área, y aquellos que fueron desplazados del centro. En primer lugar, fueron tres los intendentes que estuvieron en la gestión del municipio durante el periodo analizado. De la mano de una serie de actualizaciones y reformulaciones a los instrumentos de planificación y gestión, durante los tres mandatos se avaló el proceso de 
verticalización siguiendo las tendencias que el mercado impuso en la ciudad, desde distintos discursos, siempre apelando a la idea de progreso, y "desarrollo".

Quienes desplegaron la lógica mercantil en la producción del espacio urbano fueron las constructoras, desarrolladores, inmobiliarias, e inversores privados. Fueron quienes llevaron adelante los cambios de perfil urbanístico de la ciudad a partir de distintos emprendimientos de vivienda multifamiliar en altura y quienes luego los comercializaron a partir de una serie de estrategias de marketing enfatizando en sus características, y los beneficios que el centro de Bernal garantizaba. Priorizaron en sus discursos una modalidad de acceso al centro para aquellos que poseen altos ingresos, lo que confiere a que en materia urbana se produzca un proceso de elitización.

Esto desató la movilización de aquellos que se sintieron afectados por el avance de los edificios en la zona, y ante ello desarrollaron acciones colectivas irrumpiendo en un espacio de conflicto con el objeto de modificar decisiones, situaciones o hechos particulares. La asamblea que se destacó en este caso fue Bernal Unido, que intentó reivindicar sus derechos, manifestar sus elecciones con respecto a las formas de vida y valores, y expresarse en contra de determinadas transformaciones en el centro bernalense. Al mismo tiempo, tendieron a sostener demandas "conservadoras" que apuntaron al mantenimiento del orden existente, y no incorporaron otro tipo de reclamos vinculados a la población con imposibilidad de acceso o expulsión del centro. Entre las actividades que llevaron adelante se destacan las marchas, autazos, ruidazos, reparto de folletería informativa, petitorios de firmas de adhesión, pasadas por las casas de Bernal para contar al resto de los vecinos la problemática, y hasta una consulta pública. Esta última actividad fue acompañada por algunas universidades como la UNQ y la UTN quienes participaron en cooperación y asesoramiento, con colaboración de aquellos técnicos y profesionales locales. Aunque todo pareció indicar que el trabajo colectivo funcionaba, estas instituciones terminaron haciéndose a un lado en su participación, y acabaron actuando en alianza con el municipio y en contra de los intereses de la asamblea.

Luego de algunos años, y lejos de lograr un freno al proceso de verticalización, Bernal Unido perdió terreno y desapareció como agrupación. Pese a sus intentos de incorporar técnicos y profesionales a los encuentros, de llevar adelante distintas actividades para visibilizar el reclamo, y de vincularse con diferentes medios de comunicación y otras agrupaciones con las que compartían demandas, la agrupación no logró posicionarse como tal ni reivindicar sus derechos. Algunos factores 
explicativos se vinculan, por un lado, a la escasa cantidad de vecinos involucrados y movilizados, lo que les quitó visibilidad; en segundo lugar, que muchos se conformaron con una serie de "logros" adquiridos, como la construcción de una plaza y la ampliación de la zona residencial exclusiva; y por último, que la presión recibida por parte de distintos sectores de gran poder político y económico terminó debilitando las instancias de encuentro entre sus integrantes por miedo e incertidumbre.

Por su parte, los comerciantes también tuvieron un rol destacado en el proceso, aunque con una diversidad de discursos. Mientras algunos no quisieron ceder frente al boom del proceso de verticalización y se aliaron a los reclamos de Bernal Unido, otros mostraron un cierto entendimiento y aceptación a los edificios porque los consideraron inevitables en el área céntrica y que podrían ser la garantía de que residentes de Bernal se quedasen. Sin embargo, se mostraron reacios a que la construcción sea en cualquier lado, esté poco regulada, y se pierda la esencia de pueblo. Estos discursos mostraron una tendencia a una lógica vinculada a la elección de qué tipo de ciudad es la que quieren vivir, con un fuerte sesgo conservador.

El análisis de las lógicas y prácticas de los actores propició la identificación de ciertos impactos y tendencias del proceso estudiado. La modalidad de construcción estudiada produjo una intensificación de las asimetrías en la ciudad y la expulsión de habitantes. El problema radicó en la posibilidad de acceso a este tipo de emprendimientos, y eso produjo distintas percepciones en torno al nivel de ocupación de los mismos. Los martilleros sostuvieron que el porcentaje de inquilinos ocupando los edificios es alto, en detrimento de aquellos que están a la venta y pese a la posible existencia del perfil comprador. Otros actores, vecinos y/o comerciantes, tuvieron una percepción diferente y manifestaron que la ocupación de los departamentos es baja. Esto se explica por la existencia de departamentos construidos exclusivamente para vender, y que quedan a la espera, propiciando un proceso especulativo de valorización. En este caso, la propiedad multifamiliar se comporta como reserva de valor, como medio de acumulación de riqueza y atesoramiento, volviéndose un bien de cambio porque la inversión en el mercado inmobiliario brinda un refugio seguro para el capital. En este sentido, el encarecimiento del costo del suelo se convierte en el elemento central del proceso de generación y distribución inequitativa del ingreso y en uno de los elementos determinantes del acceso al suelo urbano y de las posibilidades de localización para diferentes sectores de la sociedad. Es esta una de las maneras en que puede visualizarse la forma en que opera el modelo extractivo en la ciudad, extrayendo renta del suelo 
urbano a través de la mercantilización de la vivienda, y dificultando su acceso a todos los sectores, excluyendo a una parte importante de la población que es la que luego recibe los impactos más negativos producto del avance de la lógica privada en la construcción de ciudad.

Considerando lo expuesto y retomando la premisa con la que se partió en este trabajo, el proceso de verticalización fue en aumento en la subcentralidad bernalense, produciendo modificaciones que dan lugar a procesos de renovación urbana competitivos, marcando de este modo un dominio de los procesos especulativos llevados a cabo en la ciudad que promueven modalidades de construcción para sociedades selectivas y desiguales, que intensifican y producen asimetrías en la nueva ciudad excluyente. Esta tesis ha aportado evidencia empírica, tanto cuantitativa como cualitativa, sobre diversas aristas de un fenómeno sutil e incipiente, vinculado a procesos de gentrificación. Por un lado, se produjo una reinversión en el centro -por sus particularidades- y con ello un alza del valor del suelo, fenómenos abordados de manera descriptiva a través del relevamiento realizado, expresado espacialmente en los cambios en el uso del suelo, que fueron trabajados con cartografía temática. Por otra parte, las entrevistas realizadas permitieron dar cuenta del proceso constante de aumento en el precio del suelo, la vivienda y la locación comercial. Esto fue acompañado por la llegada de actores con el capital necesario para acceder a los emprendimientos que comenzaron a manifestarse en la zona, y que fueron fundamentales en los procesos que llevaron a una apropiación de diferenciales de renta. Además, los cambios en los servicios -mayor presencia de entidades bancarias privadas, comercios de marca y categoría, entre otros- y el entorno urbano fueron claves para entender el proceso de modernización que implicó el avance de la verticalización. Por último, la tesis realiza un aporte a partir del análisis cualitativo, en torno a la caracterización de una de las aristas vinculadas a la gentrificación, evidenciando procesos de desplazamiento de grupos que no contaban con los ingresos necesarios para seguir residiendo en el centro. Aquí, el foco está puesto en aquellos desplazamientos producto de una "inevitable" reinversión de capital en un sector, produciendo que la gentrificación quede asociada a los efectos del avance de emprendimientos residenciales multifamiliares -y con todo lo que ello conlleva-, como la generación de nuevos patrones de segregación socio-espacial en sociedades que ya son desiguales, re-agrupando a la población en base a sus ingresos, así como a la identidad social. 
En este sentido, el trabajo cualitativo realizado permite observar consecuencias de estos desplazamientos vinculados, por un lado a factores residenciales, pérdida de centralidad, infraestructuras, aumento de costos de transporte y de oportunidades de acceso a los servicios de centralidad y de espacio público, que redundan en una disminución de la calidad de vida de sectores urbanos desplazados. Por otra parte, fue posible observar elementos de disminución en lazos sociales y laborales, de erosión de prácticas identitarias, de sentido de pertenencia y de oportunidades de injerencia en la elección de los cambios urbanos que afectan al entorno inmediato. Asimismo, como resultado de este trabajo, cabe problematizar no sólo las tensiones voluntario/involuntario - forzado/electivo de los desplazamientos por presión de mercado que afectan diferencialmente, tendiendo a la conformación de espacios de centralidad excluyentes y homogéneos, sino también los lugares de acogida para estos residentes desplazados, en el marco de oportunidades de acceso al suelo urbano distrital que oscilan entre la escasez y la virtual inexistencia. En este sentido, se realizan aportes al debate más amplio sobre los procesos de desposesión y disputa urbana atravesados por una perspectiva socioeconómica que complejiza el análisis sobre procesos considerados inevitables, producto de las transformaciones urbanas vinculadas a la modernización y el desarrollo, promovidas por el Estado en su rol empresarial, y acompañadas por los sectores conservadores de la ciudadanía local.

En síntesis, la tesis aporta evidencias sobre las múltiples modalidades y aristas de un proceso de intensificación de las asimetrías socio-espaciales en Bernal, donde lo habitacional se encontró limitado por las dinámicas del mercado inmobiliario, que continuaron definiendo las condiciones de acceso a la vivienda, y no solucionando la situación de déficit habitacional, incidiendo en los sectores más vulnerables, y en aquellos de clase media. Esto llevó a que se produzcan distintos efectos expresados en situaciones de desplazamiento, expulsión y desposesión, vinculados a fuerzas económicas y sociales más amplias que produjeron una serie de cambios profundos en el centro, generando que un grupo de residentes ya no pueda vivir ahí o no se identifiquen con su lugar de residencia de hace unos años atrás. También el desplazamiento se vinculó a un proceso excluyente donde algunos hogares se vieron apartados del área que terminó siendo destinada a nuevos residentes con ingresos más altos. 
En cada uno de estos desplazamientos, imperó la lógica de despojo mediante la usurpación excluyente de la centralidad, que reclama aún más espacio para aquellos con mayores recursos, profundizando la injusticia social que impide a determinados grupos defender su derecho a quedarse, y ejercer su derecho al espacio urbano. El resultado final es la creación de espacios aburguesados, homogéneos, carentes de diversidad para no entrar en conflicto con las demandas de clases medias y bajas. Es aquí donde queda de manifiesto la relación entre la expulsión o la ausencia de oportunidades de acceso, los desplazamientos y el derecho a vivir, gozar y permanecer en la centralidad. En estos términos queda expresado un modelo de desarrollo que viene reforzando históricamente diversas desigualdades territoriales.

De manera complementaria, y subordinada a esta cuestión, existieron desplazamientos de población, ligados a una lógica electiva que llevó a que se produzcan ciertos abandonos de viviendas, ya sea por la existencia de situaciones de inseguridad, o por la disposición de esas unidades funcionales en el mercado inmobiliario dado el creciente precio en alza que garantizaba el centro. A la expectativa se encontraron los grandes inversores urbanos, quienes lograron poner en marcha los diversos proyectos residenciales en altura para obtener grandes ganancias.

A la luz del emergente empírico, resulta importante problematizar la clasificación de actores adoptada en esta tesis. Se utiliza una clasificación que permite ordenar el trabajo, e identificar a los principales actores que intervienen en la producción de la ciudad. Sin embargo, frente al análisis de los impactos producidos por el proceso de verticalización, se pudieron identificar por un lado aquellos actores vinculados a la lógica de la elección y que fueron reactivos frente al proceso, y por otro, actores desplazados del centro, forzados por el mercado. En este sentido, ambos actores, emergentes empíricos del estudio realizado, permiten observar los límites de la clasificación inicial para dar cuenta de la totalidad del universo en el caso de estudio. Al respecto, se entiende que estos actores son resultantes de los procesos de disputa, y marginales en los procesos decisorios de producción del espacio urbano, entendiendo así las dificultades para clasificarlos dentro de las categorías previstas inicialmente. Esto, a su vez, introduce la necesidad de profundizar en una posible tipificación de actores desentrañando las complejas articulaciones y características de sectores reactivos al proceso, desplazados por el mismo, demandantes de centralidad con solvencia para fines residenciales, demandantes de centralidad con fines de 
atesoramiento, y conservadores de centralidad por elección; todos protagonistas del proceso estudiado.

Por último, cabe señalar que existió un hallazgo empírico que no fue previsto durante la investigación y que no responde a los objetivos propuestos, pero es posible recuperar de manera tal que puedan trazarse nuevos ejes de discusión. En continuación con las expresiones del proceso de verticalización en el centro de la localidad de Bernal, respecto de las clases medias, la ausencia de una política de crédito dificultó el acceso a la vivienda propia, en un contexto de aumento exponencial de la propiedad inmobiliaria. Esta situación produjo en algunos casos que se acentúe el fenómeno de la movilidad residencial de población de altos ingresos hacia urbanizaciones privadas. Así, nos encontramos con la paradoja de que en muchos casos, termina resultando más accesible - o con diversas posibilidades de financiación, facilidades de pago o acceso a un créditouna propiedad en un barrio privado que un departamento para una familia tipo en el área central. Este fenómeno, aunado al aumento de la inseguridad como problemática urbana, así como a las demandas ligadas al estilo de vida de las clases medias y altas, también pudo contribuir a que el desplazamiento de población se lleve a cabo.

En continuación con las discusiones competentes a esta investigación, en torno a los debates entre territorio y desarrollo, se aportaron elementos para problematizar el modelo de ciudad imperante, basado en la lógica neoextractiva que se consolidó en los últimos años, mediante el avance de la modalidad de residencia multifamiliar en altura, generando rentas extraordinarias provenientes del tan codiciado suelo urbano del centro. Desde esta perspectiva, se construyó un ideario de desarrollo mediante un sistema donde primó la lógica de mercado en alianza con la lógica política, y que construyó un tipo de ciudad para un único sector social. Y es así como la ciudad terminó atravesando un proceso que responde a una planificación del poder económico, encarnado en las grandes corporaciones inmobiliarias, que son las que contribuyen de manera decisiva a formar el valor del suelo, y son éstas las que actúan con la habilitación del poder político, que les facilita una normativa permisiva para construcciones que muchas veces funcionan como inversiones a la espera de una valorización mayor. El Estado local entonces interviene para que el proceso de gentrificación se produzca, al desplegar diversas estrategias de "desarrollo urbano" en un contexto de difusión del empresarialismo urbano, entendido como el posicionamiento estatal en materia de 
política pública urbana tendiente a facilitar la realización del capital sobre el territorio, considerando a éste como un mero receptáculo para las inversiones. Así, el Estado municipal promueve modificaciones del entorno físico urbano como sinónimo de desarrollo, dando lugar a una perspectiva sesgada y fisicalista, vinculada a la idea de que las transformaciones de las formas espaciales y el entorno constructivo generan transformaciones socioeconómicas virtuosas.

En este contexto, el Estado municipal dejó pasar la oportunidad de financiar el acceso al hábitat de sectores medios y también populares, al no implementar instrumentos específicos enfocados en la distribución de recursos fiscales y en la captación de parte de la valorización inmobiliaria producida por decisión normativa a través de la modificación de la zonificación. Por el contrario, la aplicación de un esquema básico de instrumentos impositivos basado en permisos de construcción y tasas municipales, caracterizado además por la laxitud de sus regulaciones y la implementación de periódicas excepciones -a través de la figura del exhorto-, contribuyó de manera decisiva a incrementar las expectativas especulativas. Al mismo tiempo, esta configuración de la política urbana local resultó seriamente limitada en su capacidad de cumplir con uno de los principios básicos de toda recomendación vigente en materia de política urbana de hábitat: el reparto equitativo de las cargas y los beneficios del proceso de urbanización, manifestado en este caso por una fuerte y rápida densificación vinculada al proceso de verticalización del centro de Bernal. Es así como el Estado asume un doble rol, ya que por un lado garantiza concesiones al capital y por el otro, tiene la necesidad de regularlo, y se encuentra de esta manera en un intento por lograr un equilibrio entre alentar el extractivismo urbano y amortiguar sus impactos sociales, ecuación que en el caso de estudio abordado en esta investigación ha expuesto un fuerte sesgo hacia el primero de los términos, mientras que la amortiguación de los impactos sociales ha sido virtualmente inexistente.

Desde esta perspectiva es que se puede leer la otra cara del desarrollo. Mientras la ciudad y más particularmente el centro de Bernal se expone a un proceso de modernización y de densificación, se fue expresando un modelo de desarrollo que refuerza las desigualdades territoriales, es decir, un "maldesarrollo" que promueve la explotación, la desigualdad y la injusticia. Se insiste en la ocupación, construcción, apropiación y transformación del espacio urbano considerando al territorio y al suelo de la ciudad como una mercancía producto de la materialización concreta e histórica de vastas formas de organización social, cuyos componentes necesarios para su 
delimitación son el ejercicio de poder a través de un actor hegemónico como el Estado y también de otros actores ligados a la lógica económica de producción que lo disputan. Y es de esta manera que se continúa reproduciendo un modelo de desarrollo desde el cual se busca específicamente la maximización de ganancias para un grupo selectivo, en detrimento de otros sectores que quedan excluidos, sin considerar la multidimensionalidad e integralidad que implica el concepto.

En síntesis, se va instalando un discurso eficientista sobre el territorio, que apela a la noción de desarrollo entendido como una fuerza transformadora que redunda en el progreso del ámbito urbano. Sin embargo, al analizar el territorio y la ciudad, se puede entrever un espacio de disputa por la centralidad entre una diversidad de actores que despliegan prácticas atravesadas por proyectos e intereses distintos y contrapuestos.

Considerando las características de la Maestría en Políticas de Desarrollo, y teniendo en cuenta el paradigma basado en la teoría crítica asumida en esta investigación, el cual repercute en una práctica investigativa que otorga protagonismo al esquema investigación-reflexión-acción, se busca aportar insumos de conocimiento potencialmente útiles para generar cambios y una disminución en la desigualdad de oportunidades en este contexto. La búsqueda de transformación social se basa en la participación comprometida con la investigación, la colaboración desde la reflexión personal crítica y los aportes para la acción, susceptibles de convertirse en insumos para políticas públicas orientadas al desarrollo entendido desde una perspectiva integral y multidimensional. Es así que los resultados de este estudio constituyen un punto de partida para la realización de aportes críticos susceptibles de enriquecer el arsenal conceptual y metodológico a la hora de presentar algunos lineamientos de política urbana potenciales en el contexto municipal.

Por un lado, propiciar la instrumentación concreta a través de planes y proyectos en el marco del planteo de Plan Estratégico Quilmes 2030 actualmente vigente, el cual se caracteriza por un diagnóstico para el desarrollo urbano y territorial, que propone ejes de acción de poca precisión, y sin un desarrollo de los instrumentos a construir y utilizar para llevarlos a cabo. Cabe señalar que el actual cambio de gestión introduce mayor complejidad a la posibilidad de esta propuesta. No obstante, dado el carácter genérico del plan y la continuidad en las líneas generales que muestra este plan respecto a los anteriores, permite proponer la idea de la necesidad de diseñar e implementar políticas 
e instrumentos concretos en lugar de la realización de un nuevo plan estratégico de diagnóstico y lineamientos generales de carácter indicativo.

Además, y en concordancia con el planteo principal de esta tesis, resulta importante proponer la construcción de instrumentos que permitan el financiamiento del desarrollo urbano de otras áreas del distrito, a partir de la regulación de los procesos de verticalización y refuncionalización de los centros y subcentros del partido. La instrumentación de políticas de captación y recuperación de las plusvalías que el mismo Estado genera, en el marco de las leyes provinciales 8912 y 14449 (de ordenamiento territorial y usos del suelo, y acceso justo al hábitat respectivamente) contribuiría a la factibilidad de concreción de estos lineamientos de política urbana tendientes al desarrollo integral, equitativo y solidario de la totalidad del territorio municipal, en consonancia con las recomendaciones vigentes a nivel internacional previstas en algunos documentos tales como la Nueva Agenda Urbana de Hábitat III-ONU (2017), y el Plan de Acción Regional para la implementación de esa Nueva Agenda Urbana en América Latina y el Caribe, para el periodo 2016-2036.

Por otra parte, a partir del proceso estudiado y las limitaciones observadas es posible proponer la implementación de mecanismos democráticos de participación efectiva que incorporen una perspectiva multiactoral, que reconozca los diferenciales de poder existentes, superando las limitaciones de todas las modalidades participativas implementadas. En este sentido, un organismo institucional que incorpore la multiplicidad de actores sociales que disputan el acceso al suelo urbano, las modalidades de urbanización y las elecciones vinculadas a las formas de producir el entorno urbano bajo modalidades participativas efectivas, representativas, y que supere el enfoque tradicionalmente consultivo no vinculante, para convertirse en un instrumento decisorio con voz y voto en la arena política que dirime la instrumentación de estas decisiones normativas. De esta manera constituye una modalidad concreta de efectivizar políticas tendientes a incrementar el derecho a la ciudad y al acceso al hábitat urbano de la población.

Por último, resulta importante incorporar al diseño de políticas urbanas de desarrollo los efectos e impactos de los procesos y tendencias de urbanización que se generan en el partido. Estudios como el aquí presentado, destacan elementos susceptibles de incorporar al diagnóstico de los impactos generados por un conjunto de factores multiescalares: obras de infraestructura, modificaciones de normativas y 
decisiones de desarrollo inmobiliario en la escala local; modelos de acumulación, tendencias de urbanización de escala metropolitana, inversión especulativa de excedentes en stock habitacional de reserva de valor, y disputas y reapropiación de clase por la centralidad urbana en la escala meso y macro. En este sentido, el abordaje empírico de impactos en procesos de desplazamiento vinculados a la gentrificación permite proponer la necesidad de trazar lineamientos respecto a la posibilidad de identificar situaciones de gentrificabilidad, con el propósito de tomar medidas preventivas para pensar políticas de desarrollo tendientes a disminuir estos impactos en otras subcentralidades del partido. Estos sectores que manifiestan tendencias incipientes y que un mediano plazo podrían sufrir procesos de similares características, deberían ser el foco de atención prioritario para elaborar medidas tendientes a modificar dichas tendencias expulsivas y segregatorias, y generar posibilidades de acceso al hábitat urbano más equitativas.

Como cierre a este apartado de conclusiones, y con el fin de establecer futuras líneas de investigación para profundizar y complejizar el análisis se presentan a continuación algunas temáticas susceptibles de desarrollar en futuras investigaciones y en otra instancia formativa correspondiente al doctorado en geografía, en el marco de una trayectoria académica cuyo eje central de interés son las implicancias ambientales y sociales, diferenciales, que tiene la expansión residencial y producción de suelo urbano en el ámbito metropolitano.

Mientras en esta tesis de maestría se profundizó en una de las múltiples aristas que explican el proceso de expansión urbana, poniendo énfasis en los aspectos normativos de la rezonificación de usos del suelo que impactan en la densificación y verticalización de los centros y subcentros urbanos, nuevas líneas de indagación se abren respecto a las tendencias de expansión sobre áreas vulnerables del litoral metropolitano como parte constitutiva de un mismo fenómeno de urbanización y de disputa de clase por el suelo urbano. Mientras por un lado, se da la reapropiación y elitización de los centros, por otro lado, la disputa se traslada a zonas periféricas de reserva, tradicionalmente ocupadas por sectores populares, que constituyen áreas vulnerables con alto riesgo hídrico y características de humedales.

De esta forma, se propone analizar el proceso de expansión urbana vinculado a procesos sociales de ocupación y producción del suelo urbano en áreas ribereñas del litoral sur metropolitano, que resultan de interés estratégico para la realización del 
capital en productos residenciales orientados a sectores de altos ingresos. Se procura en esta instancia establecer sólidas bases de conocimiento orientado a la producción de una tesis doctoral que pueda ofrecer aportes al conocimiento de los aspectos explicativos de estas dinámicas urbanas, con particular énfasis en el avance sobre el área ribereña de la localidades de Bernal y Quilmes, y los partidos de Berazategui y Avellaneda; territorios actualmente en disputa por diversos proyectos inmobiliarios de gran escala llevados adelante por distintos actores privados en alianza con los Estados municipales.

Cabe aclarar que las líneas de investigación y las propuestas aquí mencionadas no pretenden obturar la posibilidad de plantear otros ejes de debate y profundización que el desarrollo de la tesis habilita, sino dejar planteados algunos caminos por donde seguir indagando. 


\section{Bibliografía}

Abramo, P. (2011) La producción de las ciudades latinoamericanas: mercado inmobiliario y estructura urbana. Quito: OLACCHI.

Acosta, A. (2012) "Extractivismo y neoextractivismo: dos caras de la misma maldición”. En Cronicón: El Observatorio latinoamericano, recuperado de: https://cronicon.net/paginas/Documentos/paq2/No.23.pdf

Aguilar, L. (2009) "Marco para el análisis de las políticas públicas”. Mariñez, F., y Garza, V. (Ed.) Politica pública y democracia en América Latina del análisis a la implementación (pp. 11-32). México, D. F: Miguel Ángel Porrúa.

Alexandri, G., González, S., y Hodkinson, S. (2016) Geografías del desplazamiento en el urbanismo de América Latina. INVI, N³1 (88), 9-25.

Altschuler, B. (2008) Territorio y desarrollo: aportes de la geografía y otras disciplinas para repensarlos. Theomai, $\mathrm{n}^{\mathrm{o}} 27-28$.

Azamar Alonso, A., y Ponce Sánchez, J. I. (2015) El neoextractivismo como modelo de crecimiento en América Latina: El caso de México. Economía y Desarrollo, 154 (1), 185-198. Recuperado de: http://scielo.sld.cu/scielo.php?pid=S0252$\underline{85842015000200014 \& \text { script }=\text { sci arttext\&tlng }=\text { pt }}$

Baer, L. (2011). El mercado de suelo formal de la Ciudad de Buenos Aires en su contexto metropolitano. Dinámica de precios de terrenos, desarrollo inmobiliario y acceso a la vivienda en la década de dos mil. Tesis doctoral, Facultad de Filosofía y Letras, Universidad de Buenos Aires.

Baer, L. (2012) Mercado de suelo y producción de vivienda en Buenos Aires y su área metropolitana. Tendencias recientes de desarrollo urbano y acceso a la ciudad. $R i$ URB, Revista Iberoamericana de Urbanismo, $\mathrm{N}^{\circ}$ 8, pp. 43-58.

Barrionuevo, C. (2011) Técnicas de Investigación social y diseño de instrumentos de recolección de datos. Universidad Nacional de La Plata.

Blanco, J. (2007) "Espacio y territorio: elementos teórico-conceptuales implicados en el análisis geográfico”. Fernández Caso, María Victoria y Gurevich, Raquel (Coord.). Geografía. Nuevos temas, nuevas preguntas. Buenos Aires: Biblos.

Blanco, J. y Apaolaza, R. (2016) Políticas y geografías del desplazamiento. Contextos y usos conceptuales para el debate sobre gentrificación. INVI, N³1(88), 27-71. 
Blanco, A., Fretes Cibils, V. y Muñoz A. (Eds) (2016) "Introducción”. Expandiendo el uso de la valorización del suelo: la captura de plusvalias en América Latina y el Caribe. EE.UU.: BID. Recuperado de: https://publications.iadb.org/es/expandiendoel-uso-de-la-valorizacion-del-suelo-la-captura-de-plusvalias-en-america-latina-y-el

Borja, J. (2011) Espacio público y derecho a la ciudad. Viento del Sur. Por una izquierda alternativa.

Borsdorf, A. (2002) "Barrios cerrados en Santiago de Chile, Quito y Lima: tendencias de la segregación socio-espacial", Cabrales, L. F. (ed.) Latinoamérica: Países abiertos, ciudades cerradas. Guadalajara: Universidad de Guadalajara/UNESCO, 581-610.

Borsdorf, A. (2003) Cómo modelar el desarrollo y la dinámica de la ciudad latinoamericana. EURE, No 86, pp. 37-49, Santiago de Chile.

Capdeville, J., Ceconato, D., y Mandrini, M. R. (2013) Segregación urbana y mercantilización del territorio. Iberoamerica de Urbanismo, $\mathrm{N}^{\circ} 9,47-71$. Recuperado de: https://core.ac.uk/download/pdf/41826777.pdf

Carlos, A. F. A. (1992) La cidade. São Paulo: Contexto.

Carlos, A. F. (2005) La utopía de la gestión democrática de la ciudad. Scripta Nova: revista electrónica de geografía y ciencias sociales, $\mathrm{N}^{\circ} 9$.

Carlos A. F. A. (2014) La ciudad como privación y la reapropiación de lo urbano como ejercicio de la ciudadanía. Scripta Nova. Revista Electrónica de Geografía y Ciencias Sociales, N493. Recuperado de: http://www.ub.edu/geocrit/sn/sn-493/49308.pdf

Casgrain, A., y Janoschka, M. (2013) Gentrificación y resistencia en las ciudades latinoamericanas. El ejemplo de Santiago de Chile. En Andamios. Revista de Investigación Social, № 22. Ciudad de México: Universidad Autónoma de México.

Ciccolella, P. (2007) "Transformaciones recientes en las metrópolis latinoamericanas". En Fernández Caso, M.V. y Gurevich, R. (coord.) Geografia: nuevos temas, nuevas preguntas. Buenos Aires: Editorial Biblos,

Ciccolella, P. (2011) "Metrópolis latinoamericanas ¿Territorios subregulados, espacios del capital?”. En Ciccolella, P. Metrópolis latinoamericanas: más allá de la globalización. Quito: Olacchi. 
Ciccollela, P., y Vecslir, L. (2012) Dinámicas, morfologías y singularidades en la reestructuración metropolitana de Buenos Aires. riURB, Revista Iberoamericana de Urbanismo, Nº, p. 23-41.

Ciccolella, P., Vecslir, L., y Baer, L. (2015) Revitalización de subcentros metropolitanos. Buenos Aires entre la ciudad dispersa y la ciudad compacta. Contexto, Revista de la Facultad de Arquitectura de la Universidad Autónoma de Nuevo León, $\mathrm{N}^{\circ} 9$ (11).

Cirio, G. (2016) Territorio y lugar en las concepciones e instrumentos de planificación territorial municipal. El Partido de Quilmes, Buenos Aires, Argentina, 2004-2014. Tesis de Doctorado en Geografía, FaHCE-UNLP.

Cirio, G. (2018) "Política urbana y conflictos sociales. Una revisión crítica sobre el proceso de rezonificación del partido de Quilmes, Buenos Aires (2004-2014)". En Jornadas Platenses de Geografía, FaHCE, UNLP. La Plata.

Clark, E. (2005) "El orden y la simplicidad de la gentrificación: un reto político", en Rowland Atkinson y Gary Bridge (eds.) Gentrification in a Global Context: The new urban colonialism. Oxon: Routledge.

Clichevsky, N., y Rofman, A. (1989) Planificación urbana y regional en la Argentina. Una revisión crítica. Ciudad y territorio, 79-1, pp. 61-71.

Cortizas, L. (2016) Expansión urbana cerrada y representaciones sociales. La mirada de los habitantes del barrio Villa Alcira en torno a las incidencias socio territoriales del country Nuevo Quilmes (Bernal). Tesina de Grado para acceder al título de Licenciada en Geografía. FaHCE-UNLP. Recuperado de: http://www.memoria.fahce.unlp.edu.ar/tesis/te.1316/te.1316.pdf

Cosacov, N. (2014) Habitar la centralidad. Trayectorias residenciales y uso del espacio urbano de residentes en Caballito, Buenos Aires. Tesis doctoral. FCS-UBA.

Cosentino, A. (2005) Ingenierías Financieras Innovativas para el Desarrollo de Proyectos de Infraestructura. Documento del Fondo del Capital Social (FONCAP), Mimeo.

Cravino, M. C. (2001) "La propiedad de la tierra como un proceso. Estudio comparativo de casos en ocupaciones de tierras en el Área Metropolitana de Buenos Aires". Land Tenure Issues in Latin America Conference, Birmingham. 
Cravino, M. C. (2006) Las villas de la ciudad. Mercado e informalidad urbana. Los Polvorines, Bs. As.: Instituto del Conurbano, Universidad Nacional de General Sarmiento.

Cravino, M. C. (2008) Vivir en la villa: relatos, trayectorias y estrategias habitacionales. Universidad Nacional de General Sarmiento.

Cravino, M. C., Del Río, J. P. y Duarte, J. I. (2008) "Un acercamiento a la dimensión cuantitativa de los asentamientos y villas del Área Metropolitana de Buenos Aires". En Cravino et al. Los mil barrios (in)formales. Aportes para la construcción de un observatorio del hábitat popular del Área Metropolitana de Buenos Aires. Los Polvorines, Universidad Nacional de General Sarmiento.

Cuenya, B. (2016) La política urbana frente a la mercantilización y elitización de la ciudad: algunas reflexiones y referencias a la situación argentina. Cuaderno urbano,

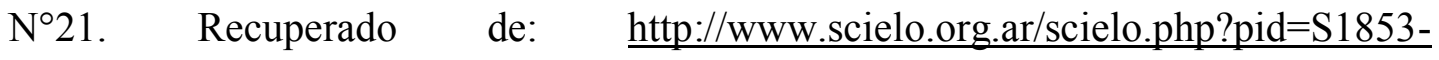
$\underline{36552016000200008 \& \text { script }=\text { sci abstract\&tlng }=\text { en }}$

Cuenya, B. y Corral, M. (2011) Empresarialismo, economía del suelo y grandes proyectos urbanos: el modelo de Puerto Madero en Buenos Aires. EURE, vol 37, $\mathrm{N}^{\circ} 111$, pp.25-45. Recuperado de: https://scielo.conicyt.cl/scielo.php?pid=S0250$\underline{71612011000200002 \& \text { script }=\text { sci } \text { arttext\&tlng }=\mathrm{e}}$

Delgadillo, V. (2016) "Prólogo" en Rodríguez, M.C. y Di Virgilio M.M (comps.) Territorios, políticas habitacionales y transformaciones urbanas, Espacio Editorial. Buenos Aires.

Del Río, J. P. (2008) "El acceso al suelo en la política habitacional en el área metropolitana de Buenos Aires. Notas metodológicas sobre un objeto problemático". X Jornadas de Investigación del CIG y Depto. de Geografía, UNLP. Recuperado de: http://www.fuentesmemoria.fahce.unlp.edu.ar/trab eventos/ev.800/ev.800.pdf

Del Río, J. P. (2012). El lugar de la vivienda social en la ciudad: un análisis de la política habitacional desde el mercado de localizaciones intra-urbanas y las trayectorias residenciales de los habitantes. Tesis doctoral. FaHCE, UNLP.

De Mattos, C.A. (1997) "Dinámica económica globalizada y transformación metropolitana: hacia un planeta de archipiélagos urbanos". VI Encuentro de Geógrafos de América Latina. Buenos Aires.

De Mattos, C.A. (2007) Globalización, negocios inmobiliarios y transformación urbana. Nueva Sociedad, 212, 82-96. 
DGEyC (2019) Dirección General de Estadísticas y Censos. Recuperado de: https://www.estadisticaciudad.gob.ar/eyc/

Díaz Parra, I., y Apaolaza, R. (2018) "Una propuesta metodológica para identificar gentrificación y gentrificabilidad a partir de los censos de población”. 1er encuentro de discusión metodológica sobre análisis espacial urbano. Buenos Aires: FFyLUBA.

Di Virgilio, M. (2014) Diferencias sociales en los procesos de movilidad residencial intraurbana en el AMBA. Quivera, $\mathrm{N}^{\circ} 16(1), 11-37$.

Di Virgilio, M.M., y Guevara, T. (2014) Gentrificación liderada por el Estado y empresarialismo urbano en la ciudad Autónoma de Buenos Aires. Estudios Sociales Contemporáneos, 11:12-23.

DOUyT, Dirección Provincial de Ordenamiento Urbano y Territorial (2007) Lineamientos Estratégicos para la Región Metropolitana de Buenos Aires. Provincia de Buenos Aires, Ministerio de Infraestructura, Subsecretaría de Urbanismo y Vivienda.

DPE (2019) Dirección Provincial de Estadísticas. "Informe Censo Villa Itatí - Villa Azul Provincia de Buenos Aires". Censo en Barrios Populares de la provincia de Buenos Aires. Ministerio de Economía, Subsecretaría de Política y Coordinación Económica. Recuperado de: http://www.estadistica.ec.gba.gov.ar/dpe/images/Informe Censo Villa Itat $\% \mathrm{C} 3 \% \mathrm{~A}$ D__Villa_Azul_1.pdf

Duhau, E. y Giglia, A. (2008) Las reglas del desorden. Habitar la metrópoli. México: Siglo XXI. Recuperado de: https://leerlaciudadblog.files.wordpress.com/2016/05/duhau-y-giglia-las-reglas-deldeorden-habitar-la-metrc3b3poli.pdf

Escobar, A. (1996) La invención del tercer mundo. Construcción y deconstrucción del desarrollo. Bogotá: Norma.

Escobar, A. (2007). "La economía y el espacio del desarrollo: Fabulas de crecimiento y capital". La Invención del Tercer Mundo. Construcción y deconstrucción del desarrollo.

Féliz, M. (2012) "Neoextractivismo, neodesarrollismo y proceso de acumulación de capital: ¿Superando el ciclo stop-and-go? Argentina, 2003-2012”. VII Jornadas de Sociología, FaHCE, UNLP. Recuperado de: http://www.memoria.fahce.unlp.edu.ar/trab_eventos/ev.1887/ev.1887.pdf 
Ferrero, M. M., y Gallego, A. (2012) "Ciudades exclusivas: entre el discurso de la participación y el modelo securitario”. VII Jornadas de Sociología (UNLP). La Plata, Argentina.

Recuperado

de:

http://www.memoria.fahce.unlp.edu.ar/trab_eventos/ev.1896/ev.1896.pdf

Garay, A. (2007) Lineamientos estratégicos para la región metropolitana de Buenos Aires. Subsecretaría de Urbanismo y Vivienda, Dirección Provincial de Ordenamiento Urbano y Territorial.

Garófoli, G. (1991) “Desarrollo económico, organización de la producción y territorio". En Vázquez, A. y Garófoli, G. Desarrollo económico local en Europa. Madrid: Colegio de Economistas. Capítulo 10. Recuperado de: http://www.yorku.ca/ishd/CUBA.LIBRO.06/DEL/CAPITULO10.pdf

Giarracca, N., y Teubal, M. (2010) "Disputas por los territorios y recursos naturales: el modelo extractivo”. ALASRU Nueva Época, N5, 113-133.

Guba, E., y Lincoln, Y. (2002) "Paradigmas en competencia en la investigación cualitativa”. En Derman, C. y J. Haro (comps.) Por los rincones. Antología de métodos cualitativos en la investigación social. (pp. 113-145). La sonora: el colegio sonora.

Gudynas, E. (2010) El nuevo extractivismo progresista: tesis sobre un viejo problema bajo nuevas expresiones. El Observador, N8, Observatorio Boliviano de Industrias Extractivas.

Haesbaert, R. (2002) Territórios alternativos. São Paulo: Contexto.

Haesbaert, R. (2004). Dos múltiplos territórios à multiterritorialidade. Porto Alegre.

Haesbaert, R. (2011) El mito de la desterritorialización. Del "fin de los territorios" a la multiterritorialidad. México: Siglo XXI.

Hamnett, C. (2003) Gentrification and the middle-class remaking of inner London, 1961-2001. Urban Studies, N40, pp. 2401-2426.

Harvey, D. (1989) From managerialism to entrepreneurialism: The transformation in urban governance in late capitalism. Geografiska Annaler. Series B, Human Geography, vol. 71, No 1, 3-17. Recuperado de: http://dx.doi.org/10.2307/490503

Harvey, D. (2001) Espacios del capital. Hacia una geografía crítica. Madrid: Ediciones Akal. Edinburgh University Press.

Harvey, D. (2003). Espacios de esperanza. Madrid: Ediciones Akal. 
Harvey, D. (2004) El Nuevo Imperialismo: Acumulación por desposesión (Vol. 26). Ediciones Akal.

Harvey, D. (2008) El derecho a la ciudad. Dialnet, New left review, N53(4), 23-39.

Hernández, R., Fernández, C., y Baptista, P. (2010) Metodología de la investigación. México D.F.: mcgraw-hill / interamericana editores, S.A. de C.V.

Hidalgo, R. y Janoschka, M. (eds.) (2014) La ciudad neoliberal. Gentrificación y exclusión en Santiago de Chile, Buenos Aires, Ciudad de México y Madrid. Universidad Católica de Chile, Santiago de Chile.

Hiernaux, N.D., y Lindón, A. (1993) El concepto de espacio y el análisis regional. Secuencia, N²5, 89-100, México.

Hirschman, A. O. (1961) La estrategia del desarrollo económico. Buenos Aires, Fondo de cultura económica.

Ibáñez, E. A. y Brie, R. (2001) Diccionario de Sociología. Madrid: Editorial Claridad.

Janoschka, M. (2002) El nuevo modelo de la ciudad latinoamericana: fragmentación y privatización. EURE No85, Santiago de Chile. Recuperado de: https://scielo.conicyt.cl/scielo.php?script $=$ sci arttext\&pid=S0250$\underline{71612002008500002}$

Janoschka, M. (2006) El modelo de ciudad latinoamericana. Privatización y fragmentación del espacio urbano en Buenos Aires: el caso Nordelta. Buenos Aires a la deriva. Transformaciones urbanas recientes, Buenos Aires, 96-131.

Janoschka, M. (2016) Gentrificación, desplazamiento, desposesión: procesos urbanos claves en América Latina. INVI, N³1(88), 27-71.

Janoschka, M. y Sequera, J. (2016) Gentrificación en América Latina: abordaje de las políticas y las geografías del desplazamiento. Geografía urbana.

Jaramillo, S. (1999) El papel del mercado del suelo en la configuración de algunos rasgos socio-espaciales de las ciudades latinoamericanas. Territorios, Universidad del Rosario, Bogotá.

Jaramillo, S. (2003) Los fundamentos económicos de la participación en plusvalías. Bogotá: CEDE-Universidad de los Andes, Lincoln Institute of Land Policy. 
Karol, J. (2014) "Reconocimiento de actores sociales en la planificación y la gestión Urbana. Notas Teóricas". Cátedra de Teorías Territoriales y Planificación Territorial. Recuperado de http://blogs.unlp.edu.ar/planificacionktd/

Kothari, M. (2015) The global crisis of displacement and evictions: a housing and land rights response. Rosa Luxemburg Stiftung, Nueva York.

Lander, E. (2014) "El Neoextractivismo como modelo de desarrollo en América Latina y sus contradicciones". En Jornadas sobre (Neo) extractivismo y el futuro de la democracia en América Latina: Diagnóstico y retos. Berlín, Alemania. Recuperado de: http://mx.boell.org/sites/default/files/edgardolander.pdf

Lechner, N. (1997) Tres formas de coordinación social. Revista de la Cepal, $\mathrm{N}^{\circ} 61$. https://bibliotecavirtual.unl.edu.ar/ojs/index.php/NuevaEpoca/article/view/150/180

Lefebvre, H. (1972) La revolución urbana. Madrid: Alianza Editorial.

Lefebvre, H. (1975) El derecho a la ciudad (3ed.) Barcelona: Península.

Leva, G., Fernández, G. y Paz, S. (2006) Informe técnico y evaluación de resultados. Jornada de participación ciudadana. Auditorio de la Universidad Nacional de Quilmes. Recuperado de http://hm.unq.edu.ar/Rezonificacion/Reporte\%20final\%20_HCD FINAL.pdf

Ley, D. (1988) Social upgrading in six Canadian inner cities. The Canadian Geographer 32, $\mathrm{N}^{\circ} 1$, pp. 31-45.

Linares, S. (2011) Análisis y modelización de la segregación socioespacial en ciudades medias bonaerenses mediante sistemas de información geográfica: Olavarría, Pergamino y Tandil (1991 -2001). Tesis de Doctorado en Geografía, Universidad Nacional del Sur. Recuperado desde: http://repositoriodigital.uns.edu.ar/bitstream/123456789/510/1/Tesis\%20Doctorado \%20Santiago \%20Linares.pdf

Linares, S. (2012) Aportes de la ecología urbana y modelos neoclásicos para analizar la diferenciación socioespacial en ciudades medias bonaerenses: Pergamino, Olavarría y Tandil (2001). Revista Huellas, n ${ }^{\circ} 16$, pp. 13-35.

López Morales, E. (2013) Gentrificación en Chile: aportes conceptuales y evidencias para una discusión necesaria. Revista de Geografía Norte Grande Vol.56, pp. 31-52.

Mançano Fernandes, B. (2008) "Sobre la tipología de los territorios", en Postgrado en Geografía de la UNESP, Campus de Presidente Prudente. Recuperado de: http://web.ua.es/es/giecryal/documentos/documentos839/docs/bernardo-tipologia-deterritorios-espanol.pdf 
Maraggi, I. (2017) Resistir al avance extractivista: Las Comunidades Mapuche Paynemil, Kaxipayiñ y Campo Maripe frente a los conflictos territoriales en Loma La Lata y Loma Campana, Neuquén. Tesina de grado. FaHCE, UNLP. Recuperado de: http://www.memoria.fahce.unlp.edu.ar/tesis/te.1476/te.1476.pdf

Marcos, M. y Mera, G. (2011) La dimensión espacial de las diferencias sociales. Alcances y limitaciones metodológico-conceptuales de las herramientas estadísticas para abordar la distribución espacial intraurbana. Revista Universitaria de Geografia, Vol. 20, pp. 41-65, Universidad Nacional del Sur Bahía Blanca, Argentina https://www.redalyc.org/pdf/3832/383239103002.pdf

Marcuse, P. (1985) Gentrification, abandonment and displacement. Connection, causes and policy responses in New York City. Journal of urban and contemporary law, $\mathrm{N}^{\circ} 28, \quad$ pp. 195-240. Recuperado de: http://openscholarship.wustl.edu/law urbanlaw/vol28/iss1/4

Marengo, M. C. (2013) Extensión urbana e intervenciones habitacionales: el caso de la ciudad de Córdoba (Argentina). Cuadernos de Vivienda y Urbanismo, Vol. 6 (12), páginas 280-301. Bogotá. Recuperado de https://revistas.javeriana.edu.co/index.php/cvyu/article/view/7037

Marradi, A., Archenti, N., y Piovani, J.I. (2007) Metodología de las Ciencias Sociales. Buenos Aires: Emecé. Capítulos 3, 5, y 14.

Martínez Toro, P. (2005) La integración subregional y la caracterización funcional, morfológica del fenómeno de metropolización en el área de influencia metropolitana de Cali. Actas latinoamericanas de Varsovia, (28), 67-92.

Martínez Salgado, C. (2012) El muestreo en investigación cualitativa. Principios básicos y algunas controversias. Ciência \& Saúde Coletiva, 17 (3):613-619. Recuperado de: http://www.scielo.br/pdf/csc/v17n3/v17n3a06.pdf

Matus, C. (1987) Política, Planificación y Gobierno. Fundación ALTADIR. ISBN 980300-316-X

Meyer, K. y Bahr, J. (2001) Condominios in greater Santiago de Chile and their impact on the urban structure. Die Erde, $\mathrm{N}^{\circ} 132$.

Molano Camargo, F. (2016) El derecho a la ciudad: de Henri Lefebvre a los análisis sobre la ciudad capitalista contemporánea. Folios, Segunda época, N 44, pp. 3-19. Bogotá, Colombia. 
Narodowski, P. (2007) La Argentina pasiva: desarrollo, subjetividad, instituciones, más allá de la modernidad: el desarrollo visto desde el margen de una periferia, de un país dependiente. Prometeo Libros Editorial. Capítulo 1.

Narodowski, P. y Chain, L. (2009) "Economía para empezar por el principio. Una guía para aprender la economía y formular proyectos". Manual 2 ( $1^{\mathrm{a}}$ ed.) Economía y desarrollo. Para entender las cosas desde la periferia". Buenos Aires: Aulas y Andamios.

Oszlak, O., y Donnell, O. (1984) Estado y políticas estatales en América latina: hacia una estrategia de investigación. Documentos del CEDES, N⒋

Oszlak, O. (2018) Derecho a la ciudad y derecho al espacio urbano. Voces en el Fénix, año $8, N^{\circ} 71$.

Pérez Luco, R., Lagos, L., Mardones, R., y Sáez, F. (2017) Diseños de investigación y muestreo cualitativo. Lo complejo de someter la flexibilidad del método emergente a una taxonomía apriorística. Investigación Cualitativa en Salud, Vol. 2.

Pintos, P. (2011) "La praxis del urbanismo neoliberal en humedales de la cuenca baja del río Luján”. Centro de Investigaciones Geográficas. FaHCE, UNLP.

Pintos, P. (2012) "Paisajes que ya no serán. Acumulación por desposesión e hibridación pseudourbana de humedales en la cuenca baja del río Luján, Argentina”, en Barrera Lobatón, S. y Monroy Fernández, J. (eds.) Perspectivas sobre el paisaje. Serie Perspectivas ambientales, Facultad de Ciencias Humanas, Universidad Nacional de Colombia, Bogotá, pp. 189-217.

Pírez (1995) Actores y gestión de la ciudad. Ciudades N²8, México. Recuperado de: http://www.cedet.edu.ar/Archivos/Bibliotecas/pirez actores.pdf

Pírez, P. (2006) La privatización de la expansión metropolitana en Buenos Aires. Economía, sociedad y territorio. Vol. 6, №21. Págs. 31-54.

Pírez, P. (2014) La mercantilización de la urbanización. A propósito de los "conjuntos urbanos” en México. Estudios Demográficos y Urbanos, Vol. 29(3)(87), 481-512.

Pírez, P. (con la colaboración de N. Cosacov) (2016) "El derecho a la ciudad y la reestructuración neoliberal en Buenos Aires: movilizaciones de sectores populares (“insolventes") y clases medias (“solventes”): ¿Una extensión conceptual?”. En Álvarez Enríquez, L. (coord.) Ciudadanía y nuevos actores en grandes ciudades, México: Juan Pablos Editor. 
Portillo Riascos, L. H. (2014) Extractivismo clásico y neoextractivismo, ¿ Dos tipos de extractivismos diferentes?. Revista Tendencias, Vol. 15(2). Colombia.

Prevot Schapira, M. F. (2002) Buenos Aires en los años 90: metropolización y desigualdades. EURE (Santiago), Vol. 28(85), 31-50.

Raffestín, C. (1993) Por una geografia del poder. San Pablo: Ática.

Ramos Galarza, C. (2015) Los paradigmas de la investigación científica. Av. Psicol, Vol. 23 (1). Recuperado de: https://www.researchgate.net/publication/282731622 LOS PARADIGMAS DE L A_INVESTIGACION_CIENTIFICA_Scientific_research_paradigms

Ramírez, L. (2016) Movilidad residencial y trayectorias habitacionales: un análisis teórico-metodológico de estudios realizados en el Área Metropolitana de Buenos Aires. Tesina de grado, FaHCE, UNLP.

Reese, E. (2011) Instrumentos de gestión urbana, fortalecimiento del rol del municipio y desarrollo con equidad. Carajillo de la Ciudad, Revista Digital del Programa en Gestión de la Ciudad UOC. Año 3.

Repetto, F. (2009) "El marco institucional de las políticas sociales: Posibilidades y restricciones para la gestión social". En Chiara, M. y M.M. Di Virgilio, (Orgs.) Gestión de la política social. Conceptos y herramientas. Buenos Aires: Prometeo.

Ríos, D. (2005) Producción privada del espacio urbano residencial y estado. El caso de la Mega-urbanización cerrada Nordelta en el municipio de Tigre. Revista de Temas Sociales Kairós, año 9, № 16. Recuperado de: http://www.revistakairos.org

Robirosa, M. (2002) La participación en la gestión. Justificación, malos entendidos, dificultades y estrategias. Mundo Urbano, $\mathrm{N}^{\circ} 18$. UNQ.

Rodríguez, M.C. (2007) Políticas del hábitat, desigualdad y segregación socio-espacial en el Área Metropolitana de Buenos Aires. Buenos Aires: Área de Estudios Urbanos Instituto de Investigaciones Gino Germani.

Rodríguez, I. y Mollá, M. (2002) "Urbanizaciones cerradas en Toluca y Puebla". En Cabrales, F. (coord.) Latinoamérica: países abiertos, ciudades cerradas. Guadalajara: Universidad de Guadalajara-UNESCO, 511-538.

Rodríguez, M. C., y Di Virgilio, M. (2011) (comps.) Caleidoscopio de las políticas territoriales. Un rompecabezas para armar. Buenos Aires: Prometeo. Capítulo 1.

Rodríguez, A., y Abramo, P. (2012). Centralidades en transformación y regeneración urbana en Bilbao. Europa: La ciudad central en el sistema urbano, $\mathrm{N}^{\circ} 63$. 
Rofman A. (2015) Deudas de la democracia en el ámbito de las economías regionales. Voces en el Fénix, $\mathrm{N}^{\circ} 52$.

Rostow, W. W. (1965) Las etapas del crecimiento económico: un manifiesto no comunista. Fondo de Cultura Económica.

Sabatini, F., Robles, M., y Vásquez, H. (2009) Gentrificación sin expulsión, o la ciudad latinoamericana en una encrucijada histórica. Revista 180, 18-25.

Sassen, S. (1999) La ciudad global. Nueva York, Londres, Tokio. Buenos Aires, Eudeba.

Sassen, S. (2014) Expulsions: brutality and complexity in the global economy. Cambridge, Harvard University Press.

Segura, R. (2012) Elementos para una crítica de la noción de segregación residencial socio- económica: desigualdades, desplazamientos e interacciones en la periferia de La Plata. Quid Vol. 16, №2 (106-132). Recuperado de: https://publicaciones.sociales.uba.ar/index.php/quid16/article/view/1118

Segura, R. (2014) El espacio urbano y la (re)producción de desigualdades sociales. Desacoples entre distribución del ingreso y patrones de urbanización en ciudades latinoamericanas. desiguALdades.net Working Paper Series $\mathrm{N}^{\circ} 65$, Berlín. Recuperado de: https://refubium.fu-berlin.de/bitstream/handle/fub188/22077/65WP-Segura-Online.pdf?sequence $=1 \&$ is Allowed $=y$

Shiva, V. (1995) Abrazar la vida. Mujer, ecología y desarrollo. Horas y Horas, pp. 1975, Madrid.

Slater, T. (2009) Missing Marcuse: on gentrification and displacement. City, №13 (23), 292-311.

Slipak, A. (2013) “¿De qué hablamos cuando hablamos de reprimarización? Un aporte al debate sobre la discusión del modelo de desarrollo". VI Jornadas de Economía Crítica: Economía Política y Política Económica. Facultad de Ciencias Económicas, UNCuyo, Mendoza. Recuperado de: https://www.academia.edu/7188437/ De qu\%C3\%A9 hablamos cuando hablamos de reprimarizaci\% $\% 3 \% \mathrm{~B} 3 \mathrm{n} \_$Un_aporte_al_debate_sobre la discusi $\% \mathrm{C} 3 \% \mathrm{~B} 3 \mathrm{n} \_$de 1 modelo_de desarrollo

Soja, E. (2013) Posmoderm geographies. The reassertion of space in critical social theory. Nueva York: Verso. 
Souza, M. L. de. (1995) "O território: sobre espaço e poder, autonomia e desenvolvimento". Castro, I. E. de, Gomes, P. C. da C., Corrêa, R. L. (orgs.) Geografia: conceitos e temas, Rio de Janeiro: Bertrand, p. 77-116.

Stake, R. (1994) “Case Studies”. Denzin N. y Lincoln, Y. (eds.) The Sage Handbook of Qualitative Research. California: Sage

Stake, R. (1999) Investigación con estudios de caso. Madrid: Morata. Capítulo 1.

Svampa, M. (2008) "La disputa por el desarrollo: territorio, movimientos de carácter socio-ambiental y discursos dominantes", en Svampa, M. (2008) Cambio de época. Movimientos sociales y poder político, Buenos Aires: Siglo XXI.

Svampa, M. (2011) "Extractivismo neodesarrollista y movimientos sociales ¿Un giro ecoterritorial hacia nuevas alternativas?". Grupo Permanente de Trabajo sobre Alternativas al Desarrollo (Comp.) Más allá del desarrollo, Fundación Rosa Luxemburgo. Quito: El Conejo, pp. 185-216.

Svampa, M., y Viale, E. (2014) Maldesarrollo. La Argentina del extractivismo y el despojo. (Vol. 3088). Katz editores.

Tella, G. (1996) La zonificación urbana en su primer escenario. Web Architecture Magazine, $\quad \mathrm{N}^{\circ} \quad 3 . \quad$ Recuperado de: http://www.arranz.net/web.arch$\underline{\text { mag.com } / 3 / \text { coll } / \text { coll3t.html }}$

Tellier, L.N., y Vainer, C.B. (Eds.) (2013) Las transformaciones de las metrópolis de las Américas. $\mathrm{N}^{\circ} 8$. Editorial Externado de Colombia.

Teubal, M. (2008) "Expansión de la soja transgénica en la Argentina”. Recuperado de: http://ase.tufts.edu/gdae/Pubs/rp/wg/AgricultureBook_Span/PromesasPeligrosCh4Te $\underline{\text { ubal.pdf }}$

Theodore, N., Peck, J., y Brenner, N. (2009) Urbanismo neoliberal: la ciudad y el imperio de los mercados. Temas sociales, $\mathrm{N}^{\circ} 66,1-11$.

Tobío, O. (2011) Entre la acción territorial directa y las "piedras de papel": movimientos sociales y modelo de desarrollo en la Argentina. Revista Geográfica de América Central, N², 1-11.

Tobío, O. (2012) Territorios de la incertidumbre. Apuntes para una geografía social (Colección Cuadernos de Cátedra), Buenos Aires: Universidad Nacional de San Martín, p.168. 
Topalov, C. (1979) La urbanización capitalista: algunos elementos para su análisis. México: Edicol. Capítulos 1 y 7.

Torres, P. (2004) La política de las políticas públicas: propuesta teórica y metodológica para el estudio de las políticas públicas en países de frágil institucionalidad. CEPAL, Serie Politicas Públicas, $\mathrm{N}^{\circ}$ 93. Santiago de Chile.

Torres, H. (2006) El mapa social de Buenos Aires 1940-1990. Serie Difusión No 3. Dirección de Investigaciones. Facultad de Arquitectura, diseño y urbanismo, UBA.

Truffello, R., e Hidalgo, R. (2015) Policentrismo en el Área Metropolitana de Santiago de Chile: reestructuración comercial, movilidad y tipificación de subcentros. EURE (Santiago) Vol.41, No122. Recuperado de: https://scielo.conicyt.cl/scielo.php?pid=S0250$\underline{71612015000100003 \& \text { script }=\text { sci_arttext\&tlng=e }}$

Unceta Satrustegui, K. (2009) Desarrollo, subdesarrollo, maldesarrollo y postdesarrollo. Una mirada transdisciplinar sobre el debate y sus implicaciones. Carta Latinoamericana, $\mathrm{N}^{\circ} 7$, Montevideo, CLAES.

Valdés, E. (2007) "Fragmentación y segregación urbana. Aportes teóricos para el análisis de casos en la ciudad de Córdoba”. Depto. de Geografía, UNC. Recuperado de: https://ffyh.unc.edu.ar/alfilo/anteriores/alfilo-18/pdf/valdes.pdf

Valles, M. (1999) Técnicas cualitativas de investigación social. Reflexión metodológica y práctica profesional. Madrid: Síntesis. Capitulo 3. Recuperado desde: https://metodologiaecs.files.wordpress.com/2014/11/vallesmiguel-tc3a9cnicascualitativas-de-investigacic3b3n-social-1999.pdf

Vecslir, L. y Baer, L. (2011) "Reestructuración urbana y mercados de suelo en las centralidades metropolitanas de Buenos Aires". Actas del I Congreso Latinoamericano de Estudios Urbanos, Universidad Nacional de General Sarmiento, Los Polvorines.

Vidal Koppmann (2007) Transformaciones socio-territoriales de la región metropolitana de Buenos Aires en la última década del siglo xx. La incidencia de las urbanizaciones privadas en la fragmentación de la periferia. Tesis de doctorado en Ciencias Sociales. FLACSO- Argentina.

Villafuerte Solís, D. (2014) Neoextractivismo, megaproyectos y conflictividad en Guatemala y Nicaragua. Espiral (Guadalajara), N²1(61), 109-141. Recuperado de: http://www.scielo.org.mx/scielo.php?script $=$ sci arttext\&pid=S1665$\underline{05652014000300005}$ 
Villarreal Cantú, E. (2010). Políticas Públicas. En: (Pre) Textos para el análisis político. Disciplinas, reglas y procesos. México. Flacso. 


\section{Anexo}

\section{Figuras y tablas}

Figura 1: Mapa usos de suelo en Bernal Centro.

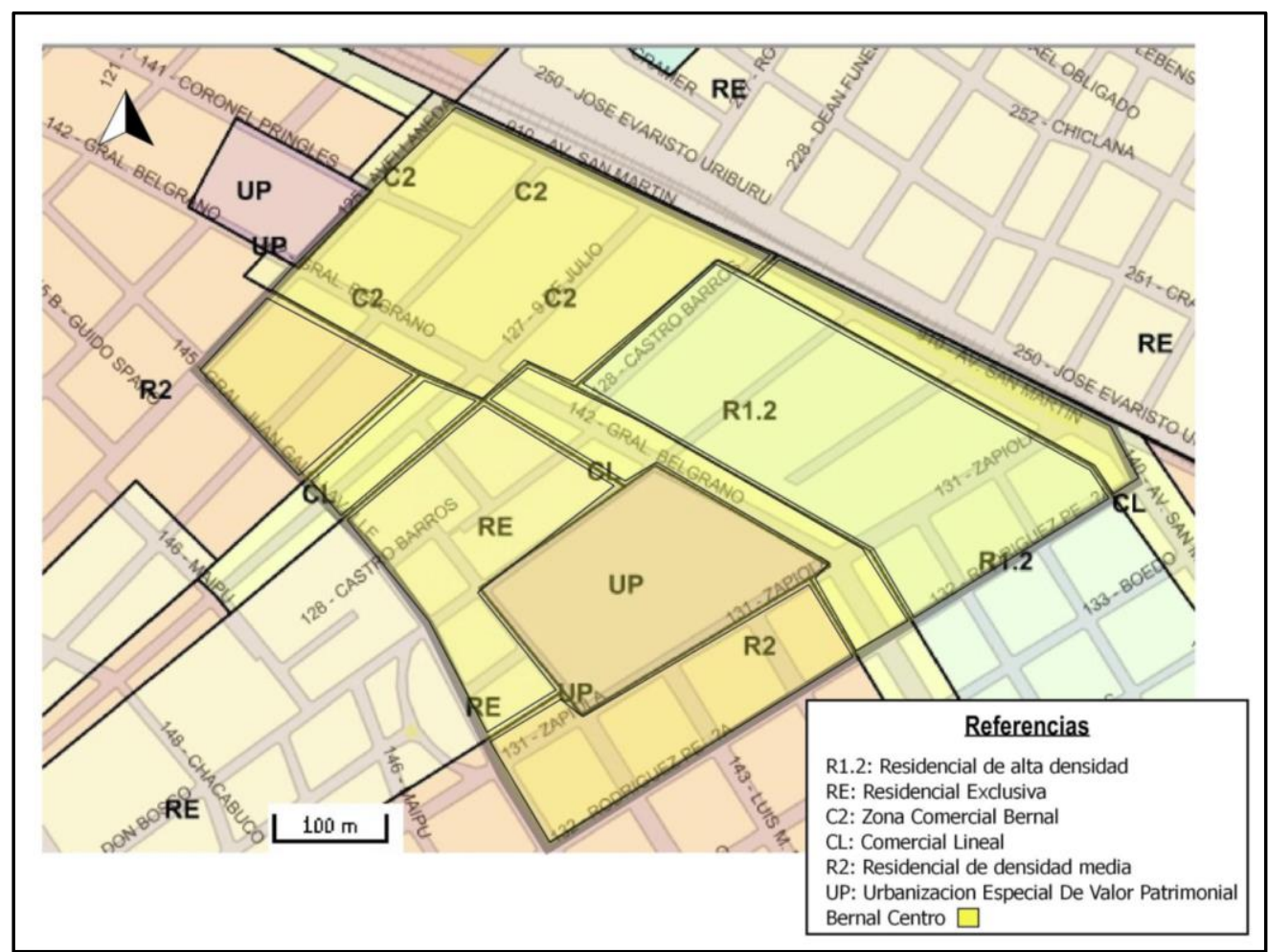

Fuente: Elaboración propia a partir de datos de UrBAsig. Recuperados de: http://www.urbasig.gob.gba.gob.ar/urbasig/

Tabla 1: Cruce de variables, tipo de vivienda y régimen de tenencia a nivel partido. Censo 2001.

\begin{tabular}{|c|c|c|c|c|c|c|c|}
\hline AREA \# 06658 & Quilmes & & & & & & \\
\hline \multirow{2}{*}{$\begin{array}{c}\text { Tipo de } \\
\text { vivienda }\end{array}$} & \multicolumn{2}{|c|}{ Régimen de tenencia } & & & & & \\
\hline & $\begin{array}{l}\text { Propietario } \\
\text { de la } \\
\text { vivienda y } \\
\text { terreno }\end{array}$ & $\begin{array}{l}\text { Propietario } \\
\text { sólo de la } \\
\text { vivienda }\end{array}$ & Inquilino & $\begin{array}{l}\text { Ocupante } \\
\text { por } \\
\text { préstamo }\end{array}$ & $\begin{array}{l}\text { Ocupante } \\
\text { por trabajo }\end{array}$ & $\begin{array}{c}\text { Otra } \\
\text { situación }\end{array}$ & Total \\
\hline Casa tipo A & 85.252 & 2.930 & 6.572 & 5.645 & 267 & 2.338 & 103.004 \\
\hline Casa tipo B & 12.801 & 3.230 & 654 & 2.155 & 48 & 827 & 19.715 \\
\hline Rancho & 679 & 293 & 31 & 128 & 8 & 89 & 1.228 \\
\hline Casilla & 4.267 & 1.695 & 235 & 998 & 23 & 486 & 7.704 \\
\hline Departamento & 8.449 & - & 2.624 & 819 & 126 & 327 & 12.345 \\
\hline
\end{tabular}




\begin{tabular}{|l|r|r|r|r|r|r|r|}
\hline $\begin{array}{l}\text { Pieza/s en } \\
\text { inquilinato }\end{array}$ & 31 & 5 & 326 & 50 & 3 & 2 & 417 \\
\hline $\begin{array}{l}\text { Pieza/s en hotel } \\
\text { o pensión }\end{array}$ & 1 & - & 31 & 8 & 2 & - & 42 \\
\hline $\begin{array}{l}\text { Local no } \\
\text { construido para } \\
\text { habitación }\end{array}$ & 40 & 4 & 46 & 57 & 22 & 7 & 176 \\
\hline Vivienda móvil & 8 & 2 & 1 & 5 & 1 & 4 & 21 \\
\hline Total & 111.528 & 8.159 & 10.520 & 9.865 & 500 & 4.080 & 144.652 \\
\hline & & & & & & & \\
\hline NSA : & 21.736 & & & & & & \\
\hline
\end{tabular}

Indec 2001. Redatam. Números absolutos viviendas.

Tabla 2: Cruce de variables, tipo de vivienda y régimen de tenencia a nivel partido. Censo 2010.

\begin{tabular}{|c|c|c|c|c|c|c|c|}
\hline AREA \# 06658 & Quilmes & & & & & & \\
\hline $\begin{array}{l}\text { Tipo de vivienda } \\
\text { particular }\end{array}$ & $\begin{array}{l}\text { Régimen } \\
\text { de } \\
\text { tenencia }\end{array}$ & & & & & & \\
\hline & $\begin{array}{l}\text { Propietario } \\
\text { Vivienda y } \\
\text { terreno }\end{array}$ & $\begin{array}{l}\text { Propietario } \\
\text { Vivienda }\end{array}$ & Inquilino & $\begin{array}{l}\text { Ocupante } x \\
\text { préstamo }\end{array}$ & $\begin{array}{l}\text { Ocupante } x \\
\text { trabajo }\end{array}$ & $\begin{array}{l}\text { Otra } \\
\text { situación }\end{array}$ & Total \\
\hline Casa & 116211 & 7602 & 14109 & 9669 & 475 & 3825 & 151891 \\
\hline Rancho & 762 & 174 & 38 & 139 & 3 & 81 & 1197 \\
\hline Casilla & 3541 & 990 & 243 & 644 & 26 & 298 & 5742 \\
\hline Departamento & 9043 & 811 & 5954 & 835 & 105 & 261 & 17009 \\
\hline $\begin{array}{l}\text { Pieza en } \\
\text { inquilinato }\end{array}$ & 71 & 12 & 736 & 36 & 3 & 5 & 863 \\
\hline $\begin{array}{l}\text { Pieza en hotel } \\
\text { familiar o pensión }\end{array}$ & 14 & 4 & 105 & 10 & 1 & 2 & 136 \\
\hline $\begin{array}{l}\text { Local no } \\
\text { construido p/ } \\
\text { habitación }\end{array}$ & 82 & 5 & 95 & 34 & 25 & 17 & 258 \\
\hline Vivienda móvil & 5 & 7 & - & 1 & 1 & - & 14 \\
\hline Total & 129729 & 9605 & 21280 & 11368 & 639 & 4489 & 177110 \\
\hline NSA: 124 & & & & & & & \\
\hline
\end{tabular}

Indec 2010. Redatam. Números absolutos viviendas.

Tabla 3: Nivel educativo que cursa o cursó + completó el nivel (si o no) a nivel partido para Censo 1991, 2001 y 2010.

\begin{tabular}{|c|c|c|c|}
\hline Censo & 1991 & $\mathbf{2 0 0 1}$ & $\mathbf{2 0 1 0}$ \\
\hline Primario completo & 133.148 & 50.381 & 110.049 \\
\hline
\end{tabular}




\begin{tabular}{|c|c|c|c|}
\hline Secundario completo & 43.320 & 20.763 & 86.321 \\
\hline Terciario completo & 9.350 & 4.745 & 21.919 \\
\hline Universitario completo & 7.962 & 6.441 & 19.714 \\
\hline $\begin{array}{c}\text { Postuniversitario } \\
\text { completo }\end{array}$ & Sin datos & Sin datos & 1.553 \\
\hline Total & 193.780 & 82.330 & 239.556 \\
\hline Porcentaje & 8,93 & 13,5 & 18 \\
\hline
\end{tabular}

Indec 1991, 2001 y 2010. Números absolutos personas.

Tabla 4: Datos absolutos de déficit habitacional simple y compuesto de los partidos de la RMBA. Censos 2001 y 2010.

\begin{tabular}{|c|c|c|c|c|c|c|c|}
\hline PARTIDOS RMBA & $\begin{array}{l}\text { Total de } \\
\text { hogares } \\
2001\end{array}$ & $\begin{array}{c}\text { Total de } \\
\text { viviendas } \\
\text { particulares } \\
\text { habitadas } \\
2001\end{array}$ & $\begin{array}{c}\text { Deficit } \\
\text { habitacional } \\
\text { cuantitativo } \\
\text { simple } 2001\end{array}$ & $\begin{array}{c}\text { Deficit } \\
\text { habitacional } \\
\text { cuantitativo } \\
\text { compuesto } \\
2001\end{array}$ & $\begin{array}{l}\text { Total de } \\
\text { hogares } \\
2010\end{array}$ & $\begin{array}{c}\text { Deficit } \\
\text { habitacional } \\
\text { cuantitativo } \\
\text { simple } 2010\end{array}$ & $\begin{array}{c}\text { Deficit } \\
\text { habitacional } \\
\text { cuantitativo } \\
\text { compuesto } \\
2010\end{array}$ \\
\hline LOMAS DE ZAMORA & 164.405 & 155.579 & 8.826 & 16.673 & 188.844 & 21.540 & 27.154 \\
\hline LA PLATA & 177.004 & 172.140 & 4.864 & 16.372 & 221.313 & 11.425 & 24.713 \\
\hline ALMIRANTE BROWN & 133.779 & 127.057 & 6.722 & 16.347 & 156.918 & 14.304 & 21.632 \\
\hline QUILMES & 144.652 & 137.714 & 6.938 & 16.130 & 177.110 & 13.393 & 20.724 \\
\hline MERLO & 119.620 & 114.168 & 5.452 & 15.542 & 147.716 & 12.333 & 19.560 \\
\hline FLORENCIO VARELA & 84.953 & 81.114 & 3.839 & 15.838 & 113.135 & 9.007 & 18.613 \\
\hline MORENO & 95.525 & 91.659 & 3.866 & 12.784 & 124.016 & 9.891 & 16.757 \\
\hline GENERAL SAN MARTIN & 119.097 & 114.019 & 5.078 & 10.295 & 133.202 & 11.810 & 15.662 \\
\hline TIGRE & 79.792 & 73.297 & 6.495 & 13.165 & 108.558 & 9.942 & 15.611 \\
\hline LANUS & 135.436 & 130.434 & 5.002 & 8.932 & 149.594 & 12.462 & 14.606 \\
\hline MALVINAS ARGENTINAS & 72.950 & 66.878 & 6.072 & 12.292 & 89.338 & 9.152 & 13.500 \\
\hline AVELLANEDA & 100.834 & 97.523 & 3.311 & 7.117 & 113.142 & 9.481 & 12.217 \\
\hline PILAR & 58.304 & 55.665 & 2.639 & 8.439 & 82.671 & 6.855 & 11.865 \\
\hline BERAZATEGUI & 75.598 & 71.500 & 4.098 & 9.554 & 93.164 & 6.916 & 11.255 \\
\hline ESTEBAN ECHEVERRIA & 62.931 & 60.108 & 2.823 & 7.450 & 85.952 & 7.997 & 11.183 \\
\hline TRES DE FEBRERO & 102.204 & 98.816 & 3.388 & 6.169 & 112.588 & 8.434 & 10.337 \\
\hline SAN MIGUEL & 65.689 & 61.684 & 4.005 & 7.961 & 80.627 & 7.638 & 10.236 \\
\hline JOSE C. PAZ & 56.004 & 52.559 & 3.445 & 9.072 & 71.722 & 6.014 & 9.382 \\
\hline ESCOBAR & 45.335 & 42.621 & 2.714 & 6.711 & 59.981 & 5.105 & 8.325 \\
\hline MORON & 93.972 & 91.013 & 2.959 & 5.000 & 106.902 & 5.966 & 7.426 \\
\hline SAN ISIDRO & 88.039 & 85.936 & 2.103 & 5.422 & 97.213 & 5.383 & 6.754 \\
\hline SAN FERNANDO & 42.048 & 39.541 & 2.507 & 4.865 & 49.384 & 4.639 & 6.231 \\
\hline HURLINGHAM & 47.902 & 45.756 & 2.146 & 4.104 & 55.122 & 4.719 & 6.179 \\
\hline VICENTE LOPEZ & 91.400 & 89.753 & 1.647 & 3.428 & 99.286 & 4.297 & 5.703 \\
\hline EZEIZA & 29.569 & 28.549 & 1.020 & 3.882 & 44.487 & 2.826 & 5.531 \\
\hline
\end{tabular}




\begin{tabular}{|c|c|c|c|c|c|c|c|}
\hline ZARATE & 27.625 & 26.261 & 1.364 & 3.206 & 34.013 & 2.898 & 4.529 \\
\hline ITUZAINGO & 44.401 & 42.425 & 1.976 & 3.734 & 51.444 & 3.370 & 4.449 \\
\hline GENERAL RODRIGUEZ & 18.107 & 17.734 & 373 & 1.808 & 24.926 & 2.202 & 3.895 \\
\hline BERISSO & 22.712 & 21.869 & 843 & 2.906 & 27.449 & 1.671 & 3.780 \\
\hline PRESIDENTE PERON & 14.503 & 14.048 & 455 & 2.360 & 21.422 & 1.300 & 3.390 \\
\hline CAMPANA & 22.770 & 21.861 & 909 & 2.299 & 28.111 & 2.134 & 3.235 \\
\hline LUJAN & 26.176 & 25.397 & 779 & 1.665 & 32.524 & 1.546 & 2.419 \\
\hline SAN VICENTE & 11.813 & 11.538 & 275 & 1.323 & 17.116 & 739 & 2.240 \\
\hline ENSENADA & 14.657 & 14.145 & 512 & 1.706 & 17.443 & 957 & 2.111 \\
\hline CAÑUELAS & 11.471 & 11.090 & 381 & 980 & 15.312 & 662 & 1.336 \\
\hline BRANDSEN & 6.765 & 6.552 & 213 & 609 & 8.324 & 308 & 668 \\
\hline LA MATANZA & 333.882 & 315.477 & 18.405 & 38.111 & 484.909 & 79.571 & 101.295 \\
\hline GENERAL LAS HERAS & 3.743 & 3.640 & 103 & 253 & 4.641 & 175 & 299 \\
\hline EXALTACION DE LA & 6.792 & 6.586 & 206 & 620 & 9.101 & 475 & 840 \\
\hline CRUZ & 10.755 & 10.418 & 337 & 1.093 & 14.656 & 627 & 1.294 \\
\hline MARCOS PAZ & & & 129.090 & 306.217 & & 320.164 & 466.936 \\
\hline TOTAL & & & & & & \\
\hline
\end{tabular}

Fuente: Atlas ID, Subsecretaría de Planificación Territorial de la Inversión Pública. Recuperado de: $\underline{\text { https://atlasid.planificacion.gob.ar/indicador.aspx } ? \mathrm{id}=58}$

Referencias de la tabla:

- Déficit Habitacional Simple= Total de hogares - Total de Viviendas Particulares Habitadas.

- Déficit habitacional cuantitativo compuesto= Déficit Habitacional Simple + Viviendas Irrecuperables habitadas.

- Viviendas irrecuperables se consideran a las siguientes: rancho, casilla, local no construido para habitación, en vivienda móvil, persona viviendo en la calle, y persona viviendo en una pieza en hotel familiar o en una pensión. 
2. Relevamiento en terreno. Fotografías por manzana en área de estudio.

Manzana 1: Comprende la Av. Zapiola, 26 de Julio, Rodríguez Peña y Lavalle.

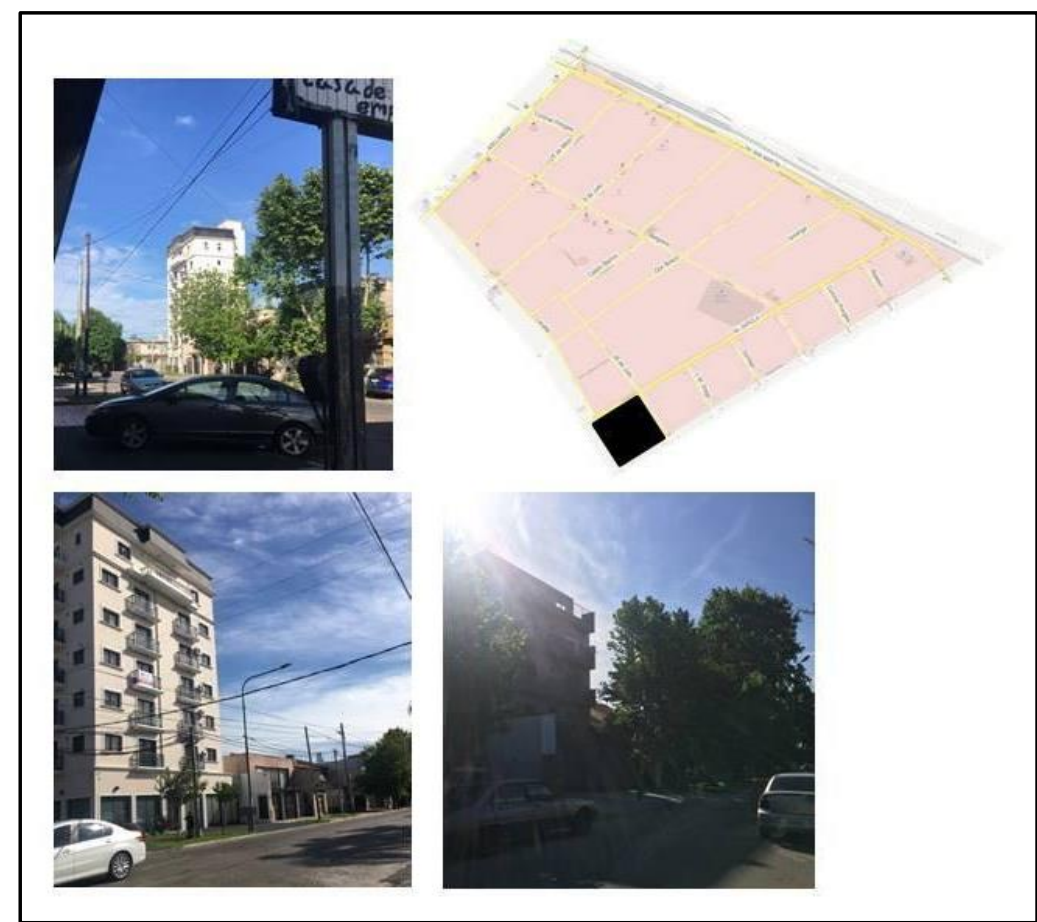

Fuente: Elaboración propia a partir de fotografías tomadas en área de estudio durante el mes de septiembre de 2019.

Manzana 2: Comprende la Av. Zapiola, Dorrego, Rodríguez Peña, y L.M. Drago.

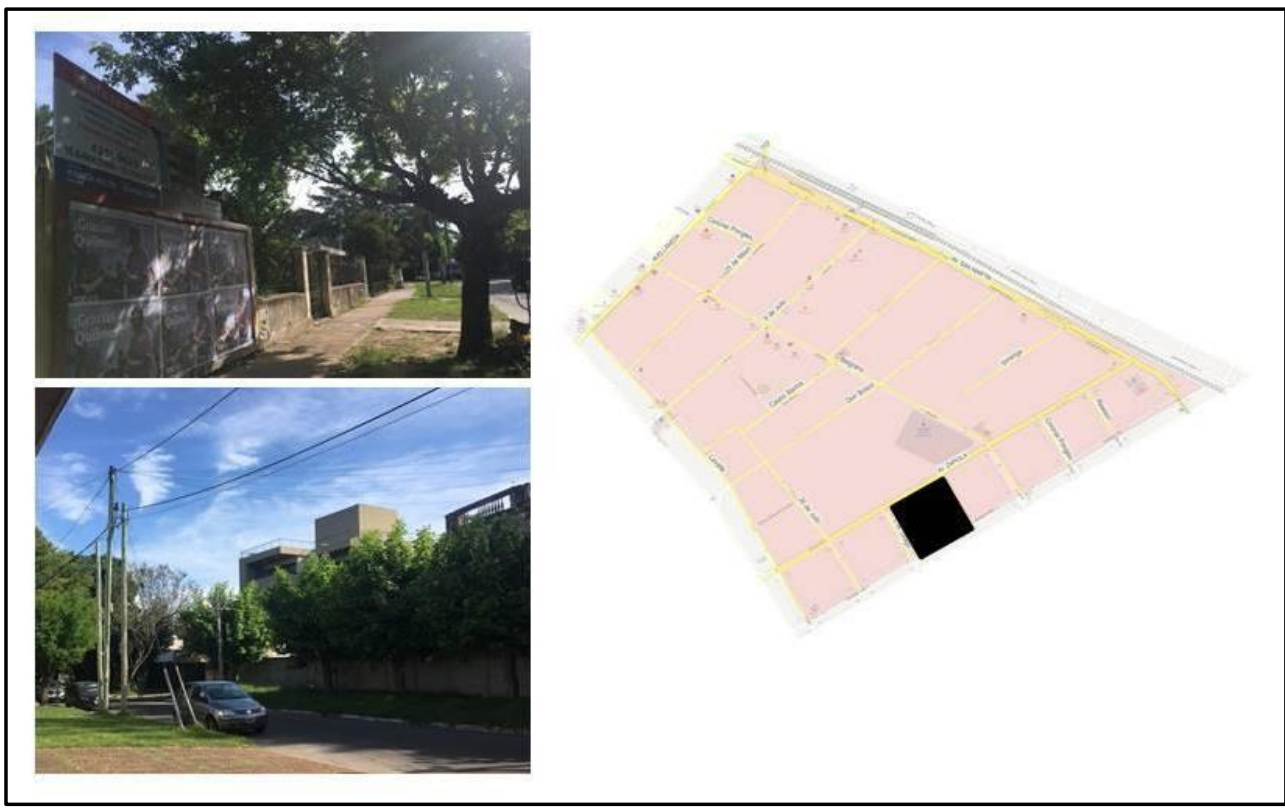

Fuente: Elaboración propia a partir de fotografías tomadas en área de estudio durante el mes de septiembre de 2019. 
Manzana 3 y 4: Comprenden la Av. Zapiola, Dorrego, Belgrano, Pringles y Rodríguez Peña.

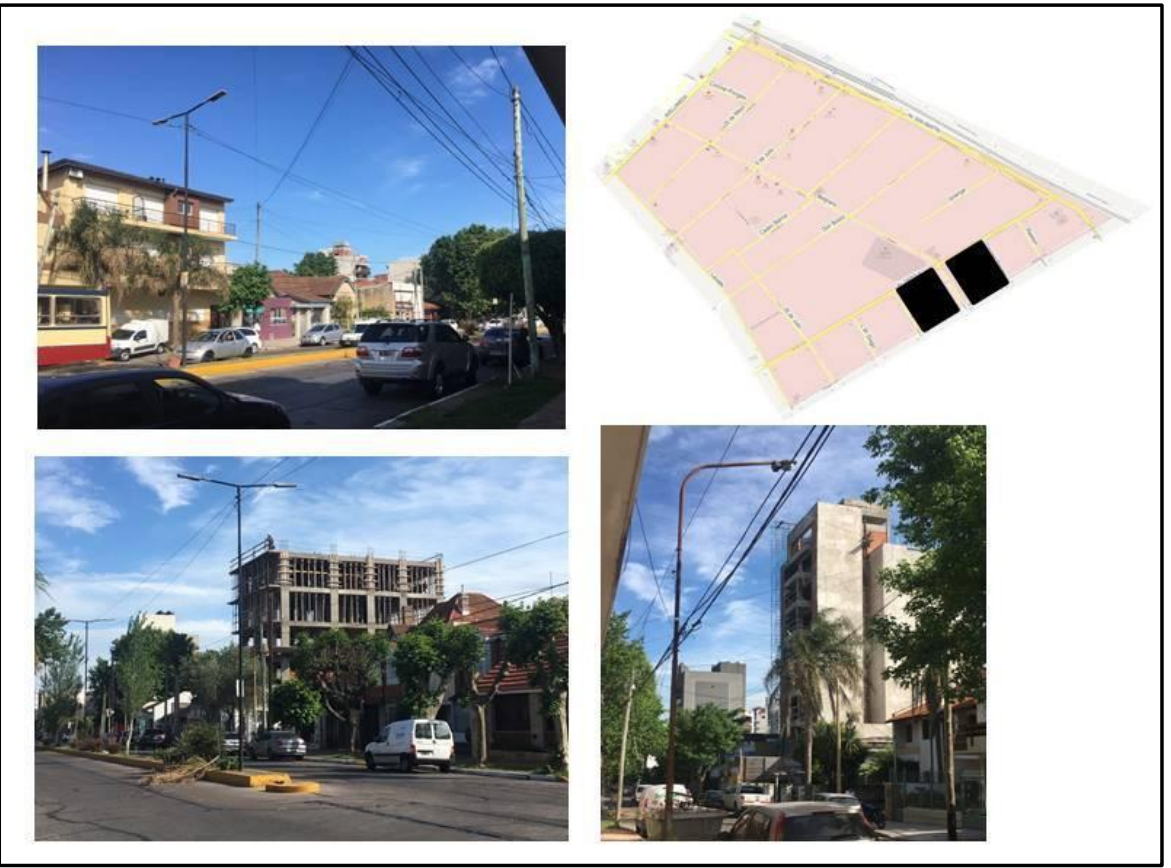

Fuente: Elaboración propia a partir de fotografías tomadas en área de estudio durante el mes de septiembre de 2019.

Manzana 5: Comprenden la Av. Zapiola, Av. San Martín, Rodríguez Peña y Rawson.

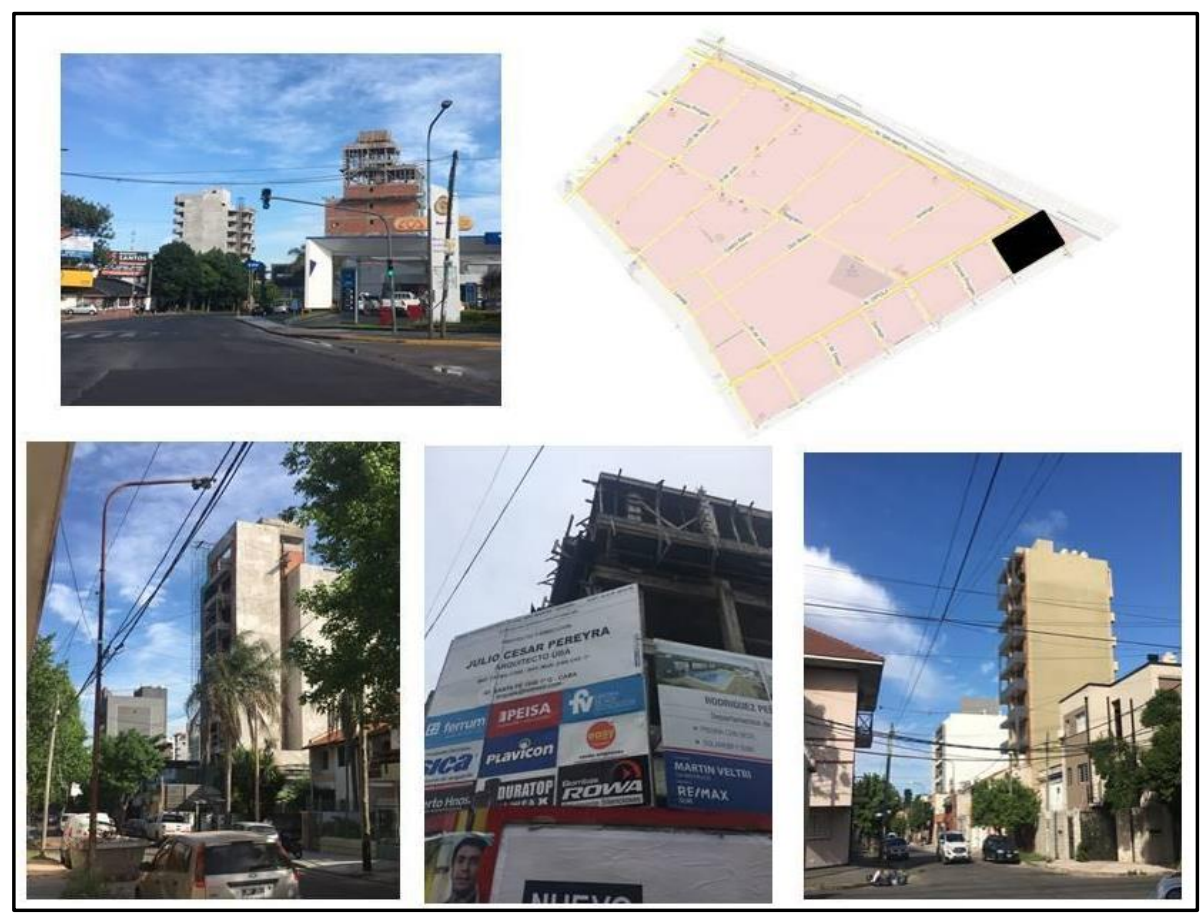

Fuente: Elaboración propia a partir de fotografías tomadas en área de estudio durante el mes de septiembre de 2019. 
Manzana 6: Comprenden la Av. Zapiola, Belgrano, Av. San Martín e Ipiranga.

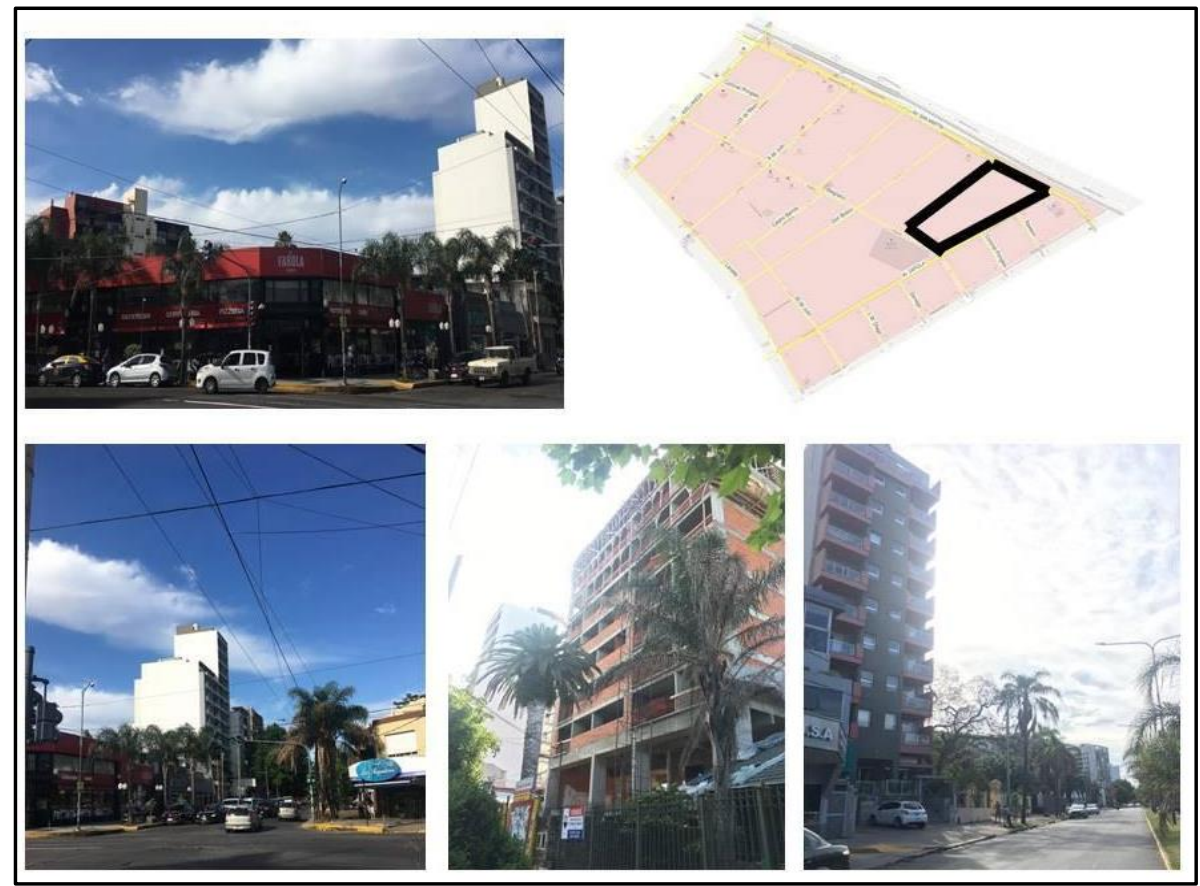

Fuente: Elaboración propia a partir de fotografías tomadas en área de estudio durante el mes de septiembre de 2019.

Manzana 7: Comprende las calles Ipiranga, Belgrano, Av. San Martín y Don Bosco.

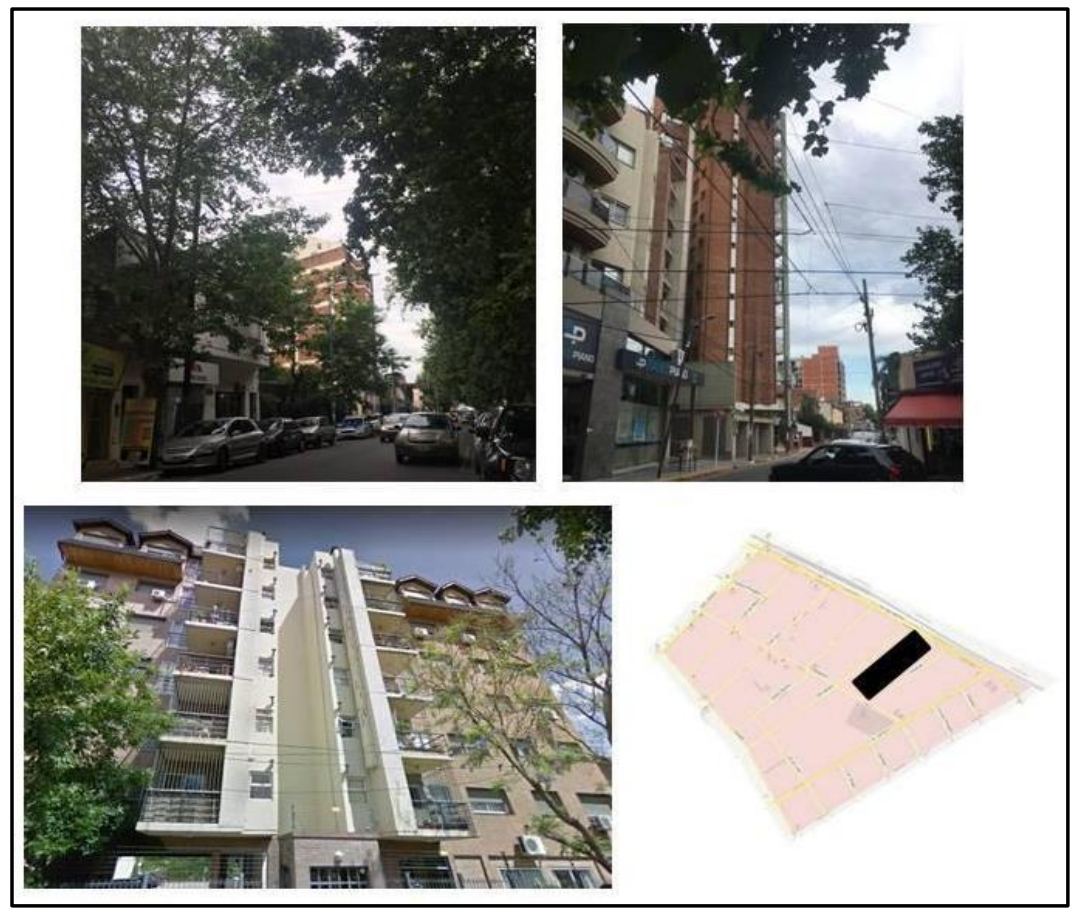

Fuente: Elaboración propia a partir de fotografías tomadas en área de estudio durante el mes de septiembre de 2019. 
Manzana 8: Comprende las calles Don Bosco, Belgrano, Av. San Martín y Castro Barros.

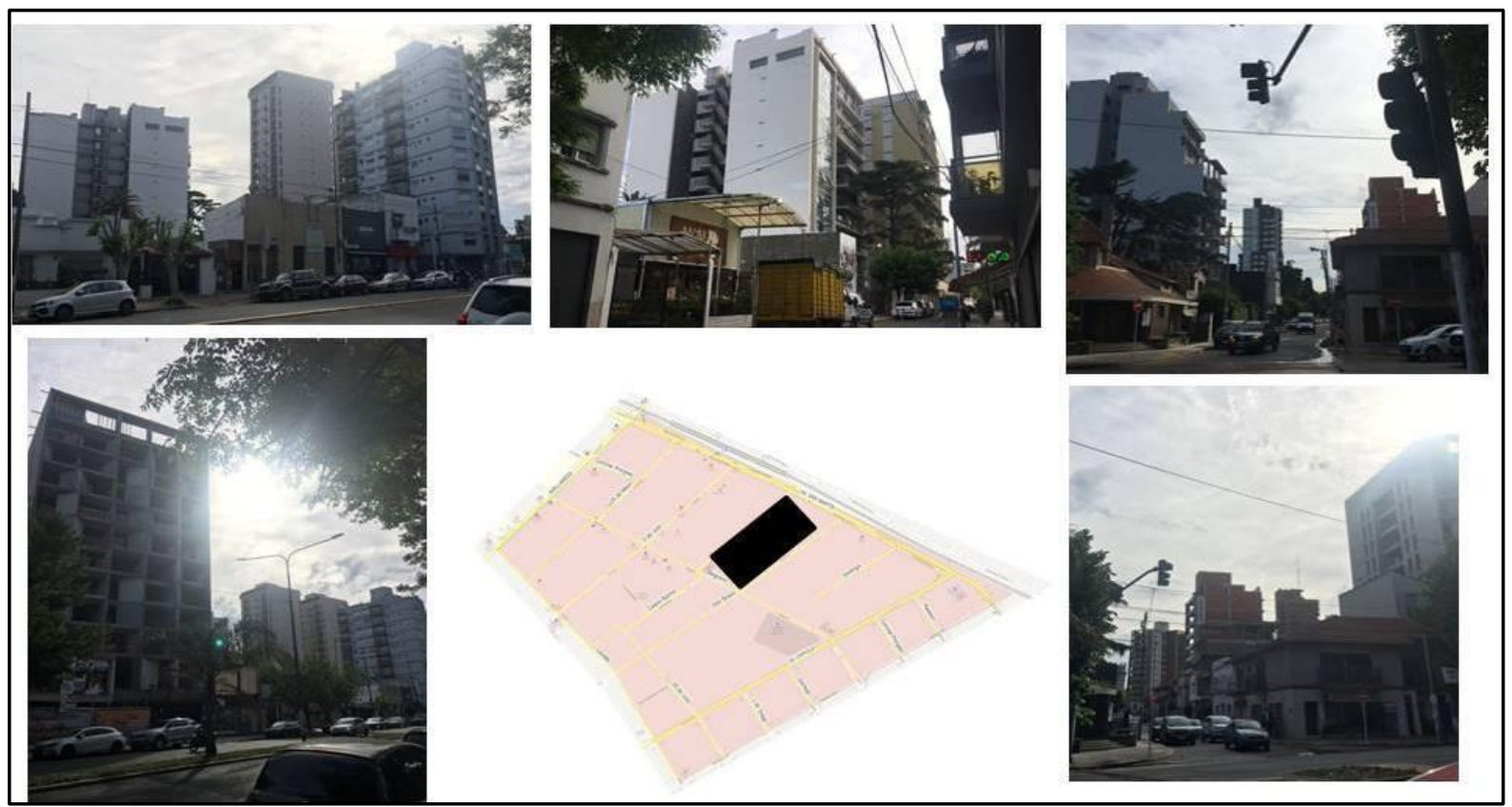

Fuente: Elaboración propia a partir de fotografías tomadas en área de estudio durante el mes de septiembre de 2019.

Manzana 9: Comprende las calles Castro Barros, Belgrano, Av. San Martin y 9 de Julio

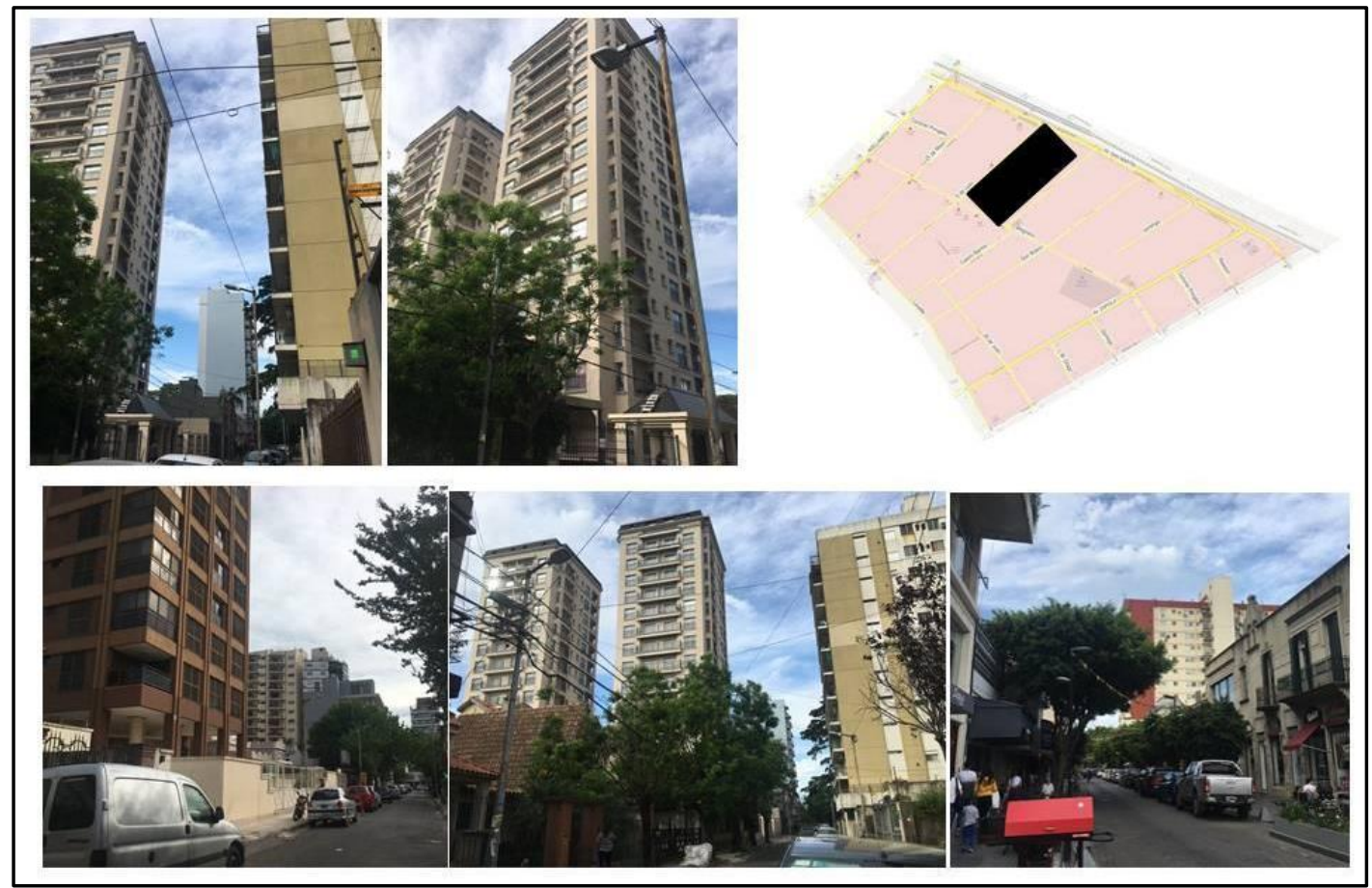

Fuente: Elaboración propia a partir de fotografías tomadas en área de estudio durante el mes de septiembre de 2019. 
Manzanas 10 y 11: La primera comprende las calles 9 de Julio, Belgrano, 25 de Mayo y Av. San Martin, la contigua está rodeada por las calles 25 de Mayo, Pringles, Av. San Martin y Avellaneda.

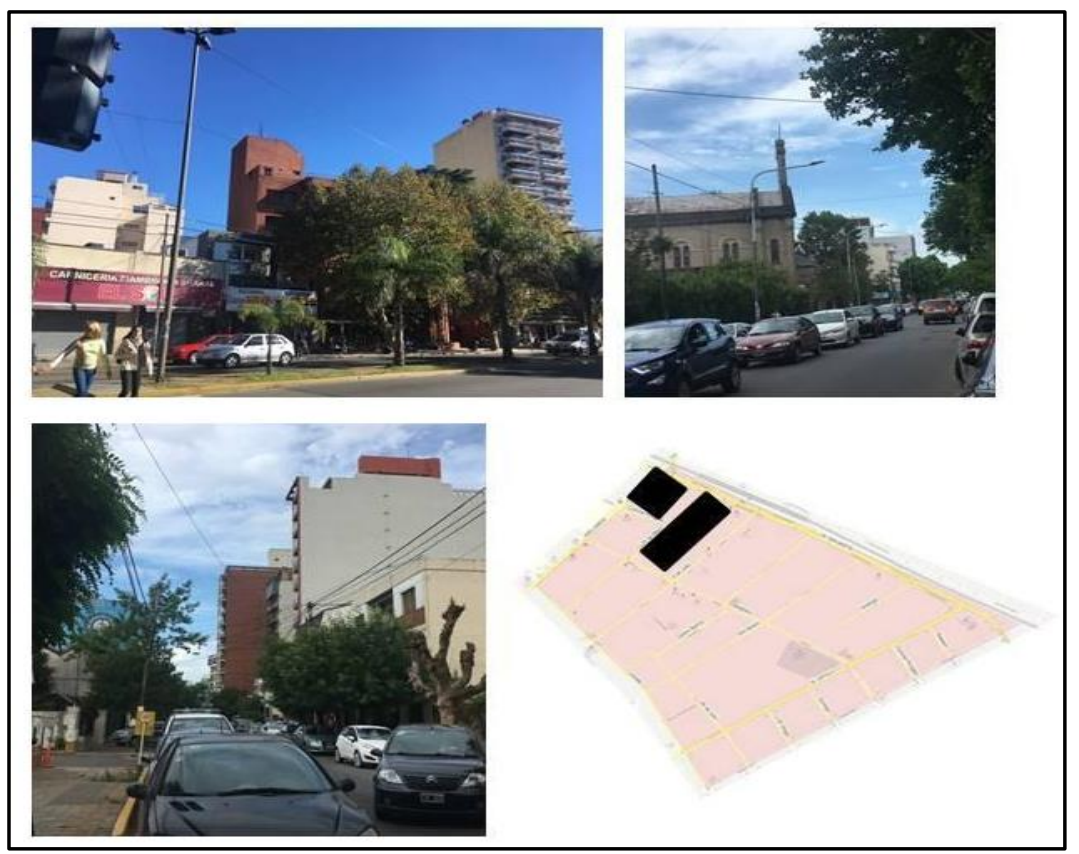

Fuente: Elaboración propia a partir de fotografías tomadas en área de estudio durante el mes de septiembre de 2019.

Manzana 12: Comprende las calles 9 de Julio, Lavalle, Belgrano y 25 de Mayo.

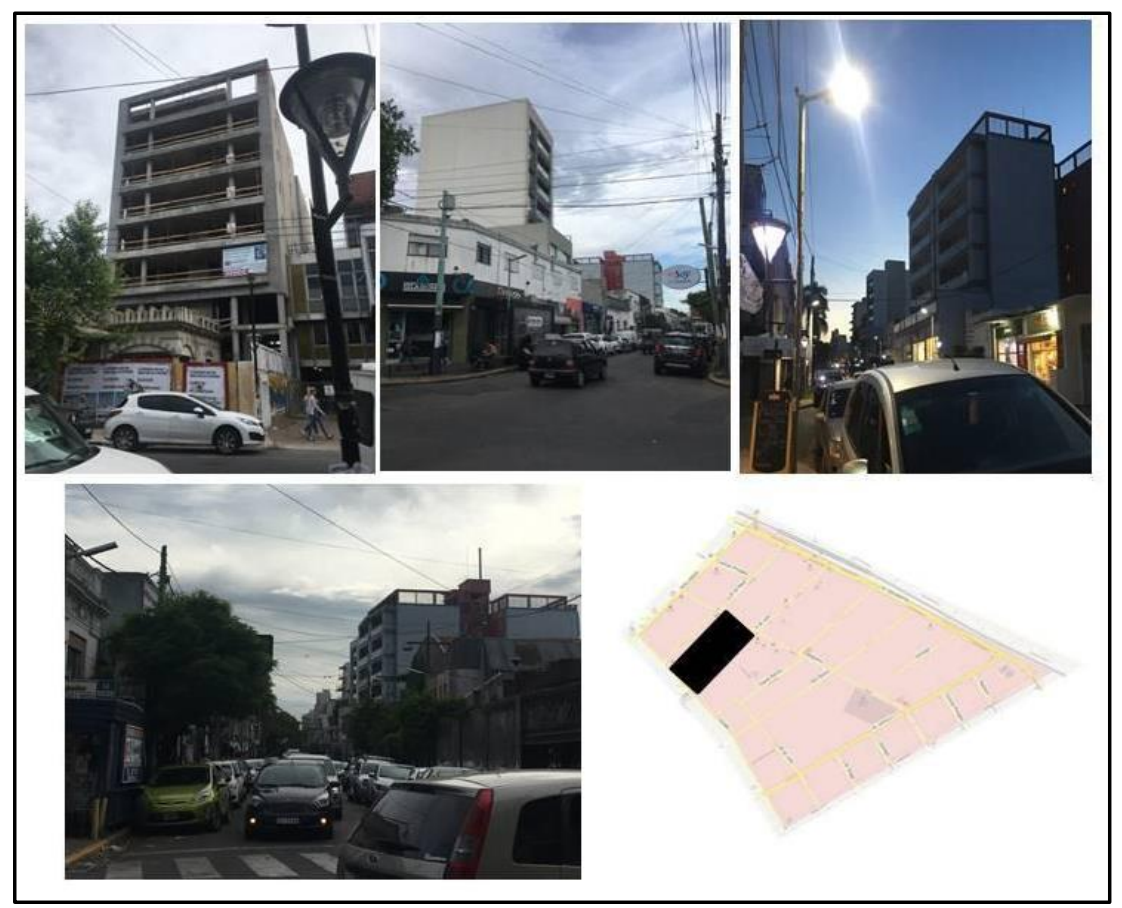

Fuente: Elaboración propia a partir de fotografías tomadas en área de estudio durante el mes de septiembre de 2019. 
Manzana 13: Comprende las calles 25 de Mayo, Lavalle, Belgrano y Avellaneda.

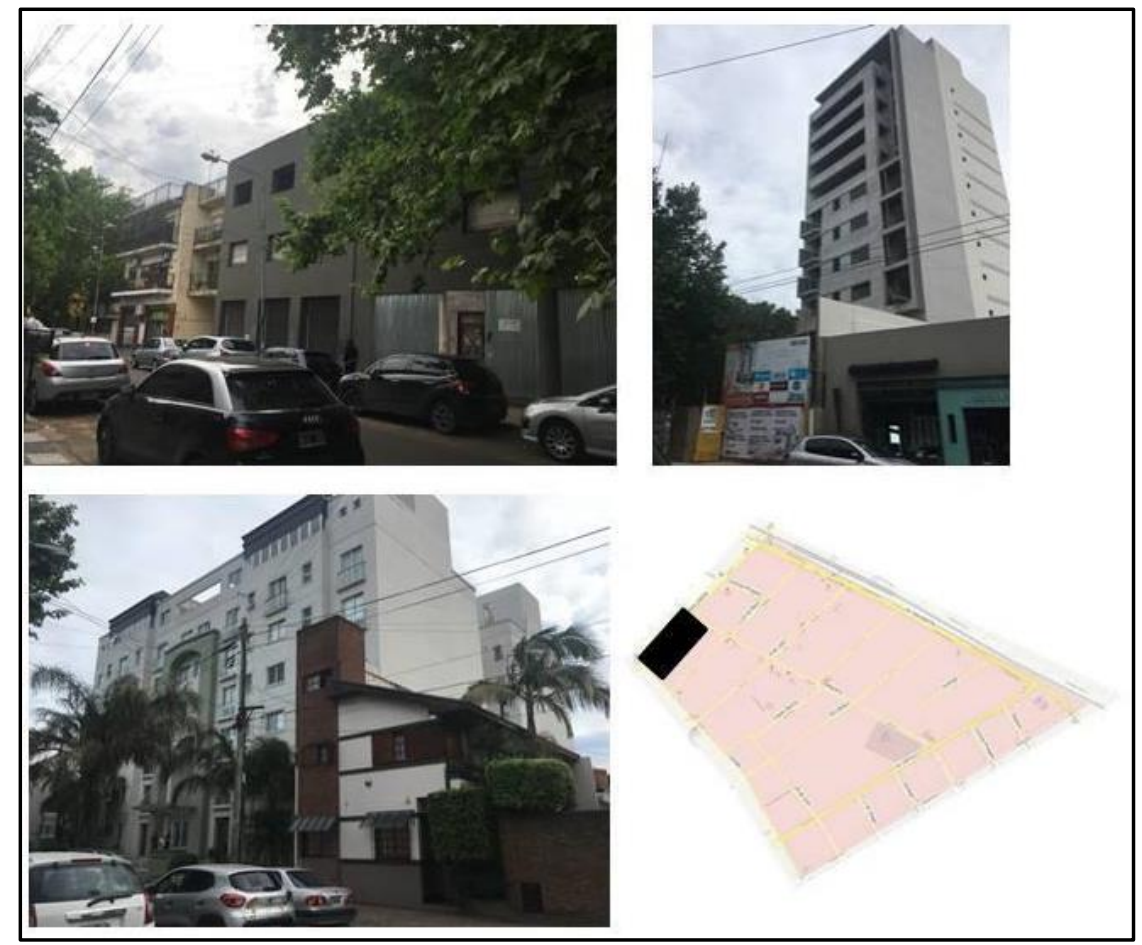

Fuente: Elaboración propia a partir de fotografías tomadas en área de estudio durante el mes de septiembre de 2019.

Manzana 14: Comprende las calles Don Bosco, 26 de Julio, Belgrano y Castro Barros.

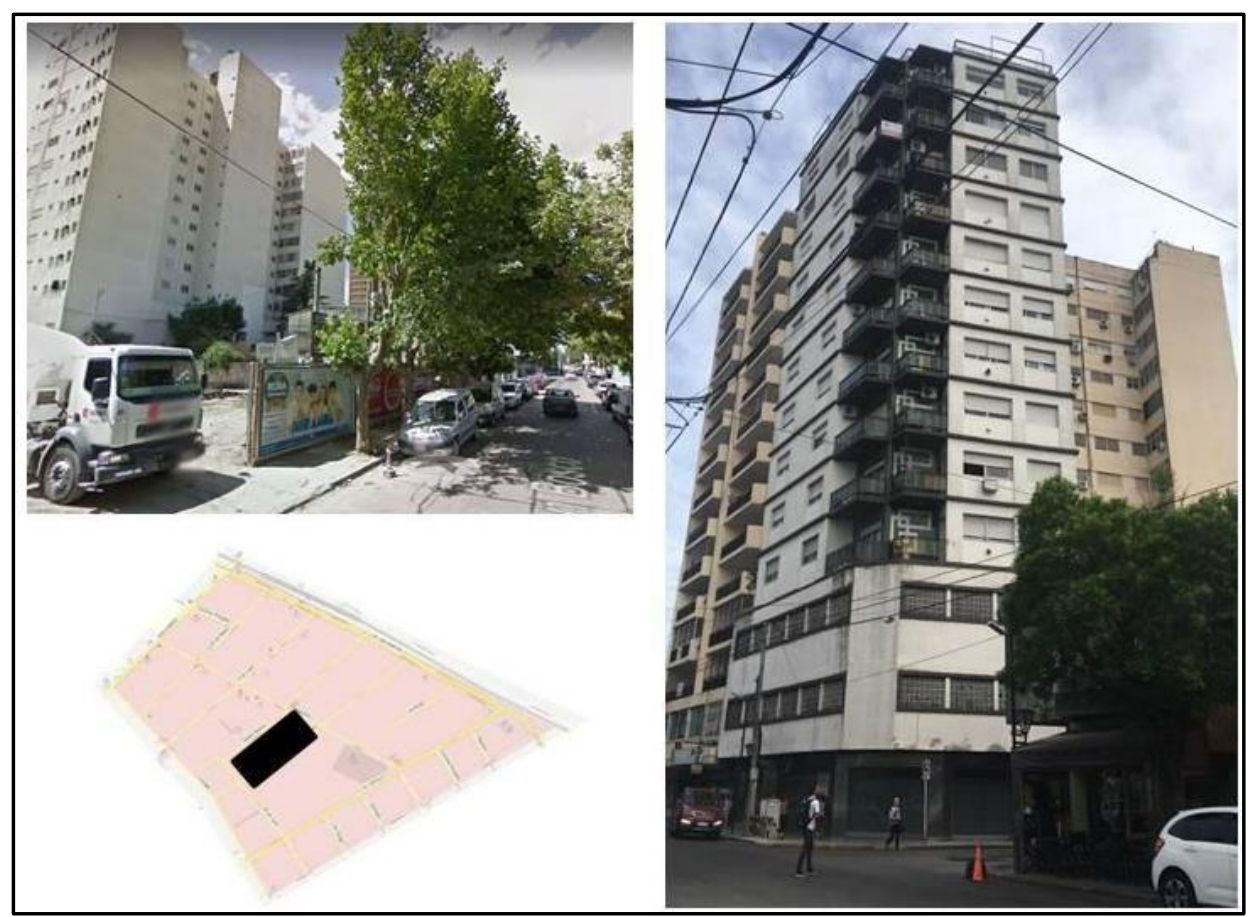

Fuente: Elaboración propia a partir de fotografías tomadas en área de estudio durante el mes de septiembre de 2019. 
Manzana 15: Comprende las calles Castro Barros, L.M. Drago, Belgrano y 9 de Julio.

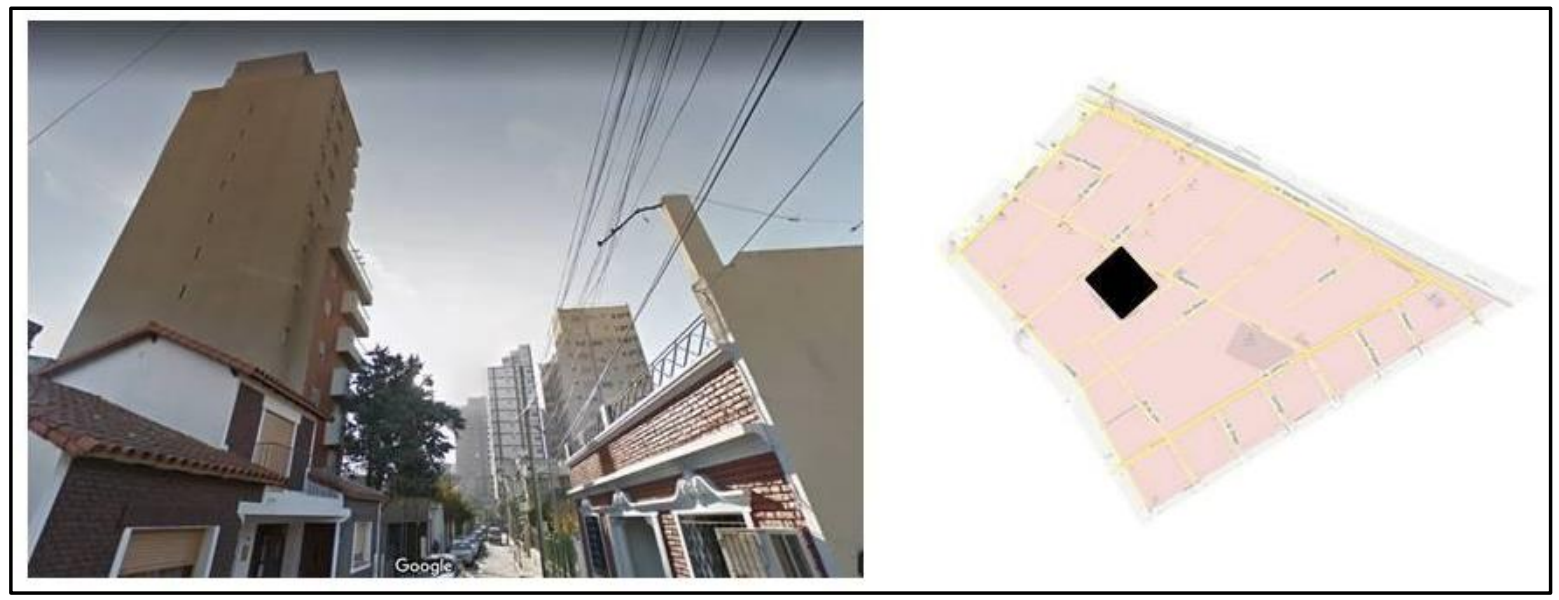

Fuente: Elaboración propia a partir de fotografías tomadas en área de estudio durante el mes de septiembre de 2019. 